\begin{tabular}{lllllllll}
\hline Senckenbergiana maritima & I & 35 & | (1) & I & $1-119$ & I Frankfurt am Main, 29 March 2005 \\
\hline
\end{tabular}

\title{
Taxonomy, biogeography and ecology of Quaternary benthic Ostracoda (Crustacea) from circumpolar deep water of the Emerald Basin (Southern Ocean) and the $S$ Tasman Rise (Tasman Sea)
}

\author{
Ilaria MazZINI
}

With 60 Figures, 13 Tables and 3 Appendix

Keywords: Quaternary Ostracoda, Systematics, Isotope Analyses, Statistics, Ecology, Pacific Ocean.

\section{Abstract}

[MAZZINI, I. (2005): Taxonomy, biogeography and ecology of Quaternary benthic Ostracoda (Crustacea) from circumpolar deep water of the Emerald Basin (Southern Ocean) and the S Tasman Rise (Tasman Sea). - Senckenbergiana maritima, 35 (1): 1-119, 60 figs., 13 tabs, 3 app.; Frankfurt am Main]

Benthic Ostracoda were recovered from 19 box core samples collected during the cruise SO 136 of the German R/V SONNE in the Tasman Sea and Southern Ocean (SW Pacific sector). The detailed taxonomic study of more than 10.000 specimens recovered from eleven box-corer samples from circumpolar deep water of the Emerald Basin (Southern Ocean) and the S Tasman Rise (Tasman Sea) led to the recognition of 34 genera and 63 species, of which 9 new to science. Additionally, ten key cosmopolitan and endemic taxa were re-studied and re-illustrated from type material from the Natural History Museum (London), the Utrecht Micropaleontological Collection, the Senckenberg Museum (Frankfurt) and the University of Canterbury (New Zealand).

Oxygen and carbon isotopic values were measured on specimens from 17 samples from the Campbell Plateau and the S Tasman Rise. In particular, four podocopid ostracod genera were analysed: the infaunal Krithe and the epifaunal Fallacihowella, Poseidonamicus and Bradleya. The stable isotopes proxies provided useful indications about the microhabitats, the diets and the temperature sensitivity of each taxon. Additionally, different calcification rates and different microhabitats were claimed to explain the different isotopic signature of adults and juveniles of Krithe.

Statistical analyses were performed on the relative abundance in percentages of 73 species identified in 19 sediment samples. Both species (R-mode) and samples (Q-mode) were grouped by cluster analyses and detrended correspondence analyses (DCA) using the software package PAST (ver. 0.94).

Q-mode cluster analyses partially supported the observations made by previous authors that the ostracod specific thresholds are controlled by the water mass characteristics. Q- and R-mode detrended correspondence analyses, on the contrary, indicated that distribution patterns must be driven by factors other than the water mass characteristics. Seven assemblages are recognised and the characteristic or most abundant species are discussed for their ecological demands. Bottom topography, sediment type, $\mathrm{CaCO}_{3}$ content, and flux of organic carbon interplay with the water mass characteristics creating a complex network of ecological gradients. Within each of the identified assemblages the species specific thresholds are not identical and often the range of the ecological gradients of the most abundant species do not include that of the characteristic species. Most likely, dynamics of co-occurring species take place which could involve Ostracoda and other benthic animals belonging to the same trophic groupings.

Author's addresses: ILARIA MAZZINI, Ludwig-Maximilians-Universität, Fakultät für Geowissenschaften, Department GeoUmwelt, Luisenstr.37, 80333 München, Germany, present address: 8 Lachie Griffin Rise, 8033 Governor's Bay, Christchurch, New Zealand, e-mail: Ilaria.Mazzini@gmx.it 


\section{Introduction}

The taxonomy of ostracods from oceanic environments is strongly influenced by the monograph compiled by BRADY (1880) on specimens collected during the CHALLENGER expedition. Many authors referred to the BRADY material and designated same as type [e.g. Bradleya arata (BRADY 1880); Legitimocythere acanthoderma (BRADY 1880); Pseudobosquetina mucronalata (BRADY 1880)] or included some of BRADY's species in new genera [e.g. Saida torresi (Brady 1880); Henryhowella dasyderma (BRADY 1880); Henryhowella melobesioides (BRADY 1869)]. In many cases reasons for taxonomic revision were poorly argued and few workers examined BRADY's specimens in detail, giving rise to unclear definitions for both genera and species. Moreover, the Quaternary ostracod fauna of the deep SW Pacific is mostly unknown. In fact, from this area BRADY described mostly shallow water forms, as did Chapman (1915) who examined samples collected during the Endeavour cruise around the coast of E Tasmania and South Australia. More recently, several studies on DSDP sites in nearby areas (WHATLEY 1983, AYRESS 1988, WHATLEY \& ColEs 1987) were completed, but these focused on MiocenePliocene ostracod assemblages.

In references to species from the Pacific Ocean, Benson (1965: 387-388) stated "generic concepts derived from the classic European and American cytheracean species groups are not usable for many if not most of the highly ornamented endemic species". There are additional questions posed by the concept of pandemic genera and one of the most important is with regard to distribution. It is difficult to explain how a podocopid ostracod can spread all over the floor of the oceans. Podocopid Ostracoda are, in fact, benthonic and they lack a pelagic larval stage. The result is then that they are 'trapped' on the sediment surface and likely not able to crawl for thousands of kilometres. Questions relating to dispersal mechanisms are still open and will only be answered after very accurate taxonomic work, integrated with isotope and ecological studies.

\section{Physiography and bottom sediments}

The transect studied in this project extends from the eastern Tasman Sea $\left(43^{\circ} \mathrm{S}\right)$ to the Campbell Plateau $\left(50^{\circ} \mathrm{S}\right)$ and westward to the Tasman Rise $\left(56^{\circ} \mathrm{S}\right)$ (Fig. 1).

The Campbell Plateau, a south-eastern extension of the New Zealand subcontinent, is bounded on its western flank by a steep escarpment sloping from about $1000 \mathrm{~m}$ to the bot- tom of the Emerald Basin (EB). The $5000 \mathrm{~m}$ deep EB extends in a NNE-SSW direction opening towards the SW Pacific basin. Its northern boundary occurs at around $51^{\circ} \mathrm{S}\left(\mathrm{D}_{\mathrm{A}-}\right.$ VEY 1977), where a group of seamounts separate the EB from the Solander Trough (ST). Terrigenous sediment is transported from the New Zealand shelf to the EB via the Solan-

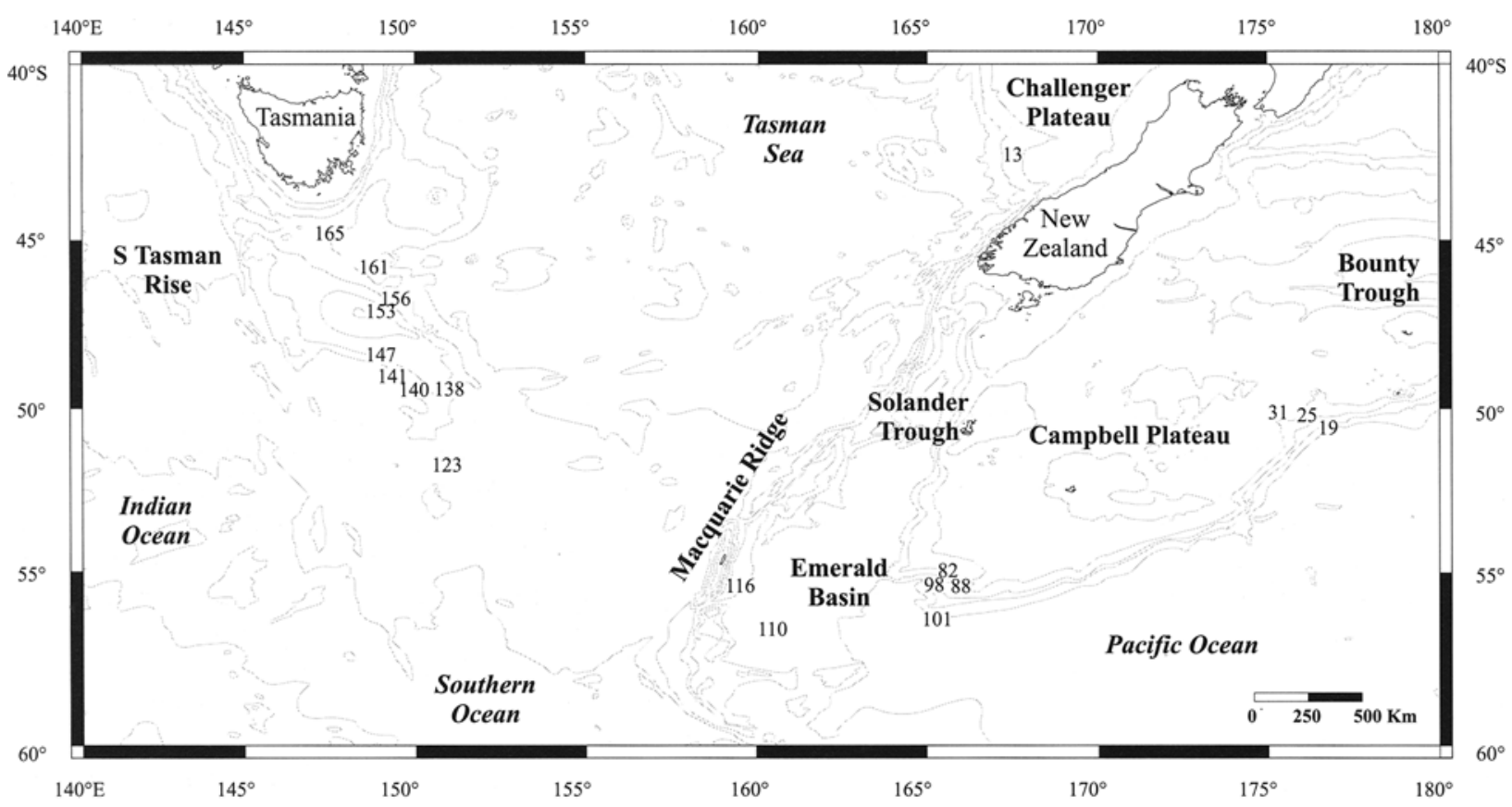

Fig. 1: Location of study area, showing bathymetry and sample localities (numbers refer to TASQWA samples, THIEDE et al. 1999). - Isobathes every $500 \mathrm{~m}$. Bathymetry from GEBCO Digital Atlas 1997 (BODC/NERC). 
der Trough. This significant sediment pathway was first identified by CARTER \& MCCAVE (1997) in the Solander Channel which extends from the continental slope of New Zealand to the base of the Trough. The terrigenous sediment bypasses the seamounts and extends south to $53^{\circ} \mathrm{S}$ (McCor 1991). The total accumulated sediment thickness reduces markedly from $1200 \mathrm{~m}$ in the $S T$ to $<800 \mathrm{~m}$ in the $\mathrm{EB}$ close to the seamounts (CARTER \& MCCAVE 1997), indicating significant interception by these topographic highs. The sediment cover in the EB consists of current-swept muds alternating with manganese nodules and a dense, benthic nepheloid layer (CARTER \& WILKIN 1999). The Emerald Basin - Solander Trough system is considered the southernmost part and the 'starting point' of the ENZOSS (Eastern New Zealand Oceanic Sedimentary System, CARTER et al. 1996). The ENZOSS is a system of regional sediment recycling driven by deep oceanic currents around the plateaux located east of the New Zealand shelf. CARTER et al. (1996) considered the system to be affected by climatic changes. During the Pliocene-Pleistocene sea level oscillations, glacial periods corresponded to periods of maximum sediment transport whereas in interglacial periods the Solander Channel was probably quiescent with sedimentary input being due almost entirely to the erosion of the existing deposits. Using bottom photographs and sediment samples CARTER \& MCCAVE (1997) were able to prove that erosion is currently taking place in the EB. They observed bottom current speeds greater than $20 \mathrm{~cm} / \mathrm{s}$ and concluded that these were mostly due to bottom currents flowing through the gaps in the Macquarie Ridge. Eddy kinetic energy values (EKE) in the EB were estimated as about 10-30 $\mathrm{cm}^{2} / \mathrm{s}^{2}$ (CARTER \& WILKIN 1999).

The Macquarie Ridge (MR) represents the western boundary of the EB. It extends for around $1400 \mathrm{~km}$ and is formed by an alignment of elevations which turns slightly to $\mathrm{SE}$ at its end. These elevations reach their maximum (about $5000 \mathrm{~m}$ ) at Macquarie Island. Two passages, almost $4000 \mathrm{~m}$ deep, separate the island from the body of the ridge. These gaps allow the flowing of current filaments from the Tasman Sea into the EB, generating rapid flows. The main flow of these currents passes around the end of the ridge and reaches the $\mathrm{EB}$ as a perturbed flow with eddies at depth exceeding $3000 \mathrm{~m}$ (CARTER \& MCCAve 1997). The western flank of the MR slopes steeply into the Tasman Sea. Few data are available on the bottom sediments and physiography of this area. EXON et al. (1995) reported manganese crusts and nodules and a minimal deposition of pelagic sediment on the area closer to the South Tasman Rise.

The South Tasman Rise (STR) is a bathymetric high with its summit as shallow as $800 \mathrm{~m}$ and a topography dominated by gentle slopes. It is separated from Tasmania by a channel reaching more than $3000 \mathrm{~m}$ of depth. The west side of the rise gently slopes until $3000 \mathrm{~m}$ where a step scarp rises, known as the Tasman Fracture Zone. The east side is bounded by a steep slope which leads to the flat abyssal plain of the Tasman Sea (EXON et al. 1995). CONNFI. \& SiKES (1997) made several petrologic examinations of samples from 12 cores from the STR. They recognised two dominant sedimentary processes: high sedimentation rates and high terrestrial inputs with fine sediments in the northern part; low sedimentation rates, low terrestrial inputs and coarse sediments in the shallow water areas. The flanks of the STR, at depths exceeding $2900 \mathrm{~m}$, display hybrid conditions, with moderate sedimentation rates, low terrestrial inputs and fine sediments. WhITMORE \& BELTON (1997) reconstructed an acoustic facies map of the STR and identified 9 different echotypes. These occur as a complicate network on the flanks and the summit of the STR, reflecting the complicated morphology of the Rise. They concluded that the major sedimentary processes taking place in the STR area are deposition of pelagic sediments, such as clays, silts and oozes, and the subsequent reworking of these sediments by gravity flows and, mostly, bottom currents. Hydrocast measurements indicate that bottom currents are variable, at times flowing west rather than east (CONNEL \& SiKES 1997). On the other hand, EXON et al. (1995) reported winnowing of the sediment on the summit of the Rise, with sediment ponds on the East, suggesting a long-term eastward bias for deep flow. The Modern superficial sediment ripples are smaller than those described from cores, suggesting that bottom currents were stronger in the past (WhitMore \& Belton 1997).

\section{Surface currents, circulation and water masses}

The surface of the Southern Ocean between Antarctica, New Zealand and Australia, displays a latitudinal distribution of a series of oceanographic fronts. These frontal structures reflect the distribution of high-latitudinal wind fields and are defined by surface water temperature, salinity and productivity proxies. From North to South the fronts are:

- the SubTropical Front (STF)

- the SubAntarctic Front (SAF)

- the Antarctic Polar Front (APF)

The transect studied for this project is located between the STF and the APF (Fig. 2). An exception is sample BX013, which is located $\mathrm{N}$ of the STF in sub-tropical waters.
The STF is recognised as the boundary between the south-east Indian Ocean and the Southern Ocean and contrasts with nutrient poor Subtropical Surface Water (STSW) to the north, and Subantarctic Surface Water (SASW) waters to the south (PASSLOW et al. 1997). The STF is characterised by high seasonal phytoplankton production which enhances particulate organic matter (POM) and dissolved organic matter (DOM) to the seafloor (FRANÇOIS et al. 1993). The STF was first recognised by DEACON (1937) as a result of observed north to south variations in salinity and temperature (34.6$35.1 \%$ and $11-13.5^{\circ} \mathrm{C}$ respectively). This front exhibits seasonal mobility, reaching $44^{\circ} \mathrm{S}$ in winter and $42^{\circ} \mathrm{S}$ in summer (CHISWELl 1994) with a summer surface isotherm at $15^{\circ} \mathrm{C}$ (THIEDe et al. 1999). 


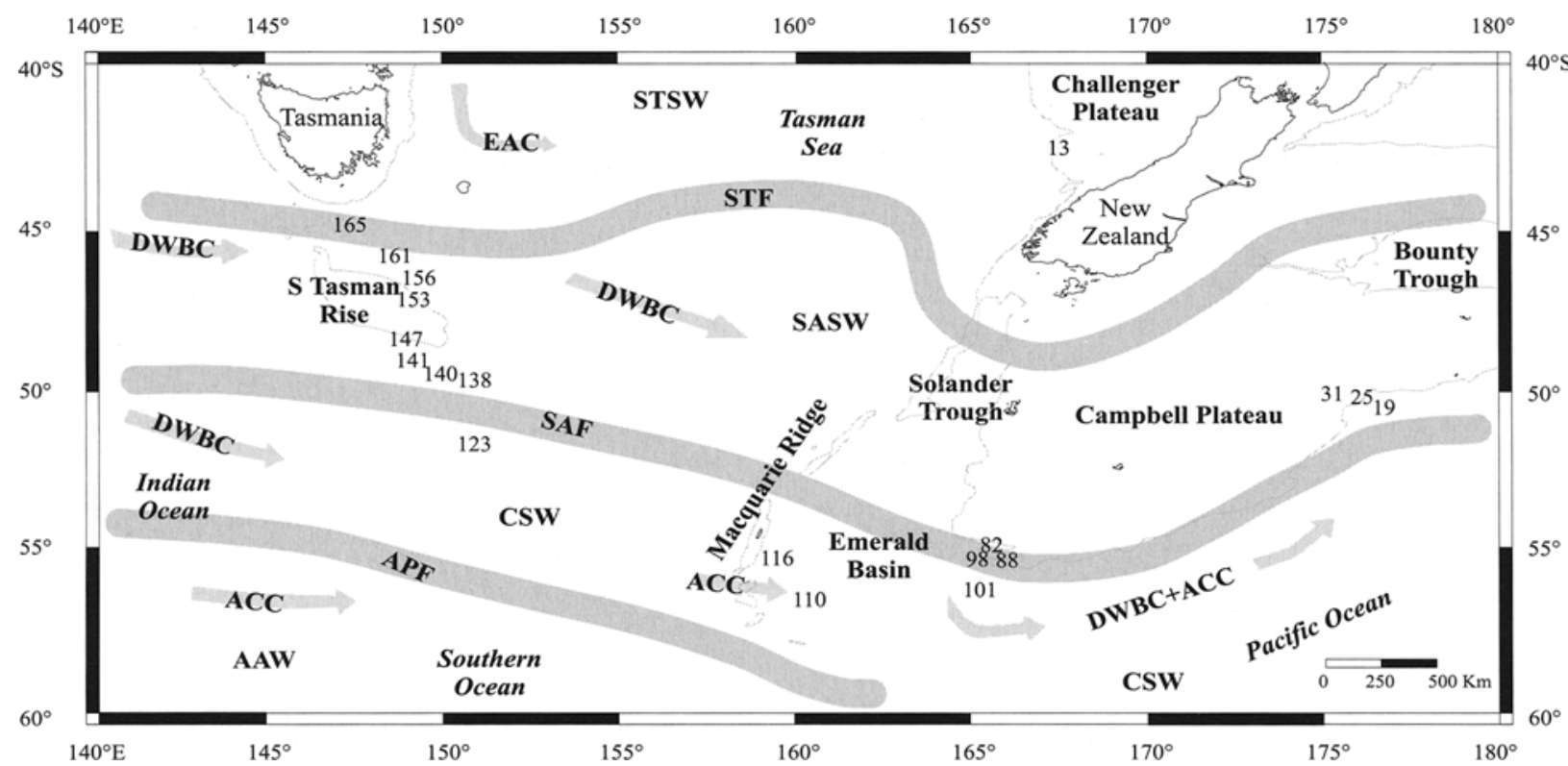

Fig. 2: Major water masses, fronts and currents in the study area. - STSW = Subtropical Surface Water; SASW = Subantarctic Surface Water: CSW = Circumpolar Surface Water; AAW = Antarctic Water; STF = Subtropical Front; SAF = Subantarctic Front; APF = Antarctic Polar Front; $E A C=$ East Australian Current;. DWBC $=$ Deep Western Boundary Current; ACC = Antarctic Circumpolar Current. - Sample sites are indicated with sample numbers (THIEDE et al. 1999). Isobath $=2000 \mathrm{~m}$.

The SAF separates low salinity (34.5\%) SASW from the cool Circumpolar Surface Water (CSW). It occurs between $48^{\circ} \mathrm{S}$ and $55^{\circ} \mathrm{S}$ in the Tasman Sea (OrSI et al. 1995 , CONNELL $\&$ SiKES 1997, Trull et al. 2001) and eastwards its distribution is influenced by bathymetry such that it deviates around the Macquarie Ridge and along the slope of the Campbell Plateau. In summer it coincides with the $8^{\circ} \mathrm{C}$ isotherm.

The APF is the northern boundary for Antarctic Water (AAW) which is characterised by temperatures lower than $5^{\circ} \mathrm{C}$. The APF has a very complex structure and has been further subdivided on the basis of temperature in to north and south subfronts occurring in an area between $52^{\circ} \mathrm{S}$ and $58^{\circ}$ S (TRUll er al. 2001).

Subantarctic Mode Water (SAMW) is the most surficial of the water masses occurring beneath the thermocline, between $400 \mathrm{~m}$ and $600 \mathrm{~m}$. CTD profiles taken during the TASQWA cruise along the Tasman Sea transect, display a lower boundary for SAMW at around $500 \mathrm{~m}$ of depth. Below SAMW, Antarctic Intermediate Water (AAIW) extends between $600 \mathrm{~m}$ and $1450 \mathrm{~m}$ of depch (Fig. 3). AAIW is formed as a result of APF sinking and is characterised by the salinity minimum (34.36-34.50\%), moderately high temperature $\left(3.20-7.00^{\circ} \mathrm{C}\right)$ and oxygen content $(3.20-4.70 \mathrm{ml} / \mathrm{l})$. Beneath AAIW the widespread Circumpolar Deep Water (CPDW) flows northward. This water mass is subdivided into three units, distinguished by chemico-physical parameters. The upper CPDWu, occurring to depths of $290 \mathrm{~m}$, is characterised by the oxygen minimum $(3.03-3.45 \mathrm{ml} / \mathrm{l})$ and by temperatures ranging between $1.60^{\circ} \mathrm{C}$ and $1.80^{\circ} \mathrm{C}$. The lower
CPDWi which occurs to depths of $3800 \mathrm{~m}$, is distinguished by a relatively high salinity $(34.71-34.73 \%$ ). The lowermost CPDW ii is characterised by low temperatures of $0.5-0.9^{\circ} \mathrm{C}$ and high oxygen content of $4.70-4.80 \mathrm{ml} / \mathrm{l}$ and occurs below $3800 \mathrm{~m}$, includes residues of North Atlantic Deep Water, Weddel and Ross Sea Deep Waters, the so-called Antarctic Bottom Water (ABW).

The water masses are deflected eastwards by the Antarctic Circumpolar Current (ACC) (Fig. 2). This current reaches the seafloor and has an average volume transport of about $130 \times 106 \mathrm{~m}^{3} / \mathrm{s}$ (THIEDE et al. 1999). It flows South of Australia, forming a weak anticyclonic gyre and a geostrophic northward current which flows west Tasmania. A small subsidiary flow into the Tasman Sea results from a deflection induced by the $\mathrm{W}$ margin of the NZ subcontinent. Approaching the Macquarie Ridge, the major flow of the $A C C$ merges with the Deep Western Boundary Current (DWBC) coming from the Tasman Sea and enters the Southwest Pacific through and around the gaps in the ridge. These flow along the margin of the Campbell Plateau but decouple at the mouth of the Bounty Trough, where DWBC flows north and ACC continues eastwards (CARTER \& MCCAVE 1997). The volume transport of the DWBC is an estimated $20 \times 106 \mathrm{~m}^{3} / \mathrm{s}$ (WARREN 1981).

The bulk of sediments studied in this work were recovered from sea floor sites covered by CPDW (only the S Tasman Rise, 1500-2000 m), CPDWi (only S Tasman Rise, 2800-3800 m) and CPDWii (S Tasman Rise and Emerald Basin, $>3800 \mathrm{~m}$ ) (Fig. 3; Appendix A). 


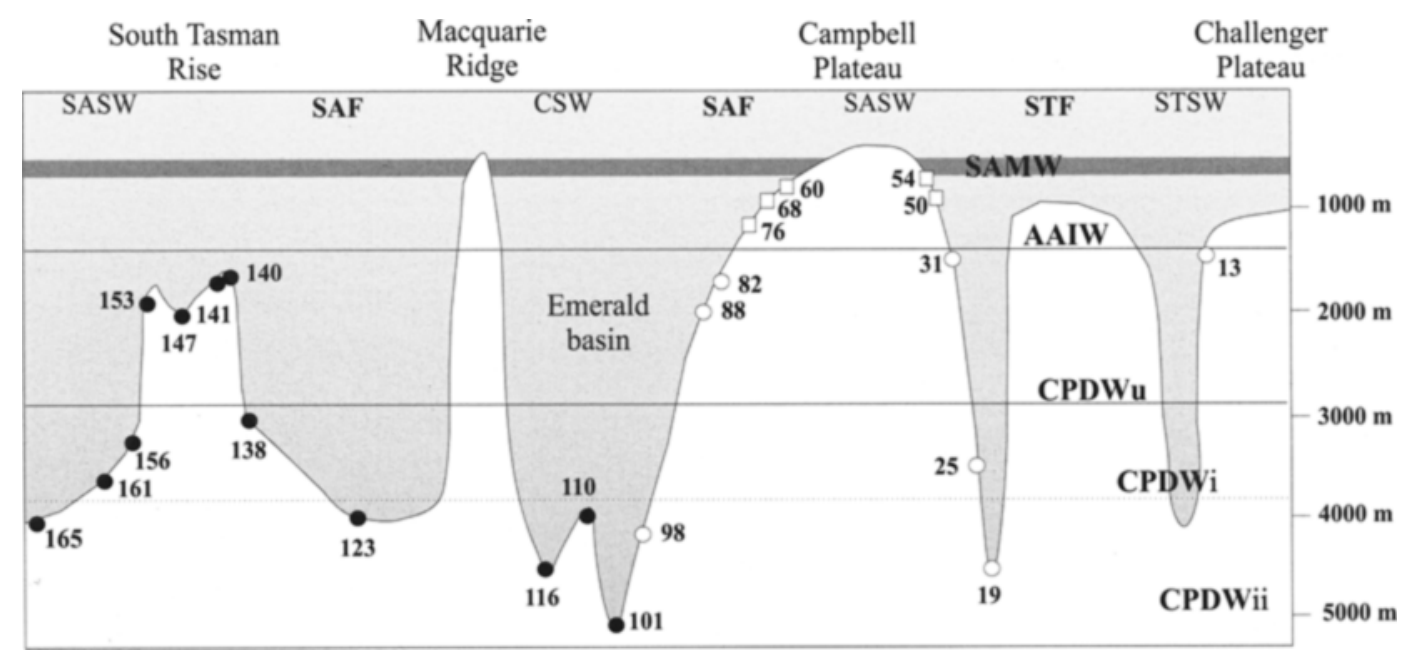

Fig. 3: Topographic profile along sampling transect showing water masses distribution and oceanic fronts position. Sampling stations are represented by sample numbers. Full circles indicate the samples used for the taxonomic, isotope and statistic analyses. Empty circles indicate the samples used for the isotope and statistical analyses. Squares indicate samples used for the isotope analyses. Water masses and fronts nomenclature as follows: SAMW = Subantarctic Mode Water $(400-600 \mathrm{~m})$; AAIW = Antarctic Intermediate Water $(600-1450 \mathrm{~m})$; CPDWu $=$ upper Circumpolar Deep Water (1450-2900 m); CPDWi = lower i Circumpolar Deep Water (2900-3800 m); CPDWii = lower ii Circumpolar Deep Water $(>3800 \mathrm{~m})$; STSW = Subtropical Surface Water; SASW = Subantarctic Surface Water; CSW = Circumpolar Surface Water; STF = Subtropical Front; SAF = Subantarctic Front.

\section{Material and methodology}

The samples used in this study were collected during the TASQWA cruise, which took place from mid-October to mid-November 1998 in the Southern Tasman Sea and the Southern Ocean. At 28 different stations ranging from $42^{\circ} \mathrm{S}$ to $57^{\circ} \mathrm{S}$ and from $146^{\circ} \mathrm{E}$ to $177^{\circ} \mathrm{E}, 29$ box-cores were successfully recovered from water depths ranging between $562 \mathrm{~m}$ and $5009 \mathrm{~m}$. The ostracods recovered from the shallower samples, from the high productivity plateaux northwest and south-east of New Zealand, were studied by Dr. T. JellineK (Forschungsinstitut Senckenberg, Frankfurt a.M., Germany) and Dr. K. Swanson (Canterbury University, Christchurch, New Zealand). The present project focuses mainly on the taxonomy of the ostracods recovered from eleven samples from the Emerald Basin and the South Tasman Rise within Circumpolar Deep Water (1450-4800 m); the isotope and statistical analyses were performed on the whole data set (17 samples). For the isotope analyses, additional specimens from five shallower samples $(562-1108 \mathrm{~m})$ were provided by Dr. T. JELLINEK (Senckenberg Museum, Frankfurt a.M.).

Two different sets of samples were available for the present project:

- SS: Surface sediment samples $(0-1 \mathrm{~cm})$. (Appendix B) For all these samples the volume is known (average volume of $400 \mathrm{ccm}$ ) and the dry volume has also been calculated. The samples were stained with Rose Bengal, and were provided by the LM University of Munich (Prof. A. AltENBACH).
- LVS: Large volume samples. (Appendix C)

The large volume sediment samples were obtained using the sediment which remained in the box-corer after other scientific needs were satisfied. These samples were provided by the Senckenberg Museum (Dr. T. JeLlineK) and were available only for the western part of the transect.

The SS-set, treated with Rose Bengal, provided around 3500 specimens from 17 samples. For some species only few adults were recovered and for others only juvenile moults, such that the systematic determination could only be made after assemblages were supplemented with material from the LVS. The latter provided about 7500 specimens from 10 samples.

Within the samples in common, the two data sets differ only in the number of specimens recovered and in their distribution within each sample. Both sets of samples were analysed using the same procedure, they were dry sieved (630, 315 and $200 \mu \mathrm{m})$ and all adult and juvenile ostracods were picked from all the size fractions. This method ensured that all adults and, depending on the species, several moult stages were obtained.

In combination, LVS and SS material has allowed the recognition of well-preserved ontogenetic sequences for most species. Additionally, councing the specimens found in the SS samples with intact soft parts and including the valves stained but without chitinous appendages preserved, the percentage of 'living' species is $1.53 \%$ of the total number of valves recovered. 


\section{Isotope Analyses}

The benthic ostracod shell is an ideal carbonate source for isotope analyses because it is composed of a stable form of carbonate, low-Mg calcite. The stable isotope composition of valves of fresh and brackish water ostracod species is routinely examined in studies of both 'natural' longer term environmental change and of anthropogenically induced alteration of aquatic habitats (KeATings et al. 2002, ANADÓn et al. 2002). However, equivalent studies of deep sea species are rarely undertaken (Didié \& BAUCH 2002). The ecological preferences and microhabitats and life histories of deep sea ostracods are poorly known, and what little information is available is usually based on functional interpretations of shell or appendage morphology or by analogy with results of observations of shallow water species observed in artificial cultures. Because initial isotopic research focussed on tests of foraminifers preserved in deep-water carbonates, it was inevitable that much of the research emphasis in terms of isotopic records and their implications would also concentrate on that group of protozoans. On that basis it is unlikely that existing, standardised isotopic profiles are likely to be compromised or replaced by equivalent records from ostracods, especially in view of the fact that the latter are in almost all cases minor constituent of the sediments being examined. For these reasons comparisons between the isotopic signature of metazoan ostracods and protozoan foraminifers are often used.

\section{Factors controlling stable isotope signals} in benthic ostracods

The isotopic signature of carbonate shells from benthic organisms is controlled by the $\delta^{18} \mathrm{O}$ and the temperature of the water at the sediment water interface during calcification, by the rate of calcification, by $\delta^{13} \mathrm{C}$ of the dissolved inorganic carbon (DIC) of the host water and by a 'vital effect' related to the physiology of the calcification process (WEFER \& BERGER 1991).

From laboratory culture data on the fresh water species Candona rawsoni, XIA et al. (1997a) demonstrated that the oxygen isotopic fractionation in ostracod calcite is affected by the water temperature. Moreover, the isotopic fractionation between ostracod shells and water is considered genus specific (CHIVAs et al. 2002) and the positive vital off-sets from equilibrium more-or-less constant within genera (HoLmES \& CHIVAS 2002). In fresh water environments the $\delta^{18} \mathrm{O}$ isotopic signature in shell calcite displays a constant positive off-set from the $\delta^{18} \mathrm{O}$ of the equilibrium calcite, probably function of vital effects (Xia et al. 1997b, Grafenstein et al. 1999). Didié \& BAUCH (2002) studied the isotopic signatures of calcite shells of the two marine genera Henrybowella and Krithe. Their results confirmed that ostracod calcite displays a positive off-set of the $\delta^{18} \mathrm{O}$ signature from the equilibrium calcite also in deep sea environments.

In benthic organisms, the $\delta^{13} \mathrm{C}$ signature at the sediment surface (epifaunal) and in the pore-water (infaunal) should reflect the $\delta^{13} C_{D I C}$ of the dissolved organic carbon (DIC) which is influenced by the DIC of the host water, by the aerobic respiration and by the anaerobic degradation of organic matter. The $\delta^{13} \mathrm{C}$ value in freshwater ostracod calcite is related to the $\delta^{13} \mathrm{C}_{\mathrm{DIC}}$ and also to microhabitats and vital effects (Xia et al. 1997b, Grafenstein et al. 1999). Didí \& BAuCH (2002) indicated that the $\delta^{13} \mathrm{C}$ values measured for ostracod valves show a different pattern with respect to foraminifers. Infaunal ostracods and foraminifers display comparable, slightly negative or slightly positive $\delta^{13} \mathrm{C}$ values whereas epifaunal foraminifers display positive $\delta^{13} \mathrm{C}$ values and epifaunal ostracods highly negative $\delta^{13} \mathrm{C}$ values. GRAFENSTEIN et al. (1999) studied the $\delta^{13} \mathrm{C}$ signature in fresh water ostracods collected in several lakes and they found out that the epibenthic species may display $\delta^{13} \mathrm{C}$ values more negative than those measured on infaunal species. They related these variations not only to the vital effect but also to the micro-scale variations of the isotopic composition of the DIC in the sediment pore waters. Their hypothesis was that in the sediment two micro-zones can be distinguished: an upper zone, "the ventilated micro-zone", in which the oxidation of organic matter will shift the pore water to negative values of $\delta^{13} \mathrm{C}$ and a lower zone where the anaerobic fermentation increases the $\delta^{13} \mathrm{C}$ in the carbonate phase. The boundary and depth of those two micro-zones may migrate, this dynamic being controlled by the oxygen partial pressure in the water and by the permeability of the sediment (GRAFENSTEIN et al. 1999).

Recently, measurements made on planktonic foraminifers cultured in scawater with different carbonate ion concentration but the same dissolved organic carbon (e.g. different $\mathrm{pH}$ ) produced different $\delta^{18} \mathrm{O}$ and $\delta^{13} \mathrm{C}$ values (SPERO et al. 1997). In particular, foraminiferal calcite formed at higher $\mathrm{pH}$ values displays lower $\delta^{18} \mathrm{O}$ values and a decrease of $0.22-0.33 \%$ of the foraminifer $\delta^{18} \mathrm{O}$ values corresponds to an increase of seawater $\mathrm{pH}$ of $0.2-0.3$ units (ZEEBE 1999). By analogy with those data, KeATINGS et al. (2002) postulate an inverse correlation between ostracod calcification rate (and isotope values) and $\mathrm{pH}$, with the calcite-water oxygen isotope fractionation depending mainly on $\mathrm{pH}$. They also suggested that the different calcification rate of different genera could be the main factor controlling the isotopic vital off-set of ostracods from the equilibrium calcite.

\section{Material and methods}

Oxygen and carbon isotopic values were measured on the four podocopid ostracod genera Krithe, Fallacihowella, Poseidonamicus and Bradleya. Although these are the most abundant genera throughout the samples studied for this project, representing more than $60 \%$ of the total fauna, enough adult specimens were recovered only from 13 of the 17 studied samples. Additional specimens from five shallower samples (562-1108 m) were provided by Dr. T. Jellinek (Senckenberg Museum, Frankfurt a.M.) (Fig. 3).

Krithe is known as an infaunal ostracod, with an experimentally proven ability to burrow in the sediment as deep as two centimetres (Majoran \& Agrenius 1995). The strongly box-framed hemicytherids Bradleya and Poseidonamicus probably live on the surface of fine, soft and stable substrate (BENSON 1975). The spinose trachyleberidid Fallacihowella is also considered epibenthic. BENSON (1975) hypothesised that the spinose ornamentation performs a mostly defensive role but 
Table 1: Sample numbers, water masses and corresponding water depths; measured benthic carbon and oxygen isotopes of Krithe, Bradleya, Fallacihowella (Fallac.) and Poseidonamicus (Poseid.).

\begin{tabular}{|c|c|c|c|c|c|c|c|c|c|c|c|c|c|}
\hline \multirow{2}{*}{ sample } & \multirow[t]{2}{*}{ water mass } & \multirow{2}{*}{\multicolumn{2}{|c|}{$\begin{array}{l}\text { water depth } \\
{[\mathrm{m}]}\end{array}$}} & \multicolumn{2}{|c|}{ Krithe } & \multicolumn{2}{|c|}{ Krithe juv. } & \multicolumn{2}{|c|}{ Bradleya } & \multicolumn{2}{|c|}{ Fallac. } & \multicolumn{2}{|c|}{ Poseid. } \\
\hline & & & & $\delta^{18} \mathrm{O}$ & $\delta^{13} \mathrm{C}$ & $\delta^{18} \mathrm{O}$ & $\delta^{13} \mathrm{C}$ & $\delta^{18} \mathrm{O}$ & $\delta^{13} \mathrm{C}$ & $\delta^{18} \mathrm{O}$ & $\delta^{13} \mathrm{C}$ & $\delta^{18} \mathrm{O}$ & $\delta^{13} \mathrm{C}$ \\
\hline 54 & SAMW & 562 & comma & & -0.12 & & & 2.83 & -4.42 & & & & \\
\hline 60 & AAIW & 601 & comma & 3.93 & -0.41 & & & 2.65 & -3.35 & 3.18 & -2.63 & & \\
\hline 50 & & 756 & comma & 3.85 & 0.25 & & & 3.04 & -2.87 & 4.31 & -2.44 & & \\
\hline 68 & & 980 & comma & 4.26 & -0.22 & & & 3.75 & -3.19 & 3.78 & -3.51 & & \\
\hline 76 & CPDWu & 1108 & comma & 5.25 & -1.05 & & & 3.52 & -3.82 & 3.64 & -3.6 & & \\
\hline 13 & & 1552 & sp. 9 & 4.31 & -1.05 & & & & & & & & \\
\hline 31 & CPDWi & 1571 & sp. 2 & 4.85 & -1.68 & & & 3.7 & -3.14 & & & & \\
\hline 140 & & 1634 & sp. 9 & 5.07 & -1.52 & 5.49 & -2.67 & 4 & -5.12 & & & 4.16 & -1.18 \\
\hline 141 & & 1660 & sp. 9 & 5.37 & -1.27 & & & & & & & & \\
\hline 82 & & 1685 & sp. 2 & 5.87 & -1.95 & & & 4.21 & -3.95 & & & & \\
\hline 153 & & 1841 & sp. 6 & 4.94 & -1.58 & & & 4.16 & -4.13 & 4.76 & -3.31 & 4.61 & -1.34 \\
\hline 88 & & 2074 & & & & & & & & & & 4.53 & -4.7 \\
\hline 147 & & 2146 & sp. 9 & 4.72 & -1.35 & 5.13 & -1.38 & & & & & 4.35 & -1 \\
\hline 138 & & 3020 & sp. 10 & 5.47 & -0.71 & 4.97 & -1.01 & & & 4.95 & -4.61 & 4.59 & -1.98 \\
\hline 156 & CPDWii & 3028 & sp. 6 & 4.64 & & & & & & & & & \\
\hline 25 & & 3211 & sp. 5 & 5.38 & -1.16 & & & & & & & 4.2 & -2.68 \\
\hline 161 & & 3685 & sp. 6 & 6.24 & -0.93 & 5.03 & -1.93 & & & 4.39 & -3.39 & & \\
\hline 165 & & 4070 & sp. 6 & & & 5.27 & -2.66 & & & 4.33 & -2.89 & & \\
\hline
\end{tabular}

also serves to extend sensory setae away from the carapace periphery. Henryhowella, a similar spinose trachyleberidid genus, is considered to live in the upper few millimetres of sediment (DIDIÉ \& BAUCH 2002).

For each analyses $50 \mu \mathrm{g}$ of calcite was required, corresponding to 10 to 16 valves of Bradleya sp., 10 to 18 valves of Poseidonamicus sp., 7 to 14 valves of Fallacihowella sp., and 10 to 12 valves of Krithe sp., using only adult valves for all taxa. Some additional measurements of juvenile moults (A-1, A-3) of Krithe sp. (15 valves) were made. Where possible, representatives of each taxon were analysed from each of the water masses sampled for this study. The analyses of Krithe were performed on one species from each sample ( $K$. sp. 2, $K$. sp. 5, $K$ sp. 6, K. sp. 9, $K$. sp. 10, described in the present study and $K$. comma Ayress, Barrows, Passlow \& Whatley 1999 , from the five shallower samples), as a consequence the resulting values refer to single species stable isotope values (Tab. 1). The analyses of the three epibenthic taxa were performed on different species from each sample, as a consequence the resulting values refer to average generic stable isotope values.

For the stable isotopic measurements a Thermo Finnigan MAT 252 Delta Plus mass spectrometer combined with the preparation unit Thermo Finnigan MAT 252 Gas Bench II was used. The analytical precision is $\leq 0.1 \%$ both for $\delta^{18} \mathrm{O}$ and $\delta{ }^{13} \mathrm{C}$. The results are given in the conventional $\delta$ notation relative to the NBS 18 and NBS 19 standard, which is equal to the Pee Dee Belemnite standard (PDB). All the analyses were performed by Dr. U. STRUCK (Geo-Bio Centrum, University of Munich).

\section{Statistical analyses}

Because samples used for this study in effect represent two data sets, the first problem to be confronted prior to embarking on any statistical analyses was how to normalise the samples. Clearly without such consideration, the results of statistical analyses for one data set, the surface samples (SS) with a small but known volume or the large volume samples (LVS) with a large and unknown volume, would have been misleading. For example, sample BX116 from the Emerald Basin, contained in total six taxa only two of which were represented in the SS samples. Without the LVS data, the presence of the two species could have been interpreted as reflecting environmental conditions, rather than being a consequence of small sample size. To avoid this problem, the two data sets were combined, the relative abundance in percentage being calculated for each of the 73 species and this then being used as the basis for multivariate statistical analyses (as recommended by HAMMER, pers. com.).

The taxonomy of the ostracods recovered from the S Tasman Rise and the Emerald Basin samples is discussed in the present study, whereas the taxonomy of the ostracods recovered from the 6 samples from the Campbell Plateau and the Challenger Plateau is based on Jellinek \& Swanson (2003) (Fig. 3).

Both species (R-mode) and samples (Q-mode) were grouped by cluster analyses and detrended correspondence analyses (DCA) using the software package PAST (ver. 0.94) (HAMmer et al. 2001). 


\section{Isotope analyses}

\section{Stable isotope signatures in deep sea ostracods}

To allow a comparison between the only data available for isotope values from deep sea Ostracoda, this study has attempted to focus on same taxa as those used by Didié \& BAUCH (2002). In addition to Krithe, Fallacihowella was chosen as a genus homeomorphic with Henryhowella to which were added two other very common epifaunal deep sea genera Poseidonamicus and Bradleya. All the measured carbon and oxygen isotope values are presented in Tab. 1 and the average stable isotope values measured on the four benthic ostracod genera and calculated for each water mass are shown in Tab. 2.

DiDiè \& BAUCH (2002) calculated an average off-set for Krithe from the equilibrium calcite about $+1.4 \%$. Adding this average off-set to the average values of $\delta^{18} \mathrm{O}$ measured for Krithe specimens from the SW Pacific, gives an estimated $\delta^{18} \mathrm{O}$ value of the equilibrium calcite of $3.15 \%$ (Fig. 4). The comparison between the isotopic values of the four studied genera and the equilibrium calcite $\delta^{18} \mathrm{O}$ value reveals that $P o$ seidonamicus and Fallacihowella show a clear positive off-set from the equilibrium calcite $(1.25 \% 0$ and $1.03 \% 0$ respectively) whereas Bradleya shows only a slightly positive off-set $(0.29 \%)$, due to the light value of $\delta^{18} \mathrm{O}$ measured on the shallower samples (Tab. I, Fig. 4). On the Iceland Plateau, the average difference of $\Delta \delta^{13} \mathrm{C}$ between infaunal Krithelepifaunal Henryhowella is about $1.34 \%$ (Didie \& BAUCH 2002) whereas in the Tasman Sea the average $\Delta \delta^{13} \mathrm{C}$ between Krithe and Fallacihowella is $2.44 \%, 1.34 \%$ between Krithe and Po-

Table 2: Average values of carbon and oxygen isotopes of benthic ostracod species (given in \%o relative to PDB) grouped according to the water masses. - When possible, analyses were performed on several samples within each water mass. The asterisk indicates measurements made on one single sample. The abbreviations used are: Fal. for Fallacihowella; Brad. for Bradleya; Pos. for Poseidonamicus; st. dev. for standard deviation; SAMW for Subantarctic Mode Water; AAIW for Antarctic Intermediate Water; CPDWu for Circumpolar Deep Water (upper); CPDWi for Circumpolar Deep Water (lower i); CPDWii for Circumpolar Deep Water (lower ii). - The temperature ranges are from THIEDE et al. (1999), the organic carbon flux $\left(\mathrm{C}_{\mathrm{org}}\right)$ values are from SCHENK (2001).

\begin{tabular}{|c|c|c|c|c|c|c|c|c|c|c|}
\hline \multirow[t]{2}{*}{ water mass } & \multicolumn{2}{|c|}{ Krithe } & \multicolumn{2}{|c|}{ Fal. } & \multicolumn{2}{|c|}{ Brad. } & \multicolumn{2}{|c|}{ Pos. } & \multirow{2}{*}{$\underset{\left[\mathrm{g} \mathrm{m}^{-2} \mathrm{a}^{-1}\right]}{\mathrm{C}_{\text {org }}}$} & \multirow{2}{*}{$\begin{array}{c}\mathbf{t} \\
{\left[{ }^{\circ} \mathrm{C}\right]}\end{array}$} \\
\hline & $\delta^{18} \mathrm{O}$ & $\delta^{13} \mathrm{C}$ & $\delta^{18} \mathrm{O}$ & $\delta^{13} \mathrm{C}$ & $\delta^{18} \mathrm{O} \delta$ & $\delta^{13} \mathrm{C}$ & $\delta^{18} \mathrm{O}$ & $\delta^{13} \mathrm{C}$ & & \\
\hline SAMW & $3.93^{*}$ & -0.27 & $3.18^{*}$ & $-2.63^{*}$ & 2.74 & -3.89 & & & $4.7-10.4$ & $6-10$ \\
\hline AAIW & 4.45 & -0.34 & 3.91 & -3.18 & 3.44 & -3.29 & & & $3.5-7.1$ & $3.20-7.00$ \\
\hline CPDWu & 4.39 & -1.49 & $4.76^{*}$ & $-3.31^{*}$ & 4.02 & -4.09 & 4.40 & -1.86 & $\sim 2.7$ & $1.60-1.80$ \\
\hline CPDWi & 5.43 & -0.93 & 4.67 & -4.00 & & & 4.40 & -2.33 & $<1.3$ & $0.90-1.60$ \\
\hline CPDWii & & & $4.33^{*}$ & $-2.89^{*}$ & & & & & $<1.3$ & $0.55-0.90$ \\
\hline average & 4.55 & -0.76 & 4.17 & -3.20 & 3.44 & -3.76 & 4.40 & -2.10 & & \\
\hline st. dev. & 0.546 & & 0.495 & 0.578 & 0.463 & 0.523 & 0.340 & 0.000 & 0.235 & \\
\hline
\end{tabular}

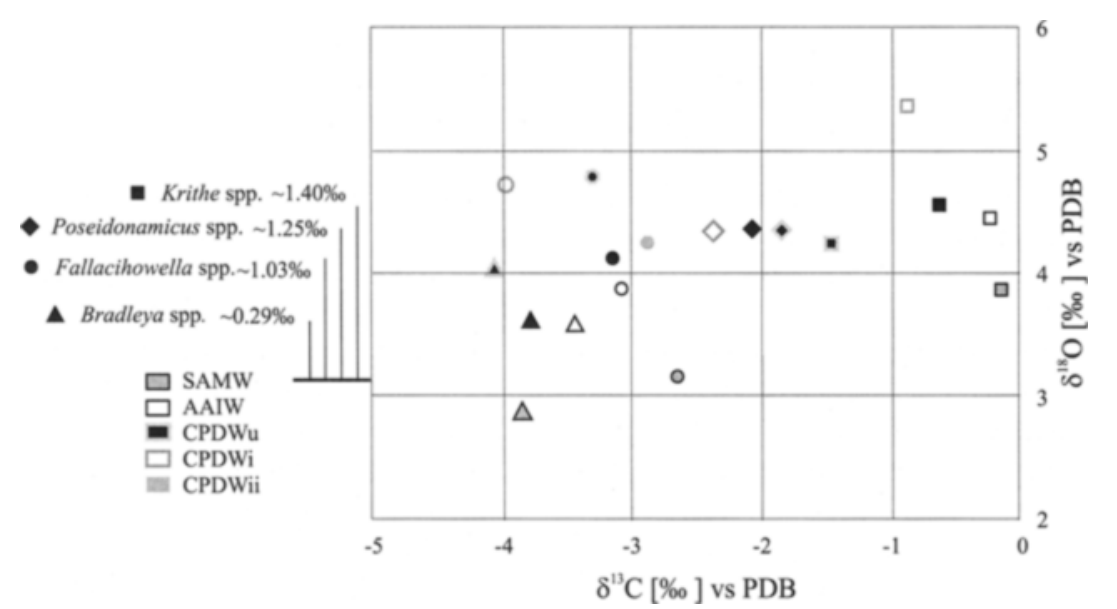

Fig. 4: Comparison between the oxygen and carbon isotope analyses on valves from the benthic ostracod genera Krithe, Poseidonamicus, Fallacihowella and Bradleya. Black symbols represent the average values of ostracod calcite calculated for each water mass (coloured symbols). Empry symbols represent the average values for each taxon. The horizontal grey bar on the left represents the estimated $\delta^{18} \mathrm{O}$ value of the equilibrium calcite calculated using the vital offset from the equilibrium calcite of the genus Krithe (DIDIE \& BAUCH 2002). The vertical bars on the left represent the average off-set of each ostracod taxon from the estimated equilibrium calcite. 
seidonamicus and 3.00\% between Krithe and Bradleya. The $\Delta \delta^{13} \mathrm{C}$ between infaunal/epifaunal ostracod taxa does not show a constant off-set within the water masses, and this probably reflects the fact that the trophic conditions vary significantly between stations.

\section{Carbon isotopic composition}

The Krithe $\delta^{13} \mathrm{C}$ values display substantial variability, ranging between 0.25 and $-1.05 \%$ within AAIW, between -1.05 and $-1.95 \%$ within the CPDWu and between -0.71 and 1.16 within the deeper water masses. The lowest value $0.12 \%$ was recorded in one sample within the SAMW. The differences in the isotopic signal within the same water masses could be linked to the species/specific vital effect. However, between $1552 \mathrm{~m}$ and $2146 \mathrm{~m}$ of depth, $\delta^{13} \mathrm{C}$ values measured for the same species, Krithe sp. 9, display a difference of $0.25 \%$ whereas equivalent analyses of Krithe sp. 5 and Krithe sp. 10 (between $3200 \mathrm{~m}$ and $3700 \mathrm{~m}$ of depth), resulted in a difference of $0.23 \%$ (Fig. 5). Additional isotopic analyses were also carried out on randomly selected juvenile specimens and the $\delta^{13} \mathrm{C}$ values from these are more negative than those measured for adult valves (empty circles in Fig. 5).

All the epibenthic species display $\delta^{13} \mathrm{C}$ values more negative than Krithe. Fallacihowella presents a $\delta^{13} \mathrm{C}$ signature which ranges between $-2.44 \% 0$ and $-3.60 \%$ within the AAIW, and between $-3.31 \%$ and $-4.61 \%$ within the deeper water masses. Above $3000 \mathrm{~m}$, the $\delta^{13} \mathrm{C}$ values tend to be depleted in $\delta^{13} \mathrm{C}$ whereas the scattered values available below this depth are slightly enriched. Bradleya is the genus showing the most negative values of $\delta^{13} \mathrm{C}$ ranging from $-2.87 \%$ o to $4.42 \%$ within the AAIW and between $-3.14 \%$ and $-5.12 \%$ within the CPDWu. Poseidonamicus displays a variable $\delta^{13} \mathrm{C}$ signature with values ranging berween $-0.79 \%$ and $-4.7 \%$ within the CPDWu, and berween $-1.98 \%$ and $-2.68 \%$ within the CPDWi.

\section{Carbon isotopic values, microhabitats, vital effects and diets}

As the $\delta^{13} \mathrm{C}$ signal is influenced by the microhabitat in which the animals live, more precise descriptions of the physico-chemical character of the benthic habitat are required if isotopic studies of extant and fossil calcite-precipitating organisms are to progress significantly. In fact to date, the description of deep-ocean benthic habitats especially, is generally limited to the infaunal/epifaunal character of the organisms they host. With respect to soft bottom substrate and foraminifers, the 'so-called' epifaunal species are considered to sink a few millimetres into the substrate, dwelling in the upper layers of the sediment whereas the dominantly infaunal species live at least $10 \mathrm{~mm}$ deep in the sediment (JORISSEN et al. 1995; HAYWARD et al. 2002). True epifaunal species are only those regarded as living in a slightly elevated positions on the sediment surface (LUTZE \& THIEL 1989). These positions are not fixed in the sediment but rather it is envisaged that the organisms may migrate as a response to fluctuations in the availability of food, or significant alterations to ambi- ent environmental conditions. As a consequence, the $\delta^{13} \mathrm{C}$ signal may also be affected by the organic carbon flux rates to the sea bottom (BuZAS et al. 1993). MACKENSEN et al. (2000) demonstrate that foraminifers migrate within the sediment and that the isotopic signal of many species is independent from the depth of the habitat.

Because many benthic ostracod and foraminiferal species occupy the same microhabitats and, in all probability, migrate within or on top of the sediment to avail themselves of more appropriate environmental conditions elsewhere, the 'contradiction' occurring in their epi-benthic $\delta^{13} \mathrm{C}$ signatures must have resulted for other reasons (e.g. vital effects and/or diet). The vital effect can generally be sub-divided into two categories: the metabolic and kinetic isotope effects. Metabolic effects reduce the $\delta^{13} \mathrm{C}$ values of the respired $\mathrm{CO}_{2}$ incorporated in the shell and kinetic effects, occur during rapid shell calcification may also result in depleted $\delta^{13} \mathrm{C}$ values (WEFER \& BERGER 1991). Since podocopid ostracods moult 8 times before reaching the adult stage (HoRNE et al. 2002), the isotopic signal in adult valves reflects environmental conditions experienced by the last moult. On the other hand, the isotopic signal of foraminifers, which progressively add carbonate to their shells, is related to the average environmental conditions experienced throughout the lifetime of the protozoans. The fact that during moulting the ostracod animal is not protected by the carapace, e.g. not safe from predators, implies that the calcification process should occur rapidly (DE DECKKER 2002). Experimental data on fresh water species indicate that the moulting process may be completed within hours or days (Turpen \& ANGell 1971; ChIvas et al. 1983).

In response to pulsed food input and varying environmental conditions, ostracods are able to modify the phasing of critical stages in their life cycle and their physiology. Shallow marine species react to extreme environmental conditions by closing their shell and reducing levels of activity and thus consuming less oxygen (PEPER 1986), many fresh water species can survive environmental stress by adopting an equivalent or deeper state of torpor (DE DECKKER 2002). Similar adaptations would also be appropriate for survival on the seafloor at bathyal and abyssal depths, to which only $1-3 \%$ of surface primary productivicy is delivered as marine snow (ANGEL 1990). Podocopid ostracods are defined as herbivores, detritivores or carnivores with few examples of commensal species (SMITH \& HORNE 2002), however the feeding habits of deep sea ostracods have not been examined in detail. Since the four investigated genera are non-swimmers, they must mainly rely on the particulate organic matter advected to the sea floor and components of the microbial assemblage for food: Hence, the different stable carbon isotopic compositions of those food sources may also have an important effect on the isotopic composition of deep-sea ostracod valves.

The $\delta^{13} \mathrm{C}$ values of Krithe measured from the Tasman Sea specimens are highly negative when compared to those measured by DIDIÉ \& BAUCH (2002) for specimens of that genus recovered at comparable depths in the North Atlantic. Although this may be related to the species/specific vital effects and the different environmental conditions where the animals live, a partial explanation of these contrasts could arise because of variations in the $\delta^{13} \mathrm{C}$ of the organic carbon being delivered to the sea floor. For example, the $\delta^{13} \mathrm{C}$ values of phytoplankton organic carbon in the Antarctic waters 
reach about $-29 \%$ whereas at northern high-latitudes, $\mathrm{NE}$ of Greenland, phytoplankton values reach $-18.5 \%$ to $-22 \%$ o (MACKENSEN et al. 2000). Since phytoplankton is a significant contributor to the flux of the organic carbon to the sea floor, it is predictable that this is one of the food sources which potentially may affect the ostracod carbon signatures. Being infaunal, it is probable that Krithe relies on the small quantities of buried organic material or, additionally, on the microbial assemblage occurring within sediment interstices.

The differences in carbon isotopic composition berween juvenile and adult specimens of the infaunal Krithe have been already observed by DidiÉ \& BAUCH (2002) and in fresh water ostracods by XIA et al. (1997b). These authors concluded that the strongly negative values in juveniles resulted from differences in microhabitats occupied through ontogeny and/or because of variations in the calcification process resulting from seasonal, temperature and productivity fluctuations. In the deep sea, where the temperature range at the sedimentwater interface is very small, it is also possible that adults and juveniles inhabit different horizons within the sediment, such that they calcify at different rates and/or that juveniles moult only during periods of significant primary production when other food sources are available for potential predators.

The $\delta^{13} \mathrm{C}$ signature of Fallacihowella shows an almost constant behaviour (Fig. 5) implying that this taxon uses analogous microhabitats and food sources at all water depths. The Fallacihowella/Bradleya $\Delta \delta^{13} \mathrm{C}$ attains a maximum value of $0.82 \%$ and an average value of $0.37 \%$. It is most likely that the two taxa occupy similar microhabitats, with Bradleya in slightly more elevated positions. The Fallacihowella/Poseidonamicus $\Delta \delta^{13} \mathrm{C}$ does not display a constant behaviour, with maximum value of $-2.63 \%$ and minimum value of $-0.71 \%$. Most likely Poseidonamicus may occupy a different microhabitat which could be partially infaunal. This hypothesis is also confirmed by the fact that some $\delta^{13} \mathrm{C}$ values of Poseidonamicus are very close to those of Krithe. The Fallacihowella/Krithe $\Delta \delta^{13} \mathrm{C}$ displays extremely negative values ranging from $1.73 \%$ to $-3.90 \%$ confirming the fact that Krithe occupies an infaunal habitat.

\section{Oxygen isotopic composition}

The $\delta^{18} \mathrm{O}$ signature of Krithe shows a general trend of lower isotope values at warmer temperatures. The $\delta^{18} \mathrm{O}$ values range between $5.25 \%$ and $3.93 \%$ within the AAIW, between $5.87 \%$ and $4.31 \%$ within the CPDWu and between $6.24 \%$ and $4.64 \%$ within the deeper water masses. Some scattered measurements made on juveniles of Krithe were made and they resulted in higher values within the CPDWu and lower values within the CPDWi water masses (empty circles in Fig. 5).

The average $\delta^{18} \mathrm{O}$ signature of the epibenthic Fallacibowella is shifted of about $0.82 \%$ o towards values lower than the average $\delta^{18} \mathrm{O}$ measured for Krithe. Fallacihowella produced values ranging between $3.18 \% 0$ and $4.31 \% 0$ within the AAIW and between $4.33 \%$ and $4.95 \%$ within the deeper water masses. This reflects a larger response to the temperature variations than that shown by Krithe, off-set is recorded within the AAIW where most of the temperature variations occur. The average off-set between the $\delta^{18} \mathrm{O}$ values of Poseidonamicus and Krithe is about $0.54 \%$. Poseidonamicus shows an almost constant $\delta^{18} \mathrm{O}$ signature with a maximum specific offset of $0.45 \%$. Bradleya displays the lowest values of $\delta^{18} \mathrm{O}$ and the average off-set with respect to Krithe is about $1.21 \%$. In general, Bradleya displays much lower $\delta^{18} \mathrm{O}$ values compared with the two other epifaunal taxa and, in some cases, the values are very close to the estimated $\delta^{18} \mathrm{O}$ value for the equilibrium calcite. Within the SAMW and the AAIW the average values of $\delta^{18} \mathrm{O}$ show a negative off-set of about $0.35 \%$ from the values estimated for the equilibrium calcite.

\section{Oxygen isotopic values, microhabitats, vital effects and temperatures}

The isotopic signature of the infaunal Krithe species should reflect the water composition of the interstitial water and its temperature. But the correlation between $\mathrm{T}$ and $\delta^{18} \mathrm{O}$ values is not linear and the influence of a 'vital effect' is also

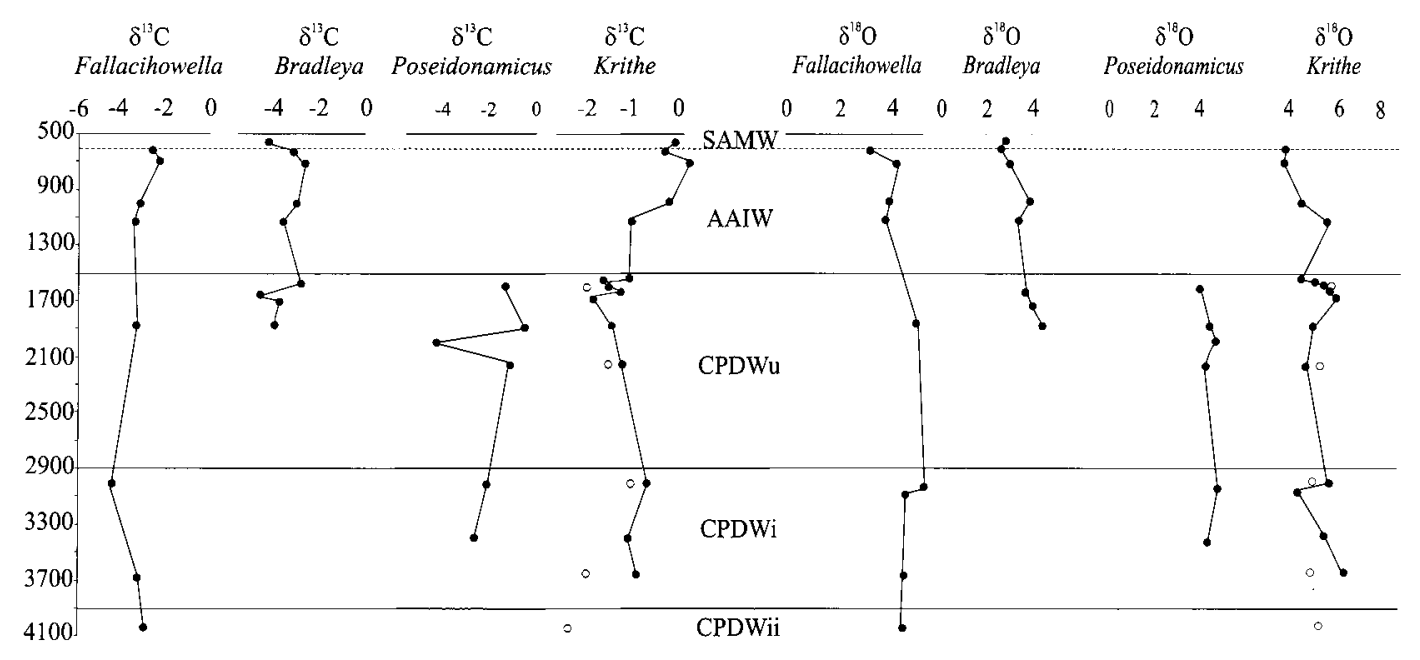

Fig. 5: Oxygen and carbon isotope records in the water column. - SAMW = Subantarctic Mode Water; AAIW = Antarctic Intermediate Water; CPDWu = Circumpolar Deep Water (upper); CPDWi = Circumpolar Deep Water (lower i); CPDWii = Circumpolar Deep Water (lower ii). Open circles indicate analyses on juveniles. 
seen as a significant influence on biogenic $\delta^{18} \mathrm{O}$ values. The species/specific effect seems to play an important role in the $\delta^{18} \mathrm{O}$ signature. In fact, between depths of $1634 \mathrm{~m}$ and 2146 $\mathrm{m}$ of depth $\delta^{18} \mathrm{O}$ values measured for the same species, Krithe sp. 9, display a difference of $0.35 \%$ whereas $\delta^{18} \mathrm{O}$ values measured on different species, Krithe sp. 5 and Krithe sp. 10 from between $3200 \mathrm{~m}$ and $3700 \mathrm{~m}$ of depth, present a difference of $0.86 \%$ (Tab. 1, Fig. 5).

The differences measured between $\delta^{18} \mathrm{O}$ values in adults and juveniles of Krithe (empty circles in Fig. 5) contradict the conclusions of DIDIÉ \& BAUCH (2002) who stated that the $\delta^{18} \mathrm{O}$ signature is independent from the moult stage data. Studies on non-marine ostracods show that juveniles and adults have a different $\delta^{18} \mathrm{O}$ signature, reflecting the fact that they probably calcify shells in different seasons (XIA et al. $1997 \mathrm{~b})$ and/or that they have different calcification rates (KeATings et al. 2002). In the deep sea, where temperatures remain constant all over the year, it is most likely that there may be an association between the different $\delta^{18} \mathrm{O}$ values in different moult stages and the different calcification rates.
Since the calcification rate seems to be controlled by the $\mathrm{pH}$ values of the ambient seawater and/or interstitial fluids, the heavier $\delta^{18} \mathrm{O}$ values of the juvenile valves may correspond to a calcification rate faster than that of adults and to a slightly lower $\mathrm{pH}$ of the microhabitat where they live.

The three epibenthic species display different patterns of $\delta^{18} \mathrm{O}$ signature. Fallacihowella and Bradleya from shallower samples have lower $\delta^{18} \mathrm{O}$ values. It is possible that they prefer to live at the water-sediment interface or in slightly elevated positions incorporating, with some vital effects, the $\delta^{18} \mathrm{O}$ value of the equilibrium calcite. In contrast, isotopic concentrations in specimens from deeper samples may reflect differences in microhabitat selection driven by the significantly reduced availability of food. Poseidonamicus $\delta^{18} \mathrm{O}$ values show a small off-set which could be explained by a low sensitivity of that genus to temperature changes within the CPDWu and CPDWi water masses and with a high sensitivity to temperature changes above $1.80^{\circ} \mathrm{C}$. In contrast with Poseidonamicus, Bradleya is recovered most commonly from warmer bottom waters with temperatures within the range of $3.2-10^{\circ} \mathrm{C}$.

\section{Statistical analyses}

\section{Cluster analysis on ostracod assemblages}

A Q-mode hierarchical cluster analysis of the total association was computed using the Chord distance measure and the un-weighted pair-group method using arithmetic average (UPGMA). By selecting a cut-off value of 0.1 for the across- cluster similarity, samples were statistically discriminated into four groups (Fig. 6A).

Cluster A consists of a single sample BX013, representing $0.11 \%$ of the total fauna and joined to the neighbour group in the near branches and is an exception with respect to the grouping structure. This clearly mirrors its peculiar geographical position, since BX013 is the only sample of the data
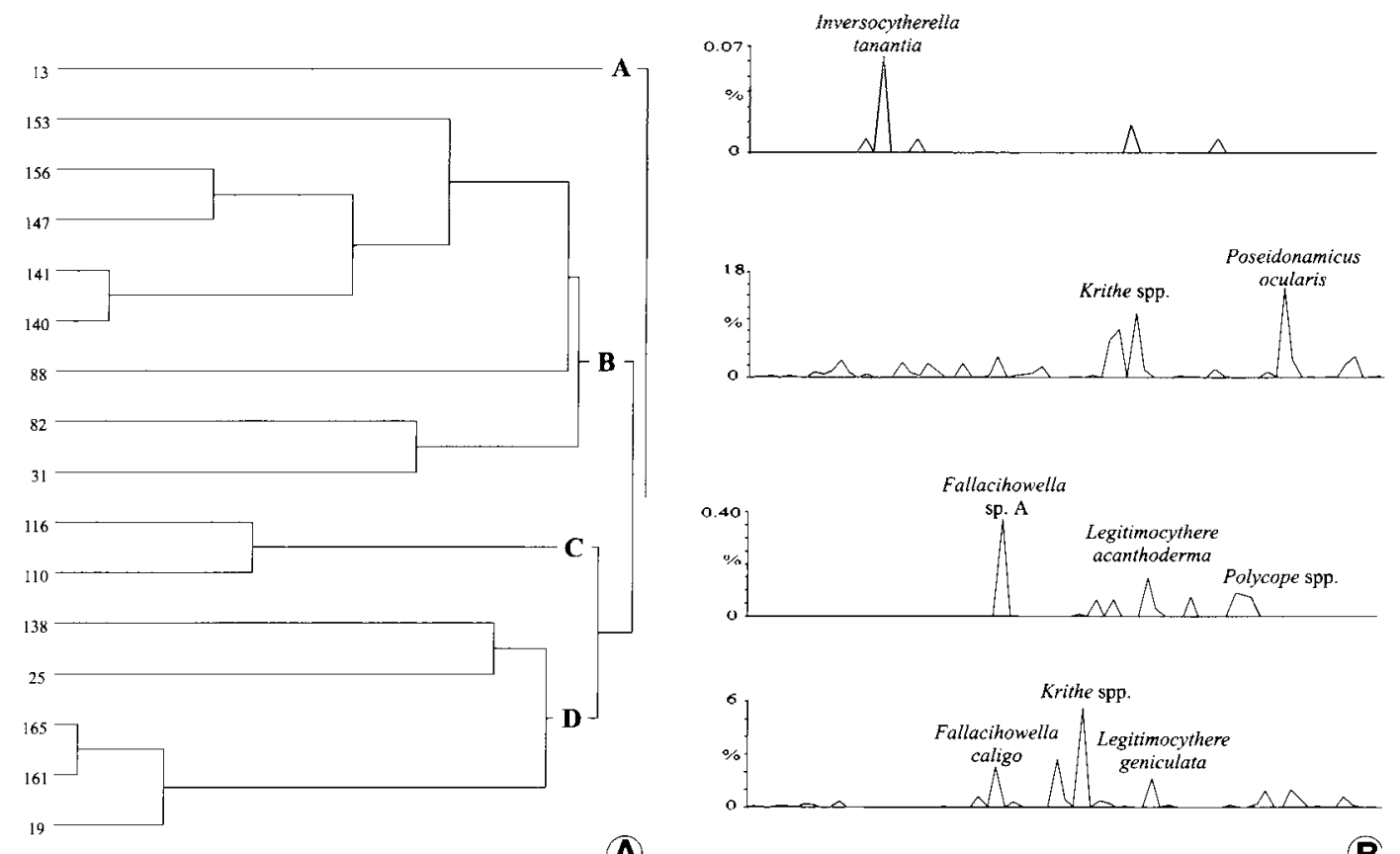

(A)

Fig. 6: Q-mode hierarchical cluster analysis plot of the complete data set. - A: Capital letters indicate the clusters identified by a cut-off value of 0.1. - B. For each cluster, the plot of the relative abundance in percent of the total ostracod fauna is figured with the indication of the dominant species. 
set located on the Challenger Plateau and N of the Subtropical Front. It also reflects the fact that the ostracod fauna is anomalous with respect to the remaining samples, in the sense that the assemblage although extremely small, is dominated by Platycopina (Fig. 6B).

Cluster B represents approx. $80.46 \%$ of the total fauna and includes a large number of taxa. This cluster is dominated by various species of Krithe and by Poseidonamicus ocularis (Fig. 6B). The appearance of sample BX156 in this cluster is probably due to down-slope contamination by some species which normally inhabit shallower localities on the $S$ Tasman Rise. In particular the small graphic distance between BX147 and BX156 (Fig. 6A) can be explained with the dominance in both samples of Krithe sp. 9.

Cluster $\mathrm{C}$ is formed by the two samples from the Emerald Basin, representing $0.93 \%$ of the total fauna. The assemblage is dominated by Fallacihowella sp. A. and characterised by the presence of two Polycope species, not represented elsewhere within the data set (Fig. 6B).

Cluster D represents around $18.50 \%$ of the total fauna and is composed by a group of deep samples from the $S$ Tasman Rise and the Campbell Plateau. The dominant taxa are various species of Krithe and Fallacibowella caligo (Fig. 6B).

\section{Detrended correspondence analyses on assemblages and species}

For a more detailed statistical analyses of the structure of the ostracod assemblage a DCA was performed on the same data set in Q- and R-mode (Fig. 7). The eigenvalues are 0.7689 for Axis 1 and 0.4628 for Axis 2 .

Although a first separation in three main groups based on water masses characteristics (CPDWu, CPDWi and CPDWii; Fig. $7 \mathrm{~A}$ ) can easily be achieved, the structure of the groups and the arrangement of the points according to the two main axes imply to a more complicated picture. Axis 1 should represent the highest variance of the data set but its influence alters with water depth. In the Q-mode DCA plot (Fig. 7A) the arrangement of the stations in cluster $B$ shows only a small deviation from the Axis 2 value and a wider spread relative to Axis 1. Cluster D on the other hand, displays an inverse pattern, with the distribution of the stations mainly controlled mainly by Axis 2 . Cluster A represents the contribution of a single sample on the Challenger Plateau and cluster $\mathrm{C}$ the rwo samples from the Emerald Basin.

The R-mode DCA plot (Fig. 7B) shows the distribution of the 73 species. Species characteristic of each group are indicated with the same symbol used for the stations to which they belong.

The Q-mode DCA further subdivides the samples within cluster B and D into several groups (Tab. 3). Group B' includes two samples from the escarpment of the Campbell Plateau (Fig. 8). Group B" includes all the samples from the $S$ Tasman Rise at water depths above $2200 \mathrm{~m}$ and a single sample from the Campbell Plateau escarpment, which is slightly deeper than those forming group B' (Fig. 8). Group B"' is represented by sample BX156, from a water depth of $3211 \mathrm{~m}$ and which is in all probability contaminated by the downslope movement of sediment from the $S$ Tasman Rise (Fig. 8). The BX156 fauna displays many affinities with the deeper samples on the $\mathrm{N}$ flank of the Tasman Rise, but it is differen-

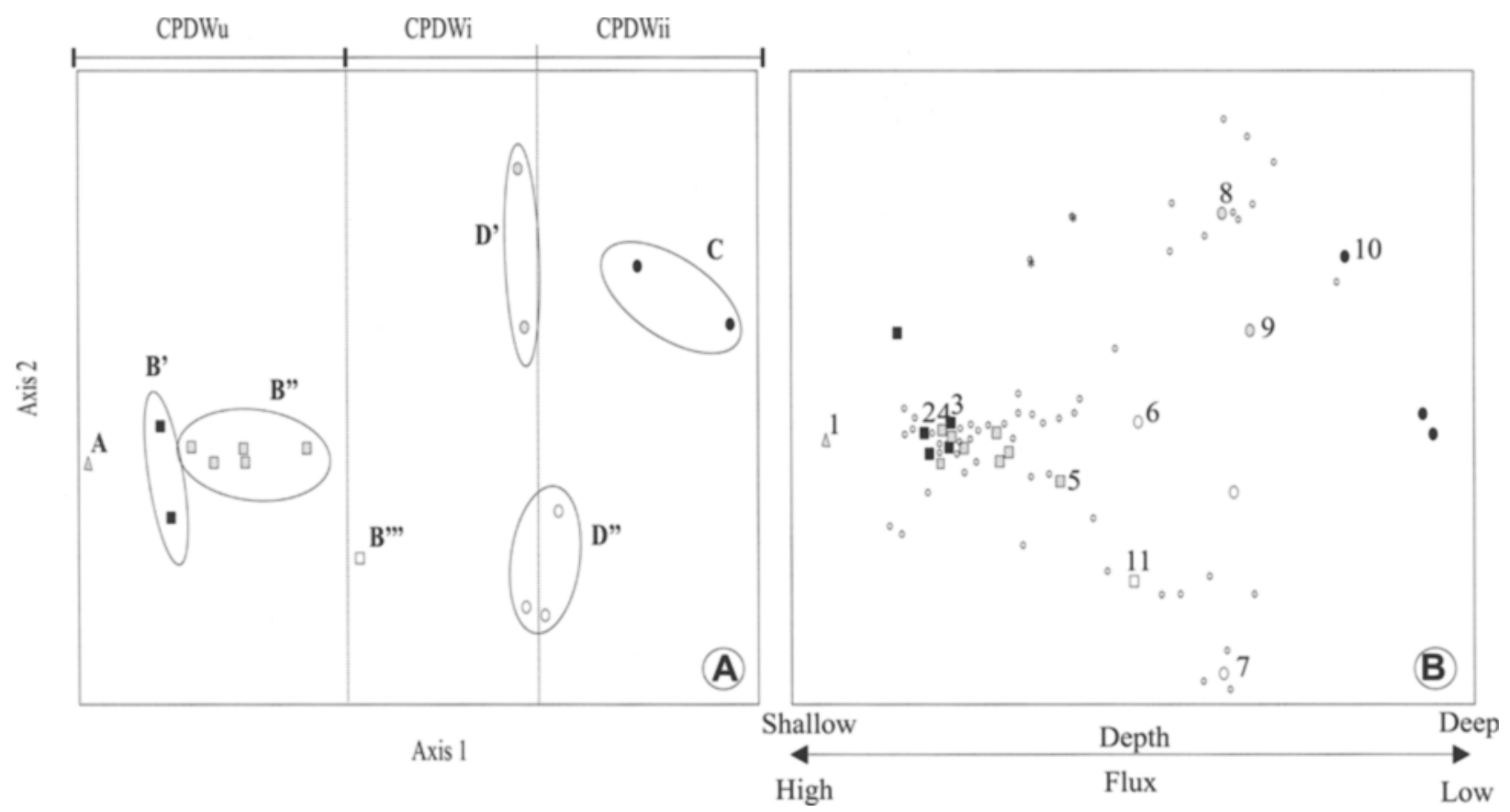

Fig. 7: Detrended correspondence analysis (DCA) diagrams. - A: Q-mode DCA diagram. Capital letters indicate the sub-division in groups of the main clusters. The stations forming each group are indicated with different symbols. - B: R-mode DCA diagram. Numbers indicate the dominant species as in Tab. 3. Symbols without numbers refer to species characteristic of the group. The ecological gradient indicated for Axis 1 is only indicative. 
tiated by the presence of abundant specimens of Krithe sp. 9 , one of the dominant species of group B". Since Krithe sp. 9 also occurs in B"' (mostly as juvenile moults), and although dominant it is not considered characteristic of the group. Fallacibowella sp. B which occurs only in this group is the second most dominant, key identifier for this group. The other dominant species in group B" are Poseidonamicus ocularis and Krithe sp. 6. The characteristic co-occurring taxa are species of Cytheropteron with a relative abundance of $7.75 \%$ (Tab. 3). Cytheropteron occurs sporadically within the other groups but four of the seven species occur exclusively in group B". In group B' the dominant species are Krithe sp. 7 and Rugo-

Table 3: Ostracod groups and water masses. - Dominant and characteristic species are indicated, numbers refer to the position of the dominant species in Fig. 7B. The relative abundance of each group is given in $\%$ of the total ostracod fauna.

\begin{tabular}{|c|c|c|c|c|c|}
\hline group & area & water mass & water depth & $\%$ & dominant and characteristic species \\
\hline A & Challenger Plateau & CPDWu & $1552 \mathrm{~m}$ & 0.11 & (1) Inversocytherella tamantia \\
\hline $\mathrm{B}^{\prime}$ & Campbell Placeau & CPDWu & $1571-1685 \mathrm{~m}$ & 7.24 & (3) Krithe sp.7, (2) Rugacythereis tethys n. sp., Bradleya spp. \\
\hline$B^{\prime \prime}$ & S Tasman Rise & CPDWu & $1634-2146 \mathrm{~m}$ & 73.04 & $\begin{array}{l}\text { (4) Poseidonamicus ocularis, (5) Krithe sp. 9, } \\
\text { Krithe sp. } 6\end{array}$ \\
\hline$B^{\prime \prime \prime}$ & S Tasman Rise & CPDWi & $3211 \mathrm{~m}$ & 0.97 & (11) Fallacihowella sp. B \\
\hline $\mathrm{C}$ & Emerald Basin & CPDWii & $3909-4467 \mathrm{~m}$ & 0.97 & (10) Fallacihowella sp. A, Polycope spp. \\
\hline$D^{\prime}$ & $\begin{array}{l}\text { S Tasman Rise } \\
\text { Campbell Plateau }\end{array}$ & CPDWi & $3020-3452 m$ & 6.44 & $\begin{array}{l}\text { (8) Krithe sp. } 1 \text {, (9) Legitimocythere geniculata n. sp., } \\
\text { Dutoitella spinaplana n. sp. }\end{array}$ \\
\hline$D^{\prime \prime}$ & $\begin{array}{l}\text { S Tasman Rise } \\
\text { Campbell Plateau }\end{array}$ & CPDWi-CPDWii & $3685-4516 \mathrm{~m}$ & 11.68 & (7) Krithe sp. 3, (6) Fallacihowella caligo \\
\hline
\end{tabular}
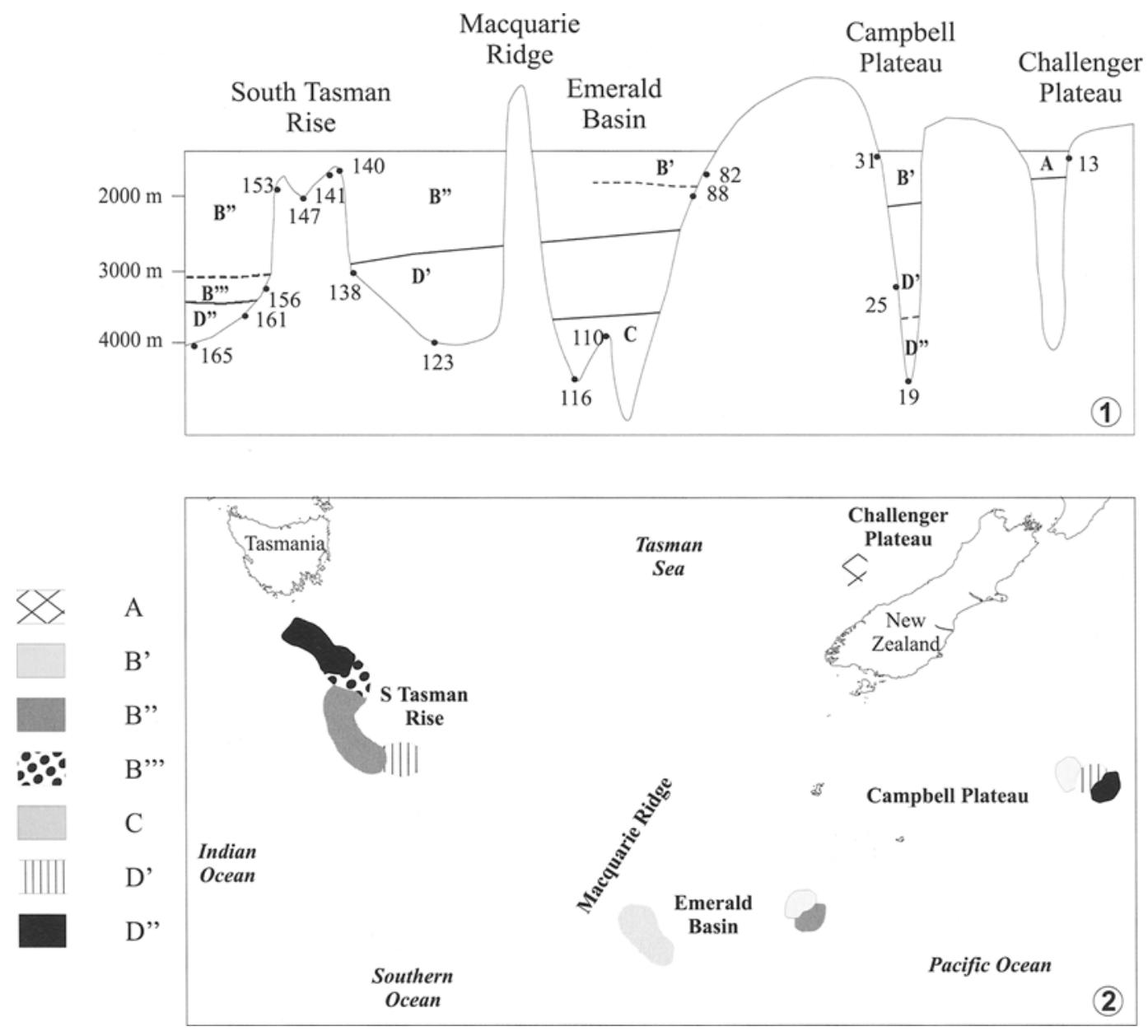

Fig. 8: Topographic profile along the sampling transect showing the geographical and bathymetrical distribution of the groups. - Full lines indicate boundaries between main clusters, dotted lines indicate boundaries between groups. 
cythereis tethys n. sp. and characteristic co-occurring species belong to the genus Bradleya (Tab. 3). Of the six species of Bradleya occurring in the data set, four are present exclusively within the $\mathrm{B}^{\prime}$ group with a relative abundance of $2.98 \%$. Group D' includes the deepest sample on the SE flank of the $S$ Tasman Rise and sample BX025 on the E flank of the Campbell Plateau. Krithe sp.1, Dutoitella spinaplana n. sp. co-occur with the dominant species Legitimocythere geniculata n. sp. (Tab. 3). Group D" includes the deepest stations on the $\mathrm{N}$ flank of the $S$ Tasman Rise and on the E flank of the Campbell Plateau, sample BX019. The few specimens recovered in this single sample are representatives of Fallacihowella caligo, one of the dominant species of group D", and of Krithe sp. 3 (Tab. 3). In Group C, Fallacihowella sp. A dominates but two co-occurring species of Polycope are characteristic of that group (Tab. 3). In Group A, Inversocytherella tanantia is the dominant and characteristic species (Tab. 3).

\section{Ostracods and ecological gradients}

The interpretation of the environmental gradients related to Axis 1 (Fig. 7) was based on sample and species points, considering the main characteristics of the water masses, the sediment type at each station, the carbonate content at several stations (THiede et al. 1999) and the organic carbon flux within each water mass (SCHENK 2001). No data were available for dissolved oxygen levels, bottom water temperatures or the primary productivity. The following considerations are appropriate to the studied area and additional research on the same or nearby areas could contribute to a better understanding of the response of ostracods to local environmental gradients.

Inversocytherella tanantia is the dominant species in group A which is the only group characterised by occupancy of a silty foraminiferal ooze substrate. Moreover, this group is located at the boundary between the CPDWu and the warmer and richer in nutrients AAIW.

Group B' is dominated by Krithe sp. 7, Rugocythereis tethys n. sp. and by four species of Bradleya which occur exclusively on the Campbell Plateau. $R$. thetys is abundant in the shallower samples from the Campbell Plateau (see Systematic section) where Bradleya is one of the most diversified and abun- dant genera (Jellinek \& Swanson 2003). Group B' represents the marginal portion of the Campbell Plateau environment with some evidence of the influence from deeper environments (Krithe sp. 7). Although R. tethys and Bradleya are characteristic of the $\mathrm{B}^{\prime}$ group, this group does not coincide with their environmental optimum which occurs in areas exposed to warmer temperatures and higher organic carbon production rates on the Campbell Plateau.

Poseidonamicus ocularis is the dominant species in group B" (Tab. 3) and occurs only in cluster B. P. ocularis appears to occur preferentially at water depths of between $1500 \mathrm{~m}$ and $2200 \mathrm{~m}$ as does Krithe sp. 9 and the co-occurring Krithe sp. 6. Several co-occurring species of Cytheropteron characterise that assemblage. Cytheropteron and Bradleya occur at similar water depths, carbon and carbonate content such that their presence or absence must be driven by other environmental gradients. Cytheropteron is considered a carnivorous genus, scavenging or predating on Polychaeta (HaRTMANN 1975). No direct observations are available on the feeding habits of Bradleya but its isotopic signature implies that it could have an opportunistic behaviour, utilising a variety of food sources. Cytheropteron structures group B" mainly along Axis 1 whereas Bradleya structures group B' mainly along Axis 2 . The species assemblage from the single sample (BX088) from the Campbell Plateau is dominated by Poseidonamicus sp. and Harleya sp. which are very rare in group B' and common in $\mathrm{B}^{\prime \prime}$. The presence in sample BX088 of several species common in group B" and characteristic for the $S$ Tasman Rise, would imply that these species were present in both areas before the Macquarie Ridge rose $2.5 \mathrm{~km}$ from the sea-floor or that they are able to migrate more than $1500 \mathrm{~km}$ through the gaps in that ridge (Fig. 8).

Group B"' is dominated by Fallacihowella sp. B, a species occurring also in group $\mathrm{D}^{\prime \prime}$. Contamination from the overlying group B' (Fig. 8) is enhanced by the position of Krithe sp. 5 (Fig. 7B) which does not structure the B'" assemblage as instead does $F$ sp. B. Moreover the ecological gradients of the two species do not overlap (Tab. 4) confirming the impact of down-slope contamination.

Group C is structured by Fallacihowella sp. A and the two species of Polycope species and not by the co-occurring Krithe sp. 3. The dominant species in group $\mathrm{C}$ are considered stenoplastic (adapted to narrow ecological gradients) living in a

Table 4: Ostracod groupings and ecological gradients. - The Krithe species occurring within each group are indicated together with their relative abundance in percent of the total ostracod fauna. The bold numbers indicate the dominant Krithe species. - Sediment type, carbonate content and temperature are from THIEDE et al. (1999), the flux rates of organic carbon are from SCHENK (2001). The abbreviation f. stands for foraminiferal.

\begin{tabular}{lllrrrrl}
\hline group & assemblage & Krithe sp. & $\%$ & $\mathrm{~T}\left[{ }^{\circ} \mathrm{C}\right]$ & $\mathrm{C}_{\text {org }}$ & $\mathrm{CaCO}_{3}$ & sediment type \\
\hline A & Inversocytherella tanantia & 9 & 0.02 & $1.80-1.60$ & $\sim 2.7$ & & silty f. ooze \\
B' & Rugocythereis thetys & 7 & 0.92 & $1.80-1.60$ & $\sim 2.7$ & $90 \%$ & fine to medium f. sand \\
B" & Poseidonamicus ocularis & $2,4,6,7,8,9$ & 10.50 & $1.80-1.60$ & $\sim 2.7$ & $>90 \%$ & f. sand \\
B"' & Fallacihowella sp. B & 3,9 & 0.49 & $1.60-0.90$ & $>1.3$ & & well sorted f. sand \\
C & Fallacibowella sp. A & $3,5,7$ & 0.15 & $0.90-0.55$ & $>1.3$ & $35-14 \%$ & diatom/radiolarian ooze \\
D' & Legitimocythere geniculata & $1,3,8,10$ & 1.88 & $1.60-0.90$ & $>1.3$ & $70-92 \%$ & medium well sorted f. sand \\
D" & Fallacihowella caligo & $1,3,5,6$ & 7.44 & $1.60-0.55$ & $>1.3$ & $70-90 \%$ & medium f. to coarse silty f. ooze sand \\
\hline
\end{tabular}


diatom/radiolarian ooze with a very low carbon content. Both genera were found with soft-parts intact and well-preserved carapaces, confirming the experimental data that ostracods can live also in environments with low carbonate content (DE DECKKER 2002).

Krithe plays an important role in the structure of the assemblages. Although not always dominant, it occurs in all the studied samples and the different species display adaptations to a broad range of ecological gradients (Tab. 4). This high tolerance can only partially be linked to the infaunal microhabitats of the species. In fact the epibenthic Fallacibowella displays a comparable tolerance, being common in 14 of the 16 samples. In particular Fallacihowella caligo is the dominant species in group D" but occurs in another 9 samples belong- ing to group $D^{\prime}$ and cluster $B$. The adaptation of this species to different ecological gradients is enhanced by its central position in the R-mode DCA plot (Fig. 7B). Coinciding with the dominance of $F$ caligo other species with lower adaptability such as Legitimocythere geniculata $\mathbf{n}$. sp. disappear, whereas they become dominant when $F$ caligo is just a co-occurring species as in group D'. It is not clear whether the variations in the dominance of $F$ caligo are linked only to environmental gradients or also to the appearance of competitive species. As it is shown in Fig. 7B, group $D^{\prime}$ is not structured by the euriplastic (adapted to broad ecological gradients) $F$. caligo, but by Krithe sp. 3 which although occurring within all the groups characterised by low $\mathrm{C}_{\text {org }}$, is dominant only in group D'.

\section{Taxonomy}

\section{Introduction}

The monograph compiled by BRADY (1880) on specimens collected during the Challenger expedition regarded 221 species of which 143 were described for the first time, together with three new genera. PuRI \& Hulings (1976) re-studied the BRADY's collection and designated lectotypes for 136 species, adding important detail to BrADY's descriptions. They also provided figures of all the species, photographs being taken with a $35 \mathrm{~mm}$ camera mounted on an optical microscope. At that time the only Scanning Electron Microscope available required the coating of the specimens resulting in permanent damage to valuable type material. For this reason, only eight species, picked from the original Challenger sediment samples, were illustrated using SEM micrographs. The illustrations, though excellent for the time, are often out of focus or do not provide enough detail so that comparison with the original material was necessary for several species. Neale (1965: 258), stated: "In studies of ecology and distribution accurate taxonomy is a sine qua non, and in this respect the species is the most significant and important unit." Additionally: "Only when the species has been satisfactorily described and established can meaningful distribution charts be constructed".

Dealing with fossil or sub-fossil Ostracoda, the Darwinian concept of phenic species is still the only one applicable. Being a morphological concept, it needs a diagnosis and a description that is based on a detailed examination. In the case of ostracods, this must include internal details as well as those of the external carapace. During this study, problems associated with the comparison with existing species often occurred at three different levels:

- Genera erected in the 19th century, which are cosmopoli$\tan$ spread and now include hundreds of species. These currently display a broad range of character variability simply because of the subjective interpretations by many authors based on the old descriptions and illustrations. In many cases the description of new species gives clear indication that underlying uncertainties remain. Such genera are, for example, Polycope, Argilloecia, Cytheropteron, Eucythere, Krithe and Xestoleberis.

- Genera erected in the 20th century with type species described in the 19 th century. In many cases, the species chosen as type was not re-described and re-examined and as a consequence, the definition of the new genera is very unclear. Such genera are Myrena, Legitimocythere and Pseudobosquetina. An exception is Bradleya Hornibrook (1952) of which the type species Cythere arata BrADY (1880) was re-illustrated by BENSON (1972).

- Genera erected in the 20th century which include species described in the 19th century. Some of the species described by BRADY (1880) and MúlLER (1908) were more recently included in fossil genera without being re-described or re-studied. As a result, the concept of genera such as Dutoitella and Henryhowella, had to be expanded to include the characters of the extant species.

It is apparent that detailed examination of all carapace characters of many of the so-called 'pandemic' genera inevitably leads to the need to divide such taxa into additional, homeomorphic genera, within which the main differences must be searched in the hinge, muscle scars and development of the inner lamella (VAN MORKHOVEN 1962: 35).

The following part includes the taxonomy of the ostracods recovered from 11 samples, from the $S$ Tasman Rise and the Emerald Basin. In some cases, additional material from the shallower samples was provided by Dr. T. JELlineK (Senckenberg Museum, Frankfurt am Main).

The classification adopted herein is that of HarTMANN \& PURI (1974) with certain modifications. Taxonomic description of the genera and/or species include all the characters recognisable externally with particular attention being given to the internal characters. Special care has been taken of the use of a terminology that is unambiguous. For the surface features the terminology given in SYLVESTER-BRADLEY \& BENSON (1971) has been used. Some new terms have been used as well and their meaning is explained in the text. For the hinge description the terminology proposed by GRUNDEL (1974) has been used. Each species has been illustrated with SEM micrographs. 
All types and figured specimens are catalogued and housed in the collection of the Micropaleontological Section of the Forschungsinstitut Senckenberg, Frankfurt am Main (Germany).

Abbreviations used:

$\mathrm{C} / \mathrm{Cs}=$ carapace/s; L/Ls = Left valve/s; R/Rs = Right valve/s; $\mathrm{A}=$ adult; $\mathrm{A}-1$ = penultimate instar; $\mathrm{A}-\mathrm{n}=$ other instar; $\mathrm{PM}=$ posterior margin; $A M=$ anterior margin; $\mathrm{PT}=$ posterior tooth; $A T=$ anterior tooth; $P S=$ posterior socket; $A S=$ anterior socket; $\mathrm{MS}=$ muscle scars; $\mathrm{SCT}=$ sub-central tubercle.

Very rare $=1-5$ valves

Rare $=6-15$ valves

Common $=16-50$ valves

Very common $=51-100$ valves

Abundant $>101$ valves.

Carapaces are counted as two valves.

Order Myodocopida SARS 1866
Suborder Cladocopina SARS 1866
Family Polycopidae SARS 1866

Genus Polycope SARS 1866

Type species: Polycope orbicularis SARS 1866.

Remarks: KEMPF $(1986,1995)$ cited more than 160 species of Polycope, covering a time span from the Devonian to Recent. For most described species definitions are based on the soft anatomies at the expense of equivalent detail for the carapace morphology. Many species are known from the Antarctic and are mainly illustrated by HARTMANN (1985, 1987, 1993) with drawings of the soft parts. There is little published information relating to this genus in the Recent of the Pacific Ocean, especially in the vicinity of New Zealand.

AYress (1988) recorded two species from the Pleistocene of the Indian and Pacific Ocean and YASSINI (1995) reported two additional species from the Recent of the south-eastern Australian Shelf. WARNE (1990) studying ostracods from the late Tertiary of Victoria (Australia), stated that Polycope species with strongly ornamented carapace are more abundant in deeper-water facies than weakly ornamented species. If this may be true for Tertiary palaeoenvironments, the data from the Emerald Basin contradict this theory, since the two weakly ornate species were found at one of the deepest stations of the transect (4462 $\mathrm{m}$ of depth).

\section{Polycope sp. A \\ (Figs. 9A-F)}

Material: 1 adult $C, 1$ juvenile $C, 2$ juvenile valves. SMF Xe 21452.

Dimensions: L 0.67/0.62; R 0.67/0.62.

Distribution: Holocene of the Emerald Basin. Rare in sample BX116 (4462 m).

Description: Sub-round in shape, with an antero-ventral concavity. Carapace periphery with densely packed punc- tuation and small circular structures aligned on the ventral side. These structures resembling funnel pores are scattered. Although the carapace contained soft parts, no setae were detected exiting from these pores. Along the outermost margin the surface is densely punctuate. Marginal ornamentation is bounded towards the interior by flat, smooth and thin ridges, which intersect to form a trapezoidal meshwork. These ridges occur on the ventro- lateral surfaces and extend to medial valve surface. They are lacking on the dorsal margin, which is truncate and corresponds, Internally, to an horizontal bar in the $\mathrm{L}$ and a smooth groove in the $\mathrm{R}$. The groove is bounded, on both ventral and dorsal sides, by anti-slip bars. The marginal zone is very narrow. Along the margin, in the $R$, a deep and smooth furrow is located to accommodate the protruding margin of the $L$. The MS were not visible.

Remarks: Because of its shape, this species resembles $P$. brevis MÚLler (1908: 82, pl. 11 figs. 6-10) from the Gauss Station (Antarctica). MüLER reported a length of 0.70 for his juvenile specimen and described the ornamentation as consisting of ridges and punctuation medially, clearly a feature lacking in $P$ sp. A. This species is also similar to $P$ aff. $P$. frequens MÚler (1894), as illustrated in BONADUCE et al. (1975: pl. 3 figs. 6-7) from the Adriatic Sea at depths exceeding $100 \mathrm{~m}$. The latter reference included no additional descriptive text relating to either ornamentation or detail of the inner carapace. As a result this comparison remains subjective.

This species is considered autochthonous because all the specimens were stained with Rose Bengal and 2 Cs with soft parts were recovered.

Polycopesp. B

(Figs. 9G-L)

Material: 2 adult Cs. - SMF Xe 21453.

Dimensions: L $0.60-0.62 / 0.57-0.60 ; \mathrm{R} \quad 0.60-0.62 /$ $0.55-0.57$.

Distribution: Holocene of the Emerald Basin. Very rare in sample BX116 (4462 m).

Description: Round in shape, with a heavily punctuate surface. Along the outer margin, the surface is rough and is ornamented with an irregular network of small rectangular meshes interspersed with scattered punctae. The remainder of the external surface is covered with round, papillate punctae. In correspondence with the MS the punctae are not present and the outline of the MS is enhanced by lines made of short foveolae, with the longer side parallel to each other. Internally, the dorsal margin is horizontal. It corresponds, in the $\mathrm{R}$ to a tiny, smooth and shallow groove bounded, on both ventral and dorsal sides, by anti-slip bars. It opens at the extremities towards the smooth furrow, which is slightly expanded at margins. In the $\mathrm{L}$, the protruding margin that runs along the valve is truncated in correspondence of the dorsal margin where it enlarges, fitting the R. An additional closing mechanism is located just behind it and consists of two shallow and elongate sockets in the $\mathrm{L}$ fitting the extremities of the anti-slip bar that runs along the inner margin of the R. MS 


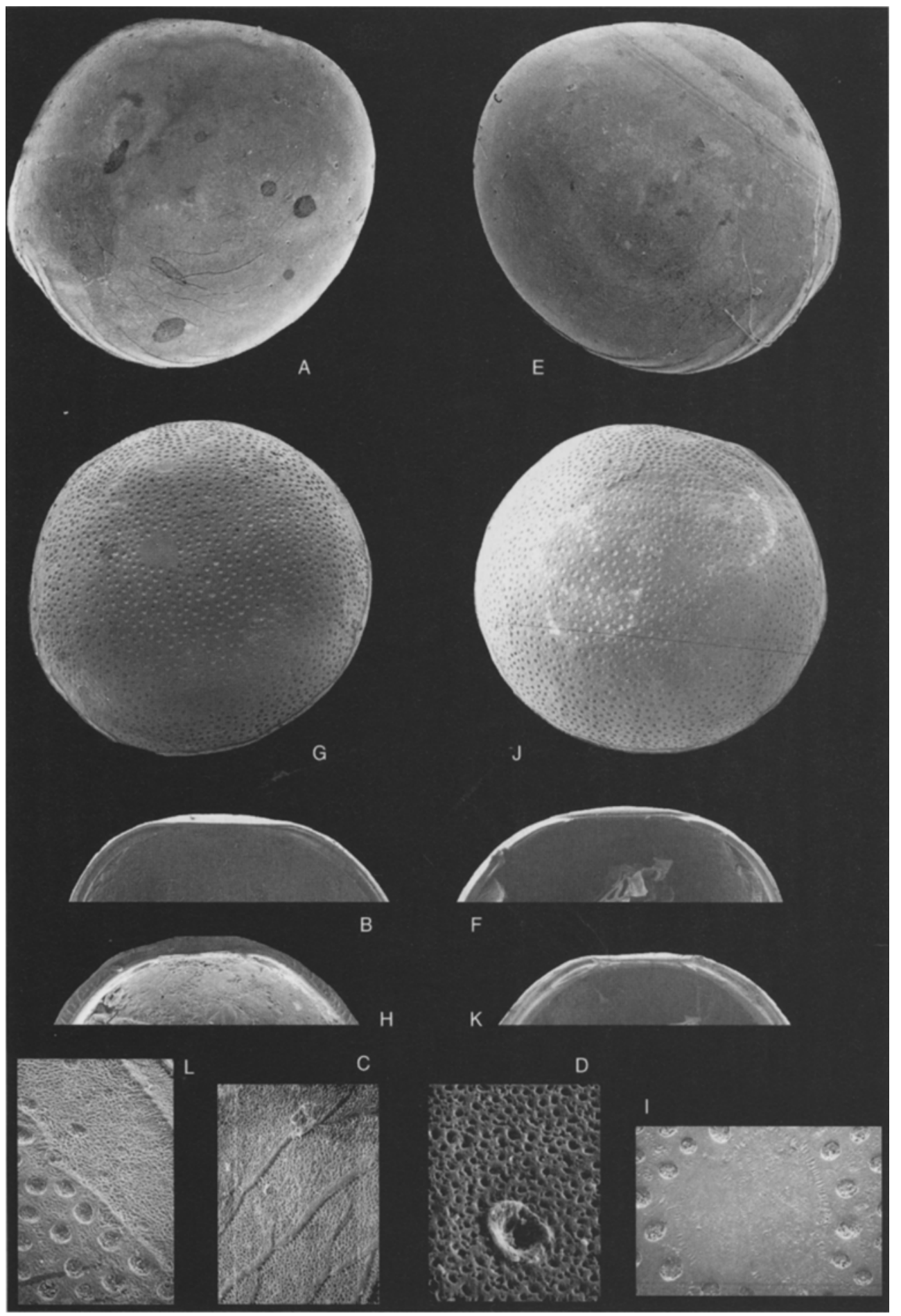

Fig.9: A-F: Polycope sp. A.

Recent, sample BX116, Emerald Basin, off south coast South Island, New Zealand; S55 $40.03^{\prime}$ E159 $25.00^{\prime}$, 4462 m. - C A: L (0.67/0.62), external view; B: hinge of L; C: detail of the lateral ornamentation, $\times 250$; D: detail of a funnel pore on the outer margin, $\times 950$; E: R (0.67/0.62) external view; F: hinge of R. SMF Xe 21452.

G-L: Polycope sp. B.

Recent, sample BX116, Emerald Basin, off south coast South Island, New Zealand; S55 $40.03^{\prime}$ E1 $159^{\circ} 25.00^{\prime}$, $4462 \mathrm{~m}$. - C G: L (0.62/0.57) external view; H: hinge of L; I: external expression of the central muscle scars and central surface ornamentation $\times 200$; J: $\mathrm{R}(0.62 / 0.57)$ external view; $\mathrm{K}$ : hinge of $\mathrm{R}$; L: detail of the lateral ornamentation, $\times 350$. SMF Xe 21453. - All magnifications are $\times 80$ unless otherwise stated. 
consisting of three drop shaped scars, converging towards the dorsal side. Their position is eccentric and shifted dorsally.

Remarks: This species resembles $P$ suhrmeyeri HaRTMANN (1993) from the Antarctica. This latter is slightly larger $(0.69 / 0.63)$ and its ornamentation apparent, especially on the marginal ridges.

This species is considered autochthonous because all the specimens were stained with Rose Bengal and $1 \mathrm{C}$ was recovered with soft parts.

\author{
Order Podocopida G.W. Müller 1894 \\ Suborder Platycopin a SARS 1866 \\ Superfamily Cytherellacea SARS 1866 \\ Family Cytherellidae SARS 1866
}

Genus Cytherella JONEs 1849

Type species: Cytherina ovata ROEMER 1840.

Cytherella sp.

(Figs. 10A-E)

non 1880 Cythere? serratula Brady: 77, pl. 43 figs. 7a-d.

1987 Cytherella serratula. - WhATLEY \& COLEs: 81, pl. 6 fig. 31.

? 1990 Cytherella serratula. - DingLE et al.: 254, Figs. 5 A-C.

Material: 4 adult and 6 juvenile valves. - SMF Xe 21454.

Dimensions: R 1.12-1.25/0.62-0.70. juv. L $1.07-$ 0.60 .

Distribution: Holocene of the Emerald Basin. Rare in sample BX147 (2177 m).

Remarks: This species is similar to Cythere? serratula BRADY as figured by DiNGLE et al. (1990) from the SE Atlantic at water depth range of $1000-2070 \mathrm{~m}$ and by WhATLEY $\&$ COLEs (1987) from the $N$ Atlantic at water depth range of 2417-3022 m. BRADY erected this species for specimens collected from the Atlantic at water depths between $713 \mathrm{~m}$ and $2605 \mathrm{~m}$ of depth. The poor illustrations provided by PURI $\&$ Hulings (1976) add little to the description of BRADY, except for the fact that "cytherellid type" central muscle scars can be recognised. The PURI \& Hulings specimens from the West Indies which are clearly different from those illustrated by Brady for which no collection data was provided. Arello et al. (1996: pl. 6) studying Cytherella from the Tortonian-Recent of Italy, provided SEM pictures of the lectotype and a paralectotype of $C$. serratula (BRADY) from the Recent of $\mathrm{Cu}$ lebra Island (West Indies). Comparing their micrographs with those provided by DINGLE et al. (1990) and by WhatLEY \& Coles (1987), make the specific determination questionable, simply because of significant contrast in shape and posterior ornamentation. The synonymy between $C$. robusta COLALONgo \& Pasini (1980) and C. serratula sensu Whatley \& Coles (1987), as proposed by Aiello et al. (1996) is herein considered invalid, since the specimens from the $\mathrm{N}$ Atlantic are much larger (1.02 contrasting with 0.77 for the Italian speci- mens) and display an oblique anterior rim on the L. They are here considered conspecific with Cytherella sp. The specimens illustrated by DINGLE et al (1990) are shorter than Cytherella sp. (0.95-0.97) but have a very similar shape. Unfortunately his micrographs give insufficient detail about the development of the ornamentation around the anterior and posterior margins.

Further findings of better preserved material from the area of study and the comparison with BRADY's specimen would allow a more specific determination.

\author{
Suborder Podocopina SARS 1866 \\ Superfamily Bairdiacea SARS 1888 \\ Family Bairdiidae SARS 1888
}

Genus Bairdoppilata Coryeld, Sample \& Jennings 1935

Type species: Bairdoppilata martyni Coryell, SAMPLE \& JeNNINGS 1935.

Remarks: MADDOCKS (1969b) in her revision of Recent Bairdiidae, stated that Bairdoppilata is common in shallow waters, especially in tropical and sub-tropical regions. She also included in the genus $B$. hirsuta, $B$. simplex and $B$. villosa all of which BRADY (1880) recovered during the Challenger Expedition from depch of 135-2475 $\mathrm{m}$ in much colder waters. For these three species MADDOCKS suggested the use of a new subgenus, because of the "several discordant features in the carapace and genital anatomy" (1969b: 67).

\section{Bairdoppilata sp}

(Figs. 10F-H)

Material: 8 adult and 11 juvenile valves. - SMF Xe 21455.

Dimensions: L 1.32-1.37/0.92-0.97; R 1.32-1.37/ $0.80-0.90$.

Distribution: Holocene of the South Tasman Rise. Common in sample BX138 (3022 m).

Remarks: This species is referred to Bairdoppilata because of small grooves observed in the $\mathrm{L}$, which could mirror the auxiliary terminal hinge dentition typical for the genus. All specimens are extremely eroded and poorly preserved and fragments represented most of the adults.

This species is very similar in shape to $B$. simplex (BRADY) (1880: 51, pl. 7 figs. 1a-d) which was recovered at $135 \mathrm{~m}$ off Heard Island (SE of the Kerguelen Islands). BRADY reported a length of 1.30. PURI \& HULings (1976: 266, pl. 3 figs. 1114) designated a lectotype from the Atlantic material, which conformed with BRADY's description but larger dimensions (1.49/0.78-0.81). According to MADDOCKS (1969b: 77-78, Fig. 42) B. simplex is much longer and more slender (1.62$1.97 / 0.92-0.97)$, but she reported dimensions only for male specimens.

The circum-antarctic distribution proposed by MADDOCKS is confirmed by HARTMANN (1997). 

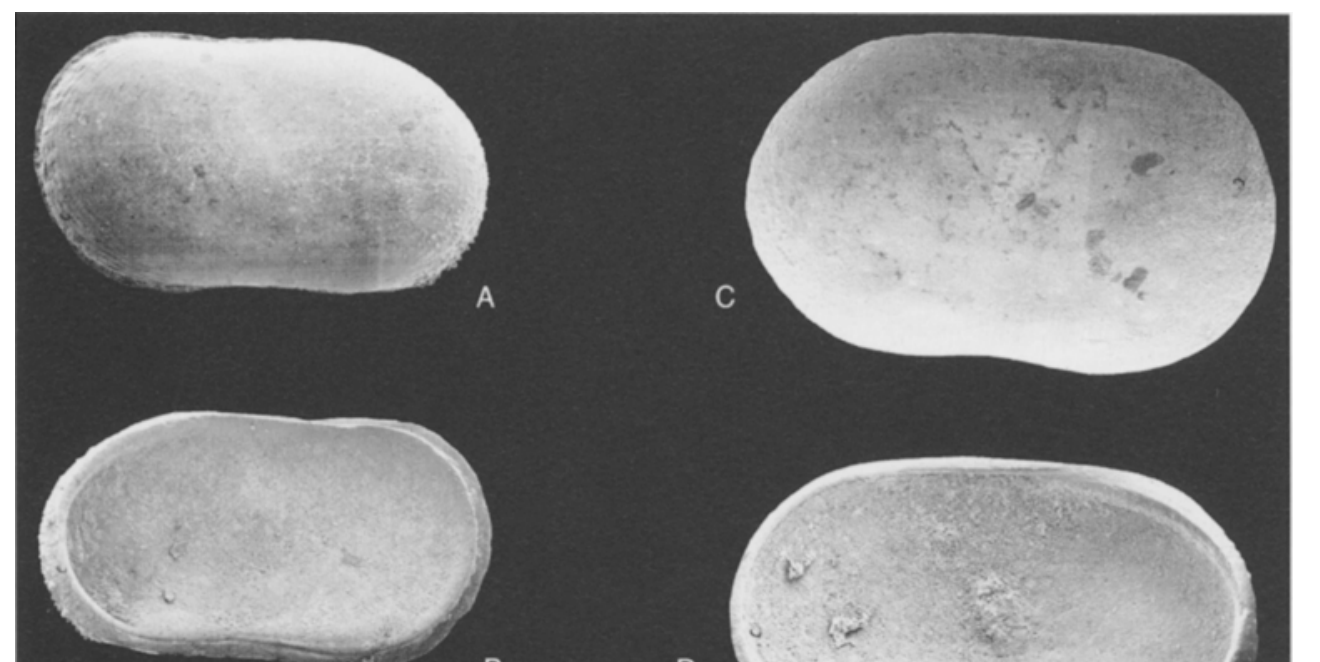

B
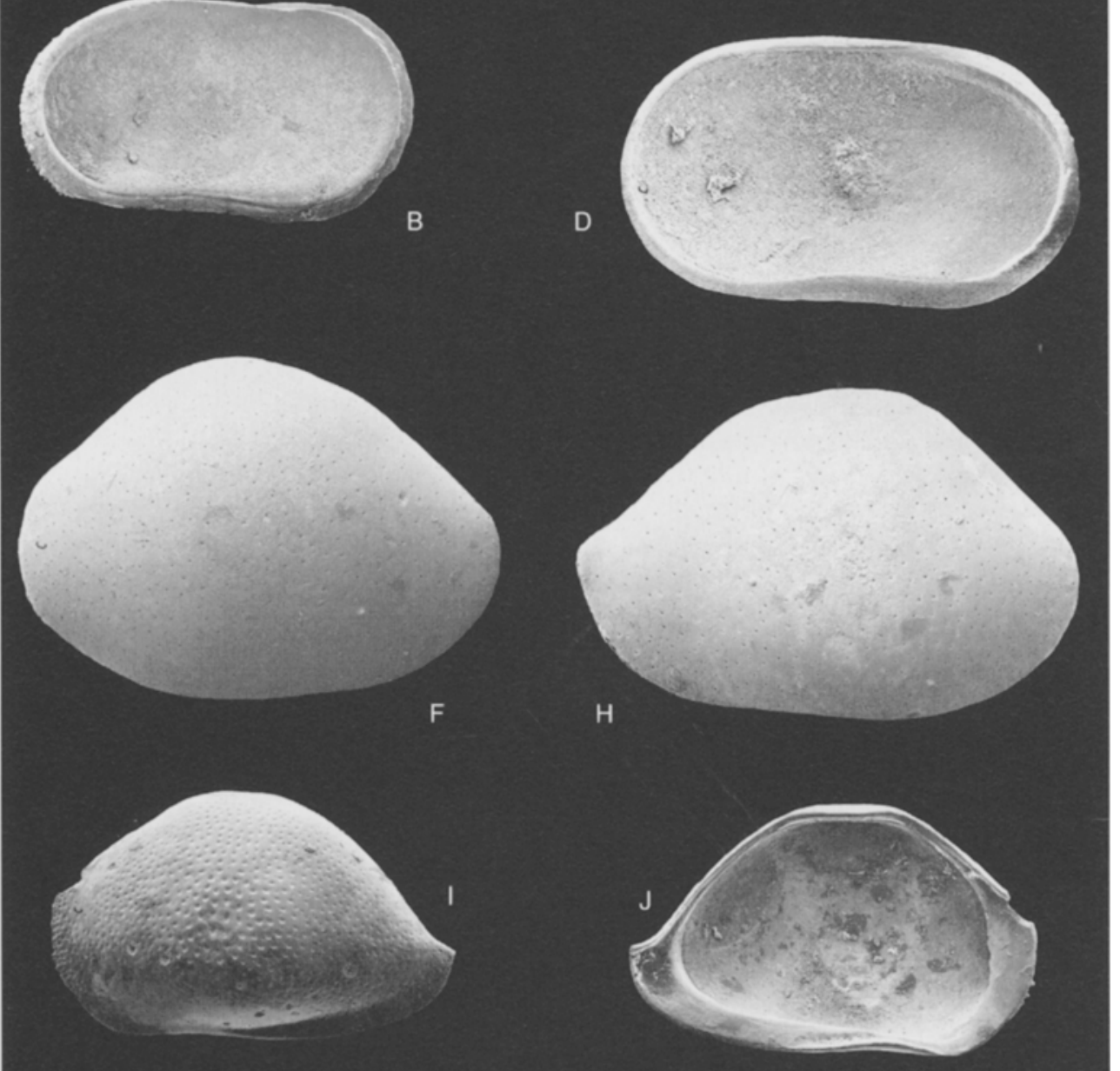

$\mathrm{H}$

$E$

G

K

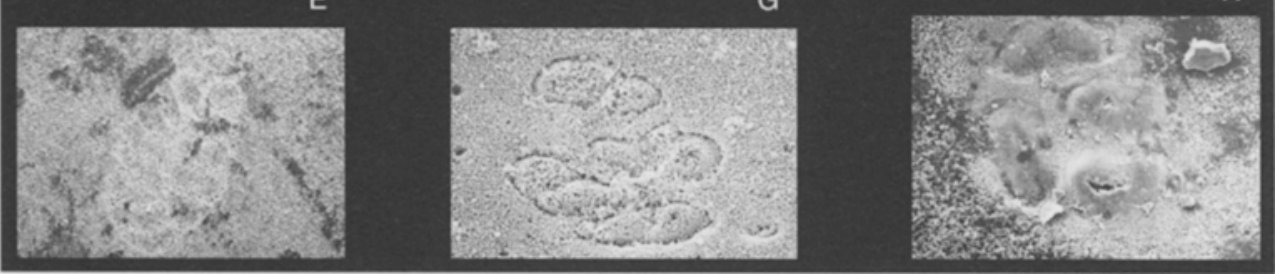

Fig.10: A-E: Cytherella sp.

Recent, sample BX147, South Tasman Rise, off south coast Tasmania, Australia; S48 $29.99^{\prime}$ E $149^{\circ} 06.75^{\prime}, 2177$ m. - juv. L (1.07/0.60); A: external view; B: internal view. SMF Xe 21454. - R (1.25/0.70); C: external view; D: internal view; E: external expression of the central muscle scar, $\times 140$; SMF Xe 21454.

F-H: Bairdoppilata sp.

Recent, sample BX138, South Tasman Rise, off south coast Tasmania, Australia; S49 $13.06^{\prime}$ E151 $05.77^{\prime}, 3022$

m. - L (1.32/0.92); F: external view; G: central muscle scars, x145. SMF Xe 21455. - H: R (1.37/0.90); external view. SMF Xe 21455.

I-K: Anchistrocheles? cf. A. ? aculeata G.W. MÜLLER 1908

Recent, sample BX140; South Tasman Rise, off south coast Tasmania, Australia;

$S 49^{\circ} 10.84^{\prime}, \mathrm{E} 150^{\circ} 10.13^{\prime}, 1636 \mathrm{~m}$. - L (1.12/0.67); I: external view; J: internal view; K: central muscle scars, $\times 200$. SMF Xe 21456 . - All magnifications are $\times 45$ unless otherwise stated. 
Family Bythocyprididae MADDOCKS 1969

Genus Anchistrocheles BRADY \& NORMAN 1889

Type species: Anchistrocheles fumata BRADY 1890.

Anchistracheles? cf. A.? aculeata G. W. Mưller 1908 (Figs. 10I-K)

Material: 3 adult and 6 juvenile valves. - SMF Xe 21456.

Dimensions: L 1.12/0.67; R 1.10-1.15/0.65-0.70.

Distribution: Holocene of the South Tasman Rise. Rare in sample BX140 (1636 m).

Remarks: The shape of the specimens is very similar to that presented for Paranesidea by MADDOCKS (1969), whereas the MS pattern clearly indicates that they should be referred to the genus Anchistrocheles. This is a poorly known genus originally based on specimens BRADY (1890) recovered in coastal waters of the Fiji Islands. MADDOCKS (1969a) included in the genus $A$. aculeata MÜLLER (1908) collected at $385 \mathrm{~m}$ of depth at the Gauss Station, Antarctica. Müller described a pitred ornamentation, small spines at the anterior margin, a single longer spine at the edge of the caudate posterior and a length of 1.10-1.15. The same species described by MADDOCKS (1969a: 113, Fig. 60M) has another spine on the anterior margin, smaller dimensions $(0.92 \mathrm{~mm}$ long) and was recovered in the S Pacific at a depth of $2056 \mathrm{~m}$. The marginal spines are broken in all the three adult specimens recovered. Doubts about the generic determination are expressed both by MADDOCKS and by HaRTMANN (1997) since this species displays characters intermediate between Anchistrocheles and Paranesidea. MadDocks (1976) emphasised the differences between $A$. aculeata and the other species of Anchistrocheles, suggesting the possibility that $A$. aculeata and allied species could be classified within the Bairdiidae. For these reasons, the present species is only tentatively referred to the genus $A n$ chistrocheles.

\section{Genus Bythocypris BRADY 1880}

Type species: Bythocypris reniformis BraDY 1880.

$$
\text { Bythocypris sp. }
$$

(Figs. 11A-C)

Material: 4 adult and 56 juvenile valves. - SMF Xe 21457-21460.

Dimensions: L 1.50/0.82; R 1.37-1.30/0.65-0.67.

Distribution: Holocene of the South Tasman Rise. Very rare in sample BX141 $(1690 \mathrm{~m})$. Common in samples BX140 (1636 m), rare in sample BX147 $(2177 \mathrm{~m})$ and very rare in sample BX153 (1874 m).

Remarks: This species is very similar to $B$. reniformis BRADY (1880: 46, pl. 5 figs. 1a-l) recovered in the Atlantic and the Pacific Ocean at sites with depths ranging from $90 \mathrm{~m}$ to $700 \mathrm{~m}$. CHAPMAN (1915) recorded the same species southeast of Australia at depth around $900 \mathrm{~m}$. MADDOCKS (1969a) extended the depth range to $1227-3100 \mathrm{~m}$ in the $S$ Atlantic and Indian Ocean respectively. It should be noticed that the specimens illustrated by MADDOCKS are $1.07-1.20 \mathrm{~mm}$ in length which agrees with the dimension of 1.09 reported by Puri \& Hulings (1976: 262, pl. 2 figs. 7-10). Brady reported a length of 1.30 for his specimens, which is more in accord with the dimensions of the valves from the Tasman Sea and reported herein. Unfortunately, the studied specimens are extremely fragile and, together with many fragments, few entire but eroded adult valves were recovered. Radial pore-canals could not be observed and no vestibula were preserved.

Superfamily Cypridacea BAIRD 1845

Family Pontocyprididae G.W. Múller 1894

Genus Argilloecia SARS 1866

Type species: Argilloecia cylindrica SARS 1866.

Remarks: This genus was erected by SARS (1866: 17) to accommodate Recent specimens from the Norwegian fjords. MadDOCKS (1969a) described 12 species from the Recent of the Indian Ocean and the South Pacific. She re-described $A$. eburnea BRADY and of four species recovered during the Challenger Expedition and ascribed to different genera: Aglaia clavata, Aglaia? pusilla, Aglaia? obtusata and Cytherella? tumida.

For those species as well as for the seven species, left under open nomenclature, inadequate drawings and descriptions provided by MADDOCKS, means discrimination of specific characteristics is difficult. McKenzIE (1967) erected the genus Australoecia to include the Recent species $A$. victoriensis from Port Phillip Bay (Australia). This genus differs from Argilloecia because the MS are arranged in a rosette and the valves are less inflated and weakly calcified. The specimens recovered in the Tasman Sea are referred to the genus Argilloecia because of their muscle pattern. The taxonomic relationship of both genera and of all the related species is not clear. On that basis, the species is left under open nomenclature.

\section{Argilloecia sp.}

(Figs. 11D-H)

Material: 21 adult and 8 juvenile valves. - SMF Xe 21461-21462.

Dimensions: Female L $0.65-0.70 / 0.30-0.32$, R $0.67-$ $0.72 / 0.37-0.40$; male L $0.72-0.75 / 0.35-0.37$, R $0.67-0.70$ / $0.27-0.30$.

Distribution: Holocene of the South Tasman Rise. Common in sample BX147 $(2177 \mathrm{~m})$ and rare in sample BX165 (4967 m).

Remarks: This species is referred to Argilloecia because the MS are organised in two parallel rows. It is close to $A$. eburnea BRADY as illustrated by BraDy (1880: 40 , pl. 4 figs. $1-15)$ recovered from the $S$ Atlantic at $3420 \mathrm{~m}$, from the Kerguelen Islands at 36-90 m and Christmas Harbour at 216 


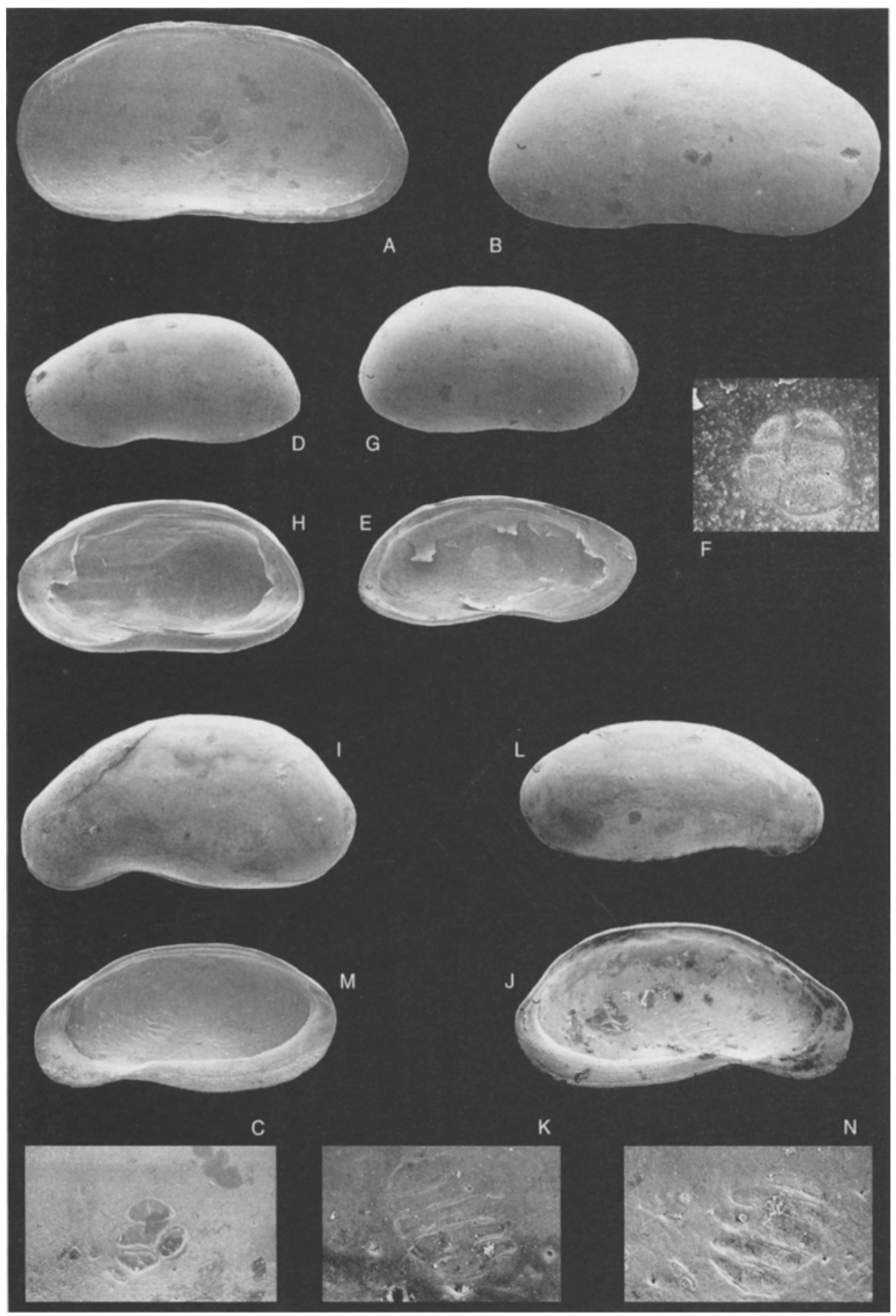

Fig. 11: A-C: Bythocypris sp.

Recent, sample BX140; South Tasman Rise, off south coast Tasmania, Australia; S49 $10.84^{\prime}$, E $150^{\circ} 10.13^{\prime}$, 1636 m. - R (1.37/0.67); A: external view, $\times 43$; B: internal view, $\times 43$; C: central muscle scars, $\times 245$. SMF Xe 21457.

D-H: Argilloecia sp.

Recent, sample BX147, South Tasman Rise, off south coast Tasmania, Australia; S48 $29.99^{\prime}$ E $149^{\circ} 06.75^{\prime}, 2177$ m. - female C (0.73/0.40/0.62); D: L (0.70/0.32) external view; E: internal view; F: central muscle scars of L, $\times 225$; G: R (0.72/0.40) external view; $H$ : internal view. - SMF Xe 21461.

I-N: Sclerochilus cf. S. reniformis G.W. MOLLER 1908

Recent, sample BX140; South Tasman Rise, off south coast Tasmania, Australia; S49 $10.84^{\prime}$, E $150^{\circ} 10.13^{\prime}$ $1636 \mathrm{~m}$. - female L $(0.77 / 0.35)$; I: external view; J: internal view; K: central muscle scars, $\times 210$. SMF Xe 21463. - female R (0.85/0.42); L: external view; M: internal view; N: central muscle scars, $\times 185$. SMF Xe 21463. - All magnifications are $\times 60$ unless otherwise stated. 
$\mathrm{m}$ of depth. As occurred commonly with the Challenger material, BRADY included specimens representing more than one species in those he nominated as types and also regularly failed to present appropriate locality data. He reported a length of 0.77 . PURI \& Hulings (1976: 259, pl. 2 figs. 5-6) designated and figured a lectotype from the Kerguelen Islands, slightly larger $(0.81 / 0.34)$ than BRAOY's. They failed to include deeper material, later isolated by MADDOCKS from Challenger collection residues. In her re-description, MADDOCKS (1969a) provided one illustration of the muscle scars (Fig. 33i) and one L outline (Fig. 8c). She also referred (1969a: 45) to wide and open vestibula in the descriptive text but illustrations of that features were not presented. Detailed comparison with the species of the Tasman Sea, which display small vestibula, was not possible.

Family Paradoxostomatidae Brady \& Norman 1889

Genus Sclerochilus SARS 1866

Type species: Sclerochilus contortus (NORMAN 1862).

\section{Sclerochilus cf. S. reniformis G. W. MƯLLER 1908} (Figs. 11 I-N)

Material: 10 adult and 3 juvenile valves. - SMF Xe 21463-21464.

Dimensions: Female L $0.77 / 0.35$, R $0.82-0.85 / 0.40$ 0.42 ; male L $0.82-0.85 / 0.35-0.37, \mathrm{R} 0.72 / 0.30$.

Distribution: Holocene of the South Tasman Rise. Very rare in sample BX153 (1874 m). Rare in sample BX140 $(1636 \mathrm{~m})$.

Remarks: This species appears to be restricted to the Southern Ocean/Southern Hemisphere, concentrated around the Antarctic. Müller (1908) reported it from the Gauss Station at $385 \mathrm{~m}$ of depth. He also reported that, S. reniformis is distinguished by the fact that it has fewer marginal pore-canals than S. contortus. NEALE (1967: 11) compared S. reniformis with the BRADY's specimens of $S$. contortus from the Chat lenger Expedition (hosted at the Natural History Museum, London) and concluded that the specimens from the Kerguelen Islands labelled as $S$. contortus are in fact $S$. reniformis. This species was also recorded by WHATLEY et al. (1998) in Halley Bay, Antarctica. The few valves found in the Tasman Rise sample are only tentatively placed in $S$. reniformis because they are not only larger, but also occur in more northerly, deeper sites.

\section{Family Cytheralisonidae JELLINEK \& SWANSON (2003)}

Genus Debissonia Jellinek \& SWanson (2003)

Type species: Debissonia pravacauda (HorNibrook 1952).

Remarks: In 1952, HorNibrook erected a new genus Cytheralison for which he described two species:
C. fava with valves posteriorly tapered, spines on the anterior and posterior areas, ridges on the dorsal margin and surface cells with vertical slit-like openings;

C. pravacauda with parallel dorsal and ventral margins, spines only around the antero-ventral margin and open subsurface cells.

Both species are characterised by the development of a foveolate tegment. The pattern of ornamentation of the tegmen is very characteristic, allowing easy recognition of the genus. Detailed observation also shows other distinctive characters, such as dorsal ridges and anterior and posterior spines.

JELLINEK \& SWANSON examined the type material from Three King Islands and divided Cytheralison into two genera, based on differences in overall shape, presence of spines at the postero-ventral edge and the position of the caudal process : Cytheralison with C. fava Hornibrook 1952 as type species and Debissonia with D. pravacauda (HorNibrook 1952) as type species.

In the samples from the Tasman Sea only the genus Debissonia is represented.

\section{Debissonia fenestrata JELIINEK \& SWANSON (2003)} (Figs. 12A-H)

Material: 71 adule and 264 juvenile valves. - SMF Xe 21465-21467.

Dimensions: Female L $0.90-0.92 / 0.50-0.53$, R 0.90 $0.92 / 0.50-0.52$; male L $0.90-0.95 / 0.50-0.52$, R $0.92-0.97 /$ $0.50-0.52$.

Distribution: Holocene of the South Tasman Rise. Abundant sample BX140 (1636 m), very common in samples $\mathrm{BX} 153(1874 \mathrm{~m})$ and BX141 (1690 m).

Remarks: Despite the fact that the specimens presented herein are slightly smaller than the dimensions of $D$. fenestrata and have less pronounced muri, the pattern of ornamentation of the tegment, arrangement of the ridges along the dorsal and ventral margin are duplicated.

\section{Debissonia cf. D. pravacauda (HoRNiBrook 1952)} (Figs. 12I-R)

Material: 5 adult and 2 juvenile valves from the Recent of Three Kings Island (North Island, New Zealand). - SMF Xe 21468 .

Dimensions: Female L 1.00/0.60, R 0.97-1.00/0.570.60; male L 0.95/0.55, R 0.97/0.57.

Distribution: Three Kings Island, off North Island, New Zealand.

Remarks: Several specimens of Debissonia from the Recent of Three Kings Island were provided by Dr. K. M. SWANSON. The pattern of dorsal and anterior ridges is very similar to $D$. fenestrata, whereas the presence of a 'spike-like process' postero-ventrally and the arrangement of the posterior ridges are features of contrast. Additionally, the hinge elements are all finely crenulate, a feature recognised for the first time in any species of Cytherallison/Debissonia. This crenulation how- 


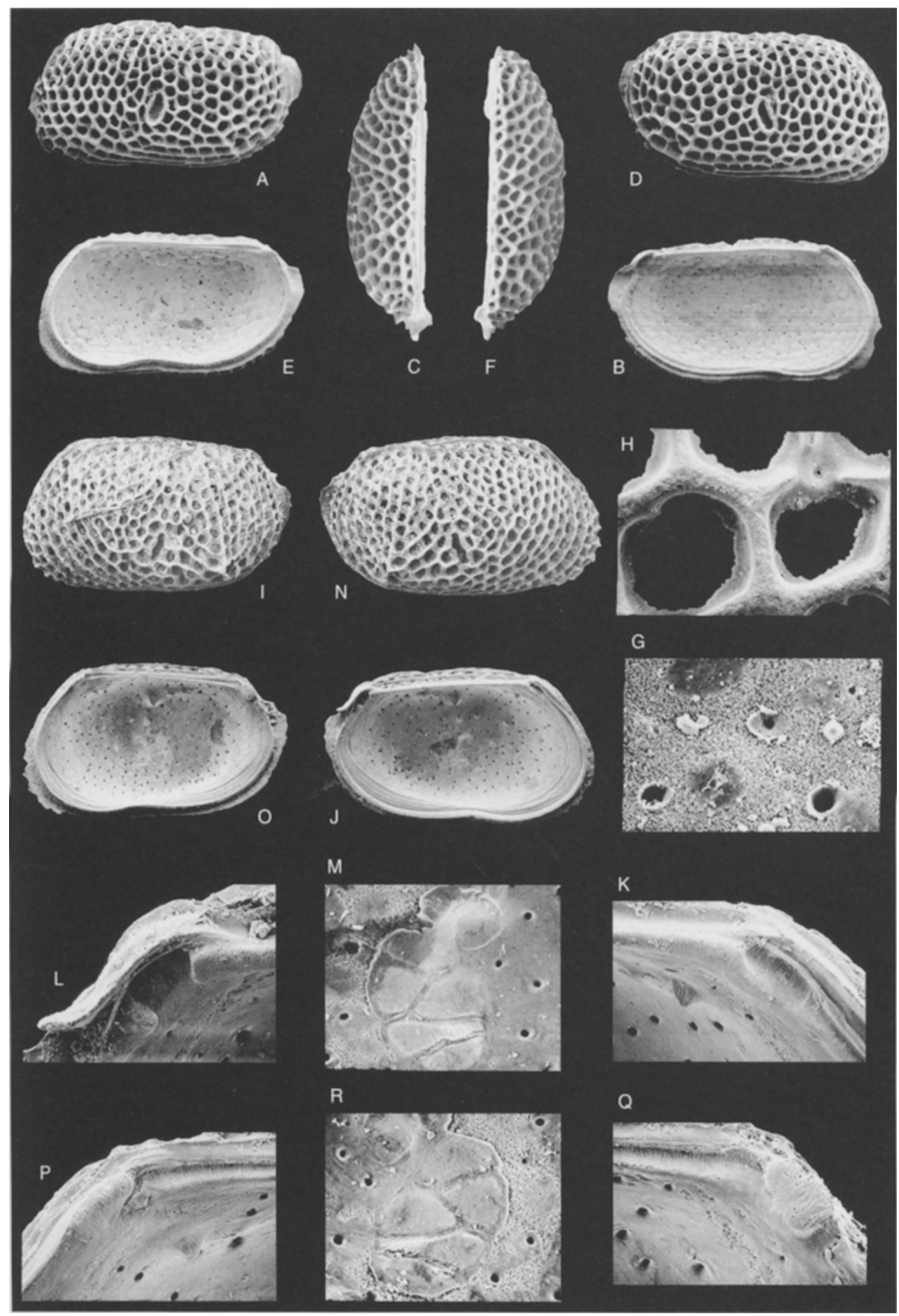

Fig. 12 A-H: Debissonia fenestrata JeLLINEK \& Swanson 2003

Recent, sample BX 140; South Tasman Rise, off south coast Tasmania, Australia; S49 $10.84^{\prime}$, E150 $150^{\circ} 10.13^{\prime}$, 1636 m. - male L (0.95/0.52); A: external view; B: internal view; C: dorsal view. SMF Xe 21465. - male R $(0.97 / 0.52)$; D: external view; $\mathrm{E}$ : internal view; $\mathbf{F}$ : dorsal view; $\mathrm{G}$ : internal view of intramural and central pore canals, $\times 415 ; \mathrm{H}$ : intramural pore-canal, $\times 415$. SMF Xe 21465 .

I-R: Debissonia cf. D. pravacauda (HoRniBROOK 1952)

Recent, Three Kings Island, off east coast North Island, New Zealand; courtesy of Dr. K.M. Swanson, Univ. Canterbury, New Zealand. - male L (0.95/0.55); I: external view; J: internal view; K: detail of anterior socket, $\times 185$; L: detail of posterior socket, $\times 185$; M: central muscle scars, $\times 200$. SMF Xe 21468. - male R $(0.97 / 0.57)$; $\mathrm{N}$ : external view; O: internal view; P: detail of anterior tooth, $\times 185$; Q: detail of posterior tooth, $\times 185$; R: central muscle scars, $\times 200$. SMF Xe 21468. - All magnifications are $\times 43$ unless otherwise stated. 
ever, is so fine that it only can be observed in well preserved specimens. For these reasons the present specimens cannot be placed in D. pravacauda with certainty.

\section{Family Cytheruridae G.W. MüLLER 1894 Subamily Cytheropterinae HaNAI 1957}

\section{Genus Cytheropteron SARS 1866}

Type species: Cythere latissima NORMAN 1865 (designated by Brady \& Norman 1889), not Brady 1867.

Remarks: Cytheropteron is a cosmopolitan cytherurid genus in which a very broad range of different morphological features are exhibited. KEMPF $(1986,1995)$ lists about 340 species of Cytheropteron, to which the species belonging to the five subgenera (Eocytheropteron ALEXANDER 1933, Infracytheropteron KaYE 1964, Aversovalva HoRNIBROOK 1952, Kangarina Coryell \& Fields 1937, Stykella Kozur 1973) and species referred to close related genera such as Kobayashiina HaNaI (1957b), Oculocytheropteron BATE (1972) and Lobosocytheropteron IsHIZAKI \& GUNTHER (1974) should be also added.

SARS (1866) described the species Cytheropteron convexum from the Christiania Fjord (Norway) and indicated this blind species (he very clearly stated "oculi nulli" in the description) as conspecific to Cythere convexa BAIRD. BRADY \& NORMAN (1889) concluded that SARs's species was not identical to BAIRD's and considered it synonymous with $C$. latissimum, recorded in 1865 in shallow waters around England. BATE (1972) erected the new genus Oculocytheropteron to include cytheropterine forms with well-developed eye tubercles. This genus was erected to accommodate the Santonian O. praenuntatum from Western Australia which is also the type species. BATE also included in the genus many Recent species of $C_{y-}$ theropteron, from the southern hemisphere. This genus was not considered by SANGUINETTI (1979), who emended the description of SARS such that the sighted Miocene species C. tuberculatum could also be accommodate in the definition of Cytheropteron. Finally, Horne \& WhITTAKer (1988) after studying Norman's material hosted in the British Museum designated a lectotype accompanied by good illustrations and a diagnosis of the genus which clearly states "eye spots absent."

Many species from the Recent of the Southern Ocean are described in general systematic papers (NEALE 1967, WHATLEY \& Ayress 1988, Ayress 1988, HarTMANN 1989, 1993, 1997) and are often left under open nomenclature. Detailed studies of this genus in the Recent of the South West Pacific are limited to the paper of SWANSON \& AYRESS (1999) on Cytheropteron testudo and related species (the C. testudo Group).

Most of the authors state that Cytheropteron exhibits a considerable variation both in external ornamentation and in details of the hinge. It is possibly for this reason, that WHATLEY \& MASSON (1979) considered Aversovalva and Lobosocytheropteron as synonyms of Cytheropteron and that HORNE \& WhitTaKer (1988) concluded that Kobayashiina was also a synonym of Cytheropteron. Those three genera differ from $C y$ theropteron mainly in the hinge structure. The hinge of the type-species C. latissimum (as illustrated in HORNE \& WHITTAKER 1988) is clearly heterodont, consisting of an elongate and gendly convex arch, which is, in the $\mathrm{L}$, continuously denticulare. Medially these denticles are smaller and more elongate. The terminal elements are in the L short, notched sockets usually consisting of three cells widening distally. The hinge of Aversovalva HoRNiBROOK is also heterodont but the bar/groove is straight and not arched and the terminal elements are simple teeth/sockets, additionally, it possesses a smooth accommodation groove over the median element in the L. The hinge of Lobosocytheropteron ISHIZAKI \& GUNTHER (1974: 38) is described by those authors as "lophodont: in the right valve, AT rounded, bifid; posterior half of the median element much thickened, a combination of tooth-sockettooth-socket; and posterior tooth trilobate like a series of three coothlets.", The hinge of Kobayashiina consists in the R "of anterior, large, knob-like split tooth, median finely crenulate furrow, and posterior tooth which consists of a row of small, elongate, knob-like teeth. Anterior tooth has a step like just below it. Median furrow has a shallow depression at anterior termination, and has no distinct interior raised margin except at middle where anterior finely crenulate and arched part turns into straight, more or less coarsely crenulate part. Inside of the shell swells up so as to form elongate tooth-like projection at middle of interior margin of furrow. Hingement of left valve complementary, except anterior socket which has a prominent antislip-tooth-like projection on its inner margin" (Hanal 1957b: 30).

SWAnson \& Ayress (1999: 158) stated that males and females of some species of Cytheropteron are easily distinguished, the male being less high and more elongate. On the contrary WHATIEY \& MASSON (1979) stated that the sexual dimorphism is absent or not strongly developed. I would agree with the second opinion since sexual distinction proved difficult to discriminate, at least for the material studied herein. For this reason, and because soft parts were not available, the distinction between males and females was not always possible.

Whatley \& MASSON (1979) listed about 40 species of $C y$ theropteron from the Quaternary to the Recent of Great Britain which they proposed could be clustered into six "species groups" based on external carapace features. None of the species described herein could be easily ascribed to the those groups but some of them could fit the informal groupings reported in AYress (1988) for specimens from the Late Pliocene to Quaternary of the eastern Indian and south-western Pacific Oceans. Besides the morphological similarity, it is quite unclear what is the meaning of those groups since they include species geographically widespread and adapted to different environmental conditions (e.g. from the Mediterranean to the Indian Ocean and from the shallow sea to the deep ocean as for the C. acutalatum Group).

\section{Cytheropteron sp. A \\ (Figs. 13A-N)}

Material: 120 adult and 132 juveniles valves. - SMF Xe 21469-21472.

Dimensions: Female L $0.75-0.82 / 0.42-0.50$, R 0.82 $0.85 / 0.55-0.60$; male L $0.70-0.87 / 0.40-0.50$, R $0.75-0.87$ / $0.50-0.55$. 


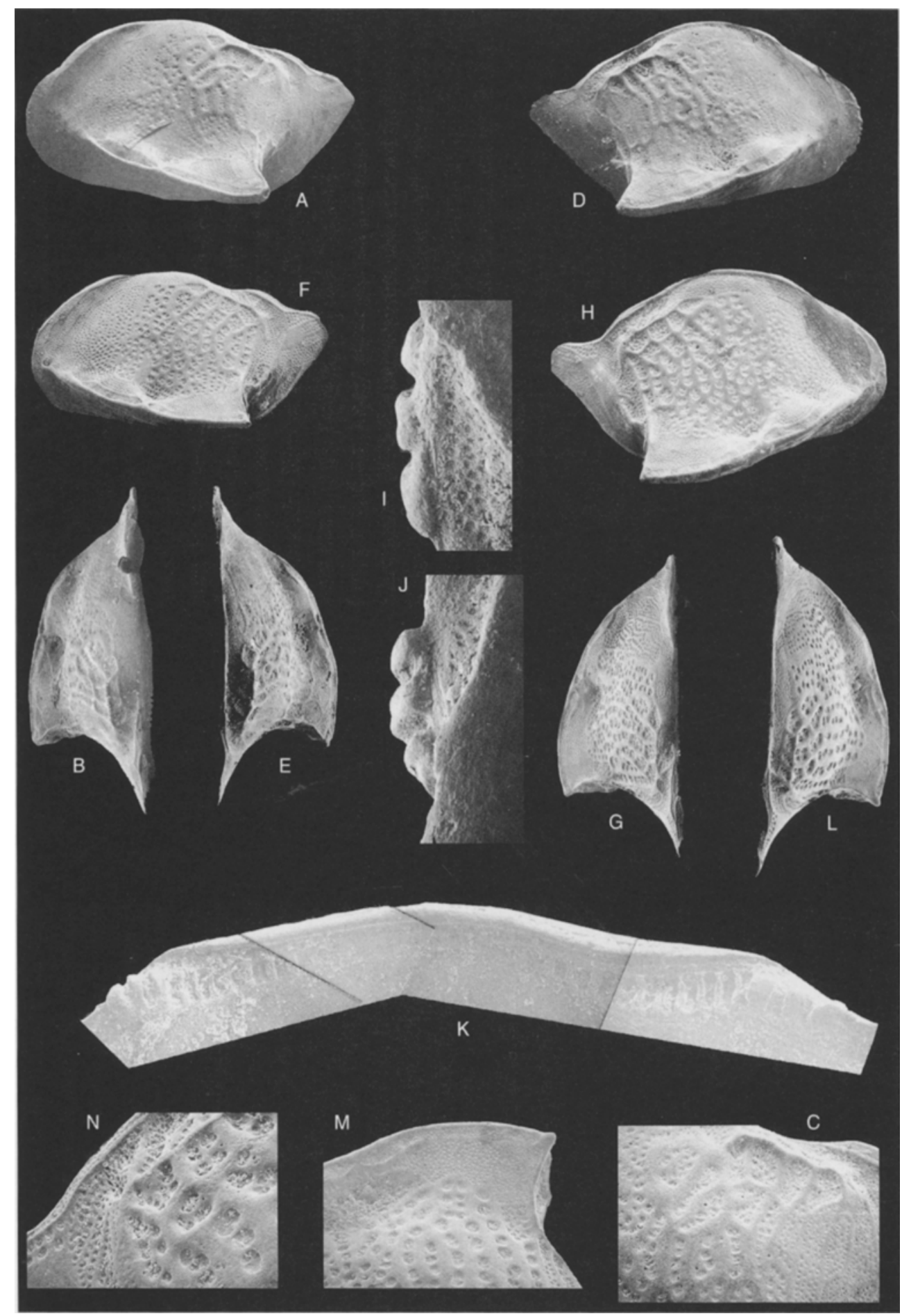

Fig. 13: A-N: Cytheropteron sp. A

Recent, sample BX140; South Tasman Rise, off south coast 'Tasmania, Australia; $\$ 49^{\circ} 10.84^{\prime}$, E $150^{\circ} 10.13^{\prime}$, $1636 \mathrm{~m}$.

A-E: Morphotype with small fossae and large vertical muri. - female L (0.82/0.50); A: external view; B: dorsal view; $\mathrm{C}$ : detail of the ornamentation at the postero-dorsal ridge, $\times 112$. SMF Xe 21469. - female $\mathrm{R}(0.82 / 0.55)$; D: external view; E: dorsal view. SMF Xe 21469.

F-K: Morphotype with large fossae and thin vertical muri. - male L $(0.70 / 0.40)$; F: external view; G: dorsal view. SMF Xe 21469. - female R (0.85/0.60); H: external view; I: dorsal view of the anterior toothlets, $\times 430$; J: dorsal view of the posterior toothlets, $\times 430$; K: detail of the hinge, $\times 200$. SMF Xe 21469 .

L-N: Morphotype with large fossae and large vertical muri. - male R (0.87/0.55); L: dorsal view; M: detail of the ornamentation on the dorsal part of the alar process, $\times 95 ; \mathrm{N}$ : detail of the ornamentation at the postero-dorsal ridge, $\times 155$. SMF Xe 21469 . - All magnifications are $\times 60$ unless otherwise stated. 
Distribution: Holocene of the South Tasman Rise. Abundant in sample BX140 (1636 m), common in samples BX141 (1690 m) and BX153 (1874 m).

Description: A large species of Cytheropteron, with strongly asymmetric valves. Maximum length above midheight at the apex of the upturned caudal process. Maximum height at mid-length. Dorsal margin sinuous in L, arched in $\mathrm{R}$. Anterior margin asymmetrically rounded in $\mathrm{L}$, evenly rounded in R. Posterior margin caudate above mid-height; caudal process wider in $\mathrm{L}$ and longer in $\mathrm{R}$. Ventral margin obscured by the alar process. Alar process well developed, with shallow alar pit and a short and blunt apical spine. Surface covered with round punctae widening towards the middle. At posterior margin, small round punctae are included in elongate meshes. On the alar process, meshes are sub-rectangular to sub-triangular and on the caudal process they display no clear pattern. The central part of the caudal process may be smooth. Postero-dorsal ridge situated medially between a double row of four deep meshes each containing smooth round fossae. Scattered round fossae are also visible on the postero-medial area and may be separated by shallow vertical muri. On the ventral area of the alar process, ornate by small punctae, three faint ridges occur. Normal pore-canals simple and large with one extremely large at the posterior edge of the dorsal ridge. In dorsal view, maximum width around mid-length at the maximum convexity of the alar process.

Internally: inner lamella broad, with deep vestibula; anterior vestibulum narrow, posterior moderately wide. The postero-ventral margin bears short perpendicular ridges dividing the external part into 6-8 sub-rectangular meshes. Marginal pore-canals long, straight and simple, 8-10 anteriorly and 4-7 posteriorly. Hinge antimerodont. In the $\mathrm{R}$, the terminal elements consist of well-developed triplets of toothlets, the most external two of which are bilobate. The strong denticulation of the median sinuous element thins medially. L elements complementary, with evident hinge ears and deep sockets.

Adductor scars consisting of a vertical row of four scars with the lowermost small and elongate, the second lowermost elongate and the two uppermost elongate, slightly diverging anteriorly. Frontal scars consist of a posteriorly open Ushaped and a small circular anterior scar above it.

Remarks: The peculiar ornamentation and shape of this species displays a high degree of variability. The pattern of the basic element of the ornamentation is constant (same number of vertical muri and fossae) whereas their dimensions can vary. The different proportions of the specimens are probably related to sexual dimorphism. Three different morphotypes were recognised and are illustrated in Fig. 13:

- with small fossae and large vertical muri (A-E)

- wirh large fossae and thin vertical muri $(\mathrm{F}-\mathrm{K})$

- with large fossae and large vertical muri (L-N)

C. sp. A differs from C. sp. B in the shape of the alar process, which is more developed in $C$. sp. A to the extent that it obliterates the ventral margin on both valves. This species do not fit any of the groups reported by AYrESS (1988).

\section{Cytheropteron sp. B}

(Figs. 14A-F)

Material: 41 adult and 65 juveniles valves. - SMF Xe 21473-21475.

Dimensions: Female L $0.87-0.90 / 0.47-0.50$, R $0.72-$ $0.85 / 0.47-0.50$; male L $0.72-0.82 / 0.42-0.47$, R $0.72-0.80 /$ $0.42-0.45$.

Distribution: Holocene of the South Tasman Rise. Very common in sample BX153 (1874 m) and common in sample BX141 (1690 m).

Description: A large species of Cytheropteron with strongly asymmetric valves. Maximum length above midheight at the apex of the caudal process. Maximum height medially. Dorsal margin sinuous in L, arched in R. Anterior margin asymmetrically rounded in $\mathrm{L}$, evenly rounded in $\mathrm{R}$. Posterior margin with caudal process above mid-height, upturned in the L. Ventral margin straight, partially obscured by the ventral ala. Alar process well developed, with deep alar pit and a strong, laterally directed, apical spine. On ventral parts of the alar process three blade-like ridges occur, the lowermost being the more prominent and which partially covers the ventral margin. Surface covered by a complex array of round fossae and small punctae. Punctae located marginally, organised in polygonal meshes and separated by flat and smooth muri, particularly evident on the alar process. Punctae found on the tip of the caudal process slightly larger. On the remaining external surface large round fossae are scattered, each possessing 5-6 oval depressions encircling a single round hollow. At the posterior cardinal angle, four sub-rectangular meshes form a horizontal row below the small postero-dorsal ridge. Ventral surface with small punctae which, near to the ventral margin, are arranged in sub-rectangular meshes. Normal pore-canals are simple and large. In dorsal view, maximum width at apical spine and alar process with a slight anterior bulge.

Internally: inner lamella broad with deep vestibula, anterior vestibulum very reduced, posterior wide. The posteroventral margin with a flange carrying short perpendicular ridges. Marginal pore-canals long, straight and simple, 8-10 anteriorly and 4-7 posteriorly. Hinge antimerodont. In the $\mathrm{R}$, terminal elements consist of well developed triplets of toothlets; the median arched element is strongly denticulate, with denticles becoming wider and shorter towards medially. L elements complementary with evident hinge ears.

Adductor scars consisting of a vertical row of four scars with the lowermost oval, the second lowermost elongate, the second uppermost elongate and S-shaped and the uppermost oval. Frontal scats consists of one posterior oval-shaped and one small, circular anterior scar antero-dorsally.

Remarks: Although many adult specimens of this species were recovered, most of them were corroded. On Figs. $14 \mathrm{~A}-\mathrm{F}$ a non-eroded female $\mathrm{R}$ and an eroded male $\mathrm{L}$ are figured. There are some minor differences in the ornamentation, which herein are attributed to the different preservation states and sexual dimorphism. Only six well preserved Rs were recovered. Because of the poor preservation and of the uncertainty relating to variations in ornamentation, this taxon has been left under open nomenclature. 


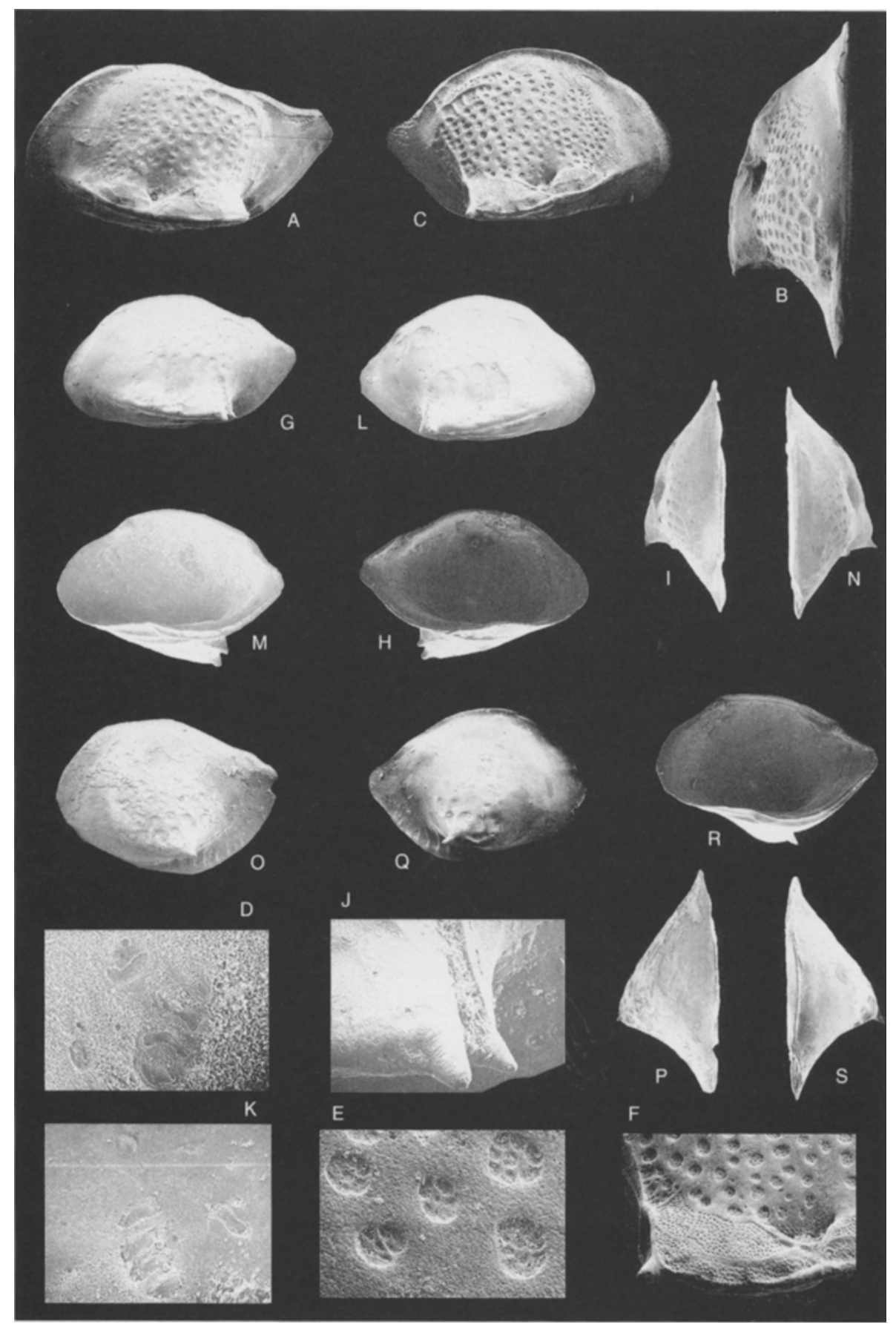

Fig. 14: A-F: Cytheropteron sp. B

Recent, sample BX 141; South Tasman Rise, off south coast Tasmania, Australia; $\$ 49^{\circ} 08.34^{\prime}$, E149 $54.98^{\prime}, 1640$ m. - male L (0.82/0.47); A: external view; B: dorsal view. SMF Xe 21473. - female $\mathrm{R}(0.72 / 0.47)$; C: external view; D: central muscle scars, $\times 176$; E: detail of the ornamentation with ornate sub-round fossae, $\times 468$; F: detail of the ornamentation at the alar process showing the sub-rectangular meshes including small round punctae and the sub-round fossae, x109; SMF Xe 21473.

G-N: Cytheropteron dibolos n. sp.

Recent, sample BX 140; South Tasman Rise, off south coast Tasmania, Australia; $\$ 49^{\circ} 10.84^{\prime}$, $\mathrm{E} 150^{\circ} 10.13^{\prime}, 1636 \mathrm{~m}$. - female L $(0.60 / 0.37)$, holotype; G: external view; H: internal view; I: dorsal view; J: detail of the apex of the alar process, $\times 300$; K: central muscle scars, $\times 209$. SMF Xe 21476. - female R (0.60/0.37), paratype; L: external view; M: internal view; N: dorsal view. SMF Xe 21477.

O-S: Cytheropteron sp. C

Recent, sample BX140; South Tasman Rise, off south coast Tasmania, Australia; $449^{\circ} 10.84^{\prime}$,

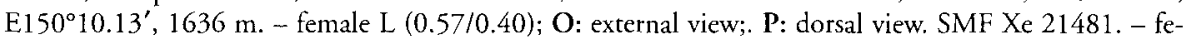
male R (0.55/0.37); Q: external view; R: internal view; S: dorsal view. SMF Xe 21481. - All magnifications are $\times 56$ unless otherwise stated. 
This species is tentatively included in the C. pneumatopotanus Group sensu Arress (1988: 512-513). This group is supposed to be endemic to the Australasian/Western Pacificl Eastern Indian Oceans region.

\section{Cytheropteron dibolos $\mathrm{n} . \mathrm{sp}$.} (Figs. 14G-N)

1988 Cytheropteron sianae SMITH 1983. - AYRESS: 498, pl. 17 figs. $15-17$. (= nomen nudum)

Derivation of name: From the Greek adjective dibolos = two pointed; referring to the double spines on the alar process.

Holotype: Female L (0.60/0.37), Figs. 14G-K. - SMF Xe 21476.

Paratypes: 49 adult and 39 juveniles valves. - SMF Xe 21477-21480.

Dimensions (of paratypes): Female L 0.55-0.60/0.350.37 , R 0.57-0.60/0.35-0.37; male L 0.57-0.62/0.30-0.35, R $0.57-0.60 / 0.32-0.35$.

Type localitys: RV SONNE cruise no. SO 136, site 30 station 140; box-corer sample from the $S$ Tasman Rise, off $S$ Tasmania, Australia, at $1636 \mathrm{~m}$ water depth; $549^{\circ} 10.84^{\prime}$, $\mathrm{E} 150^{\circ} 10.13^{\prime}$.

Distribution: Holocene of the South Tasman Rise. Rare in samples BX141 (1690 m) and BX153 (1874 m), common in sample BX140 (1636 m).

Diagnosis: Sub-ovate in shape with elongate punctae on the median part of the surface and smooth extremities. Weakly developed alar process with deep alar pit and two apical spines which are separated by a vertical furrow.

Description: A medium sized species of Cytheropteron. Maximum length at mid-height, maximum height medially. Dorsal margin evenly arched. Anterior margin asymmetrically rounded. Posterior margin caudate at mid-height, slightly concave above. Ventral margin sinuous. Alar process weakly developed, with deep alar pit and a strong laterally directed apical spine. Postero-ventrally to the alar process, a second horizontally-directed spine occurs. These two spines are separated dorsally, by a vertical deep furrow which ends slightly below carapace mid-height. Ventrally alar process with two blade-like ridges, the uppermost of which carries a second spine on the posterior edge. The ventral-most part of the caudal process, just below the apical spines of the ala, with three round fossae. Carapace margin smooth, remaining surface reticulate with vertical elongation of meshwork exaggerated vertically. Short ridge at posterior cardinal angle, extending to the anterior angle in the R. Normal pore-canals simple and scattered, a row of four parallel to the alar margin. In dorsal view, maximum width at apical spine.

Internally: inner lamella of moderate width, with vestibula very close to the internal surface of the valves. Anterior vestibulum small, posterior vestibulum narrow. The postero-ventral margin with flange, bearing perpendicular short ridges, which divide the flange in seven elongate meshes. Marginal pore-canals very short, straight and simple, six anteriorly and four posteriorly Hinge antimerodont. In the R, terminal ele- ments faintly lobate whereas the median arched element is strongly denticulate, with thin denticles medially. L elements complementary.

Adductor scars consisting of a vertical row of four scars with the lowermost oval, the lower middle elongate and boomerang-shaped, the upper two dumbbell-shaped and the uppermost very thin and small. The frontal scars consist of a posterior V-shaped scar and probably a small circular dorsally.

Remarks: C. sianae as illustrated by Ayress (1988: 498, pl. 17 figs. 15-17) in his unpublished $\mathrm{PhD}$ thesis, is a synonym of this new species. AYRESS named his specimens after a species described by SMITH (unpublished Ph.D. thesis). Since those theses have not been published and those description were not formally published (see also KEMPF 1986, 1995) the name is invalid and is therefore not used herein. AYREss found only six specimens of this species in the Pleistocene of the Indian Ocean. Although his specimens are smaller $(0.42 / 0.24)$ the description of the peculiar apex of the alar process, the shape, ornamentation and the internal features are the same as those I attribute to $C$. dibolos $\mathrm{n}$. sp. This species is included in the C. acutalatum Group sensu Arress (1988: 491).

This species resembles $C$. massoni WhatLeY \& COLES (1987: 63, pl. 2 figs. 15-17) which is, however, more slender and lacks the double spine at the alar apex. ;moreover the delicate punctate ornamentation is only weakly developed. It was recovered from the Lower Pliocene and Quaternary of the N Atlantic.

It is also very close to $C$. hamatum SARS sensu WHATLEY $\&$ Masson (1979: 236, pl. 3 figs. 4, 8, 11-13) from the Quaternary of the NE Atlantic. I have some doubts about the synonymy between the two species. WHATLEY \& MASSON examined material from the NORMAN collection, taking into account that BRADY \& Norman (1889) included C. vespertilio in $C$. hamatum. It is not clear whether the slide they studied and which was labelled "Stoksund, Norway", was also labelled C. hamatum, or if the latter reflects the opinion of those authors, without checking the type material. However, examination of the description and of the plates of SARS (1928: 226, pl. 104 fig. 2) in his "An account on the Crustacea from Norway" is instructive. The two species exhibit contrasting dorsal outlines, apical spines and alar processes which show significant differences in shape. In fact, the SARS species has a hamiform spine (hence the name) as opposed to a straight simple spine found on the other species, which also bears a second spine on the posterior side of the ala. AYRESS (1988: 476-478, pl. 16 figs. 14-18) tentatively assigned specimens from the Pleistocene of the Pacific and Indian Ocean to $C$. hamatum following conclusions reached by WhATLEY \& MASsON. The two species differ in the outline, the taxon from the Atlantic being more slender. Significantly, the dimensions given by WHATLEY \& MASSON $(0.52-0.58 / 0.31-0.34)$ do not correspond to those measured by this author from the plate (0.51-0.53/0.25-0.28). In the description provided by AYrESS, the double apical spine is not mentioned whereas in the illustrations this feature is highlighted by the deep vertical furrow described by AYress as one of the fossae, extending onto the posterior alar surface. Compared with $C$. dibolos n. sp., it has a more pronounced surface ornamentation, lacks the dorsal ridge on the $\mathrm{R}$, and has a different apex on the alar process. 
C. bispinosa Dingle (1984) from the Falkland Plateau displays the same double spinosity, but displays a totally different hinge (straight crenulate median and smooth terminal elements) and in this author's opinion is more closely allied to Aversovalva.

\section{Cytheropteron sp. C}

(Figs, 14O-S)

Material: 9 adult valves. - SMF Xe 21481-21484.

Dimensions: Female L 0.55-0.57/0.37-0.40, R 0.55$0.57 / 0.37-0.40$.

Distribution: Holocene of the South Tasman Rise. Very rare in samples BX140 (1636 m), BX141 (1690 m), BX153 (1874 m), rare in sample BX138 (3022 m).

Description: A small sub-ovate species of Cytheropter on. Maximum length above mid-height, maximum height medially. Dorsal margin gently arched. Anterior margin asymmetrically rounded. Posterior margin caudate at midheight. Ventral margin asymmetrically arched, with expanded posterior half. Alar process weakly developed, cone-shaped with a strong apical spine. Surface smooth except for the central area where large circular punctae occur. On the posteroventral margin a single row of large elongate punctae runs parallel to the outer margin. Normal pore-canals simple and very thin. Ventral surface of the alar process smooth. In dorsal view, triangular in shape, maximum width at the apical spine.

Internally: inner lamella moderately wide, with narrow vestibula close to the internal surface of the valves. Anterior and posterior vestibula narrow. Marginal pore-canals straight and simple, 4 anteriorly and 3 posteriorly, which alternate with an equivalent number of false canals. Hinge antimerodont. $\mathrm{R}$ terminal elements consist of small trilobate teeth; groove slightly convex and faintly denticulate. L elements complementary.

MS could not be studied due to the poor preservation of the material.

Remarks: This species is very similar to $C$. paucipunctatum Whatley \& Coles (1987: 63, pl. 2 figs. 18-20) from the Quaternary of the Atlantic. The latter is smaller and narrower $(0.42 / 0.24)$, has smaller and scattered punctae up to the dorsal margin and round punctae on the postero-ventral margin. This species was recorded by AYRESS (1988: 463, pl. 16 figs. 4-5) from the Pleistocene of the Indian and Pacific Ocean and was also figured as Cytheropteron sp. 1 by WHATLEY \& AYRESS (1988: pl. 1 figs. 6a-b). AYress (1988) in his remarks indicated there were similarities between $C$. paucipunctatum and the unpublished more rotund species $C$. adamanteus, which would better fit with $C$. sp. C. Because of a lack of specimens, this species has been left under open nomenclature in the present study.

This species is tentatively included in the C. bathypacifica Group sensu AYRESS (1988: 450-451), which is a diverse group, widespread from the North Atlantic Ocean to the Southwest Pacific Ocean.

\section{Cytheropteron sp. D \\ (Figs. 15A-C)}

Material: 17 adult and 5 juvenile valves. - SMF Xe 21485-21486.

Dimensions: Female L $0.70-0.72 / 0.37-0.40$, R $0.65 /$ 0.40; male L $0.67-0.70 / 0.35-0.37$, R $0.65-0.70 / 0.37-0.40$.

Distribution: Holocene of the South Tasman Rise. Common in sample BX153 (1874 m).

Description: A large species of Cytheropteron. Valves moderately calcified. Maximum length above mid-height, maximum height at anterior cardinal angle. Valves elongate with arched dorsal margin. Anterior margin asymmetrically rounded with thin marginal rim. Posterior margin with medial caudal process better which is developed in L. Postero-ventral margin obscured by the alar process. Alar process moderately developed, with shallow sub-central alar pit, from which two flat ridges originate. Blunt terminal spine. Posterior dorsal ridge present at the cardinal angle. Surface of the valves ornate with many small punctae which decrease in size towards the valve margins. On the alar process the punctae form two rows, separated in the middle of the process by a smooth band. Normal pore-canals simple and narrow. Ventral surface of the alar process with three secondary ridges, protruding at posterior. The most dorsal of the ridges is visible also in lateral view, giving the appearance of a double spinosity at the posterior edge of the ala. In dorsal view, maximum width medially. Alar process truncate posteriorly, forming a step-like connection with the most protruding ventral ridge.

Internally: dorsal margin arched, anterior margin asymmetrically rounded, ventral margin slightly concave in the oral region. Along the posterior half of the ventral margin a row of 6 sub-rectangular meshes occurs. Anterior vestibulum well developed, posterior vestibulum narrow. Radial pore-canals sinuous, about 7-9 anteriorly and 3-4 posteriorly.

Hinge antimerodont, similar to that described for $C$. $c a$ putanatinum $\mathrm{n}$. sp. but with larger terminal elements.

Adductor scars consisting of a vertical row of four scars with the uppermost being elliptical whereas the lower three are elongate and the lower middle displaying an anterior expansion. The frontal scars consist of a V-shaped posterior and a circular anterior slightly above it.

Remarks: This species differs from C. caputanatinum $\mathbf{n}$. sp. in the smaller punctae, the less arched $\mathrm{R}$ dorsal margin, the presence of well-developed and protruding ridges on the ventral side and the stepped posterior outline in dorsal view. It differs from $C$. sp. $E$ in slightly smaller dimensions, the more uniformly distributed smaller punctae and the slender caudal process.

C. sp. D is very similar to C. planaltum GuerNet (1985: 286, pl. 4 figs. 4-5) described from upper and middle Eocene sediments from the Indian Ocean. C. planaltum is smaller, has more uniformly distributed punctae and a small ridge on the ocular sinus. GUERNET described the hinge as: a median crenulate element and two marginal elements, sockets or teeth, in opposite direction to that of the median element and, apparently, not lobate (translated from the French), which brings into question the determination that this taxon belongs in Cytheropteron. 


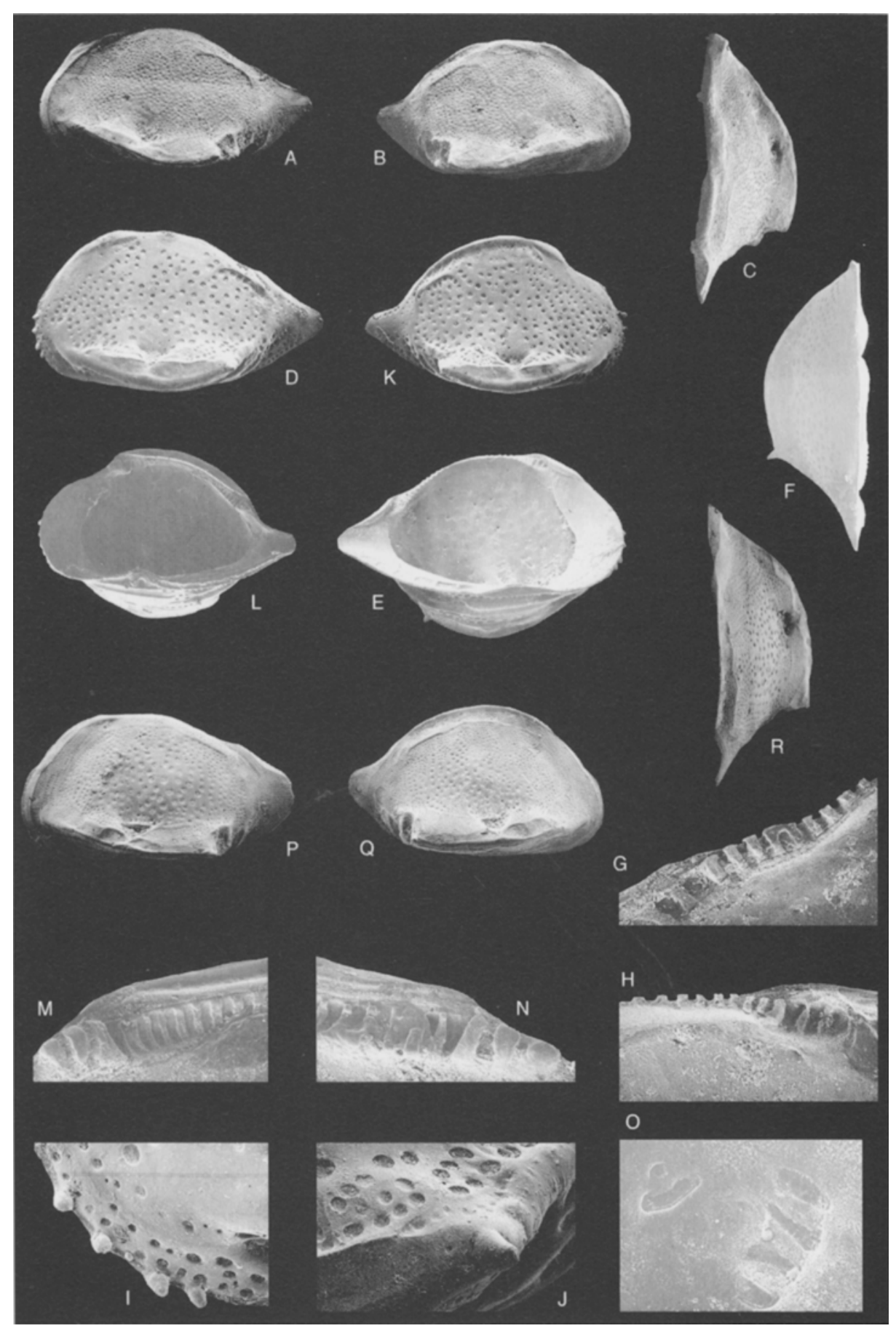

Fig. 15: A-C: Cytheropteron sp. D

Recent, sample BX153, South Tasman Rise, off south coast Tasmania, Australia; $\$ 47^{\circ} 46.85^{\prime}$, E147 $55.13^{\prime}, 1874$ m. - male L $(0.70 / 0.37)$; external view. - SMF Xe 21485. male R (0.65/0.37); a) external view; b) dorsal view. SMF Xe 21485

D-O: Cytheropteron caputanatinum $\mathrm{n}$. sp.

Recent, sample BX147, South Tasman Rise, off south coast Tasmania, Australia; S48 29.99', E $149^{\circ} 06.75^{\prime}, 2177 \mathrm{~m}$. - female L (0.72/0.45), paratype; D: external view; E: internal view; F: dorsal view; G: detail of the posterior elements of the hinge, $\times 208 ; \mathrm{H}$ : detail of the anterior elements of the hinge, $\times 208$; I: detail of the anterior marginal denticles, $\times 240$; J: detail of the posterior part of the alar process, $\times 145$. SMF Xe 21488 . - female $\mathrm{R}(0.65 / 0.45)$, holotype; K: external view; L: internal view; $M$ : detail of the posterior elements of the hinge, $\times 208$; $\mathrm{N}$ : detail of the anterior elements of the hinge, $\times 208$; $\mathrm{O}$ : central muscle scars, $\times 208$. SMF Xe 21488 .

P-R: Cytheropteron sp. E

Recent, sample BX140; South Tasman Rise, off south coast Tasmania, Australia; $\$ 49^{\circ} 10.84^{\prime}$, E150¹0.13', 1636 m. - male L (0.70/0.40); P: external view. SMF Xe 21493. - male R (0.65/0.42); Q: external view; R: dorsal view. SMF Xe 21493. - All magnifications are $\times 58$ unless otherwise stated. 
It is included in the $C$. pneumatopotanus Group as described in Ayress (1988: 512-513). This group is supposed to be endemic to the Australasian/Western Pacific/Eastern Indian Oceans region.

\section{Cytheropteron caputanatinum $\mathrm{n} . \mathrm{sp}$.} (Figs. 15D-O)

Derivation of name: Composed of two Latin words, the noun caput = head and the adjective anatinus = of a duck; referring to the shape of the valves which resembles, in outline, the profile of a duck.

Holotype: Female R (0.65/0.45), Figs. 15K-O. - SMF Xe 21487.

Paratypes: 158 adult and 123 juvenile valves. - SMF Xe 21488-21492.

Dimensions (of paratypes): Female L $0.65-0.72 / 0.40$ 0.45 , R $0.65-0.75 / 0.45-0.47$; male L $0.72-0.75 / 0.37-0.40$, R $0.67-0.77 / 0.45-0.47$.

Type locality: RV SONNE cruise no. SO 136, site 30, station 147; box-corer sample from the $S$ Tasman Rise, off $S$ Tasmania, Australia, at $1690 \mathrm{~m}$ water depth; $\$ 48^{\circ} 29.99^{\prime}$, E149 $06.75^{\prime}$.

Distribution: Holocene of the South Tasman Rise. Rare in sample BX141 (1690 m); common in sample BX153 $(1874 \mathrm{~m})$; very common in sample BX147 (2177 m); abundant in sample BX140 (1636 m).

Diagnosis: Sub-ovate in shape with surface covered with large, round punctae. Anterior margin finely denticulate. Weakly developed alar process with deep alar pit.

Description: A large, inequivalve species of Cytheropteron. Valves well calcified. Maximum length just below midheight, coinciding with the edge of the caudal process, maximum height at anterior cardinal angle. $L$ elongate-ovate with dorsal margin gently arched. $\mathrm{R}$ ovate, with dorsal margin arched and sloping abruptly towards the anterior. Anterior margin asymmetrically rounded with 4-8 small on the ventral half. Posterior margin strongly caudate just below mid-height. Caudal process large and better developed in $\mathrm{L}$, with two rows of punctae parallel to the dorsal and ventral margins, otherwise smooth. In lateral view, ventral margin partially obscured by the alar process. Alar process well developed, smooth at the edge with sub-central deep alar pit from which two faint longitudinal ridges extends anteriorly and posteriorly respectively and form a boundary between the smooth and punctate areas of the alar process. Apex spinose. Short dorsal ridges at both cardinal angles in $\mathrm{L}$, only at posterior in R. Remainder of the valve punctate. Punctae smooth and round, those on the dorsal margin and on the caudal process are smaller. Normal pore-canals simple. Ventral surface of the alar process with faint punctae and four horizontal ridges. In dorsal view, maximum width at the anterior third.

Internally: dorsal margin arched; anterior margin asymmetrically rounded; ventral margin concave in the mouth area. Along the posterior half of the ventral margin a row of 6-7 sub-rectangular meshes is located. Anterior vestibulum wide, posterior vestibulum narrow. Radial pore-canals straight but curved at extremities about 7 anteriorly, 3-4 posteriorly.
At anterior they are concentrated ventrally where they exit through small denticles.

Hinge antimerodont. Terminal elements consisting of three small elongate teeth/sockets; median elements continuously denticulate. The sub-central part of the bar with small, flat denticles. In the $\mathrm{R}$, a well-developed anti-slip bar extends between the two cardinal angles.

MS consisting of a vertical row of four adductor and two distinct frontal scars. The lowermost adductor is oval, the second is dumbbell-shaped, the third is elongate with posterior swelling, the uppermost is oval. The frontal scars consist of an elongate posterior scar, tilted in an $45^{\circ}$ angle the adductors and a small and round anterior scar. In some juveniles these two scars are very close to each other, creating an asymmetrical V.

Remarks: This new species does not fit the definition of the C. testudo Group as reported in SWANSON \& AYrESS (1999) because of the deep alar pit, the spiny posterior edge of the alar process which is not parallel to the ventral margin. It is included in the $C$. pneumatopotanus Group sensu Avress (1988: 512-513). This group is supposed to be endemic to the Australasian/Western Pacific/Eastern Indian Oceans region.

It is similar in its shape and ornamentation to species of $C$. from the Late Eocene of New Zealand, and in particular to C. sp. 1 Ayress (1996: 17, pl. 1 fig. 12) and C. sp. 1 Ayress (1994: Fig. 12). C. caputanatinum n. sp. differs from both in its larger dimensions and equal size of the punctae.

C. caputanatinum n. sp. is also similar to Oculocytheropteron mascarade AYRESS \& RATHBURN (as published by WhATLEY et al. 1998: 122-123, pl. 3 figs. 5-6) which yet displays an ocular node, a less sinuous dorsal margin of the $\mathrm{R}$ and punctae of different sizes. C. caputanatinum n. sp. differs from $C y$ theropteron abyssorum BRADY (sensu WHATLEY et al. 1988: 181, pl. 3 figs. 5-7) because the new species displays larger punctae, a round alar process in dorsal view and a denticulate anterior margin. Moreover, C. abyssorum displays an upturned caudal process on both valves.

\section{Cytheropteron sp. E \\ (Figs. 15P-R)}

Material: 13 adult and 12 juvenile valves. - SMF Xe 21493-21494.

Dimensions: Female L $0.75 / 0.42$, R $0.72 / 0.45$; male L $0.67-0.70 / 0.37-0.40$, R $0.65-0.70 / 0.42-0.45$

Distribution: Holocene of the South Tasman Rise. Very rare in sample BX141 $(1690 \mathrm{~m})$; common in sample BX140 (1636 m).

Description: A large species of Cytheropteron. Valves weakly calcified. Maximum length above mid-height, maximum height at anterior cardinal angle in $\mathrm{L}$, at mid-length in R. L elongate sub-rectangular with dorsal margin gently arched. R ovate, with dorsal margin gently arched. Anterior margin asymmetrically rounded with thin marginal rim. Posterior margin with medium-sized caudal process located medially. Caudal process up-turned in R. In lateral view, ventral margin partially obscured by the alar process. Alar process 
well developed, with deep, triangular pit, with peripheral ridge. Apex blunt and spinose. Dorsal ridge more evident in posterior half. Surface of the valves composed of punctae and flat muri. On the alar process the muri form sub-rectangular meshes enclosing small punctae. This type of ornamentation is duplicated on all the remainder of the carapace except that the muri merge to form irregular meshes, i.e. more triangular at posterior, and elongate at anterior. The central part of the lateral surface, between the dorsal ridge and the region immediately above the ala, lacks the muri and has much larger punctae so that the dimensions of the punctae are decreasing from the centre to the margins of the valves. Normal pore-canals simple, large and funnel type. Ventral surface of the alar process with small punctae organised in polygonal meshes and separated by slightly raised ridges. In dorsal view maximum width at mid-length. Alar process truncate at posterior.

Internally: ventral margin concave around the oral region. Anterior vestibulum wide, posterior vestibulum narrow. $\mathrm{Ra}$ dial pore-canals straight, 6 anteriorly and 3 posteriorly.

The antimerodont hinge could not be studied in detail because of poor preservation of the specimens. MS observed only in an adult $\mathrm{L}$; identical to those described for $C$. caputanatinum $\mathrm{n}$. sp.

Remarks: This species is very similar to $C$. sp. 1 AYREsS (1998: Fig. 12). The main difference between $C$. sp. E and $C$. sp. 1 is the presence of spines on the antero-ventral margin in C. sp. 1 (which may be eroded in the specimens studied herein due to bad preservation) and the more developed and upturned caudal process of $C$. sp. E.

C. sp. $\mathrm{E}$ is distinguished from C. caputanatinum $\mathrm{n}$. sp. by its surface ornamentation, different valve and alar process shape. It also displays minor contrasts in the arrangement and type of normal and marginal pores. The few specimens recovered and poor preservation prevented a more specific taxonomic determination.

This species is included in the C. pneumatopotanus Group as described in Ayress (1988: 512-513). This group is supposed to be endemic to the Australasian/Western Pacific/Eastern Indian Oceans region.

Genus Pelecocythere ATHERSUCH 1979

Type species: Pelecocythere sylvesterbradleyi ATHERSUCH 1979.
Remarks: This genus was originally erected on Recent specimens from the NE Atlantic, off SW Ireland, at depths of 3680-3697 m. The species known from Miocene to Quaternary show a broad geographic distribution (Tab. 5).

Cytheropteron? trinidadensis VAN DEN BOLD (1960) was referred to Pelecocythere by Whatley \& Coles (1987) without indications that VAN DEN BOLD's type material from the Eocene-Miocene of Trinidad had been re-examined. The description of the MS given by VAN DEN BOLD (1960: 176-177, pl. 5 figs. $5 \mathrm{a}-\mathrm{c}$ ) is in contrast to that presented by ATHERSUCH for the type species. Unfortunately internal feature was not described for either $P$. galleta or $P$. purii, however the descriptions of the other species indicate this as a very variable character in which adductor may be divided or not and the frontal scars divided or trilobate. Another species which probably belongs to Pelecocythere was figured (without formal description) as Eocytheropteron by BENSON (1975b: Fig. 9/3).

\section{Pelecocythere sp. \\ (Figs. 16A-B)}

1988 Pelecocythere sp. - Whatley \& Ayress: 739 ff, pl. 2 fig. 8 b.

non 1988 Pelecocythere sp. - WhATLEY \& AYREss: 739 ff, pl. 2 fig. 8 a.

1988 Pelecocythere robusta DowNING 1985. - AYREss: 666-668, pl. 24 figs. 4-5. (= nomen nudum)

non 1988 Pelecocythere robusta DoWNING 1985. - Ayress: 666-668, pl. 24 figs. 3-8. (= nomen nudum)

1988 Pelecocythere robusta DOWNING 1985. - AYRESs: 666-668, pl. 24 fig. 6. (= nomen nudum)

Material: 5 adult and 2 juveniles valves. - SMF Xe 21495-21496.

Dimensions: Female L $0.60-0.65 / 0.42-0.50$, R $0.65 /$ 0.42 .

Distribution: Holocene of the South Tasman Rise. Very rare in samples BX141 (1690 m) and BX153 (1874 m).

Description: Strongly asymmetric valves, with the $\mathrm{L}$ much higher than the $\mathrm{R}$. Dorsal margin arched in the $\mathrm{L}$, straight in the R. Anterior rounded with a smooth rim, posterior bluntly pointed. Ventral margin slightly rounded and partially obscured by alar process. Maximum length slightly above mid-height; maximum height medially in $\mathrm{L}$ and at anterior cardinal angle in the $\mathrm{R}$. Maximum width at mid-

Table 5: Species of Pelecocythere from the Quaternary and their distribution.

\begin{tabular}{lllc}
\hline Pelecocythere & author & locality & depth [m] \\
\hline sylvesterbradleyi & ATHERSUCH 1979 & NE Atlantic & $3680-3697$ \\
purii & NEALE 1988 & NE Atlantic & $4000-5000$ \\
foramena & WhATLEY \& COLES 1987 & N Atlantic & \\
galleta & WHATLEY, CHADWICK, COXILL \& TOY 1988 & S Scotia Sea & 1408 \\
robusta & AYRESS 1988 & Indian \& Pacific & $?$ \\
sp. & AYRESS \& WHATLEY 1988 & Indian \& Pacific & $?$ \\
\hline
\end{tabular}




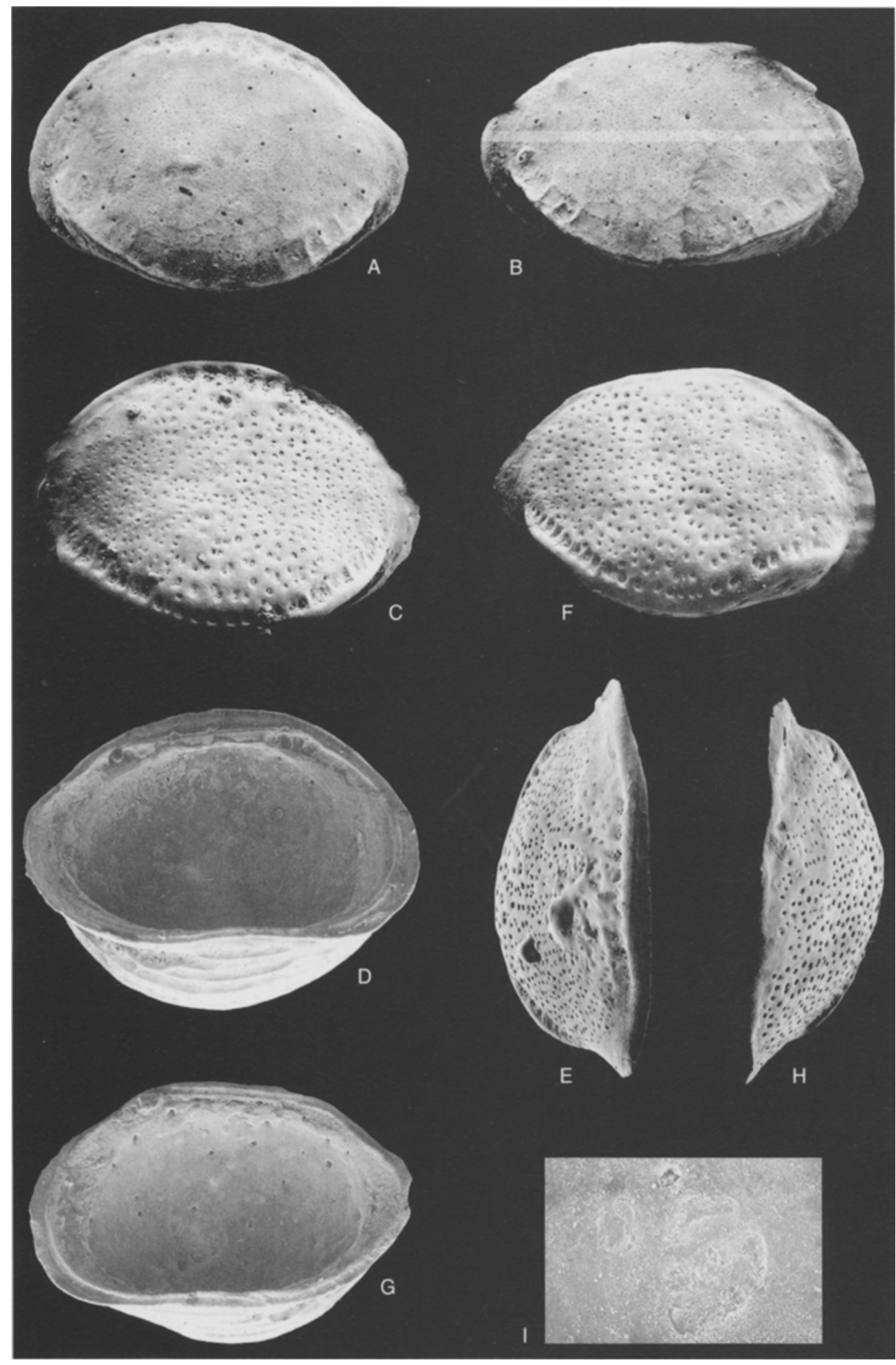

Fig. 16: A-B: Pelecocythere sp.

Recent, sample BX141, South Tasman Rise, off south coast Tasmania, Australia; S49 08.34', E149 $9^{\circ} 4.98^{\prime}$, $1690 \mathrm{~m}$. - female L (0.65/0.50); external view. SMF Xe 21495. - female R (0.65/0.42); external view. SMF Xe 21495.

C-I: Pelecocythere galleta Whatley, CHadwinc, Coxill \& ToY 1988

Recent, sample BX156; South Tasman Rise, off south coast Tasmania, Australia; S47 $00.09^{\prime}$, E149 $30.93^{\prime}$ $3208 \mathrm{~m}$. - female L (0.67/0.47); C: external view; D: internal view; E: dorsal view. SMF Xe 21497. - female R $(0.67 / 0.42)$; F: external view; G: internal view; H: dorsal view; I: detail of the central muscle scars, $\times 255$. SMF $\mathrm{Xe} 21497$. All magnifications are $\times 85$ unless otherwise stated. 
length. Surface covered by a faint reticulation consisting of polygonal meshes. Each mesh contains 10-14 circular pits. On the muri, large sieve-type pores occur both in disjunctive and conjunctive positions. Alar process smooth and without spines extending ventrally, starting from the anterior rim to just forward of the caudal process. Alar process carinate dorsally with faint, short perpendicular ridges. Three secondary ridges are located on the ventral side of the ala, more prominent and blade-like shaped in the posterior half. Along the dorsal ourline of the L, a narrow area with short, vertical ridges is developed, corresponding with the median hinge element.

Internally: dorsal margin arched in the $\mathrm{L}$ and straight in the $\mathrm{R}$, ventral margin concave in the oral region. Vestibula not developed, calcified inner lamella wider anteriorly, selvage strong, flange moderately wide. Marginal pore-canals few and slightly sinuous, 6-8 anteriorly, 4-5 posteriorly. Hinge antimerodont. In the $\mathrm{R}$ posterior element very elongated and lobate ( $4-6$ lobes). The AT is less lobate ( 4 lobes) and more prominent than the PT. Median groove not pronounced, smooth and narrow. Median bar smooth. Above the median bar, a wide groove occurs to accommodate the dorsal margin of the $\mathrm{R}$. The groove extends from the centre of the posterior element to the centre of the anterior.

The MS consist of four adductor scars arranged in a vertical row. The lowermost scar is oval shaped, the two middle scars are elongate, the upper one bean-shaped to clovershaped. Antennular scar open U-shaped with the asymmetrical wings pointing to anterior. The upper wing can be smaller, forming an 8-shaped frontal scar.

Remarks: This species is in some characters identical to one of the specimens of Pelecocythere sp. recovered by WHATLEY \& AYRESS (1988: pl. 2 fig. 8) from the Indian Ocean. The two specimens they illustrated belong to two species differing for the shape of the alar process and the ornamentation of the dorsal margin. Only the specimen figured in fig. $8 \mathrm{~b}$ is regarded by the present author as conspecific with the specimens from the South Tasman Rise, because of the similar narrow dorsal area with short, vertical ridges and the shape of the alar process.

AYress (1988: 666-668, pl. 24 figs. 4-8) reported in his unpublished thesis the species $P$. robusta which was described by DOWNING (1985) in her unpublished thesis. Since those theses have not been published and the description were not formally published (see also KEMPF 1986, 1995) the name is invalid and is therefore not used herein. It is also clear from AYREsS illustrations that included in that assemblage were specimens representative of species other than $P$. robusta. This is also apparent from his description of $P$. robusta, in which the alar process is described as variable from "blade-like flush" to "thick rim rounded in cross-section". Ayress also noted that the two morphotypes were isolated geographically since forms with rimmed carina occurred between $2052 \mathrm{~m}$ and $3341 \mathrm{~m}$ of depth, whereas those with blade-like carina were found at depths of 1253-1591 m. He also reported two more findings of $P$. robusta at $4202 \mathrm{~m}$ and $2876 \mathrm{~m}$ of depth, which would expand the depth-range of the species but it is not clear to which morphorype they should be referred. In his description, AYRESS identified the characters of both morphotypes not only failing to accommodate those with respect to the definition of
P. robusta but then stating that the specimens could be grouped into two different species. The specimens studied herein refer to the morphotype with the blade-like carina and micropunctate surface.

Because there were so few specimens available for this study and all were poorly preserved, this taxon has been left in open nomenclature.

Pelecocythere galleta Whatley, Chadwick, Coxill \& Toy 1988 (Figs. 16C-I)

* 1988 Pelecocythere galleta Whatley, Chadwick, Coxill \& Toy: 187, pl. 5 figs. 8-10.

1998 Pelecocythere galleta. - WHATLEY, MOGUILEVSKY, RAmos \& Coxill: 123, pl. 3 figs. 13-14.

Material: 6 adult and 3 juvenile valves. - SMF Xe 21497.

Dimensions: Female L $0.65-0.67 / 0.42-0.47$, R $0.62-$ $0.67 / 0.40-0.42$.

Distribution: Holocene of the South Tasman Rise. Rare in samples BX156 (3208 m).

Remarks: This species was erected to accommodate specimens from the South Scotia Sea with a strongly punctate exterior and a row of pits dorsal to the alar process. I do not agree with Whatley et al. (1998a) who included Pelecocythere sp. WHATLEY \& AYRESS (1988) in the synonymy of the present species. In fact those two taxa exhibit significant contrasts, especially in the ornamentation of the dorsal margin and the shape of the ventral carina. Additionally, Pelecocythere sp. AyrESS \& WHATLEY does not display the pits on the dorsal side of the carina, considered typical of the present species.

Subfamily Cytherurinae G.W. MÜLLER 1894

Genus Hemicytherura ELOFSON 1941

Type species: Cythere cellulosa Norman 1865 (emended by WHITTAKER 1981).

Remarks: The genus Hemicytherura was described by NORMAN as a subgenus of Cytheropteron, based on Recent material from the N Atlantic. HorNibrook (1952: 58) raised it to generic status but in his diagnosis he failed to include the presence of the ocular spot as a characteristic of the genus, despite the fact that this was used by CORYELL \& Fieldo (1937) as a feature to distinguish it from Kangarina. VAN MORKHO. VEN (1963) considered Kangarina as a subgenus of Hemicytherura, based on Miocene material from Panama. Another significant morphological difference is that Kangarina species possess an alar process, a feature which is not developed in Hemicytherura. In the current literature, many species which do not posses an ocular spot are referred to Hemicytherura, which based on current practice shows considerable morphological plasticity. 
Hemicytherura sp.

(Figs. 17A-I)

Material: 4 adult valves. - SMF Xe 21498.

Dimensions:? Female L 0.65/0.40, R 0.60/0.40.

Distribution: Holocene of the South Tasman Rise. Very rare in sample BX147 $(2177 \mathrm{~m})$.

Remarks: This species does not present an ocular structure which suggest it may be more appropriately referred to Kangarina, rather than Hemicytherura. However, this taxon has true anterior pore-canals instead of false canals found on Kangarina. H. sp. is very similar to $H$. stationis (G.W. MüLLER 1908: 112-113, pl. 16 figs. 4, 7) which MULLER described as having an ocular spot based on 29 adult and 6 juvenile specimens from $385 \mathrm{~m}$ water depth, at the Gauss Station, Antarctic. WHATLEY et al. $(1988,1996)$ referred to this species, specimens from the Scotia Sea, recovered from a depth range of 990-2370 m. They stated (1988: 176) that "the multicostate ornament of this species serves to distinguish it from all other members of the genus". From their illustrations (1988: pl. 1 figs. 17-20; 1998: pl. 3 figs. 19-20) it is obvious that those specimens do not possess an ocular spot. Hartmann (1997: 141), although recognising a similarity between the species described by MülLER and by WHATLEY et al., expressed doubts about those identifications without presenting evidence to support that conclusion. He reported a length of 0.45 for specimens recovered in Antarctic waters, a dimension that would not fit $H$. stationis $(0.57-0.66$ as reported by MülLER). This problem will only be resolved when additional live material of both Kangarina and Hemicytherura is examined and described in detail.

Genus Aversovalva HoRnibroOK 1952

Type species: Aversovalva aurea HORNıBROOK 1952.

Remarks: This genus was first described by HorNIBROOK as a monotypic subgenus of Cytheropteron. Using recent specimens from New Zealand he observed a reversal of proportions of the valves as well as a hinge with smooth and crenulate median elements. CRANE (1965) raised Aversovalva to generic status, when she described two species from the Upper Cretaceous of the Gulf Coast area (USA). Some workers rejected this generic status (i.c. NEALE 1975) whereas others considered Aversovalva a junior synonym of Cytheropteron (i.e. Whatley \& Masson 1979, Horne \& WhitTaker 1988).

As well as the New Zealand species of Hornibrook, Aversovalva was also recorded in the Quaternary sediments of the N Atlantic (Whatley \& Coles 1987), the Pacific and Indian Ocean (Ayress 1988) and of the Antarctic (G.W. Múller 1908, HaRTMANN 1997).

Aversovalva cf. A. antarctica (G.W. MULLER 1908) (Figs. 17J-N)

Material: 3 adult and 4 juvenile valves. - SMF Xe 21499.
Dimensions: Female L 0.45/0.27; male L 0.45/0.25; R $0.47 / 0.27$.

Distribution: Holocene of the South Tasman Rise. Rare in sample BX140 (1636 m).

Remarks: This species, although represented by only a few specimens, is regarded as autochthonous, because some of the juvenile specimens were stained with Rose Bengal and contained remains of soft parts. It is very similar to $A$ antarti$c a$ described by G.W. Müller (1908: 115-117, pl. 16 figs. 2, 8 ) based on two female specimens and one juvenile recovered from $385 \mathrm{~m}$, at Gauss Station, Antartica. It must be acknowledged that among the specimens studied herein, one L (Fig. $17 \mathrm{M})$ displays an apex of the alar process with a short, horizontally directed spine, all the others however have a suppressed and sub-rounded alar apex. This variation was also noticed by MüLler, but on the R: In the specimens described the apex was clear only in the $\mathrm{R}$, in $\mathrm{L}$ suppressed, cut but not broken, in the other specimens the apex was on both valves nearly identically well developed (1908: 116, translared from German). Moreover, Müller did not describe or figure the internal features of the valves so that the generic attribution is mainly based on the similarity of the dimensions, ornamentation and overall shape. MüLLER tentatively assigned his specimens to Eucytherura, due to the peculiar shape of the first antenna and of the furca. Despite the fact that Müller's description was made almost 100 years ago, it still remains the only published data on living specimens of Aversovalva.

\section{Family Cytherideidae SARS 1925}

Genus Eucythere Brady 1868

Type species: Cythere declivis Norman 1865 (designated by BRADY \& NORMAN 1889).

\section{Eucythere sp. \\ (Figs. 18A-F)}

Material: 23 adult and 18 juvenile valves. - SMF Xe 21500-21503.

Dimensions: Female L $0.60-0.65 / 0.40-0.45$, R 0.60 $0.65 / 0.38-0.42$; male L $0.62 / 0.42$, R $0.62-0.67 / 0.40-0.42$.

Distribution: Holocene of the South Tasman Rise. Common in sample BX140 $(1636 \mathrm{~m})$ and very rare in samples BX141 $(1690 \mathrm{~m})$ and BX153 $(1874 \mathrm{~m})$.

Remarks: This species is similar to E. laevis described from the Middle Eocene-Lower Miocene of the North Atlantic by Coles \& Whatley (1989). Eucythere sp. is larger, does not have a scalloped anterior margin and is without strong sexual dimorphism. It is also similar to $E$. (Eucythere) sp. 8 AYRESS (1988) from the Pliocene-Pleistocene of the western Pacific Ocean which is slightly smaller and because it has a crenulate hinge elements is more correctly accommodated in Rotundracythere MANDELSTAM (1958a). It is also very similar to Rotundracythere sp. E JELLINEK \& SWANSON (2003) which is larger, has a network of faint ridges on the outer surface and displays a peculiar postero-dorsal angle on the L. Notwith- 


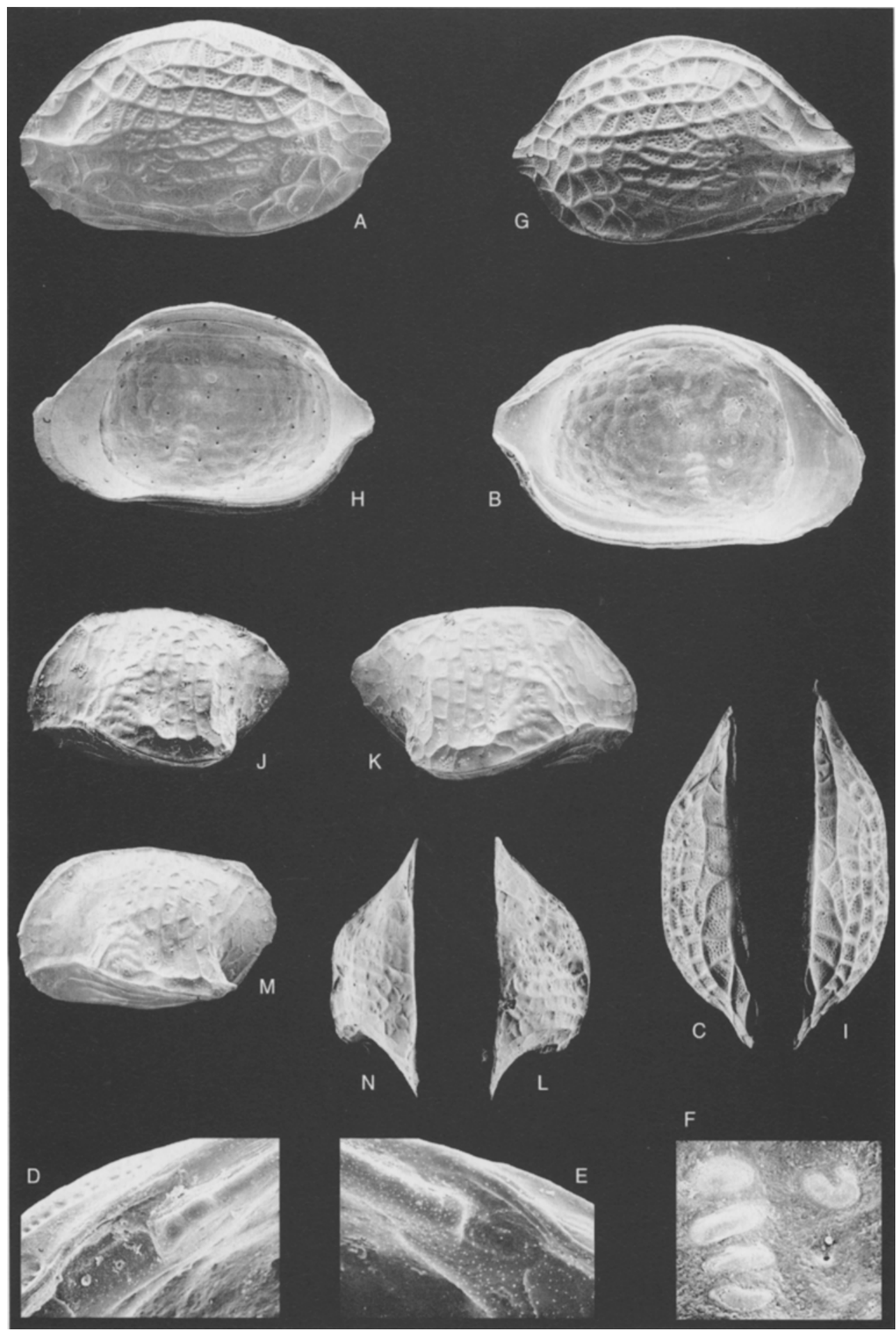

Fig. 17: A-I: Hemicytherura sp.

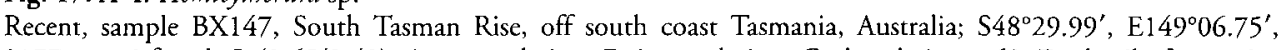
$2177 \mathrm{~m}$. - ? female L (0.65/0.40); A: external view; B: internal view; C: dorsal view, $\times 68$; D: detail of posterior hinge elements, $\times 440$; E: detail of the anterior hinge elements, $\times 440$; F: central muscle scars, $\times 265$. SMF Xe 21498. - ? female R (0.60/0.40); G: external view; $\mathrm{H}$ : internal view; I: dorsal view, $\times 105$. SMF Xe 21498.

$\mathrm{J}-\mathrm{N}$ : Aversovalua cf. A. antartica (G.W. MÜlLER 1908)

Recent, sample BX 140; South Tasman Rise, off south coast Tasmania, Auscralia: S49 $10.84^{\prime}$, E150 $10.13^{\prime}$ 1636 m. - male L (0.45/0.25); J: external view. SMF Xe 21499. - male R (0.47/0.27); K: external view; L: dorsal view. SMF Xe 21499. - female L (0.45/0.27); M: external view; N: dorsal view. SMF Xe 21499. - All magnifications are $\times 88$ unless otherwise stated. 

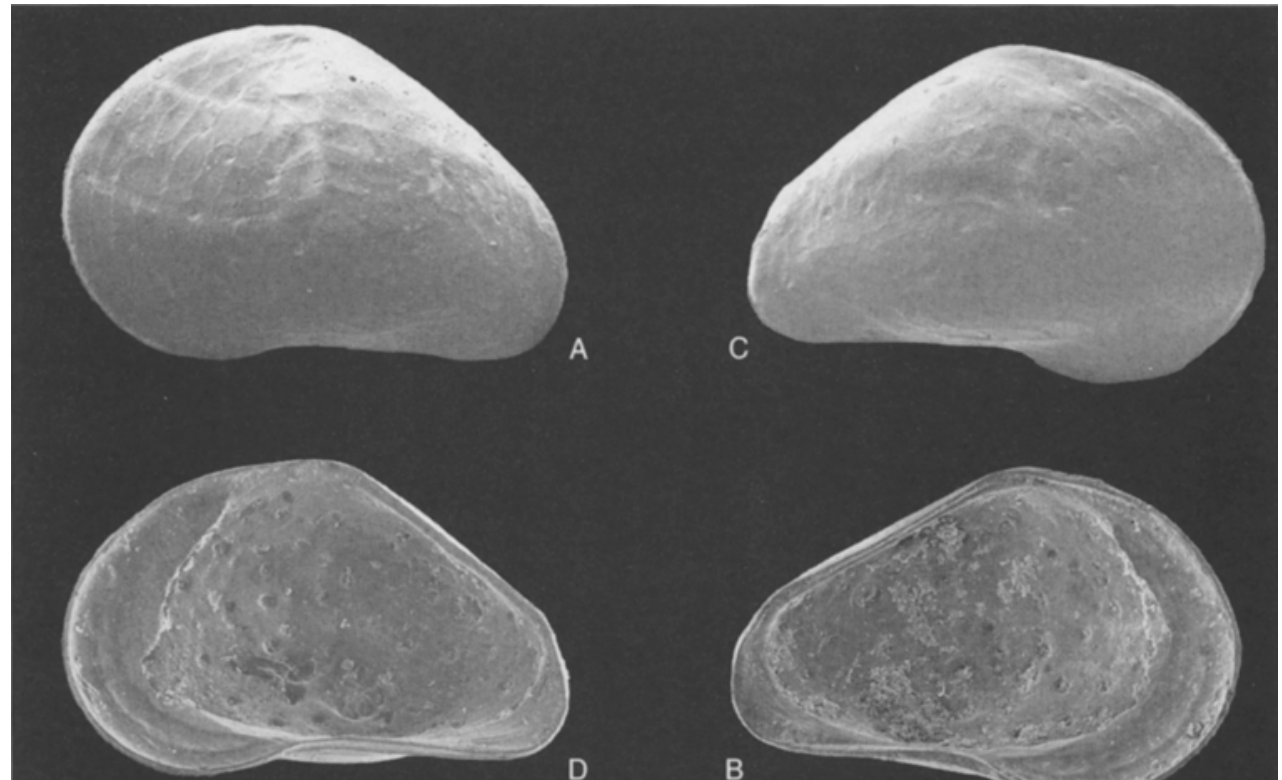

D

B

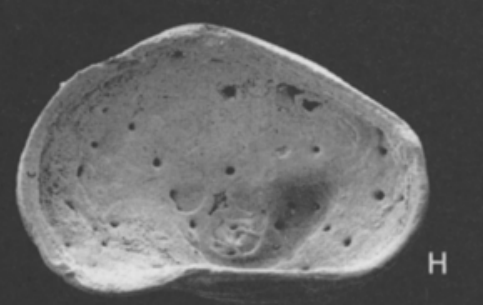

G
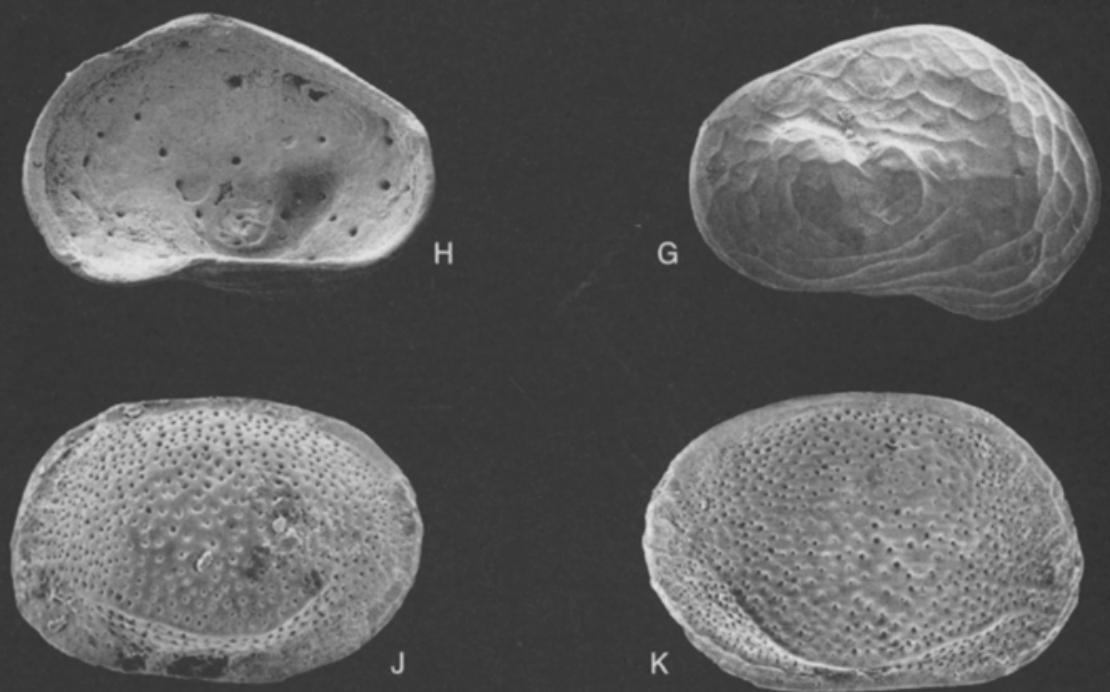

$E$

$\mathrm{F}$

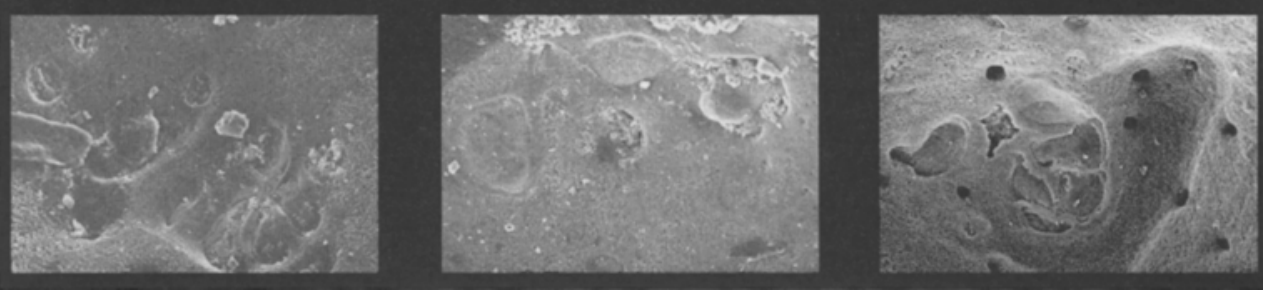

Fig. 18: A-F: Eucythere sp.

Recent, sample BX140; South Tasman Rise, off south coast Tasmania, Australia; $\$ 49^{\circ} 10.84^{\prime}, \mathrm{E} 150^{\circ} 10.13^{\prime}$, 1636 m. - male L (0.62/0.42); A: external view; B: internal view. SMF Xe 21500. - male R (0.62/0.40); C: external view; D: internal view; E: detail of the central muscle scars, $\times 232$; F: detail of the mandibular scars, $\times 265$. SMF Xe 21500.

\section{G-I: Rotundracythere sp.}

Recent, sample BX153, South Tasman Rise, off south coast Tasmania, Australia; S47 $46.85^{\prime}$, E147 $55.13^{\prime}$, 1874 m. - R (0.50/0.32); G: external view; H: internal view; I: central muscle scars, x178. SMF Xe 21504.

J-K: Saida sp.

Recent, sample BX140; South Tasman Rise, off south coast Tasmania, Australia; $\$ 49^{\circ} 10.84^{\prime}, \mathrm{E} 150^{\circ} 10.13^{\prime}$, 1636 m. - male L (0.50/0.32); J:external view. SMF Xe 21506. - male R (0.52/0.32); K: external view. SMF Xe 21506. - All magnifications are $\times 88$ unless otherwise stated. 
standing the rich material, the specimens are not very well preserved and the details of the hinge (smooth elements) were visible only on broken adult valves. Despite this, these specimens have been confidently assigned to Eucythere.

Two short, stout false pore-canals are characteristic which are located in the dorsal part of the anterior margin; they were observed in all specimens.

\section{Genus Rotundracythere MANDELSTAM 1958}

Type species: Eucythere rotunda Hornibrook 1952.

Remarks: MANDELSTAM erected this genus to accommodate specimens previously classified as belonging to Eucythere, but with a less rounded and elongate posterior and in the crenulate elements of the hinge. The genus appears to be restricted to the southern hemisphere and to the South Pacific and South Atlantic Oceans in particular. Records of Rotundracythere indicate a stratigraphic range of Upper Eocene-Recent.

\section{Rotundracythere sp.}

(Figs. 18G-I)

Material: 3 adult and 6 juvenile valves. - SMF Xe 21504-21505.

Dimensions: L $0.50-0.52 / 0.32-0.37$, R 0.50/0.32.

Distribution: Holocene of the South Tasman Rise. Very rare in samples BX140 $(1636 \mathrm{~m})$ and BX153 (1874 m).

Remarks: This is a peculiar species of Rotundracythere, characterised by two sub-central nodes, on the external carapace. The MS are also anomalous for a $R$.: the lowermost two scars, which are usually the largest, are smaller with the second one sub-divided into rounded posterior and triangular anterior parts; the uppermost two scars are large and fused posteriorly, the uppermost being angled posteriorly; the frontal scar is broadly $U$ shaped with strongly asymmetrical wings, the anterior-most very reduced. Unfortunately, in the specimens recovered the hinge was not well preserved.

A species with clear antimerodont hinge recovered by AYRess \& Rathburn (in prep.) from a depth of $907 \mathrm{~m}$ in the waters of Prydz Bay, Antartica. Another species of Rotundracythere displaying two central nodes is Rotundracythere polonezensis (BŁASZYK 1987) from the Oligocene of King George Island (West Antarctic). This Oligocene species is quite smaller $(0.48 / 0.32 / 0.30$ reported for a carapace) with larger pits over the valve surface.

\section{Family Cytheridae BAIRD 1850}

Genus Saida HorNIBRoOK 1952

Type species: Saida truncala HorNibrook 1952.

Remarks: This genus was erected for Recent specimens from $174 \mathrm{~m}$ of depth off Big King Island (North Island, New Zealand). Hornibrook (1952: 67, pl. 18 figs. 290-292) in- cluded in it also Cythere torresi Brady (1880: 67, pl. 19 figs. $8 \mathrm{a}-\mathrm{c}$ ) from $279 \mathrm{~m}$ of depth of Torres Straight (N Australia). Saida has fossil representatives from the Cretaceous of Western Australia (NEAlE 1975), from the Oligocene-Miocene of Australia, (McKenzie 1974, Whatley \& Downing 1983, MCKenzie et al. 1991), of New Zealand (Hornibrook 1952, Ayress 1995) and of the North Atlantic (Whatley \& Coles 1987) and the Pleistocene of the Indian and Pacific Ocean (AYress 1988). Some fossil representatives have also been found in Europe from the Cretaceous of Germany (GRÜNDEL 1966, Herrig 1968), of Holland (Szczechura 1965), the Eocene of France (DeLTel 1964) and of Italy (Ascoli 1969), the Miocene of Northern Italy (Ciampo 1984), the Upper Pliocene of the South Aegean Island Arc in Greece (SissingH 1972), the Pliocene of China (Gou \& CHEN 1988) and the Pliocene-Pleistocene of Southern Italy (Colalongo \& PasinI 1980).

As well as the type species and BRADY species, Recent occurrences are few. KEIJ (1975) recorded the genus in the South China Sea between 110 and $677 \mathrm{~m}$ of depth; Cronin (1983) in the central Atlantic between depths $220 \mathrm{~m}$ and $1070 \mathrm{~m}$, YASSINI (1995) recovered Recent specimens along the south-eastern Australian coasts whereas Whatley et al. (1998) found it in the Scotia Sea at $2370 \mathrm{~m}$ of depth. The following is the first record of the genus from Recent sediments of the Tasman Sea.

\author{
Saidasp. \\ (Figs. $18 \mathrm{~J}-\mathrm{K}$ )
}

Material: 4 adult and 1 juvenile specimen. - SMF Xe 21506

Dimensions: Female R 0.52/0.35; male L $0.50 / 0.32$, R 0.52/0.32.

Distribution: Holocene of the South Tasman Rise. Rare in sample BX140 (1636 m).

Description: A medium-sized Saida with almost parallel dorsal and ventral margins. Anterior and posterior asymmetrically rounded, anterior depressed ventrally. Maximum length slightly above mid-height, maximum height at midlength. In dorsal view, maximum width in the posterior half. Surface covered with round pits which decrease in size towards the margins. Weak alar process, with a smooth peripheral carina. Internally, dorsal margin straight, ventral margin convex in oral region. Narrow anterior and posterior vestibula. Hinge lophodont with all elements smooth. MS were not visible.

Remarks: This species is very similar to Saida limbata Colalongo \& Pasini (1980) sensu Ayress (1995: Fig. 5/4-5) which is smaller than the Tasman specimens, has smooth marginal rims as well as deeper and larger pits. It is also similar to Saida sp. (WhatLey et al. 1998: 119, pl. 1 figs. 30-31) which has a slightly different ornamentation (low smooth muri forming a polygonal reticulation) and more pronounced cardinal angles. It probably represents a new species but due to the few specimens recovered it is left under open nomenclature. 
Family Loxoconchidae SARS 1926

Genus Myrena NeALE 1967

Type species: Loxoconcha meridionalis G. W. MÜLlER 1908.

Remarks: This genus is based on a single adult valve recovered by NEALE from $206 \mathrm{~m}$ in Halley Bay (British Antarctica) (Fig. 19). NEALE included in the genus Cythere grateloupiana BOSQUET 1852 from the Upper Miocene of Southwestern France as well as an unnamed species from Recent sediments of Aburatsubo Cove (Japan) which HaNaI (1961) referred to a new genus of Loxoconchidae.

MaYBuRY (1990) placed M. grateloupiana in Loxocorniculum and considered Myrena as a junior synonym of Kuiperiana BASSIOUNI. BASSIOUNI (1962) erected the genus to accommodate elongate loxoconchids from the Middle Miocene of Germany and he included in the genus Loxoconcha grateloupiana (emend. KEIJ 1957) but with some reservation because of differences in the hingement. The fact that NEALE (1967) included $C$. grateloupiana in his new genus Myrena has probably led to the postulated synonymy (MAYBURY 1990) between Myrena and Kuiperiana. This synonymy was also acknowledged by AYRESS (1993a), who compared Kuiperiana juglandica with scanning electron photographs of the single specimen of $M$. meridionalis from the British Museum, without providing a description/illustration of the latter.

On the other hand, not all authors agreed upon this synonymy. ATERSUCH \& HORNE (1984) suggested that only further detailed morphological studies may solve the problem of the synonymy between Myrena and Kuiperiana that they regarded as an "apparently extinct genus".
HARTMANN (1997: 118) without providing new material from his Antarctic samples, reported the findings of MULLLER and NEALE and left meridionalis under Myrena. MCKenZIE et al. (1991, 1993) described Myrena lindsayi from the Late Eocene of South Australia which included Kuiperiana lindsay sensu Ayress (1993a) and Palmoconcha sp. AYress (1988) from the late Pleistocene of the Indian and the Pacific Ocean. Only after detailed studies on the morphology of Myrena and Kuiperiana will their confused taxonomy and relationship be resolved.

\section{Myrena sp. \\ (Figs. 20 A-M)}

Material: 5 adult and 19 juvenile valves. - SMF Xe 21507-21509.

Dimensions: Female L $0.50 / 0.35$, R 0.50/0.35; male L $0.50-0.52 / 0.30-0.32$, R $0.47-0.50 / 0.30-0.32$.

Distribution: Holocene of the South Tasman Rise. Common in sample BX140 $(1636 \mathrm{~m})$, rare in sample BX153 $(1874 \mathrm{~m})$.

Description: A small, tumid species, with sub-parallel dorsal and ventral margins, carapace periphery forms parallelogram. Dorsal margin straight with pronounced cardinal angles; ventral margin straight, slightly sinuous in the L. Anterior margin asymmetrically rounded; posterior margin weakly caudate in upper half. Maximum length slightly above midheight, maximum height at posterior cardinal angle. Surface covered with pits arranged in concentric rows ventrally, in couplets or triplets medially and smaller and singly posteriorly and anteriorly. Normal pores sieve-type, with sieve plate re-

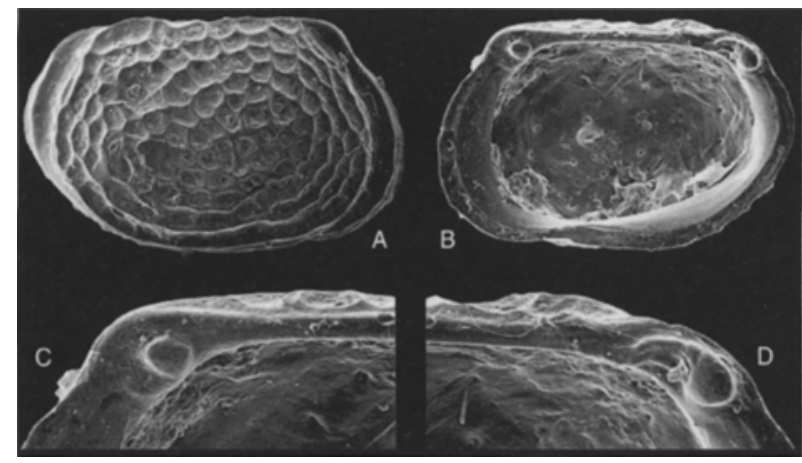

Fig. 19: Myrena meridionalis (G.W. MÜLLER 1908).

Recent from Halley Bay, Coats Land, Antarctica at $206 \mathrm{~m}$. - Holotype (NHM no. HU 13.R.12.48) designated by Neale (1967: 2021 , Fig. 7, pl. Ih,). ? Female R (0.52/0.33); A: external view, negative number $071110, \times 75$; B: internal view, negative number 071162 , $\times 75$; $\mathrm{C}$ : detail of the anterior hinge element, negative number $071165, \times 260$; D: detail of the posterior hinge element, negative number $071164, \times 260$. - Picrures were taken and provided by Dr. J WhITTAKER, Department of Palaeontology, The Natural History Museum, London. 


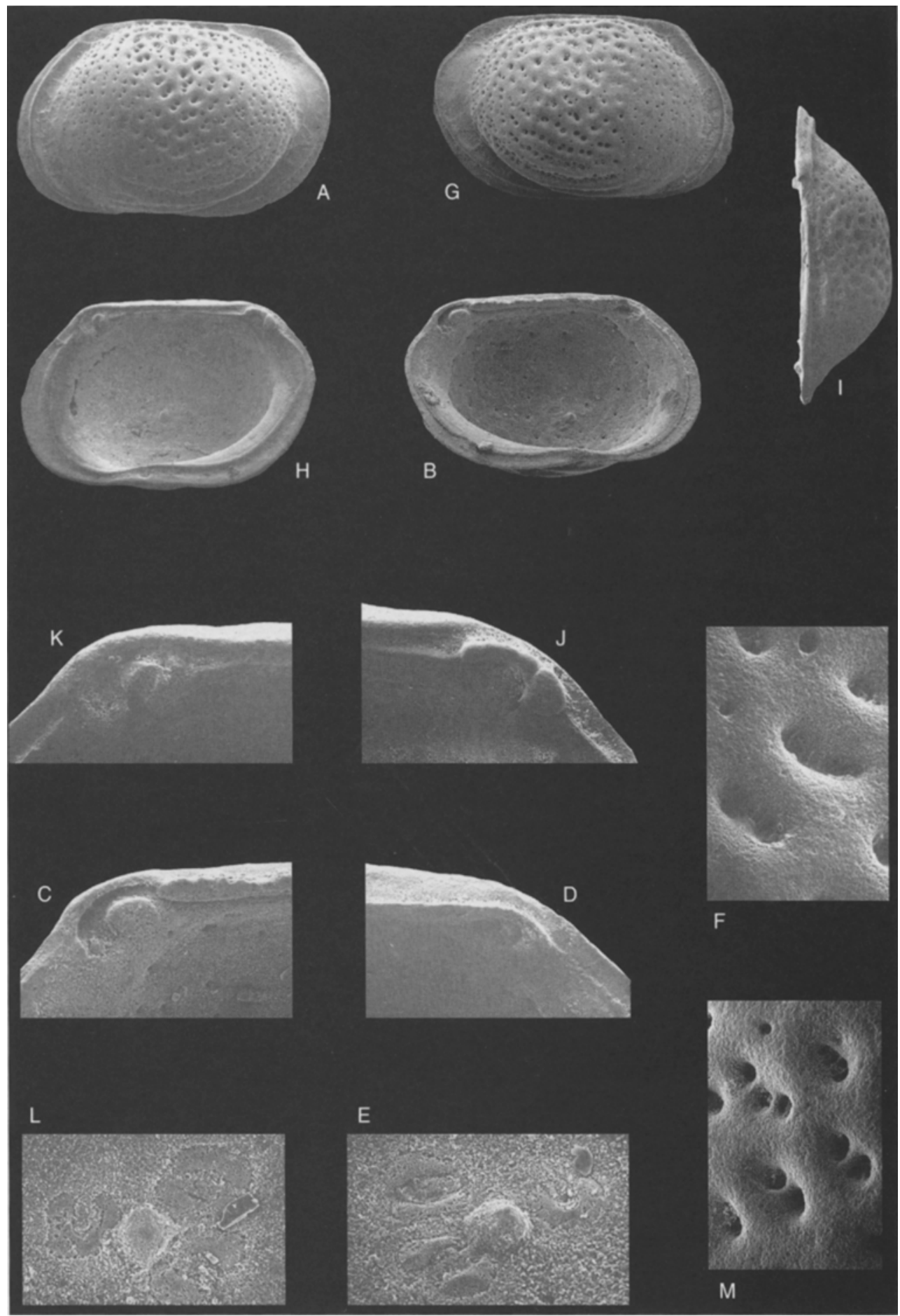

Fig, 20: Myrena sp.

Recent, sample BX 140; South Tasman Rise, off south coast Tasmania, Australia; $449^{\circ} 10.84^{\prime}, \mathrm{E} 150^{\circ} 10.13^{\prime}$, $1636 \mathrm{~m}$. - male L (0.52/0.32); A: external view; B: internal view; C: detail of the posterior socket and bar crenulate on the horizontal plane, $\times 280$; D: detail of the anterior socket, $\times 280$; E: detail of the central muscle scars with prominent fulcral point, $\times 390$; F: detail of the surface ornamentation in the central area, $\times 305$. SMF Xe 21507. - male R (0.50/0.32); G: external view; $\mathrm{H}$ : internal view; I: dorsal view; J: detail of posterior tooth and socket, $\times 280$; K; detail of the anterior tooth, $\times 280$; L: detail of the central muscle scars with prominent fulcral point, $\times 390$; M: detail of the surface ornamentation the posterior area, $\times 305$. SMF Xe 21507. - All magnifications are $\times 90$ unless otherwise stated. 
cessed. Anterior and posterior margins with fine radial ridges. Flange-like terminal areas, markedly flattened, ventral surface anteriorly and posteriorly widest.

In dorsal view valves strongly inflated, with rounded anterior and posterior rims. The hinge elements of the right valve are prominent. Maximum width medially.

Internally: dorsal margin straight, ventral margin concave in the oral region. Posterior rounded, anterior bluntly pointed. Line of concrescence not parallel to the outer margin. Normal pore-canals simple and widely spaced, 7 anteriorly and 5 posteriorly.

Hinge gongylodont. In the $\mathrm{L}$, large sub-oval PS with a sub-central round tooth, median bar stout at extremities and crenulate on the posterior horizontal plane. AS not observed due to poor preservation. In the $\mathrm{R}$, posterior element consisting of four smaller teeth followed by a larger fifth tooth., all connected forming an arch-like structure over the oval socket. The groove is smooth and surrounds the small, round AT.

Central MS are arranged in a vertical row of four, the two uppermost bean-shaped, the second lowermost slightly pointing towards the anterior, the lowest oval. Antennular scar Ushaped; fulcral point prominent.

Remarks: This species has not been referred to Loxoconcha because of the asymmetry of the hinge elements and not to Kuiperiana because this latter shows a more elongate outline.

Myrena sp. is very similar to Palmoconcha sp. AYRESS (1988: 699-670, pl. 25 figs. 22-24, pl. 26 fig. 1) from the Pleistocene of the Indian and Pacific Ocean, which displays slightly larger pits and a more pointed posterior, especially in the L. Arress did not describe the hinge in his 1988 species which, if Palmoconcha, should include a smooth median element.

The present taxon differs from Loxoconcha meridionalis G.W. MÚller (1908: 133, pl. 18 figs. 1, 9) in that it is smaller and lacks the polygonal meshwork covering the external surface. It differs from Myrena meridionalis (G.W. MúlLER 1908) as illustrated by NeALE (1967: 20-21, Fig. 7, pl. Ih,) because of the different ornamentation and the slightly different proportions (Fig. 9).

Myrena lindsayi MCKenzIE, ReYMENT \& REYMENT (1991: 152, pl. 4 fig. 4 , pl. 5 fig. 10; 1993: 89, pl. 3 figs. 4-7) in that it is non-reticulate and with smaller pits on the inflated ventral region. Additionally, all the specimens observed have no vestibula (whereas $M$. lindsayi has elongate anterior and posterior vestibula).

It differs from Kuiperiana meridionalis (G.W. MƯLLER 1908) as illustrated in WhatLey et al. (1996: 65, pl. 2 fig. 17) in the ornamentation which externally presents a polygonal meshwork with punctate solae.

Because all specimens were poorly preserved, this species is left under open nomenclature.

Family Trachyleberididae SYLVESTER-BRADLEY 1948 Subfamily Trachyleberidinae SyLVESTER-BRADLEY 1948

\section{Genus Legitimocythere COLEs \& WHATLEY 1989}

Type species: Cythere acanthoderma BraDY 1880.
Remarks: In the study of deep sea ostracods, the work of RICHARD BENSON (with special reference to faunas extracted from DSDP cores) has been pivotal establishing a research framework for the researchers. One of the problems with a number of those texts is that BENSON often used 'suggested' names for new genera which although in common usage were never formally described. For example 'Thalassocythere' and 'Hyphalocythere', first incroduced by BENSON (1977 and 1978 respectively), appear extensively in the literature. Thalassocythere is cited in KEMPF (1986) as used as a formally described genus by Ducasse \& Peypouquet (1979) and by SteINECK (1981).

COLES \& WhaTLEY (1989) erected the new genus Legitimocythere to include spinose trachyleberid species formerly questionably referred to Acanthocythereis Howe (1963) and to the two above mentioned informal genera of BENSON.

The taxonomy of this genus is complex, since the ornamentation is very similar in all species and it effectively masks any variation of valve shape. The fact that three different species could be found in the present material and the comparison with the type species and the species described by JeLLINEK \& SWANSON (2003) has led to the following observations:

- the secondary reticulation can partially or entirely be hidden by the primary ornamentation which consists of simple spines, verrucose tubercles and 'spine-groups'. The verrucose tubercles and 'spine-groups' are defined as follows:

- the verrucose tubercles, here defined as 'knots' (from their shape when abraded), are composed of on average four pointed tubercles, giving them the shape of a quadri-lobate flower. Each tubercle bears a simple pore centrally. Some knots develop a long and large 'stem'.

- the knots can turn into pointed spines, with adjacent multi-furcate spines and/or tubercles. This peculiar complex of spines and tubercles is here defined as 'spine-group' since all protuberances originate from the same base. 'Spine-groups' bear simple pores, which are not always central.

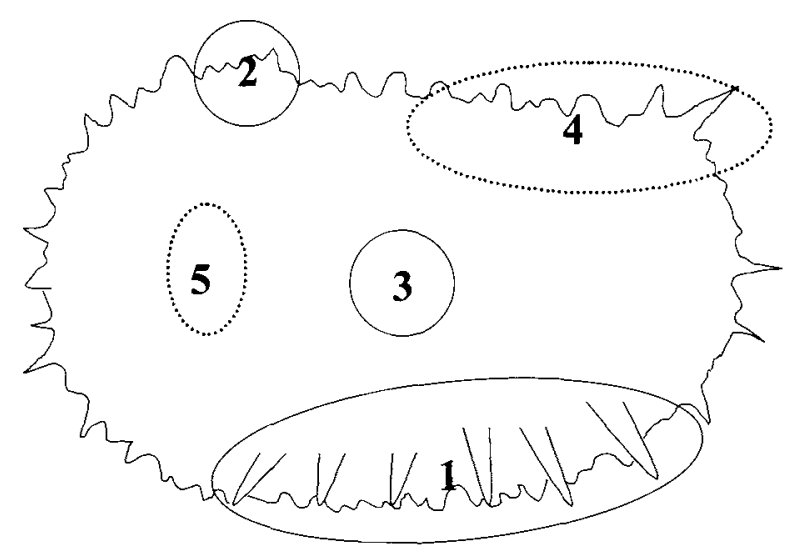

Fig. 21: Schematic drawing of Legitimocythere (left valve) showing the positions of the main spines and spine-groups. - Full circles indicate constant positions; dotted circles indicate variable positions. 
'Spine-groups' may occur in constant or in variable positions (Fig. 21). The constant positions are always occupied by 'spine-groups' in adult and A-1 specimens and by simple spines in younger instars. They are: the postero ventral row of 6 spines (1); the anterior cardinal angle (2); the sub-central tubercle (3). In adults, the variable positions may be occupied by a 'spine-group' whereas in juvenile forms they are always occupied at least by simple spines, with the remaining surface being smooth. The variable positions are the posterior margin, from the median area to the posterior cardinal angle (4) and the sub-central anterior area (5). The presence/absence of 'spine-groups' in variable positions and their number and arrangement is herein regarded as a diagnostic feature for specific determination.

\section{Legitimocythere acanthoderma (BRADY 1880)}

(Figs. 22A-L, 23)

Material: 25 adult and 107 juvenile valves, - SMF Xe $21510-21514$

Dimensions: Female L 1.12-1.17/0.65-0.70, R 1.071.15/0.62-0.65; male L 1.17-1.20/0.62-0.70, R 1.10-1.12/ $0.60-0.62$.

Distribution: Holocene of the South Tasman Rise. Very rare in sample BX140 $(1636 \mathrm{~m})$; rare in sample BX153 $(1874 \mathrm{~m})$ and abundant in BX147 $(2177 \mathrm{~m})$.

Remarks: Coles \& WHATLEY choose Cythere acanthoderma BRADY (1880) as type species for the genus Legitimocythere. BRADY (1880: 104, pl. 18 fig. 5) reported this species from seven different stations from the world oceans at water depth range $1044-4950 \mathrm{~m}$. The juvenile $\mathrm{L}$, designated as hololectotype by PuRı \& Hulings (1976: 267-268, pl. 11 figs. 16-18) was recovered from Challenger station 146, east of Prince Edward Island in the South Indian Ocean (Figs. 23AC). In the Challenger collection, hosted at the Natural History Museum (London), several slides are labelled $C$. acanthoderma and they contain 22 valves of adult and juvenile specimens belonging to different genera. None of those specimens, although spinose, exhibit the ventral row of six spines or the tubercles on the dorsal margin as the lectoholotype. For these reasons, residue from station 146 (provided by the Paleontological Department of the NHM, London) was picked and two adult Rs of Legitimocythere acanthoderma were found (Figs. 23D-F). No other species of Legitimocythere was recovered from that sample.

Legitimocythere acanthoderma was poorly defined by COLES \& Whatley (1989: 101) who stated: "This species displays a considerable degree of variation, some of which can be attributed to ontogeny, taphonomy and sexual dimorphism. However, the species differs in size, length and density of its spines and in the development of the primary reticulation." It is noted that GueRnet (1998), Dingle \& Lord (1990) and Cronin (1996) illustrate specimens of $L$. acanthoderma which differ from one another, from the specimen figured by COLES $\& W_{\text {Hatley }}$ and from the lectotype figured by PURI \& HulINGS.

The following observations were made on the two topotypes and the specimens of $L$. acanthoderma recovered from the South Tasman Rise. The ornamentation consists of verrucose tubercles, often furcate, mostly in conjunctive positions over a faint secondary reticulation. Posterior with a thick marginal rim, with long pointed spines in the ventral half and a 'spine-group' at the dorsal edge. Anterior margin with a less pronounced rim and thick, marginal spines around the entire outline. Rows of small tubercles also occur on the inner margin of both rims. At the anterior, these tubercles become larger and multilobate towards the ventral margin where they fuse with the ventral ridge. Ventral ridge with six 'spinegroups' of which the anterior-most is the better developed. The dorsal margin is characterised by a 'spine-group' on the cardinal angle, better developed on the $\mathrm{L}$, and by a series of smaller spines. A 'spine-group' with five spines is associated wich the sub-central tubercle (Fig. 22C). At an almost equal distance between the anterior margin and the SCT, two larger and more pointed 'spine-groups' occur (they occupy position 5 in Fig. 21). Both tubercles and 'spine groups' with simple pores. Along the outer ventral margin, a single row of spatulate spines occurs. In dorsal view, the posterior rim is clearly separated from the domicilial swelling by a pronounced indentation.

Internally: ventral margin concave around the oral region; dorsal margin straight. Fused zone moderately wide, selvage strong. Marginal pore-canals straight with medial swelling, often paired; $29-32$ anteriorly and $21-26$ posteriorly.

Hinge holamphidont, with smooth elements. In the $\mathrm{R}$, AT large and stepped, PT large and sub-oval. Median groove widens at extremities. In the $\mathrm{L}, \mathrm{AS}$ with a small adjacent tooth proximally. Median bar stout and thickened at both ends. Above the median bar, on the horizontal plane, a fine crenulation is present in the posterior half.

Central adductor scars arranged in a vertical row: the two ventral-most small and almost fused, the upper median elongate and the dorsal-most inclined at $45^{\circ}$ approx. with respect to the others. The frontal scar is oval with the main axis inclined vertically. Fulcral point prominent.

In juveniles, ornamentation undergoes a progressive reduction of size and number of the verrucose tubercles (Fig. $22 \mathrm{~K}$ ). The position of 'spine-groups' is preserved but the structure of the group tends to be more simple favouring long, single, pointed spines. The ventral row of spatulate spines is also preserved. The hinge is paramphidont with the marginal elements weakly lobate. The organisation of the muscle scars is as in adults but in the younger instars the lowermost two adductor scars are fused.

Apart from the distribution and depth, L. acanthoderma can be distinguished from the other species of $L$-species as follows:

- Legitimocythere sp. is larger, with stronger secondary reticulation, verrucose tubercles and 'spine-groups' suppressed in size and number.

- L. geniculata n. sp. is larger and has a single 'spine-group' on the anterior half.

- L. aculeata JELLINEK \& SWANSON (2003) is smaller, has a weak SCT; a 'spine-group' is developed at both cardinal angles and one occurs on the dorsal margin.

- L. castanea JelLINEK \& SWANSON (2003) is smaller, has two single 'spine-groups', one on the anterior surface and the other at the posterior cardinal angle. 

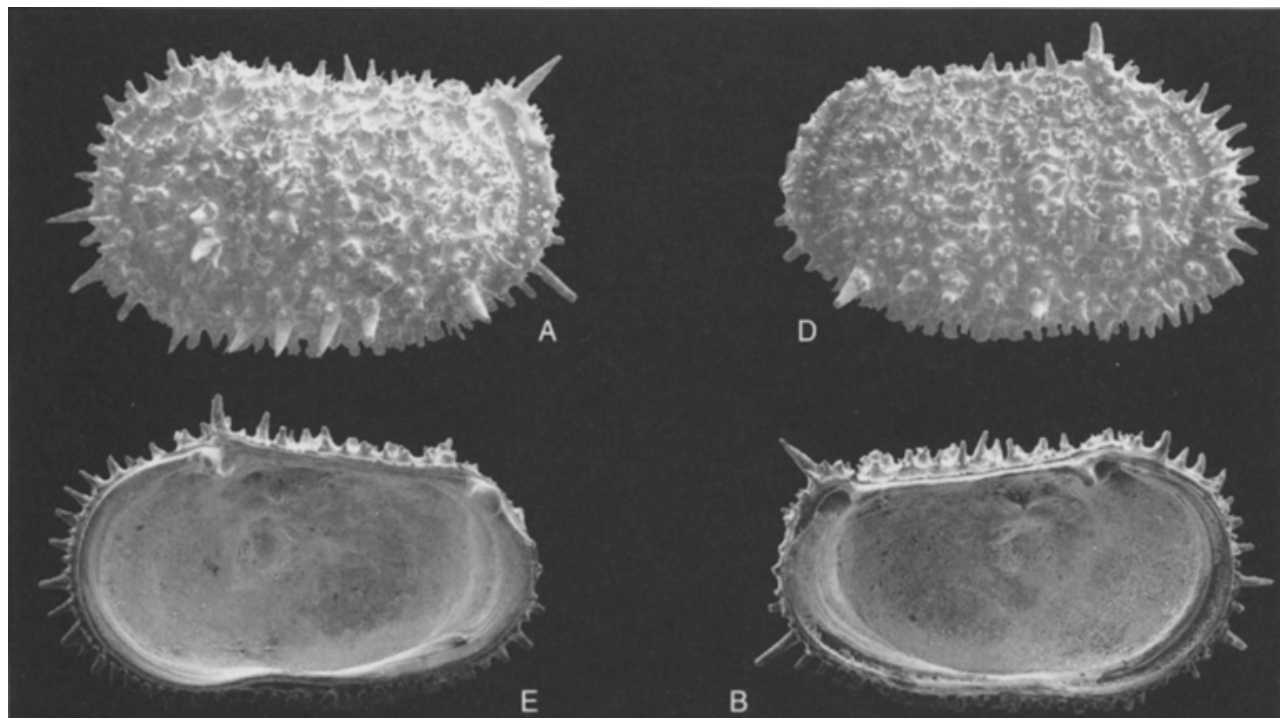

$\mathrm{E}$

B
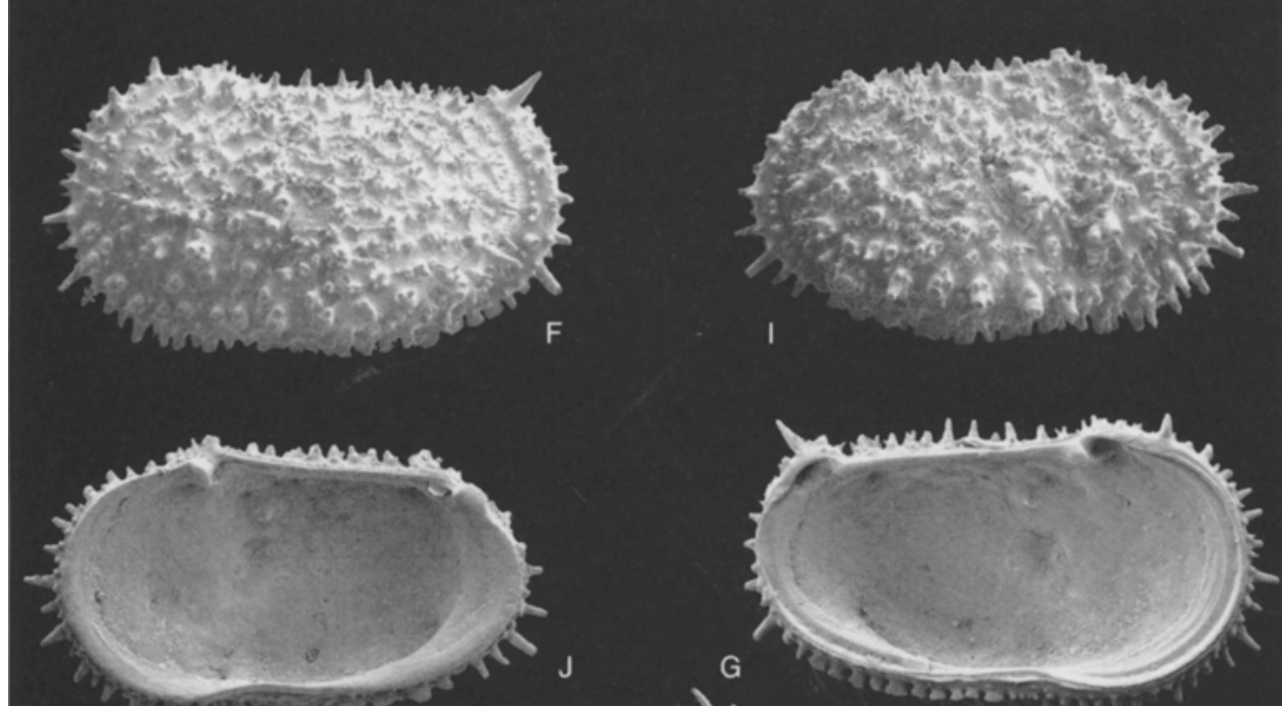

c
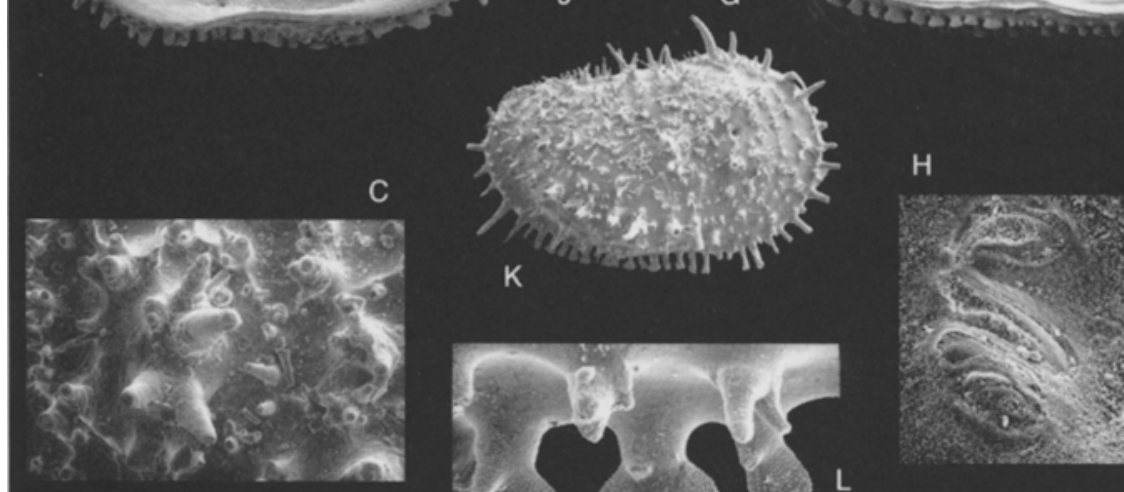

K

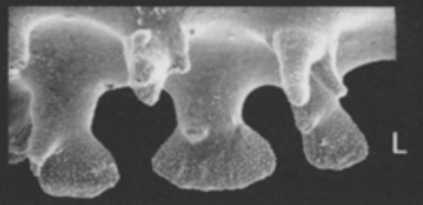

$\mathrm{H}$

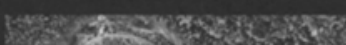

7 ,

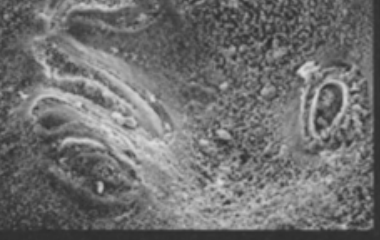

Fig. 22: Legitimocythere acanthoderma (BRADY 1880)

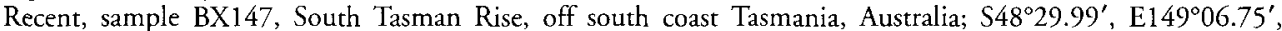
$2177 \mathrm{~m}$. - female L (1.12/0.65); A: external view; B: internal view; C: sub-central tubercle, $\times 128$. SMF Xe 21510. - female R (1.07/0.62); D: external view; E: internal view. SMF Xe 21510 - male L (1.17/0.62); F: external view; G: internal view; H: central muscle scars, $\times 230$. SMF Xe 21511. - male R (1.12/0.62); I: external view; J: internal view. SMF Xe 21511. - juv. R (0.70/0.37); K: external view; L: ventral spines, $\times 330$. SMF Xe 21511. - All magnifications are $\times 45$ unless otherwise stated. 


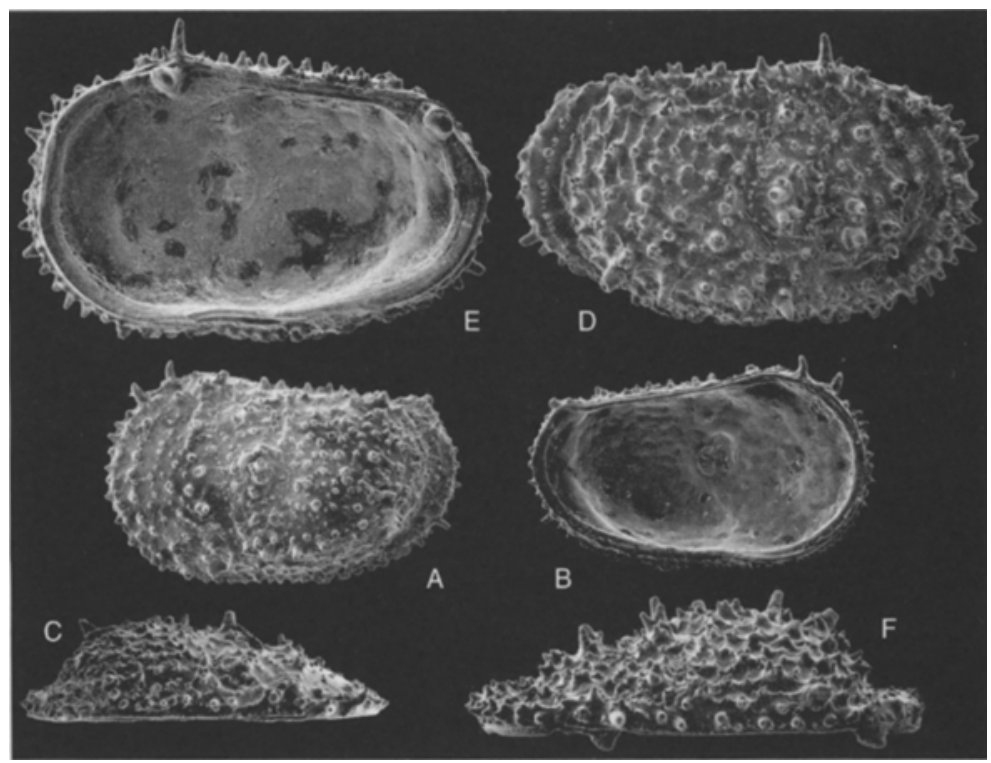

Fig. 23: Legitimocythere acanthoderma (BRADY 1880).

Recent from the $S$ Atlantic, Challenger station $146\left(\$ 46^{\circ} 46.00^{\prime}\right.$, E045 31.00'), 2443 m. - A, B, E: Hololectotype (NHM no. BM 80.38.48A), designated by PUR \& HuLINGS (1976: 267-268, pl. 11 figs 16-18). Juvenile L (0.90/0.58); A: external view, negative number 071072; B: internal view, negative number 071169; E: dorsal view, negative number $071172, \times 42$. - C,D,F: Topotype (NHM no. OS 16001), male R (1.13/0.63); D: external view, negative number 071073; C: internal view, negative number 071112; F: dorsal view, negative number $071173, \times 42$. - Pictures were taken and provided by Dr. J. WhitTakfr, Department of Palaeontology, The Natural History Museum, London.

- L.sp. A JeLlinek \& Swanson (2003) is larger, has a weaker ornamentation, with well-spaced knots and an evident reticulation.

- L. sp. B Jellinek \& Swanson (2003) is larger and carries five 'spine-groups' on the anterior surface.

\section{Legitimocythere geniculata n. sp. (Figs. 24A-M)}

Derivation of name: From the Latin adjective geniculatus = having knots, knotted; with reference to the secondary ornamentation.

Holotype: Male L (1.27/0.65), Figs. 24D-G. - SMF Xe 21515.

Paratypes: 45 adult and 152 juvenile valves. - SMF Xe 21515-21520.

Dimensions (of paratypes): Female L 1.20-1.25/0.670.70 , R 1.20-1.25/0.65-0.72; male L 1.25-1.27/0.62-0.65, R 1.22-1.25/0.62-0.65.

Type locality: RV SONNE cruise no. SO 136, site 33, station 161; box-corer sample from the $S$ Tasman Rise, off $S$ Tasmania, Australia, at $3685 \mathrm{~m}$ of water depth; $\$ 46^{\circ} 33.18^{\prime}$, E1490.96'.

Distribution: Holocene of the Emerald Basin. Very rare in sample BX110 (3907 m). Holocene of the South Tasman Rise. Common in sample BX165 (4067 m) and BX161 $(3685 \mathrm{~m})$, abundant in sample BX138 (3022 m).
Diagnosis: Sexually dimorphic, large species, characterised by an evident reticulation with knots at conjunctive positions and small single spines at disjunctive positions.

Description: A sub-rectangular to sub-oval species. Posterior margin asymmetrically (L) to evenly (R) rounded. Anterior margin evenly rounded. Ventral margin slightly sinuous, dorsal margin straight with a prominent anterior cardinal angle. Greatest height at cardinal angle, greatest length slightly above mid-height, greatest width in the posterior half, immediately behind the SCT. Onnamentation consisting of verrucose knots composed on average of 4 pointed tubercles, resulting in a quadri-lobate flower-like structure. Each with a simple pore centrally (Fig. 24L). With respect to the secondary reticulation knots position always conjunctive, whereas there are single small spines in disjunctive positions. Posterior margin with a thick marginal rim, carrying long pointed spines on the outer part and a row of small knots anteriorly. Anterior margin with a less pronounced rim and a row of thick knots proximally. On the ventral swelling a row of six 'spine-groups', with long pointed ventral spines is located, with the posterior-most best developed. The dorsal margin, from the anterior cardinal angle to the posterior equivalent, is characterised by a 'spine-group' on the anterior cardinal angle, followed by 4-5 simple spines then by three 'spinegroups' the last of which is strongest in the $\mathrm{L}$. The SCT spine-group with major spine forward directed. Outer ventral margin with a single row of blade-shaped spines. In dorsal 


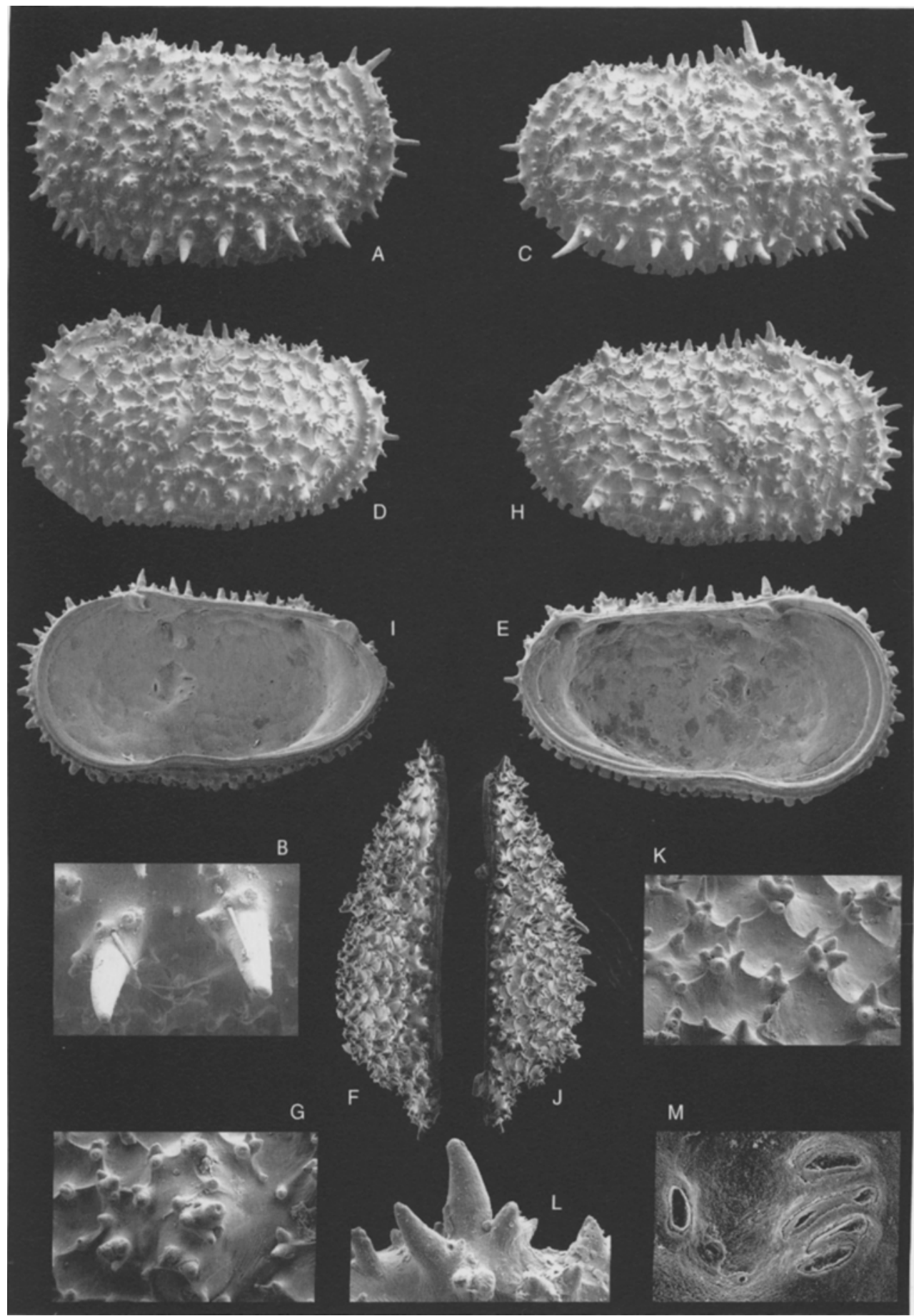

Fig. 24: Legitimocythere geniculata $\mathrm{n}$. sp.

Recent, sample BX165, South Tasman Rise, off south coast Tasmania, Australia; S45 $18.26^{\prime}$, E147 $55.13^{\prime}$, $4067 \mathrm{~m}$. - female L (1.25/0.70), paratype; A: external view; B: detail of the third and fourth spine of the ventral row, $\times 175$. SMF Xe 21516. - female R (1.22/0.67), paratype; C: external view. SMF Xe 21516.

Recent, sample BX161, South Tasman Rise, off south coast Tasmania, Australia; S46 $33.18^{\prime} \mathrm{E} 149^{\circ} 04.96^{\prime}, 3685$ m. - male L (1.27/0.65), holotype; D: external view; E: internal view; F: dorsal view; G: sub-central tubercle, $\times 138$. SMF Xe 21515. - male R (1.25/0.65), paratype; H: external view; I: internal view; J: dorsal view, $\times 40 ; \mathbf{K}$ : ornamentation on the external central surface, $\times 138$; L: spines at hinge ear, $\times 207 ;$ M: central muscle scars, $\times 188$. SMF Xe 21516. - All magnifications are $\times 43$ unless otherwise stated. 
view the posterior rim prominent and with abrupt angular separation from domicilium.

Internally: ventral margin slightly concave in the oral region, dorsal margin straight. Fused zone narrow, selvage strong, parallel to the margin. Marginal pore-canals short, straight with median swelling, often paired, 20-23 anteriorly and $8-10$ posteriorly.

Hinge holamphidont, with smooth elements. In the R, large stepped $\mathrm{A} T$ and large bean-shaped PT, connected by a thin groove. In the L, AS with a small adjacent tooth. Median bar thin and smooth. Central adductor scars arranged in a vertical row: the two ventral-most small and almost completely fused, the third is elongate and the dorsal-most inclined at $45^{\circ}$ approx. with respect to the others. Frontal scar oval with the main axis oriented vertically. Fulcral point prominent and dorsal.

In juveniles, reticulation is not yet developed however the typical positions of the 'spine-groups' of adults are already visible even in the A-4 and A-5 moults. In the early stages the hinge is paramphidont with weakly lobate terminal elements. The arrangement of the muscle scar is according to the genus but in the younger instars the two lowermost adductor scars are fused.

Remarks: Apart from distribution and depth L. geniculata n. sp. differs from the other $L$. species of as follows:

- L. acanthoderma (BRADY) is smaller, has a larger fused zone and 'spine-groups' on the anterior surface.

- L. sp. is bigger, has a posterior margin acuminate medially, lacks the secondary reticulation at anterior.

- L. aculeata JellineK \& Swanson (2003) is smaller and its SCT is weakly developed.

- L. castanea Jellinek \& Swanson (2003) is smallet and has two single 'spine-groups', one on the anterior surface and another on the posterior cardinal angle.

- L. sp. A JeluineK \& SWANSON (2003) is larger, has weaker ornamentation, with more widely-spaced knots, a weak SCT and no 'spine-groups' on the posterior part of the dorsal margin,

- L. sp. B Jellinek \& Swanson (2003) is larger, has more developed knots and five 'spine-groups' on the anterior surface.

\section{Legitimocythere sp.}

(Figs. 25A-J)

Material: 6 adult $\mathrm{R}$ and 36 juvenile valves. - SMF Xe 21521-21527.

Dimensions: R 1.27-1.42/0.77-0.82.

Distribution: Holocene of the Emerald Basin. Very rare in sample BX110 $(3907 \mathrm{~m})$. Holocene of the South Tasman Rise. Very rare in samples BX147 $(2177 \mathrm{~m})$ and BX161 $(3685 \mathrm{~m})$; rare in samples BX138 (3022 $\mathrm{m})$ and BX165 (4067 m).

Description: Sub-trapezoidal coarsely ornate form. Anterior margin rounded, bearing a series of stout knots on the flattened rim. Posterior margin acuminate medially. Dorsal margin sloping towards posterior, with a peculiar hinge- ear, enhanced by a cluster of posteriorly-directed spines. Ventral margin sinuous. Surface covered with a faint reticulation and with stout knots, better developed in adults. These knots may occur within the meshwork or be intercepted by the muri and often carry normal pore exits. Dorsal margin with pointed and large spines, ventral margin with small spatulate spines. SCT with four knots. Ventral row of six spine-groups followed anteriorly by stout knots forming a single curve with the knots on the anterior rim. Maximum height at anterior cardinal angle, maximum width at mid-length. In dorsal view, maximum width in the posterior third. External surface between the marginal rims and the zone of central swelling smooth or with very small knots, particularly evident in dorsal view, with the anterior one gently sloping from the central swelling to the rim and the posterior one narrow and flat, forming an angle with the swelling.

Internally: fused zone narrow, with straight and few medially swollen marginal pore-canals, 42-48 anteriorly and 1820 posteriorly. Posterior margin acuminate, more obvious than in external view. Ventral margin slightly arched in the oral region. Hinge holamphidont. In the R, AT stepped with a deep round socket behind; PT elongate and bean-shaped; median groove smooth and thin. A smooth groove occurs above the anterior element, probably to accommodate the hinge ear of the L. Four adductor MS arranged in a vertical row, the uppermost of which slopes posteriorly and a single round frontal scar.

In some of juveniles the frontal scar may be subdivided. The characters preserved in all the stages recovered (A-1, A-4) are the spines on the margins, which are longer and more pointed than in adults, and the ventral row of 'spine-groups', which in the younger stages are simple spines. The younger instars (A-3, A-4) display no reticulation and lack the tubercles on the zone of medial swelling. The hinge of the juveniles is paramphidont with terminal elements weakly lobate on the horizontal plane.

Remarks: Although only six adult Rs were recovered and the adult Ls were fragmentary, this species displays well defined characters. It is referred to Legitimocythere sensu JELLINEK \& SWANSON (2003) because of the identical internal characters and the very similar external surface ornamentation. However, $L$. sp. has a different outline than other species of $L$, with a more acuminate posterior. Additionally, the density of the spines varies whereas in $L$. species spines are distributed almost uniformly over the entire external surface.

Juveniles of this species are similar to Bathycythere vanstraateni SissingH (1971) recovered in the Atlantic and Pacific oceans (see Remarks in Bathycythere). It is my opinion that many of the specimens referred to Bathycythere are instead juveniles of Legitimocythere sp. or related species.

Adults of Legitimocythere sp. differ from B. vanstraateni in the larger dimensions, the presence of the secondary reticulation, the arrangement of the spines also on the antero-dorsal area, the presence of only three rows of spines on the ventral side ( $B$. has five). Juveniles of $L$. sp. differ from the specimens of $B$. recovered in the Atlantic and Pacific oceans in the more acuminate posterior, the surface reticulation, and the arrangement of the spines on the posterior surface.

It is probable that specimens recovered in sample BX165 should be referred to another species because they are smaller 


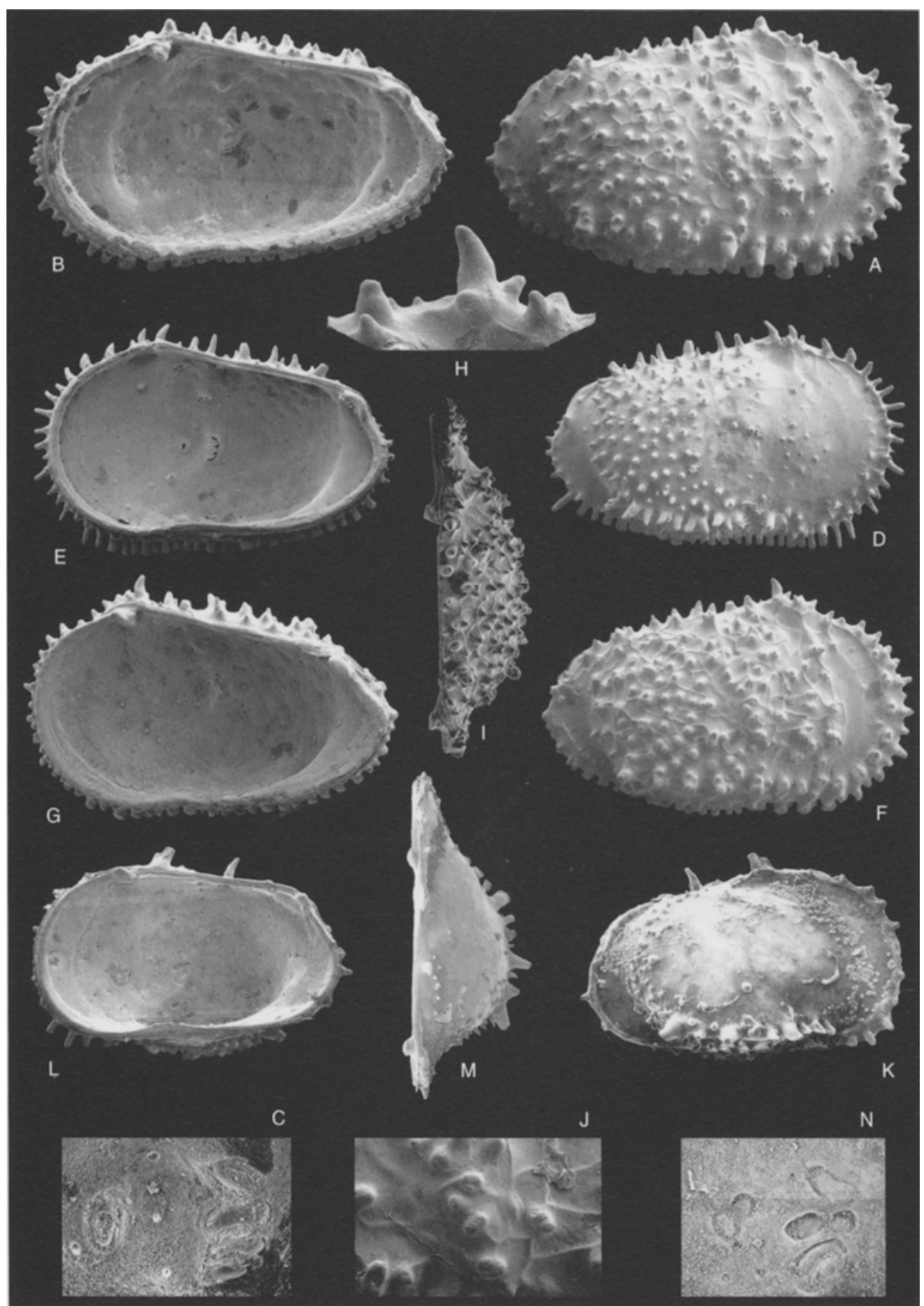

Fig. 25: A-J: Legitimocythere sp.

Recent, sample BX147, South Tasman Rise, off south coast Tasmania, Australia; S48 $29.99^{\prime}$, E149 $06.75^{\prime}$, $2177 \mathrm{~m}$. - R (1.42/0.82); A: external view; B: internal view; C: central muscle scars, $\times 144$. SMF Xe 21521. juv R (1.22/0.70); D: external view; E: internal view.SMF Xe 21521.

Recent, sample BX165, South Tasman Rise, off south coast Tasmania, Australia; S45 18.26', E147 $55.13^{\prime}$, $4067 \mathrm{~m}$. - R (1.27/0.77); F: external view; G: internal view; H: spines at hinge ear, $\times 132$; I: dorsal view; J: subcentral tubercle, $\times 92$. SMF Xe 21523.

K-N: Bathycythere vanstraateni, SisSINGH 1971

Pleistocene, Late Dryas, sourh-eastern Adriatic Sea., core 309 Adria, 503-533cm; courtesy of the Utrecht Micropaleontological Collection, Netherlands. - female R (1.15/0.70), Paratype 4; K: external view; L: internal view; M: dorsal view; $N$ : central muscle scars, $\times 140$. S 27536. - All magnifications are $\times 40$ unless otherwise stated. 
and have a slightly different ornamentation. However, the material was scarce such that it was impossible to determine whether these differences were in fact intra-specific.

\section{Genus Bathycythere SISSINGH 1971}

Type species: Bathycythere vanstraateni SISSINGH 1971.

Remarks: The genus Bathycythere was erected by SISSINGH (1971) for Pleistocene specimens collected in the Adriatic Sea (Italy). He included in the genus Cythereis ericea sensu TressLer (1941: 101, pl. 19 fig. 23) from the Recent of the North Atlantic but not C. ericea Brady (1880), most likely because the latter displays a different MS pattern. TRESSLER and BRADY described an architecture of the carapace which is more adequately accommodate in Legitimocythere, with which $C$. ericea BRADY shares also the same MS pattern.

\section{Bathycythere vanstraateni SISSINGH 1971} (Figs. 25K-N)

1889 Cythere audax Brady \& Norman: 167, pl. 17 figs. 14-15.

* 1971 Bathycythere vanstraateni SISSINGH: 410, pls. 1, 2 figs. 2-4.

? 1971 'Xandarosina'Benson \& Sylvester-BradLeY: 69, figs. 3a, b. (= nomen nudum)

1974 Bathycythere vanstraateni SISSINGH: 2:22:133140.

? 1983 Bathycythere vanstraateni. - BONADUCE et al.: $459 \mathrm{ff}$.

non 1987 Bathycythere vanstraateni. - WHATLEY \& COLES : 91 , pl. 6 fig. 3.

? 1988 Bathycythere vanstraateni. - AYRESS: 747, pl. 27 figs. 12-15.

1988 Bathycythere vanstraateni. - VAN HARTEN \& Droste: 721 ff, pl. 1 fig. 1.

? 1988 Bathycythere vanstraateni. - WHATLEY \& AYRESS: 749.

? 1990 Bathycythere vanstraateni. - COLES et al.: $294 \mathrm{ff}$.

? 1990 Indet. sp. 23. - Dingle et al.: 329, Fig. 52C.

? 1990 Bathycythere vanstraateni. - VAN HARTEN: $325 \mathrm{ff}$.

non 1993 Bathycythere vanstraateni. - DINGLE: 42-43, Fig. 25E-F.

non 1996 Bathycythere vanstraateni. - CRONIN: pl. 1 fig. 4.

? 1997 Bathycythere vanstraateni. - AYrEss et al.: $292 \mathrm{ff}$.

Remarks: Three adult and four juvenile paratypes valves (labelled S27533-27539) from different cores from the Pleistocene of the Adriatic Sea (Italy), were provided by the Micropaleontological Museum of the Utrecht University (Netherlands). The following observations were made on the Mediterranean specimens. Adults of $B$. vanstraateni (dimensions: female L 1.17/0.70, R 1.15/0.70; male R 1.17/0.67) bear small spines on the postero-dorsal area and five rows of larger spines, often bullae, ventrally. Juveniles bear no spines on the posterior half. The MS were observed both in adults and in juveniles and consisted of a divided third central muscle scar and two frontal scars. Only the adult L displayed divided second adductor scars.

SISSINGH included in B. vanstraateni, Pterygocythereis sp.? Ascoli $(1965 a, b)$ from the Recent of the Adriatic Sea and 'Xandarosina' Benson \& Sylvester-Bradley (1971) from the Recent and Pleistocene of the Mediterranean Sea, the Atlantic and the Indian oceans. More recent studies confirmed the occurrence of this species in the western Mediterranean (BONADUCE et al. 1983) but also conclude that it became extinct in the Mediterranean about 9000 years ago ("Early Holocene anoxic event", van HaRTEN \& Droste 1988: 721).

BENSON \& SYLVESTER-BRADLEY (1971) provided a drawing of 'Xandarosina' from the late Pleistocene of the eastern Mediterranean. They reported a length of 1.20 for specimens recovered at various depths $(400-3783 \mathrm{~m})$ in the Atlantic and Indian oceans, but gave no additional information.

B. vanstraateni figured by WHATLEY \& COLES (1987: 91, pl. 6 fig. 3) from Early Pliocene sediments of the North Atlantic, is small (0.66 measured from the plate as opposed to the 1.17 max length for the Mediterranean species). No details of internal features were given. This Atlantic form displays thick marginal rims and a coarse ornamentation on the posterior half of the valve. SisSINGH (1971: Fig. 4) clearly demonstrates the ontogenetic development of the species, and juveniles are drawn without posterior ornamentation, as it was observed on the paratypes during the present study.

AYress (1988: 747-749, pl. 27 figs. 12-15) recovered four specimens in Pleistocene samples from the Pacific and Indian oceans. He described the specimens as juvenile and reported 1.10/0.66 as max. dimensions. The two valves he illustrated display a posterior ornamentation and a MS pattern similar to that illustrated by SISSINGH (1974).

Dingle et al. (1990: 329, Fig. 52C) recovered two fragments listed as Indet. sp. 23 in the SE Atlantic Ocean which may also belong to Bathycythere, but fragment illustrated is too small and poorly preserved for a generic determination.

Cronin (1996: pl. 1 fig. 4) illustrated a L from the Pliocene of the North Atlantic which has a rounded posterior and many small spines on the surface of the posterior half. The ventral carina ends at the anterior cardinal angle, whereas in B. vanstraateni it extends further anteriorly. The dimensions measured from the illustration $(0.67 / 0.40)$ do not correspond to those for the Mediterranean species.

DingLe (1993: 42-43, Fig. 25E-F) recovered one single juvenile valve from $900 \mathrm{~m}$ off south-western Africa. That specimen is large (1.17/0.75) and, compared with the Mediterranean species, displays a more massive shape, the presence of well developed and pointed spines postero-ventrally and smooth anterior and posterior margins.

This species appears in taxonomic data-bases of many papers but without illustration or descriptive text, a situation which adds confusion to an existing problem. WHATLEY \& AYRESS (1988) extended the occurrence of the species to the Quaternary of North Atlantic, Indian Ocean and SW Pacific. VAN HARTEN (1990) found B. vanstraateni in the eastern MidAtlantic Ridge and COLES et al. (1990) reported Bathycythere audax (BRAdY \& Norman 1889) from the North Atlantic and the Pacific, introducing the synonymy between $B$. vanstraate$n i$ and $B$. audax. In the latter paper, the authors considered Cythere audax BRADY \& NoRMAN (1889: 167, pl. 17 figs. 14$15)$ as the senior homonym of the type species but they did 
not provide any illustrations of the specimens. Cythere audax was dredged in the North Atlantic at $806 \mathrm{~m}$ of depth, during the cruise of H.M.S. VALOROUS in 1875. Nothing more than an opinion can be expressed about this synonymy since, apart the shape and the spinose ornamentation, no indications are given by BRADY \& NORMAN about the MS pattern and with respect to the hinge: "Anterior and posterior teeth of the hinge well developed". Ayress et al. (1997) reported $B$. audax from the Tasman Sea, Chatham Rise and Kerguelen Plateau, indicating also an upper depth limit for this taxon close to the lower boundary of the AAIW.

The comparison of $B$, vanstraateni with the juveniles of Legitimocythere sp. has led to the conclusion that many of the specimens illustrated under the name of the Mediterranean genus are juveniles of Legitimocythere sp. or related species instead. Further findings of $L$. sp. together with careful descriptions of Bathycythere species could confirm this opinion.

\section{Genus Henryhowella PUR 1957}

\section{Type species: Cythere evax ULRICH \& BASSLER 1904.}

Remarks: The development of systematics of the genus Henryhowella includes data from different continents and different geological periods. In the modern literature it is obvious that several authors refer to Henryhowella forms which differ in shape, ornamentation and the development of hinge. This confusion arises because many workers did not refer to type material and because of the inadequate original illustrations and descriptions used subsequently as the taxonomic reference. As a consequence, the original diagnosis has been modified as follows (Tab. 6):
PURI (1957) erected the genus Henryhowella (= Howella 1956) based on specimens from the Tertiary of Florida. He designated as type species, Cythere evax ULRICH \& BASSLER from the Miocene of Maryland (Fig. 28) which he had previously referred to the genus Echinocythereis PURI (1954). VAN DEN BOLD (1960: 169) emended the PuRr's description comparing material from Plum Point, Maryland, with specimens from Europe (Badenian, Vienna, Austria). He pointed out the synonymy between Henryhowella evax (ULRICH \& BASSLER 1904) and Henryhowella asperrima (Reuss 1850). Some years earlier VAN DEN BOLD (1957b: 242-243), although rejecting the new genus Howella (= Henryhowella), presented a long, complex synonymy list for Echinocythereis asperrima (RFUSS 1850), which included Cythereis sarsii G.W. Müller (1894) from the Recent of the Gulf of Naples. In all probability vaN MORKHOVEN (1963) based his description on Cythereis sarsii G.W. MÜller.

Unfortunately, the description and illustration of Cypridina asperrima by REUSS is inadequate. However, the paper by KEMPF \& NINK (1993) in which topotypic material is described has proved very useful.

Comparing the pictures of the lectotypes of $H$. evax given by FORESTER (1980: pl. 4 figs. 1-2) with the specimens of $H$. asperrima illustrated by KEMPF \& NINK and the topotypic material provided from the Senckenberg Museum I can only conclude that the species are not identical and as result their synonymy is probably invalid. In Tab. 7 a comparison between the two species is schematised.

This discussion becomes more complicated when the fact that several authors included in the genus species displaying no plications in the posterior half is also taken in consideration. As was well explained by DINGLE et al. (1990), who accepted the synonymy suggested by VAN DEN BOLD (1960), that

Table 6: Comparison of the main characters given by different authors for the diagnosis of Henryhowella.

\begin{tabular}{lllll}
\hline author & posterior structure & sub-central tubercle & AT & marginal pore-canals \\
\hline ULRICH \& BASSLER 1904 & two ridges & swelling with spinose ornament & & \\
PURI 1957 & 3 rows of echinose spines & cluster of short, stubby spines & crenulate & straight \\
VAN DEN BOLD 1960 & 3 rows of echinose spines & cluster of short, stubby spines & stepped & sinuous, branching or joined \\
VAN MORKHOVEN 1963 & 3 longitudinal plications & faint & stepped & mostly straight, simple \\
\hline
\end{tabular}

Table 7: Comparison of Henryhowella evax and Henryhowella asperrima, using illustration of H. evax (kindly provided by Dr. R. BENSON, National Museum of Natural History, Washington/DC) and of $H$. asperrima (kindly provided by DR. T. JeluINEK, Senckenberg Museum, Frankfurt am Main) (see also Figs. 25A-I, 28).

\begin{tabular}{lllll}
\hline species & H. asperrima & H. evax & H. asperrima & H. evax \\
\hline valve & female $\mathrm{L}$ & fermale $\mathrm{L}$ & male $\mathrm{L}$ & male $\mathrm{L}$ \\
L/H ratio & 1.58 & 1.71 & 1.78 & 1.91 \\
maximum lenght & below median height & at median height & below median height & at median height \\
anterior margin & evenly rounded & asymmetrically rounded & evenly rounded & asymmetrically rounded \\
postero-ventral angle & rounded & symmetrically rounded & sqaured & rounded \\
\hline
\end{tabular}


in the current literature non-plicate species are usually referred to Henryhowella melobesioides (BRADY 1869) or to Henryhowella dasyderma (BRADY 1880) without reference to the type material.

The uncertainty with respect to the definicion of this genus has lead to a variety of interpretations:

- The division between plicate and non-plicate forms, with the placement of the first type to $H$. asperrima and of the second into $H$. dasyderma or $H$. melobesioides (ROSENFELD \& Bein 1978, Whatley \& Coles 1987, Dingle \& Lord 1990, Dingle et al. 1990, Guernet 1998). The criteria for separating melobesioides and dasyderma are not clear and both occur in a wide range of depths and latitudes.

- The extensive use of taxonomic loopholes such as $H$. cf. asperrima or $H$. aff. $H$. asperrima (WHATLEY \& AYRESS 1988, Guernet \& Moullade 1994) to indicate a relationship but without qualification.

- The indication of extreme variability without further refinement and inclusion of that assemblage in Henryhowella but under open nomenclature (STEINECK et al. 1988, Guernet \& Bellier 2000, Majoran \& Dingle 2001a, 2001b, DiDIÉ \& BaUCH 2002).

Henryhowella asperrima (REUSs 1850)

(Figs. 26A-I, 27B)

* 1850 Cypridina asperrima Reuss: 74, pl. 10 figs. 5a-b.

1993 Henryhowella asperrima. - KEMPF \& NINK: 95114, Figs. 1-30.

1999 Henryhowella asperrima. - BONADUCE et al.: 6061, pl. 1 figs. 1-2.

2001 Henryhowella asperrima. - DaLl'Antonia \& Bossio: 418-419, pl. 5 figs. 3-7.

Material: 24 adult and 8 juvenile valves from Tortonian sediments of the Vienna Basin [drill-hole Maustrenk 1, level $103 \mathrm{~m}, 298,2 \mathrm{~m}$ a.s.l., around $58 \mathrm{~km}$ north of Vienna (Ausrria)] kindly provided by Dr. T. Jellinek, Senckenberg Museum, Frankfurt am Main (Germany). - SMF Xe 2152821529.

Dimensions: Female L $0.65-0.75 / 0.42-0.47$, R 0.67 $0.72 / 0.40-0.45$; male L $0.74-0.77 / 0.42-0.45$, R $0.72-0.75 /$ $0.40-0.42$.

Remarks: Topotypic material is figured to allow a comparison between a fossil species, considered by many workers as the type species, and the Recent specimens from the Tasman Sea. Reuss (1850) recovered Cypridina asperrima from Middle Miocene sediments from the Vienna Basin. KempF \& Nink (1993) re-illustrated topotypic material from the Badenian of the Vienna Basin and considered $H$. asperrima as occurring only in Miocene sediments. BonADUCE et al. (1999) considered this species as fossil in the Mediterranean Sea and the Atlantic Ocean whereas Dall'Antonia \& Bossio (2001) proposed an Oligocene to Recent stratigraphic range.

\section{'Cythere' melobesioides (BRADY 1869)}

(Figs. 26J-M)

* 1869 Cythere melobesioides BRADY: 162, pl. 19 figs. $10-11$.

non 1880 Cythere melobesioides. - BraDx: 108, pl. 18 fig. 1

1976 Cythere melobesioides. - PURI \& Hulings: 255. pl. 25 figs. 1-2.

non 1990 Henryhowella melobesioides. - DINGLE et al.: 311 , Figs. 42C-F, 43A-F, 47A.

Remarks: BraDY (1869: 162, pl. 19 figs. 10-11) described as Cythere melobesioides specimens with sub-spinose ornamentation recovered from an unknown depth near Mauritius, and later (1880: 108, pl. 18 fig. 1), during the Challenger cruise, from the Cape of Good Hope at $288 \mathrm{~m}$ of depth and from the Torres Straits at $11-15 \mathrm{~m}$ of depth indicating that the specimens from the two stations were probably not conspecific (BRADY 1880: 108).

Puri \& Hulings (1976: 255, pl. 25 figs. 1-2) designated a hololectotype of Cythere melobesioides, using a specimen from the Cape of Good Hope material. In the Challenger collection, hosted at the NHM (London), there is only one slide labelled $C$. melobesioides and contains the hololectotype (no. BM 80.38.92).

Dingle et al. (1990: 311, Figs. 42C-F, 43A-F, 44A-D, 47A) assigned C. melobesioides to the genus Henryhowella but did not provide illustrations of the type material. They provided instead several micrographs of specimens from the Recent of south-western Africa which cannot be referred to $C$. melobesioides. In fact, the specimens they illustrated differ as follows from the hololectotype of $C$. melobesioides. The specimens recovered at $184 \mathrm{~m}$ (Figs. $42 \mathrm{C}-\mathrm{D}$ ) are much smaller $(0.48 / 0.26-0.24$, measured from the plate) and display an outline different from that of $C$. melobesioides, the specimens recovered at $655 \mathrm{~m}$ (Figs. 42E-F) are larger (1.10-1.12/ $0.60-0,64)$ and display a different ornamentation and outline; the specimens recovered at $941 \mathrm{~m}$ (Figs. 43A-B) are probably juveniles $(0.51-0.55 / 0.33)$ of another species; the specimens recovered at $990 \mathrm{~m}$ (Figs. 43C-E; 0.57/0.35) and at $2916 \mathrm{~m}$ (Figs. 43F, 47A; 0.43-0.45/0.25-0.30) are all smaller and display a different ornamentation and outline.

In the present author's opinion, the generic assignment of C. melobesioides to Henryhowella PURI or to Fallacihowella JELLINEK \& SWANSON requires a modification of the original diagnoses. If $C$. melobesioides is assigned to the genus Henryhowella, the definition of this genus should include non-plicate forms with different outline. If $C$. melobesioides is assigned to Fallacibowella, this genus should include forms with central muscle scars in a sub-central tubercle. For these reasons, it is preferred to keep the generic name 'Cythere' until a comparison with more specimens of $C$. melobesioides will be possible.

\section{'Cythere' dasyderma BRADY 1869}

(Figs. 26N-S)

* 1880 Cythere dasyderma BRADY: 18, 105, pl. 17 fig. 4, pl. 18 fig. 2.

1976 Cythere dasyderma. - Puri \& HuLings: 273, pl. 11 figs. 10-11. 


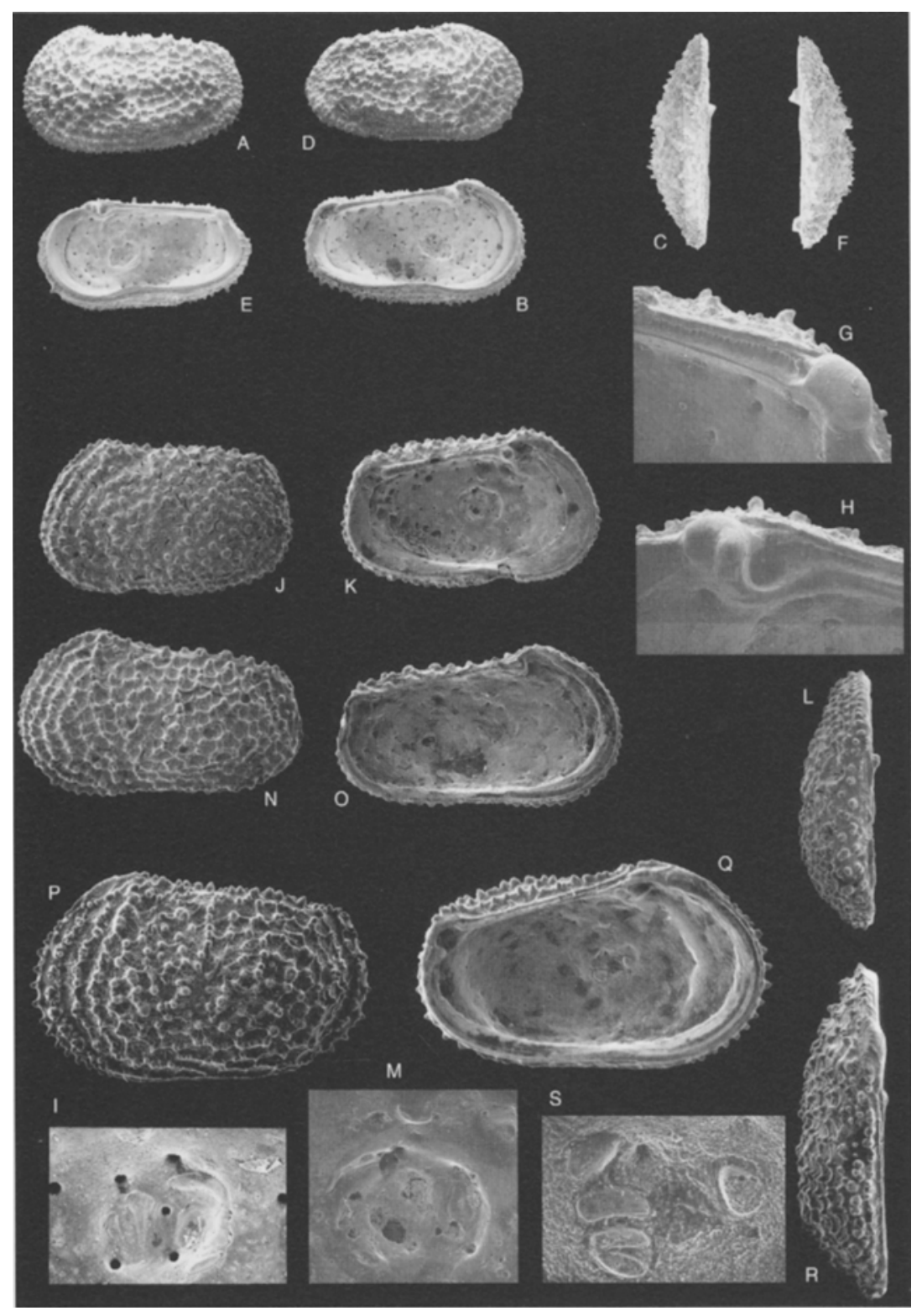

Fig. 26: A-I: Henryhowella asperrima (Reuss 1850)

Tortonian of the Vienna Basin, drill-hole Maustrenk 1, (level 103m), 298,2m a.s.l., around $58 \mathrm{~km}$ north of Vienna (Austria). Courtesy of Dr. T. JelunNek, Senckenberg Museum, Germany, - male C $(0.77 / 0.45 / 0.40)$; A: L $(0.77 / 0.45)$ external view, $\times 35$; B: internal view; $\mathrm{C}$ : dorsal view; D: $R(0.75 / 0.42)$, external view, $\times 35$; E: internal view; F: dorsal view; G: detail of the posterior hinge elements of $\mathrm{R}, \times 170$. SMF Xe 21528; H: detail of the anterior hinge elements of $\mathrm{R}, \times 170$; I: central muscle scars of $\mathrm{R}, \times 140$.

J-M: Henryhowella melobesioides (BRADY 1869)

Recent, off Cape of Good Hope, Challenger station 142, $270 \mathrm{~m}$. - Hololectotype designated by Puri \& Hulings (1976: 255, pl. 25 figs 1-2). - female L (0.90/0.55); J: external view, negative number 071089; K: internal view, negative number 071137; L: dorsal view, negative number 071181; M: detail of the central muscle scars, negative number 071138, $\times 278$. NHM no. BM 80.38.92 [pictures were taken and provided by Dr. J. WhITTAKER, Department of Palaeontology, Natural History Museum, London]

N-S: Cythere dasyderma (BRADY 1880)

Recent, S Pacific, Challenger station $296\left(\mathrm{~S} 38^{\circ} 06.00^{\prime}\right.$, W $\left.88^{\circ} 02.00^{\prime}\right), 3285 \mathrm{~m}$. Paralectotype designated by PURI \& HuLINGs (1976: 273). - male L (1.03/0.60); N: external view, negative number 071082; $\mathrm{O}$ : internal view, negative number 071124. NHM no. BM 1961.12.4.39. Hololectotype designated by Puri \& Hulings (1976: 273, pl. 11 figs 11, 10). - female L (1.20/0.72); P: external view, negative number 071080; $Q$ : internal view, negative number 071120; R: dorsal view, negative number 071177; S: detail of the central muscle scars, negative number $071121, \times 242$. NHM no. BM 1961.12.4.39 [pictures were taken and provided by Dr. J. WhITTAKer, Department of Palaeontology, Narural History Museum, London]. All magnifications are $\times 33$ unless otherwise stated. 

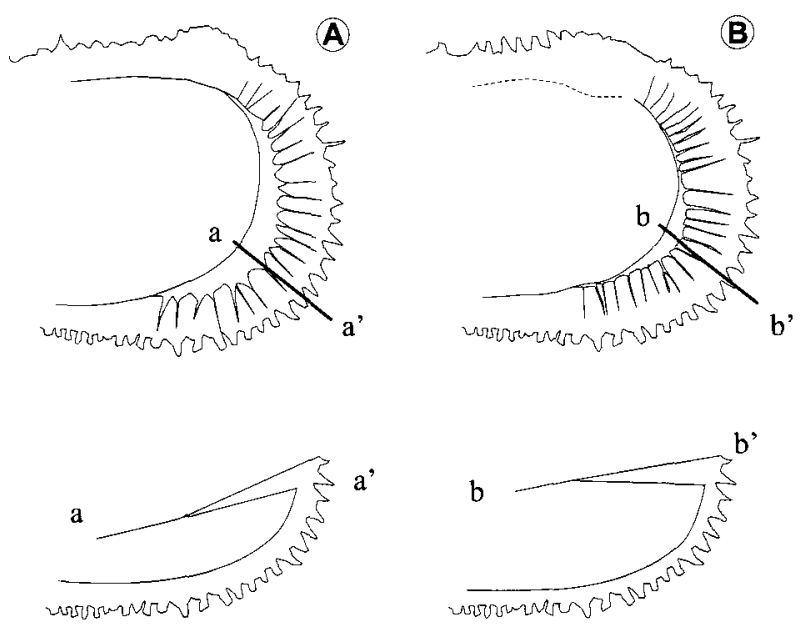

Fig. 27: Schematic drawings of the anterior vestibulum of Fallacihowella caligo (A) and Henryhowella asperrima (B) and cross-sectional profiles along lines $\mathrm{a}-\mathrm{a}^{\prime}$ and $\mathrm{b}-\mathrm{b}^{\prime}$ respectively.

non

1978 Henryhowella dasyderma. - ROSENFELd \& BEIN: 18, pl. 1 fig. 24.

non 1987 Henryhowella sp. cf. H. dasyderma. - WHATLEY $\&$ COLEs: 36 ff, pl. 5 figs. 12-13.

Remarks: BRADY (1880: 105, pl. 17 fig. 4) described as Cythere dasyderma specimens with short and blunt spines rising from the muri of "angular excavations" and which were recovered from 20 different stations with a world wide distribution and from a wide depth range $(270-4446 \mathrm{~m})$. PURI \& Hulings (1976: 273, pl. 11 figs. 10,11) designated a lectotype of Cythere dasyderma from Challenger station 296, in the $S$ Pacific. Although PURI \& Hulings stated that the hololectotype is probably a penultimate instar, observations on the material hosted at the Natural History Museum (London) have led to the conclusion that it is instead a badly preserved adult female $\mathrm{L}(1.20 / 0.72)$. The slide is labelled no. BM 1961.12.4.39 and contains another female L (1.18/0.75), probably belonging to $C$. dasyderma. A different slide, labelled with the same number, contains three paralectotypes: two juvenile $\mathrm{Ls}$, not congeneric, and a male L (1.05/0.60). The slide labelled as "topotype BM 1974-275 station 185, 155 fathoms, Torres' Straits", contains an adult R of Bythocythere arenacea BRADY (1880). In the collection, several other slides are labelled as $C$. dasyderma from station 296 and 302 . Of the 77 specimens studied, 53 show affinities with $C$. dasyderma.

ROSENFELD \& BeIN (1978: 18, pl. 1 fig. 24) were the first to refer $C$. dasyderma to the genus Henryhowella, probably driven by its spinose ornamentation. They did not re-study BRADY's material, and illustrated a L $(0.72 / 0.48$, measured from their plate) which is smaller than $C$. dasyderma.

Whatley \& Coles (1987: 36 ff, pl. 5 figs. 12-13) illustrated as $H$. sp. cf. $H$. dasyderma two specimens from Miocene and Pliocene sediments of the $\mathrm{N}$ Atlantic, a female $\mathrm{R}$ (0.95/0.60, measured from the plate) and a male $\mathrm{L}(0.81 /$ $0.46)$. They are both smaller than $C$. dasyderma and display slightly different outlines.

In the present author's opinion, the generic assignment of C. dasyderma to Henryhowella PURI or to Fallacihowella JeLLI-

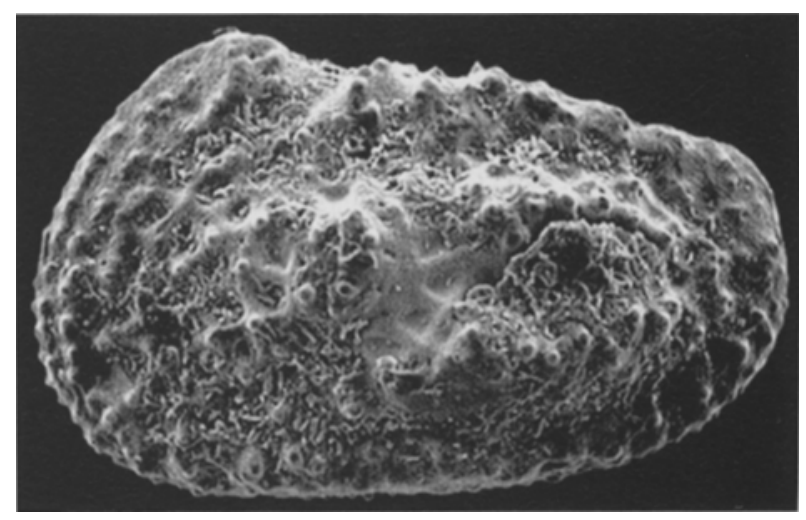

Fig. 28: SEM micrograph of Henryhowella species: Henryhowella evax (ULRICH \& BASSLER 1904).

Lectotype (USNM 35412), female L (0.77/0.45), from the Calvert Formation (Miocene), Plum Point (Maryland, USA), $\times 60$. [kindly provided by Dr. R. BENSON, Smithsonian National Museum of Natural History, Washington/DC].

NEK \& SWANSON is uncertain, complicated by the fact that the type material is badly preserved so that the internal characters cannot be clearly defined. For these reasons, it is preferred to keep the original generic name 'Cythere', until topotypic, better preserved material become available.

\section{Genus Apatihowella Jellinek \& Swanson 2003}

Type species: Apatihowella inradata JELLINEK \& SWANSON 2003.

Remarks: JELLINEK \& SWANSON compared the chitinous appendages of non-plicate forms from the Campbell Plateau (New Zealand) with the drawings available in literature on soft parts of Henryhowella sarsii sarsii from the Mediterranean. The differences in the antennal exopod and the copulatory apparatus have led them to erect the new genus Apatihowella JELLINEK \& SWANSON (2003). Differences in ornamentation, hinge structure and MS pattern have also led to the subdivision into the two subgenera $A$. (Apatihowella) and $A$. (Fallacihowella). In overall morphology of the valves, $A$. (Apatihowella) seems closer to Henryhowella than to $A$. (Fallacibowella).

Compared with $A$. (Fallacibowella), A. (Apatihowella) has a different pattern of the adductor scars, a different hinge structure and a different arrangement of the surface ornamentation, with a more enhanced sub-central swelling. For the reasons herein mentioned it is raised to generic rank as Apatihowella.

Apatihowella cf. A. rustica JeLlineK \& Swanson 2003 (Figs. 29A-H)

Material: 11 adult and 18 juvenile valves. - SMF Xe 21530-21531.

Dimensions: Female L $0.82-0.85 / 0.50-0.52$, R $0.82 /$ 0.47 ; male L $0.87 / 0.47$, R 0.90-0.92/0.45-0.47. 


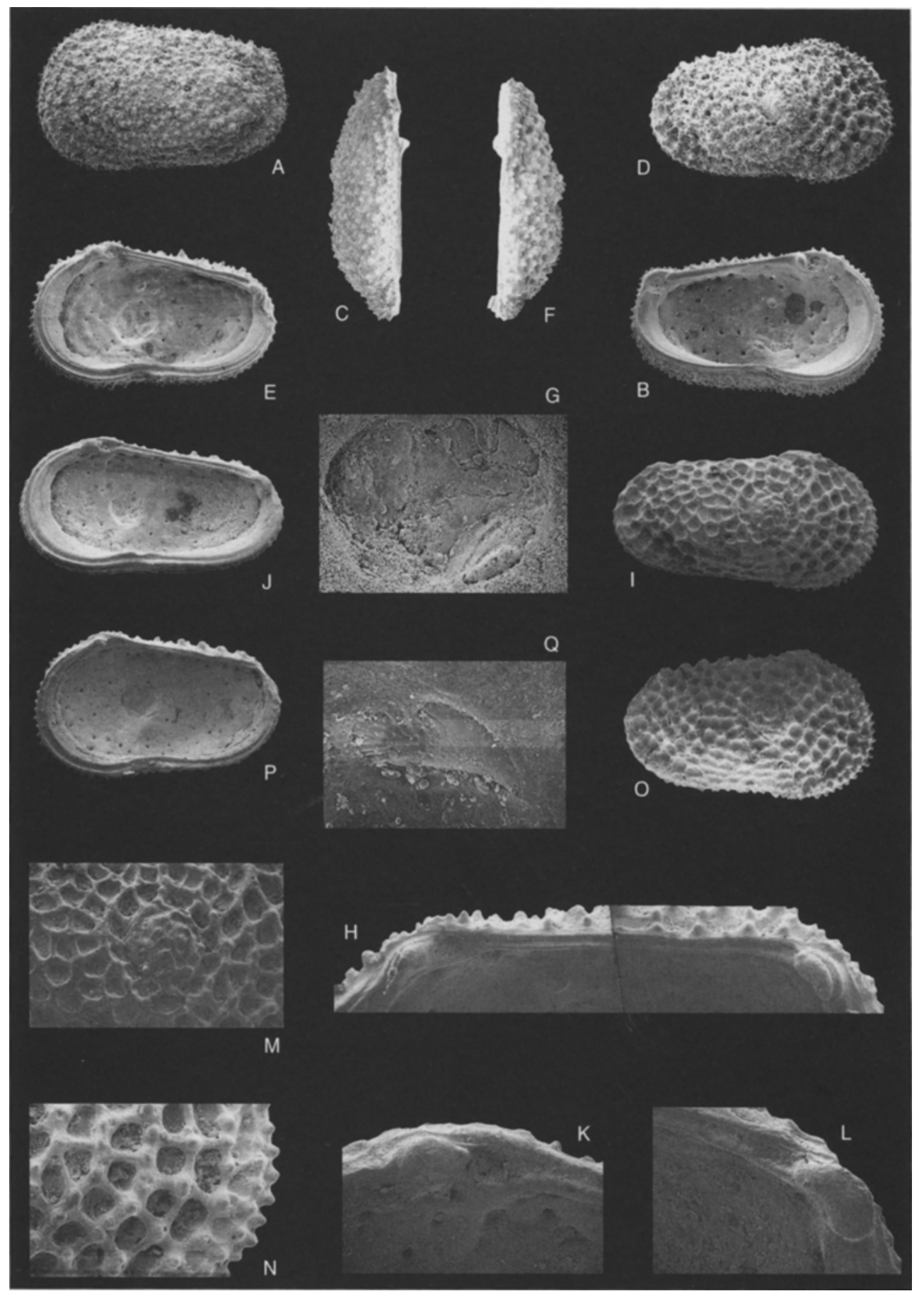

Fig. 29: A-H: Apatihowella cf. A. rustica JeLlinek \& Swanson (2003)

Recent, sample BX 140; South Tasman Rise, off south coast Tasmania, Australia; S49 $10.84^{\prime}$, E150 $10.13^{\prime}$, $1636 \mathrm{~m}$. - female L (0.85/0.52); A: external view; B: internal view; C: dorsal view. SMF Xe 21530. - female R $(0.82 / 0.47)$; D: external view; E: internal view; F: dorsal view; G: central muscle scars, $\times 167$; H: hinge, $\times 112$. SMF Xe 21530

I-Q: Apatihowella sp.

Recent, sample BX161, South Tasman Rise, off south coast Tasmania, Australia; S46 33.18', E149 $04.96^{\prime}$, $3685 \mathrm{~m}$. - male R (0.90/0.47); I: external view; J: internal view; K: anterior hinge element, $\times 185$; L: posterior hinge element, $\times 185$; M: detail of the sub-central tubercle, $\times 120 ; \mathrm{N}$ : detail of the anterior ornamentation with tubercles in conjunctive positions, $\times 120$. SMF Xe 21532. - female R $(0.85 / 0.50)$; O: external view; P: internal view; Q: detail of the uppermost central scar, $\times 425$. SMF Xe 21532. - All magnifications are $\times 43$ unless otherwise stated. 
Distribution: Holocene of the South Tasman Rise. Common in sample BX153 (1874 m). Rare in sample BX140 (1636 m).

Remarks: Few poorly preserved adult specimens were recovered. Despite this, overall shape, characteristic ornamentation organised in concentric rows of intramural nodes and intermediate sub-round fossae, large sub-central tubercle, paramphidont hinge and the arrangement and shape of MS correspond with $A$, rustica.

This species is only compared to $A$. rustica because the dimensions are slightly larger and nodes are present but not as prominent as in $A$. rustica. Greatest width is at the SCT in adult specimens whereas in juveniles this shifts posteriorly. Marginal pore-canals were not visible because of poor preservation.

\section{Apatihowellasp.}

(Figs. 29I-Q)

Material: 3 adult and 4 juvenile valves. - SMF Xe 21532.

Distribution: Holocene of the Emerald Basin. Rare in sample BX161 (3685 m).

Dimensions: Female R 0.85/0.50; male R 0.85-0.90/ $0.42-0.47$.

Remarks: This species differs from $A$. rustica JeLunNek \& SWANSON because of its slender outline, almost straight ventral margin and larger dimensions of the males. Central MS consists of four adductor scars in a vertical row and a single $V$-shaped frontal scar. The two lowermost adductor scars are drop-shaped and almost fused, the upper middle is beanshaped and slightly forward; the uppermost is deeply incised dorsally having the shape of a large $U$.

\section{Genus Fallacibowella JeLlineK \& SWANson 2003} 2003.

Type species: Fallacihowella sol JeLlineK \& SWANSON

Remarks: As already stated by TrIeBel (1950) and VAN MORKHOVEN (1962: 35) 'homeomorphic' genera have very similar shapes and ornamentation and differ in the characters of the inner lamella, mainly the hinge. The study of soft parts allows, sine dubia, the recognition of homeomorphic genera, as in the case of Fallacihowella and Henryhowella.

Besides the morphological differences already described in JELLINEK \& SWANSON for the hinge and the external morphology, the comparison of topotypic material of Henryhowella asperrima with material from the Tasman Sea has led to the recognition of differences in the inner lamella (Fig. 27). In particular, the inner lamella in specimens of Fallacihowella caligo is wider than in Henryhowella species and slopes towards the internal surface of the valve and the vestibulum is very narrow (Fig. 27A). In Henryhowella species the inner lamella is much narrower than in $F$ and is almost horizontal, resulting in a deep vestibulum (Fig. 27B). For these reasons, Fallacibowella is herein raised to generic rank.
Unfortunately, the genus Fallacihowella provides no answer about the relationship between the non-plicate forms and those 'intermediate' forms which show weak plications on the posterior half. It is likely that new findings of living specimens, displaying this 'intermediate' carapace character, will clarify their taxonomic position in the sense that they may be morphological variations or different species. For the time being, these 'intermediate' forms are grouped in Fallacihowella sp. B.

\section{Fallacihowella caligo JELLINEK \& SWANSON 2003}

(Figs. 30A-N, 27A)

Material: 189 adult and 411 juvenile valves. - SMF Xe 21533-21541.

Dimensions: Female L 1.02-1.12/0.65-0.67, R 1.071.12/0.62-0.67; male L 1.10-1.20/0.57-0.65, R 1.05-1.15/ $0.62-0.65$.

Distribution: Holocene of the South Tasman Rise. Common in samples BX141 (1690 m) and BX147 (2177 m). Very common in samples BX140 (1634 m), BX138 (3022 $\mathrm{m}), \mathrm{BX} 161(3685 \mathrm{~m})$ and BX165 $(4067 \mathrm{~m})$. Abundant in sample BX153 (1874 m).

Remarks: The male specimens from the Tasman Rise are more slender than those from the Campbell Plateau. The female specimens are slightly larger. In the shallower samples from the Tasman Rise, the juveniles exceed the number of adults which, when present, are in fragments or very eroded. On the contrary, in the deeper samples, adults are more common and better preserved.

\section{Fallacihowella sp. A \\ (Figs. 31A-M)}

Material: 3 adult and 38 juvenile valves. - SMF Xe 21542-21544.

Dimensions: Female L 1.12/0.67, R 1.05-1.10/0.62_ 0.65 .

Distribution: Holocene of the Emerald Basin. Common in samples BX110 (3907 m) and BX116 (4462 m).

Description: Valves sub-trapezoidal to sub-rectangular in shape. Greatest length at mid-height. Greatest height at anterior cardinal angle. Anterior margin wide and evenly rounded. Posterior margin asymmetrically rounded, with an obtuse angle at the posterior cardinal angle. Dorsal margin sloping posteriorly, with an incurvation medially. Ventral margin slightly concave medially. In dorsal view, greatest width posteriorly. Surface covered by star-tipped spines located on the muri of sub-rounded fossae. Spines organised in four concentric rows, parallel to the outer margin. On the sub-central posterior surface spines arranged in a random pattern.

Internally: ventral margin concave medially, additional closing mechanism developed on the flange ventrally and posteriorly. Fused zone broad, with moderately wide vestibulum antero-ventrally and narrow vestibulum postero-ventrally. Marginal pore-canals simple and straight, 25 anteriorly and 12-14 posteriorly. Hinge holamphidont. AT of R large and 


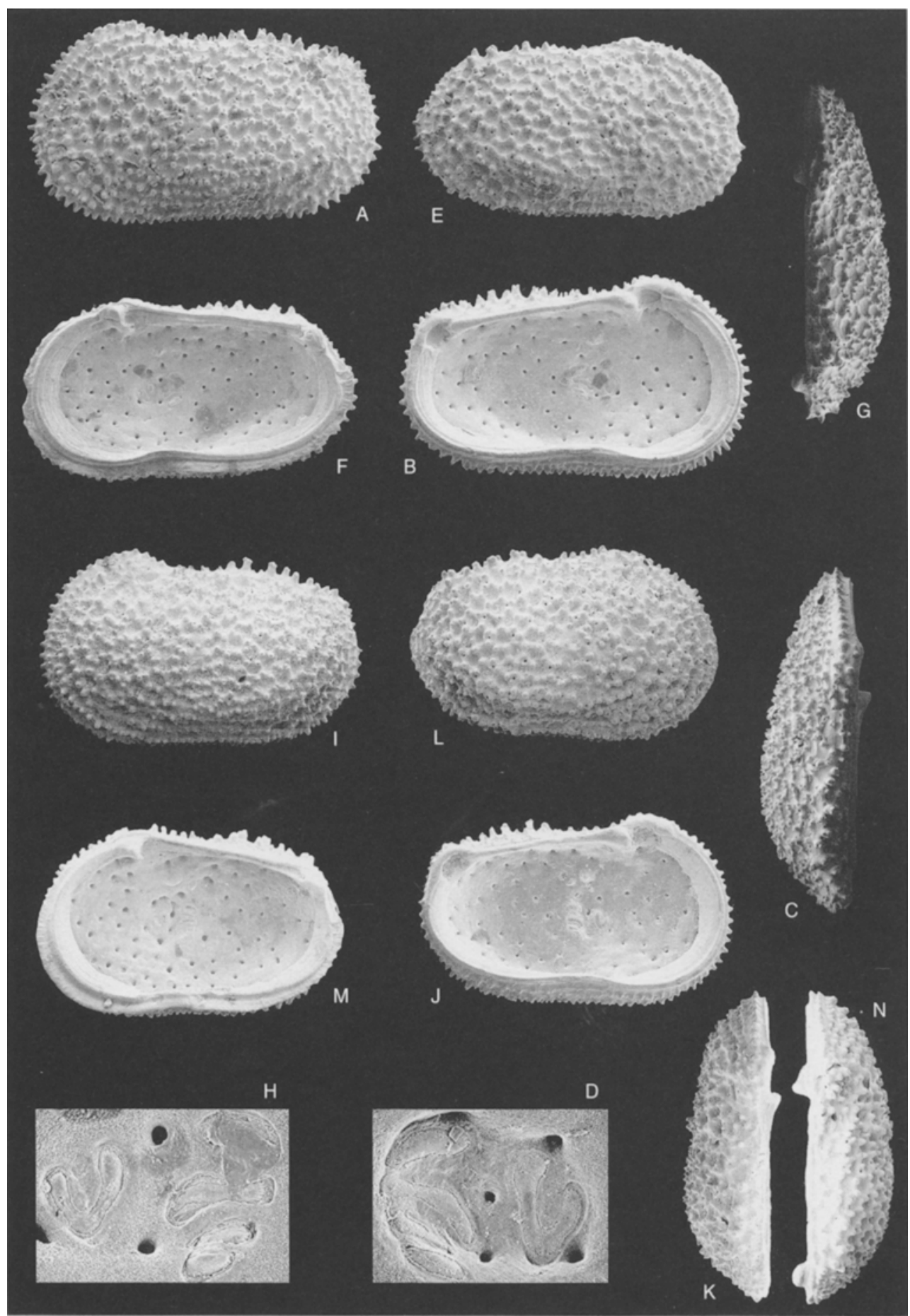

Fig. 30: Fallacihowella caligo JelLINEK \& Swanson (2003)

Recent, sample BX138, South Tasman Rise, off south coast Tasmania, Australia; S49 ${ }^{\circ} 13.06^{\prime}, \mathrm{E} 151^{\circ} 05.77^{\prime}$, $3022 \mathrm{~m}$. - male L (1.20/0.65); A: external view; B: internal view; C: dorsal view; D: central muscle scars, $\times 204$. SMF Xe 21533. - male R (1.15/0.65); E: external view; F: internal view; G: dorsal view; H: central muscle scars, $\times 204$. SMF Xe 21533 .

Recent, sample BX161, South Tasman Rise, off south coast Tasmania, Australia; S46 33.18', E149 $04.96^{\prime}$, 3685 m. - female L (1.12/0.67); I: external view; J: internal view; K: dorsal view. SMF Xe 21535. - female R (1.10/0.65); L: external view; M: internal view; N: dorsal view. SMF Xe 21535. - All magnifications are $\times 42$ unless otherwise stated. 

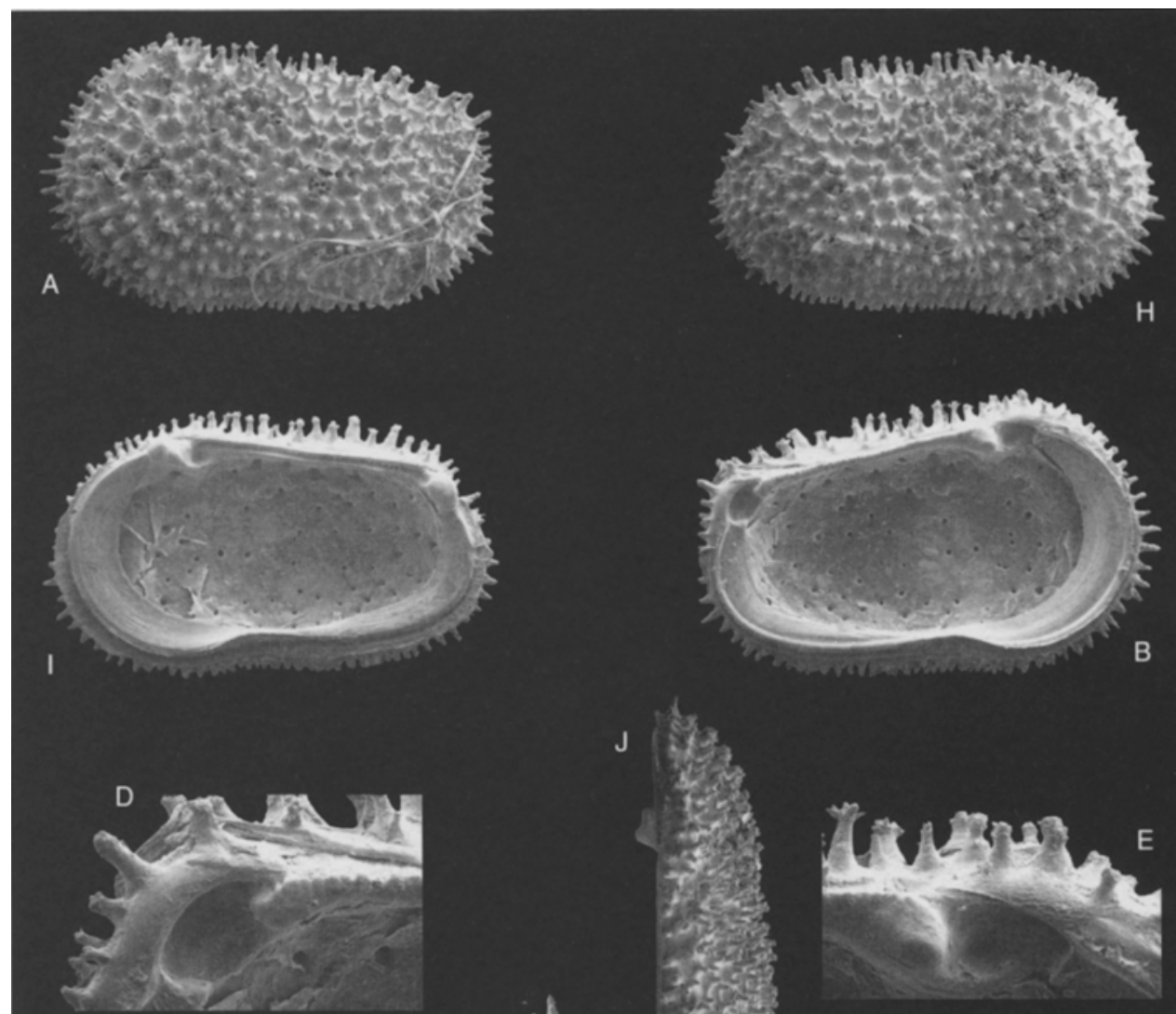

D
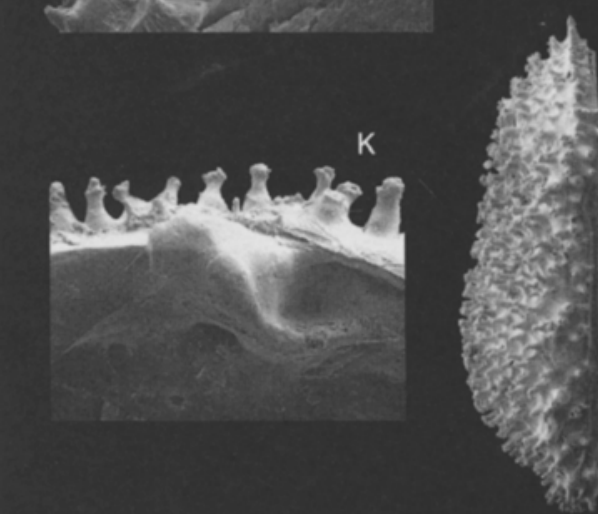

J
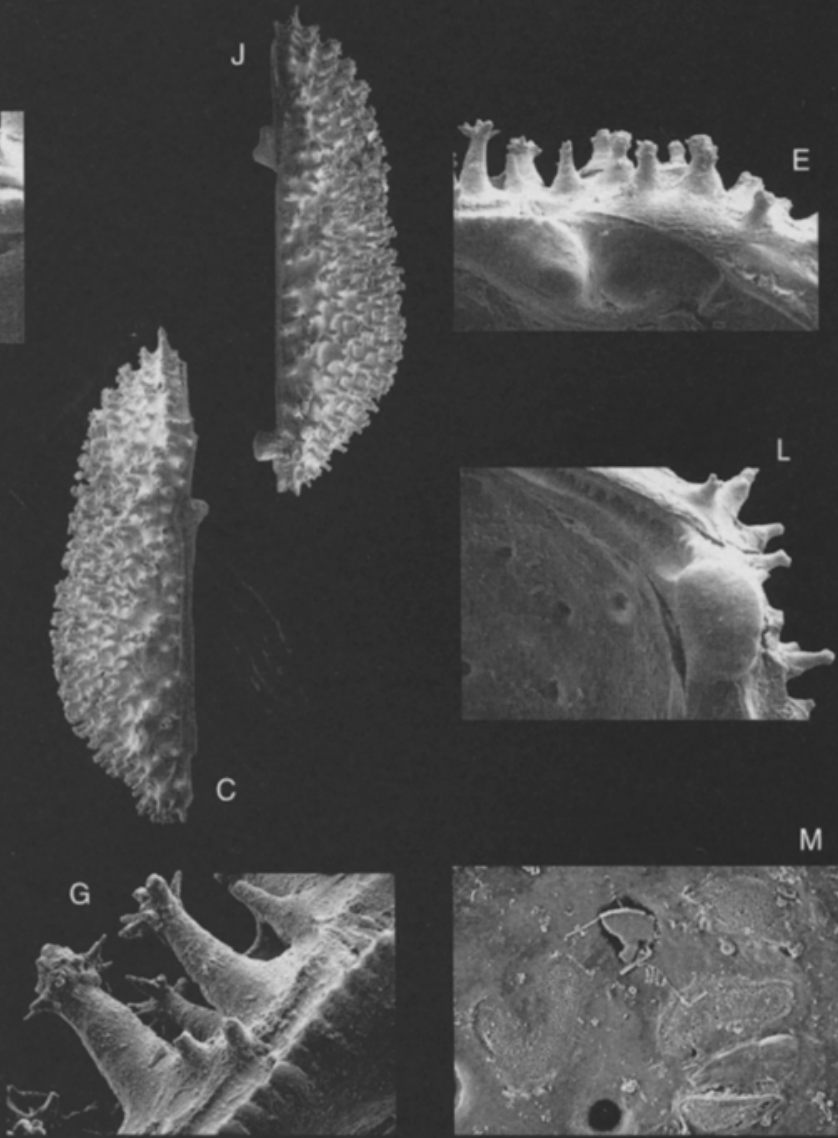

C
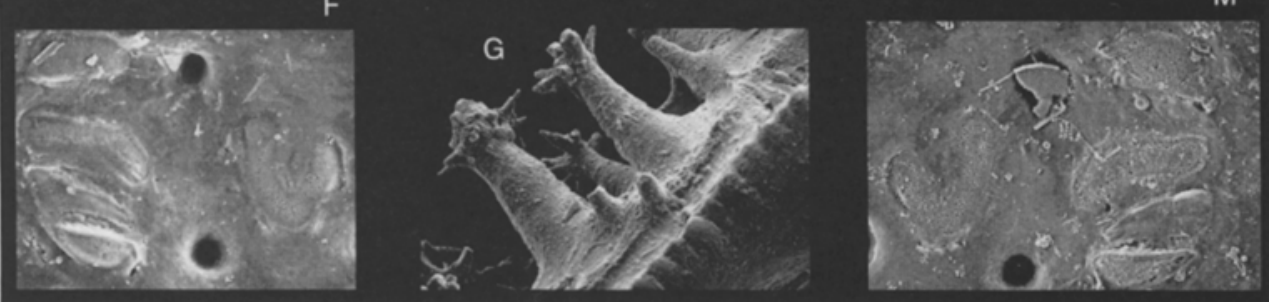

Fig. 31: Fallacihowella sp. A

Recent, sample BX116, Emerald Basin, off south coast South Island, New Zealand; S55 $40.03^{\prime}$, E159 $25.00^{\prime}$, 4462 m. - female L (1.12/0.67); A: external view; B: internal view; C: dorsal view; D: posterior socket and crenulate bar, $\times 130$; E: anterior socket, $\times 130$; F: central muscle scars, $\times 250$; G: star tipped spines and crenulate bar, $\times 320$. SMF Xe 21542. - female R (1.10/0.65); H: external view; I: internal view; J: dorsal view; K: anterior tooth and adjacent socket, $\times 130$; L: posterior tooth and crenulate groove, $\times 130$; M: central muscle scars, $\times 320$. SMF Xe 21542. - All magnifications are $\times 43$ unless otherwise stated. 
step-like in dorsal view; with a wide round socket opened posteriorly towards the crenulate median groove. PT large, stout, sub-rounded and smooth. Hinge elements on L complementary. A hinge ear is developed above the AS.

Central MS consisting in four adductor scars arranged in a row, the two lowermost of which drop shaped and intimately situated. The upper medial scar boomerang-shaped, with the anterior limb sloped ventrally. Uppermost scar is large and oval. Frontal scar large and U- or V-shaped.

Remarks: This species is very similar to $A$. sol JeLLINEK \& SWANSON (2003) from which it differs because of larger dimensions. The ecology of the two forms are also very different, $A$. sol is living in shallower waters. Because only three adult valves were recovered (even though considered living = stained with Rose Bengal) this species is left under open nomenclature.

\section{Fallacihowella sp. B}

(Figs. 32A-Q)

Material: 24 adult and 53 juvenile valves. - SMF Xe 21545-21549.

Distribution: Holocene of the South Tasman Rise. Common in samples BX147 (2177 m), BX156 (3208 m), BX161 $(3685 \mathrm{~m})$ and rare in sample BX165 $(4067 \mathrm{~m})$.

Dimensions: Female L 1.02-1.05/0.65-0.67, R 0.951.02/0.57-0.65; male L 1.07-1.10/0.60-0.65, R 1.07-1.10/ $0.57-0.60$.

Description: Valves sub-trapezoidal to sub-rectangular in shape. Greatest length at mid-height or slightly below. Greatest height at anterior cardinal angle. Anterior margin wide and evenly rounded. Posterior margin asymmetrically rounded, with an obtuse angle at the posterior cardinal angle. Dorsal margin straight, with an incurvation posterior to the anterior cardinal angle. Ventral margin slightly concave at mid-length. In dorsal view, greatest width posteriorly.

All specimens present more or less pronounced plications in the posterior area. The secondary ornamentation on adults is only partially preserved and reduced to short spines or stout tubercles covering the entire carapace, except on the marginal areas were star-tipped spines may be still preserved. The spines are both in conjunctive and disjunctive positions on the muri of sub-oval fossae. In the antero-ventral area they are organised into 3-4 rows of fossae and tubercles, arranged parallel to the outer margin. On the posterior half, some cubercles occur in loose groupings which give a sense of 'plications'. These are also evident in juveniles, especially in the L. On the plications, tubercles are usually larger and situated very close to each other. On the remaining muri, tubercles are scattered. Intramural, normal pores are rare and sieve-type. MS node lacks fossae with the smooth surface incised by 4-5 narrow slots and divided in two by $4-6$ stout tubercles, often connected at the base. Sexual dimorphism well pronounced.

Internally, ventral margin concave at mid-height. In the oral region of the $\mathrm{R}$, an additional closing mechanisms is present oral region with a horizontal row of 3-4 wedge-shaped protuberances, sometimes fused, developed on the flange close to the line of concrescence. A small triangular to subrectangular depression located on the flange mid-posteriorly, extending inwards from the selvage, may represent another additional closing mechanism but no complementary structure was observed on the R. Fused zone broad, with moderately wide vestibulum antero-ventrally and very narrow vestibulum postero-ventrally. Marginal pore-canals simple and straight, approx. 30 anteriorly and 18 posteriorly. Hinge holamphidont. In the R, AT large and stepped in dorsal view, with the proximal part wedge-shaped. Adjacent wide round socket opens posteriorly towards the smooth median groove. PT large, stout, sub-rounded and smooth. Hinge elements in L complementary. A hinge ear is developed above the AS which carries a peculiar knob on the distal part with two small spines.

Central MS consisting of four adductor scars arranged in a row. The two lowermost drop-shaped and very close to each other, almost fused. The uppermost medial boomerangshaped, with the anterior limb bent downwards. The uppermost scar is large and bean shaped. Frontal scar large and Uor V-shaped. Fulcral point pronounced.

Remarks: This species differs from $F$ sol JELLINEK \& SWANSON (2003) because it is larger and has a smooth median bar. It occurs in almost all of the samples together with $F$. caligo. In comparison with $F$ caligo, $F \mathrm{sp}$. B lacks of the wavy dorsal profile, has a straight or slightly concave ventral margin in the $\mathrm{R}$ and its greatest length is slightly below mid-height. The presence of the weak plication made it possible to differentiate the juveniles of the two species. Whereas the differences in ornamentation could represent a morphological variation of $F$. caligo, the differences in shape, dimensions and proportions allow to separate the two species. Only recovery of better preserved specimens with soft parts intact will prove/disprove that relationship.

\section{Genus Pseudobosquetina GueRNeT \& MOULl.ADE 1994} 1880.

Type species: Cytheropteron mucronalatum BRADY

Remarks: Guernet \& Mouliade (1994: 263) erected the genus Pseudobosquetina to accommodate Miocene-Pliocene specimens from the Central Atlantic. The associated text however, lacks any reference to the key characters indicated by Purr \& Hulings (1976) for the Brady's specimens GufrNET \& MOULLADE chose as types. It is also significant that in the 1994 publication only two micrographs of a single female L were provided to support their descriptive text. The Miocene specimen they figured is slightly smaller than BRADY's specimens and has a better developed alar process which overlaps the ventral margin. The alar process rises directly from the anterior margin and the slope between the posterior edge of the ala and the posterior margin carries a short, blade-like ridge which is not visible in the micrographs provided by Puri \& Hulings. Guernet \& Moullade have chosen the name Pseudobosquetina to indicate the affinities of the genus with Bosquetina KEJI 1957, as had already been noriced by other authors. Bosquetina has subdivided adductor scars and a different hinge-pattern which lacks the broad accommodation groove in the $\mathrm{L}$ and has a crenulate median element. Those authors, in a brief discussion, also compared their genus with 

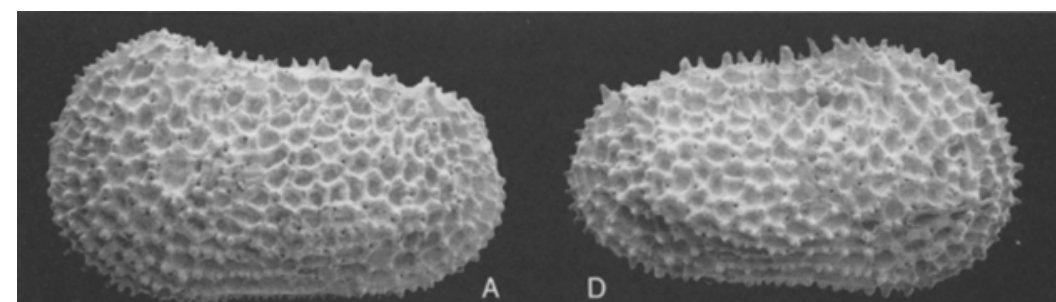

D
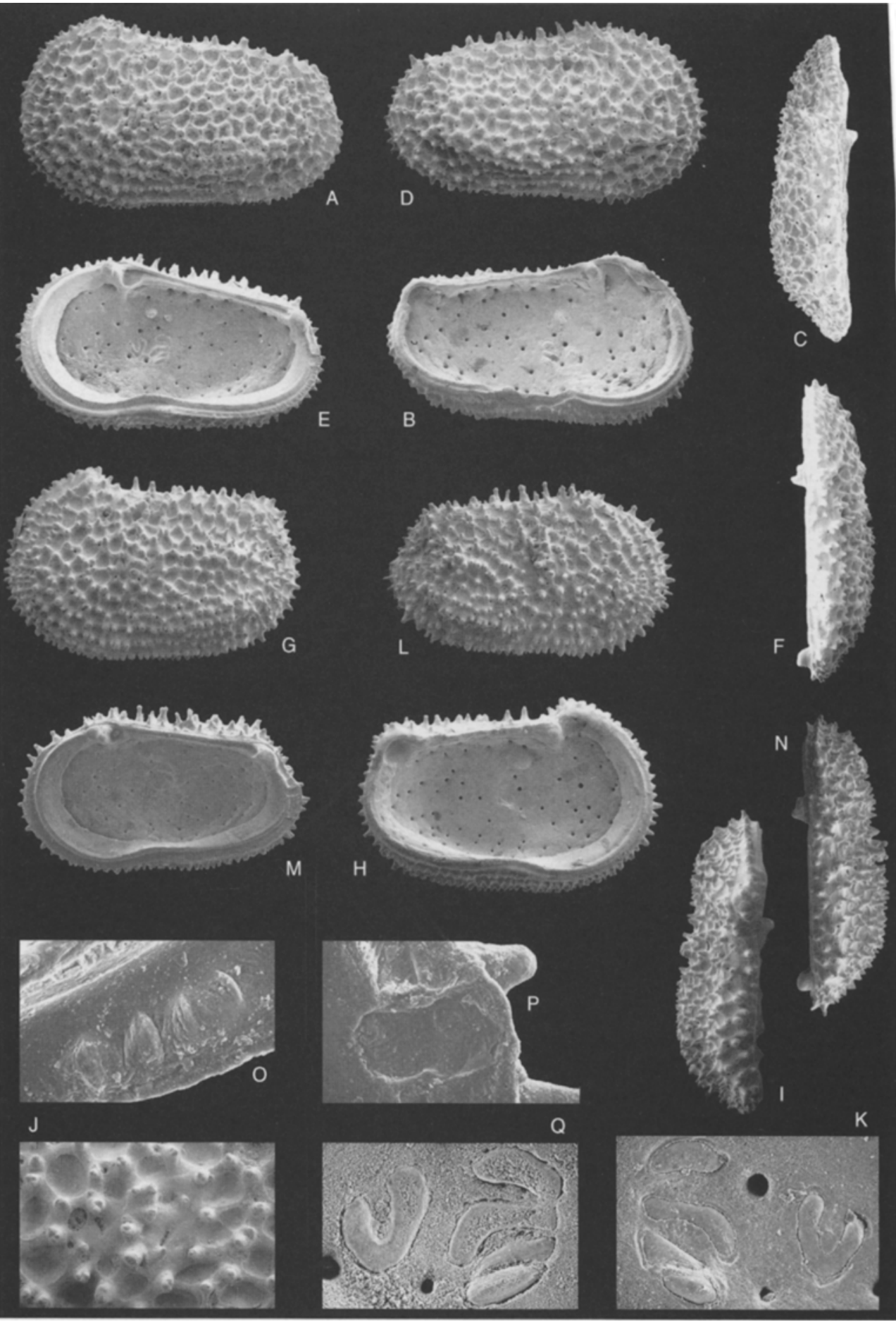

Fig. 32 Fallacibowella sp. B

Recent, sample BX161, South Tasman Rise, off south coast Tasmania, Australia; S46 33.18', E149 $04.96^{\prime}$, 3685 m. - male L (1.10/0.65); A: external view; B: internal view; C: dorsal view. SMF Xe 21545. - male R (1.07/0.57); D: external view; E: internal view; F: dorsal view. SMF Xe 21545.

female L (1.02/0.65); G: external view; H: internal view; I: dorsal view; J: detail of the muscle scar area in external view with tubercles and slots, $\times 118$; K: central muscle scars, $\times 253$. SMF Xe 21545. - female R (0.97/0.57);

L: external view; M: internal view; $\mathrm{N}$ : dorsal view; $\mathrm{O}$ : additional closing mechanism on the ventral edge, $\times 505$; P: additional closing mechanism on the posterior edge, $\times 505$; Q: central muscle scars, $\times 240$. SMF Xe 21545 . All magnifications are $\times 43$ unless otherwise stated. 
Brachycythere ALEXANDER 1933, Pterygocythereis Blake 1933, Pterygocythere HILl 1955, Bosquetina KEIJ 1957, Ruggieria KEI 1975 and Keijella RugGieri 1967. In fact, a great deal of confusion has arisen about the generic assignment of species referred to Cytheropteron mucronalatum BRADY (1880). As already indicated by GueRNET \& MOULLADE, it is probable that more than one species exist and that Pacific and Atlantic forms can be differentiated. Unfortunately, the concept of the species Cytheropteron mucronalatum to which most authors refer is unclear. Additionally, the unclear diagnoses of Brachycythere AleXander (1933) and Pterygocythere Hicl (1955) may also account for the fact that the 'mucronalatum' species were often referred to them (Tab. 8).

Brachycythere was erected to accommodate Cretaceous specimens from Texas, with Cythere sphenoides Reuss (1854) from the Upper Cretaceous of the Austrian Alps as type species. Pterygocythere was erected for Brachycythere species with a strong alar process with Cypridina alata BOSQUET (1847) from the Upper Cretaceous of the south-eastern Netherlands as type species. The two genera share similar hinges and MS and, as stated by Hill (1955: 807), "the new genus Pterygocythere includes the strongly winged forms having Brachycythere hingement." That is, for the R, a smooth anterior stepped tooth, an adjacent socket opening into a smooth groove and an elongate and coarsely crenulate posterior element; in the $\mathrm{L}$, elements are complementary with an accommodation groove above the median element. Some forms may have a crenulate AT as well. For the latter, with Brachycythere affinities, MANDELSTAM (1958a) erected the genus Digmocythere (type species Brachycythere russelli Howe \& LAW 1936). I have examined paratypoid material of Brachycythere sphenoides (Reuss) from the Cretaceous of Texas [catalogue no. SMF Xe 980, provided by DR. T. Jellinek, Senckenberg Museum, Frankfurt am Main] and made the comparative observations listed below (Tab. 8).

Pterygocythere seems as the genus closest to Pseudobosqueti$n a$ but has a much more developed alar process and a wedgeshaped outline.

Pseudobosquetina has some affinities with Carinovalva SISSINGH (1973) [type species Incongruellina (Lixouria) keiji SISSINGH 1972] which has a more symmetric outline, a more pronounced ventro-lateral keel and lacks the accommodation groove in the L. Incongruellina RUGGIERI (1958) (type species I. semispinescens RUGGIERI 1958) has well developed vestibula and a crenulate median hinge element.

Significantly, all Recent specimens of this genus have been recovered from the deep ocean. Ayress et al. (1997), comparing faunal distributions in the Pacific (Coral Sea, Chatham
Rise, Kerguelen Plateau, south-east Australian Continental Slope and Tasman Sea) postulated "Pseudobosquetina mucronalatum" had a broad depth range of 1489-3500 m.

Pseudobosquetina mucronalata (BRADY 1880) (Figs. 33A-F, 34A-N)

* 1880 Cytheropteron mucronalatum. - BRADY: 140-141, pl. 33 figs. $8 \mathrm{a}-\mathrm{d}$.

non 1941 Cytheropteron mucronalatum. - TRESSLER: pl. 19 fig. 25.

? 1971 Bosquetina mucronalatum. - PURI: 168.

? 1974 Brachycythere mucronalatum. - BENSON: 1038.

? 1975 Bosquetina fenestratum. - PEYPOUQUET: 889.

? 1975 b Pterygocythere?- Benson: 27, Fig. 9 (4).

1976 Cytheropteron mucronalatum. - PURI \& HULINGs: 307, pl. 22 figs. 14-18.

? 1979 Bosquetina fenestratum. - Ducasse \& PeYpouQUET: pl. 4 fig. 2.

non 1983 Brachycythere mucronalatum. - BENSON et al.: 435 ff, tabs. 2, 3, pl. 1 figs. 6-7.

non 1987 Bosquetina mucronalatum. - WHATLEY \& COLES: 35 ff., figs. 1, 2B, 3-4, 6, 8-12A, tab. 9, pl. 5 figs. 1-2.

non 1988 Brachycythere mucronalatum. - STEINECK et al.: 607, pl. 1 fig. 9, Fig. 4.

? 1988 Pterygocythere mucronalatum. - AYREss: 201, pl. 4 fig. 23.

non 1990 Bosquetina mucronalatum. - Dingle \& LORD: 215 ff, Fig. 2.9.

? 1990 Pterygocythere mucronalata. - VAN HARTEN: 325, tab. 2.

non 1993 Pterygocythere mucronalatum. - CORRÈGE: 265.

non 1994 Pseudobosquetina mucronalatum. - GUERNET \& Moullade: 263, pl. 2 figs. 1-2, 4.

non 1996 Pterygocythere mucronalata. - CRONIN: $41 \mathrm{ff}$, pl. 1 fig. 5.

? 1997 Pterygocythere mucronalatum. - AYRESS et al.: 292-293, Fig. 3.

non 1998 Pseudobosquetina mucronalatum. - GUERNET: 525 ff, pl. 3 fig. 4 .

non 2000 Bosquetina mucronalatum. - DiDIÉ \& BAUCH: 110 , tab. 2, pl. 4 figs. 23-24.

Material: 14 adults and 41 juveniles valves ( 1 juv. C). SMF Xe 21551-21552.

Table 8: Comparison between the main characters of the genus Pseudobosquetina and the equivalent characters in the four genera to which the species mucronalatum is more often referred to in the literature.

\begin{tabular}{lllll}
\hline Genus & anterior tooth $\mathbf{R}$ & adductor scars & frontal scars & accommodation groove $\mathbf{L}$ \\
\hline Brachycythere & smooth and stepped & subdivided & subdivided & present \\
Digmocythere & crenulate and stepped & subdivided & subdivided & present \\
Pterygocythere & smooth and stepped & not divided & V-shaped & present \\
Bosquetina & elongate and cusped & not divided & subdivided & absent \\
Pseudobosquetina & crenulate to smooth, stepped & not divided & present & \\
\hline
\end{tabular}




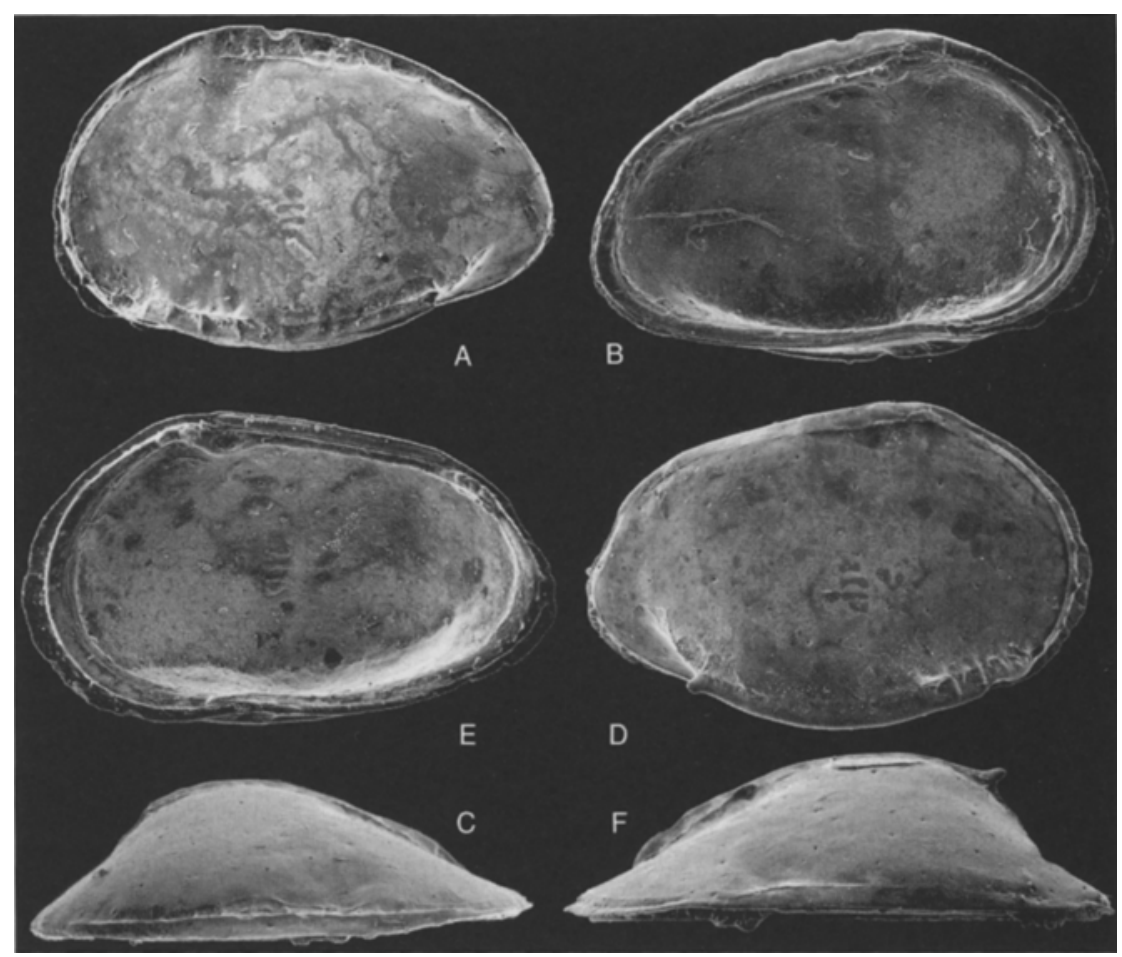

Fig. 33: Pseudobosquetina mucronalata (BRADY 1880).

Recent from the S Pacific, Challenger station 296 (S38 $06.00^{\prime}$, W88 $02.00^{\prime}$ ), $3285 \mathrm{~m}$. - A-C: Hololectotype (NHM no. BM 80.38.157), designated by Puri \& HuLINGs (1976: 307, pl. 22 figs 15, 17). L (1.31/0.87); A: external view, negative number 071101; B: internal view, negative number 071148; C: dorsal view, negative number 071182, $\times 43$. - D-F: Paralectotype (NHM no. BM 80.38.157), illustrated by Puri \& Hulings (1976: 307, pl. 22 figs 14, 16, 17). R (1.32/ 0.81 ); D: external view, negative number 071101; E: internal view, negative number 071150; F: dorsal view, negative number $071183, \times 43$. [pictures were taken and provided by Dr. J. WHITTAKER, Department of Palaeontology, The Natural History Museum, London].

Dimensions: Female L 1.30-1.40/0.87-0.90, R 1.35 1.37/0.80-0.85; male L 1.42-1.47/0.87-0.90, R 1.45-1.47/ $0.85-0.87$

Distribution: Holocene of the South Tasman Rise. Common in sample BX138 (3022 m). Holocene of the South Pacific (Brady 1880).

Remarks: $P$. mucronalata was described by BRADY (1880: 140-141, pl. 33 figs. 8a-d) who recorded it in one Atlantic and six Pacific stations. It is probable that BraDY included a number of species in his 'mucronalatum' and unfortunately it is unclear which station the figured specimen came from. The specimens illustrated subsequently by PURI \& Hulings (1967: 307, pl. 22 figs. 14-18) were from the Chile Rise in the Eastern Pacific $(3285 \mathrm{~m})$ and, as the authors stated, differ from the original description given by BRADY. At the NHM (London), besides the original slide no. BM 80.38.157 containing the hololectotype, a slide labelled with the same numbers contains three specimens: an adult $\mathrm{L}$ and a juvenile $\mathrm{L}$ of $P$. mucronalata, and a juvenile $\mathrm{R}$ belonging to a different genus. The slide of the paralectotypes contains 2 adult Rs and 1 juv $\mathrm{L}$ of $P$. mucronalata whereas the slide of the topotype, labelled no. BM 1974.380, contains a $\mathrm{L}$ of Cytheropteron.

SteINeCK et al. (1988: 608) assumed that PurI \& HutINGS had chosen a sub-adult specimen for their illustration. In the type specimens no changes of the general shape were observed through ontogeny and a less arched dorsal margin is rypical for males and for $\mathrm{R}$ in particular. The specimens illustrated by STEINECK et al. (1988) from the Upper Miocene of the central equatorial Pacific have smaller dimensions, more pronounced ridges on the dorsal sulcus which are parallel to the ala and obvious posterior spines.

The A-1 R illustrated by AYress (1988) has a sinuous alar process which is much more inflated than in $P$. mucronalata. Unfortunately, both illustrations and the description are inadequate to give a clear indication of the species he refers to as Pterygocythere mucronalatum.

The specimens illustrated from the Atlantic (TrRESSLER 1941, Whatley \& Coles 1987, Steineck et al. 1988, Dingle \& Lord 1990, CRonin 1996) have an alar process which begins at anterior margin and an ornamentation on the alar process and the dorsal margin [see in particular the specimens illustrated in Whatley \& Coles (1987) and Dingle \& LoRD (1990) displaying a slight reticulation at the posterior end of the ala]; furthermore strong spines along the lower half of posterior and/or anterior margin. The latter does not occur in the specimen illustrated by CRONIN (1996).

No opinion can be expressed about the specimens found in the Pacific Ocean by Corrège (1993) and Ayress et al. (1997) because neither descriptions nor illustrations were provided. Because of the wide geographical distribution and the 


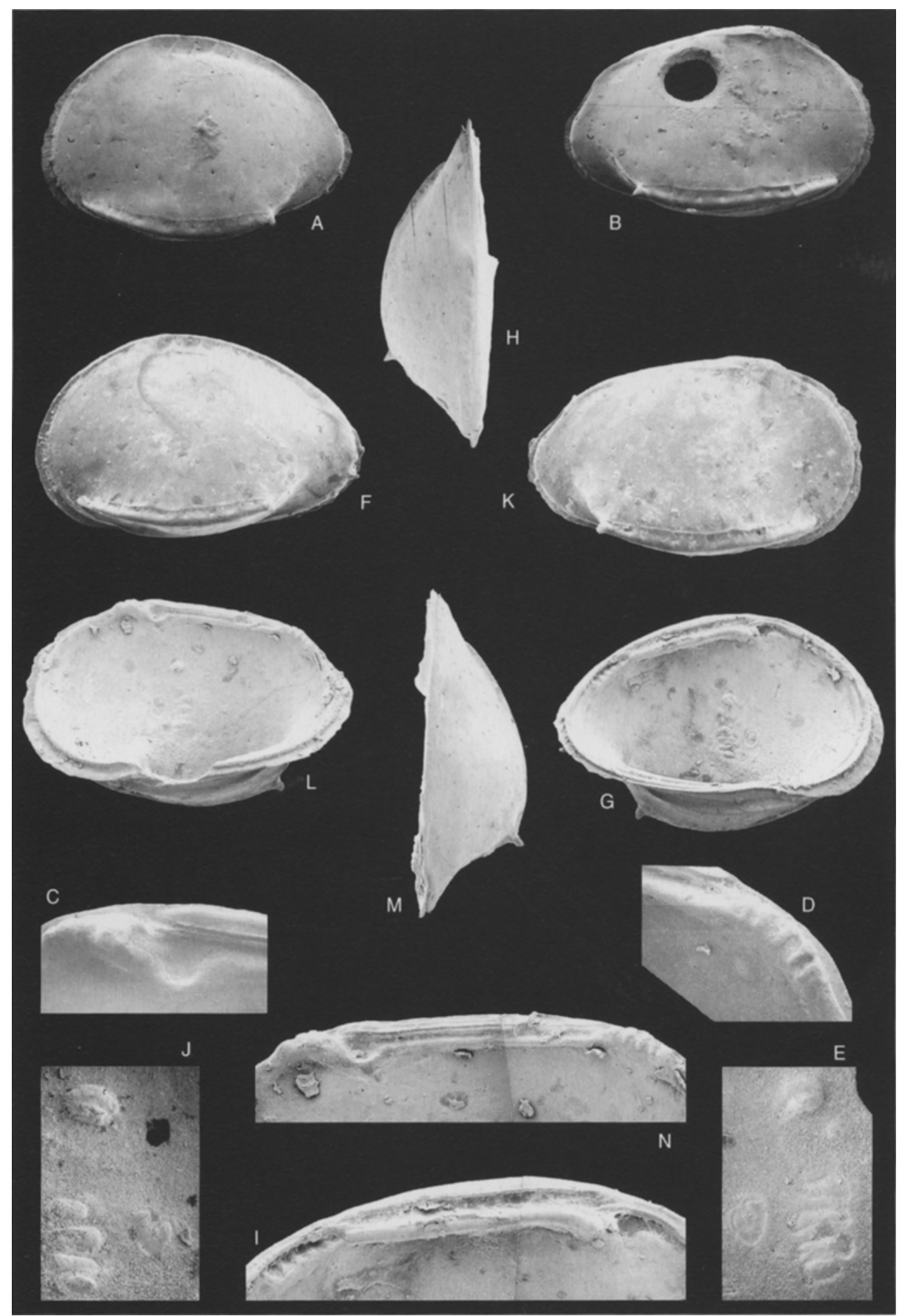

Fig. 34: Pseudobosquetina mucronalata (BRADY 1880).

Recent, sample BX138, South Tasman Rise, off south coast Tasmania, Australia; S49 $13.06^{\prime}$, E $151^{\circ} 05.77^{\prime}$, 3022 m. - female L (1.30/0.87); A: external view. SMF Xe 21551. - female R (1.35/0.80); B: external view; C: anterior hinge element, $\times 96$; D: posterior hinge element, $\times 96$; E: central muscle scars and fulcral point, $\times 100$. SMF Xe 21551. - male L (1.42/0.87); F: external view; G: internal view; H: dorsal view; I: detail of the hinge, $\times 68$; J: central muscle scars and fulcral point, $\times 98$. SMF Xe 21550. - male R (1.45/0.85); K: external view; L: internal view; M: dorsal view; $N$ : detail of the hinge, $\times 68$. SMF Xe 21551. - All magnifications are $\times 35$ unless otherwise stated. 
wide depth range of their material it is likely that there were a number of closely-related species included under $P$. mucronalata. Moreover, the distribution of $P$. mucronalata is most liked limited to the S Pacific Ocean.

\section{Genus Philoneptunus Whatley, Millson \& Ayress 1992}

Type species: Philoneptunus gravizea (HorNibrook 1952).

Remarks: This genus contains 12 species from the south-west Pacific (Late Cretaceous-Recent) and 7 onshore species from the Tertiary sediments of New Zealand (Lower Eocene-Lower Miocene Whatley, Millson \& Ayress 1992). The species found in Recent sediments are: $P$. gravizea, $P$. planaltus (Swanson 1979), P. paeminosus WhatLey, Millson \& Ayress (1992), P. provocator Jellinek \& SWANSON (2003), $P$. neesi Jellinek \& SWanson (2003), P. gigas Jellinek \& SWANSON (2003) and the new species described herein.

P. gravizea was originally described from depth of $131 \mathrm{~m}$, E of North Cape (North Island, New Zealand). P. planaltus was recovered from the Otago Shelf, east coast of South Island (New Zealand) at depths ranging from $182 \mathrm{~m}$ to $750 \mathrm{~m}$ $P$. paeminosus was considered to be a fossil species (Middle Eocene-Middle Miocene) by WhaTLey et al. (1992) but was recovered live on the Campbell Plateau around the depth of $600 \mathrm{~m}$ by JeLLiNeK \& Swanson who also referred to this species, Philoneputnus sp. recovered by SwANSON (1993) from dredge samples taken along the west coast of South Island (New Zealand) at depths of between 531-769 m. P. provocator has been recovered at approx. $1000 \mathrm{~m}$ on the Challenger Plateau, whereas $P$. gigas was found at $1547 \mathrm{~m}$ on the Challenger Plateau and between $1362 \mathrm{~m}$ and $1681 \mathrm{~m}$ on the Campbell Plateau. P. neesi was found at around $1000 \mathrm{~m}$ on the Challenger Plateau.

\section{Philoneptunus tricolonos $\mathrm{n} . \mathrm{sp}$. (Figs. 35A-L, 36A-C)}

Derivation of name: From the Greek adjective trikolonos = three-hilled; referring to the three ribs on the posterior surface.

Holotype: Female R (1.22/0.65), Figs. 35D-I. - SMF Xe 21553.

Paratypes: 154 adult and juvenile valves. - SMF Xe 21554-21557.

Dimensions (of paratypes): Female L 1.17-1.22/0.600.65 , R 1.15-1.22/0.57-0.65; male L 1.27-1.32/0.70-0.72, R 1.22-1.30/0.67-0.70.

Type locality: RV SONNE cruise no. SO 136, site 28 station 140; box-corer sample from the South Tasman Rise, off S Tasmania, Australia, at $1636 \mathrm{~m}$ water depth; $\mathrm{S} 49^{\circ} 10.84^{\prime}, \mathrm{E} 150^{\circ} 10.13^{\prime}$.

Distribution: Holocene of the South Tasman Rise. Very common in sample BX153 (1874 m). Common in samples BX140 (1636 m) and BX141 (1690 m).
Diagnosis: A large species characterised by an arched dorsal rib, a well developed horizontal ventral rib and a weak median rib which is not connected to the SCT. The surface is covered by fossae of varying sizes, with smooth solae.

Description: Shape sub-trapezoidal. Greatest length below mid-height. Greatest height at anterior cardinal angle. Anterior margin evenly rounded in $\mathrm{R}$ and truncate in L. Posterior end broadly acuminate. Dorsal margin sloped posteriorly, partially covered by the postero-dorsal rib and the antero-dorsal loop. Ventral margin straight in males, slightly convex in the oral region in females. In dorsal view greatest width at SCT. Ventrally, small spines are located: $10-13$ on the anterior margin and three on the posterior. External surface covered by ribs and fossae. The postero-dorsal rib is arched and anteriorly grades into the SCT. The weak postero-median rib is short and not connected with the SCT. The posteroventral rib with short and stout spine on posterior extremity runs parallel to the ventral margin. In dorsal view these three ribs are truncated posteriorly. The irregular sub-rounded fossae are arranged randomly, the smallest being located posteriorly and antero-dorsally. The sola are smooth and occasionally bear simple pores, peripherally. Simple pores are also located on the muri. More developed sub-vertical muri connect the dorsal loop with the ventral rib.

Internally: vestibulum not developed, wide duplicature, selvage strong. A smooth flange extends around the anterior and posterior, more developed in $\mathrm{R}$, whereas in the $\mathrm{L}$ present only in the ventral half. Marginal pore-canals simple, straight and thin, occasionally with medial swelling, 22-28 anteriorly and $10-13$ posteriorly.

Hinge paramphidont. $\mathrm{R}$ with dorsally faintly lobate terminal teeth (4-5 lobe AT, 3 lobes PT). Smooth median groove connected to the small round socket adjacent to the AT. Hinge elements of $\mathrm{L}$ complementary.

Central MS consisting of 4 adductor scars arranged in a sub-vertical row. The uppermost separated from the remainders and bean-shaped, the uppermost medial elongate, the lowermost medial beak-shaped with the point anteriorly, the lowermost oval. Frontal scar large and hook-shaped. Sexual dimorphism well developed with males much longer than females. The ornamentation is weaker in the younger instars, especially anteriorly. The dorsal and ventral ribs are always present, whereas the median rib, the SCT and the dorsal loop are usually not developed (Figs. 36A-C).

Remarks: P. tricolonos n. sp. can be distinguished from other species of $P$. from the Recent of the SW Pacific for the following reasons:

P. gravizea (HoRNiBROOK 1952) is smaller and proportionally more slender. It exhibits a more pronounced median rib, larger muri between the fossae and has a suppressed eye tubercle.

P. paragravizea Whatley, Millson \& Ayress (1992) is slightly larger and heavier. It displays a reticulate ornamentation over the external carapace, with conical pores inside the solae of the central area and fossae grading into punctae towards the ends.

P. paeminosus Whatley, Millson \& Ayress (1992) is smaller and more criangular in shape. It has less developed and shallower fossae. 


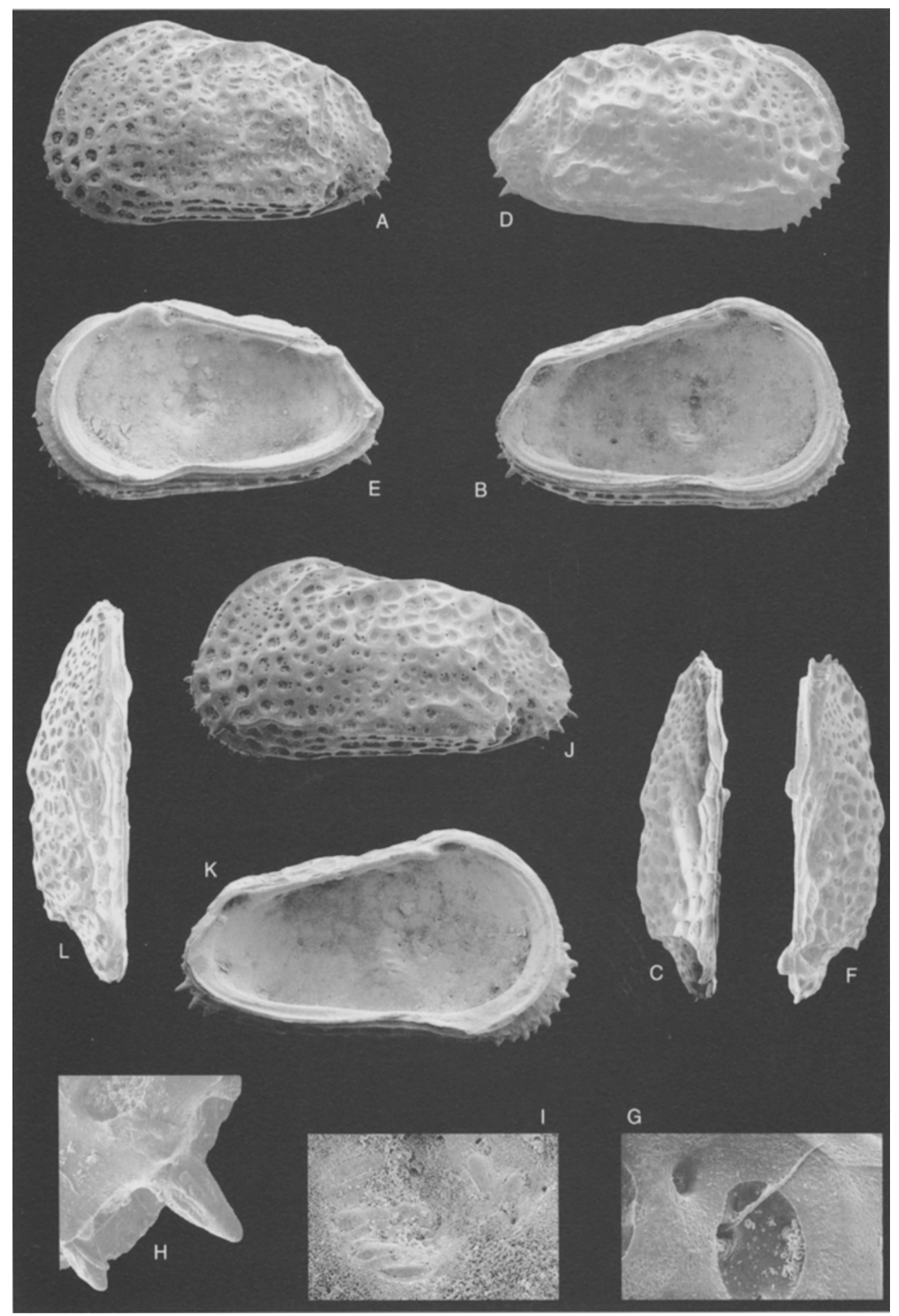

Fig. 35: Philoneptunus tricolonos n. sp.

Recent, sample BX140; South Tasman Rise, off south coast Tasmania, Australia; $\$ 49^{\circ} 10.84^{\prime}$, E $150^{\circ} 10.13^{\prime}$, $1636 \mathrm{~m}$. - female L (1.22/0.65), paratype; A: external view; B: internal view; C: dorsal view. SMF Xe 21554. female R (1.22/0.65), holotype; D: external view; E: internal view; F: dorsal view; G: detail of the ornamentation, sieve-type normal pore and open normal pore with seta, $\times 408 ; \mathrm{H}$ : detail of the marginal spines on the posterior margin in internal view, $\times 296$; I: central muscle muscle scars, $\times 308$. SMF Xe 21553. - male L (1.32/ 0.72), paratype; J: external view; K: internal view; L: dorsal view. - SMF Xe 21554. - All magnifications are $\times 44$ unless otherwise stated. 

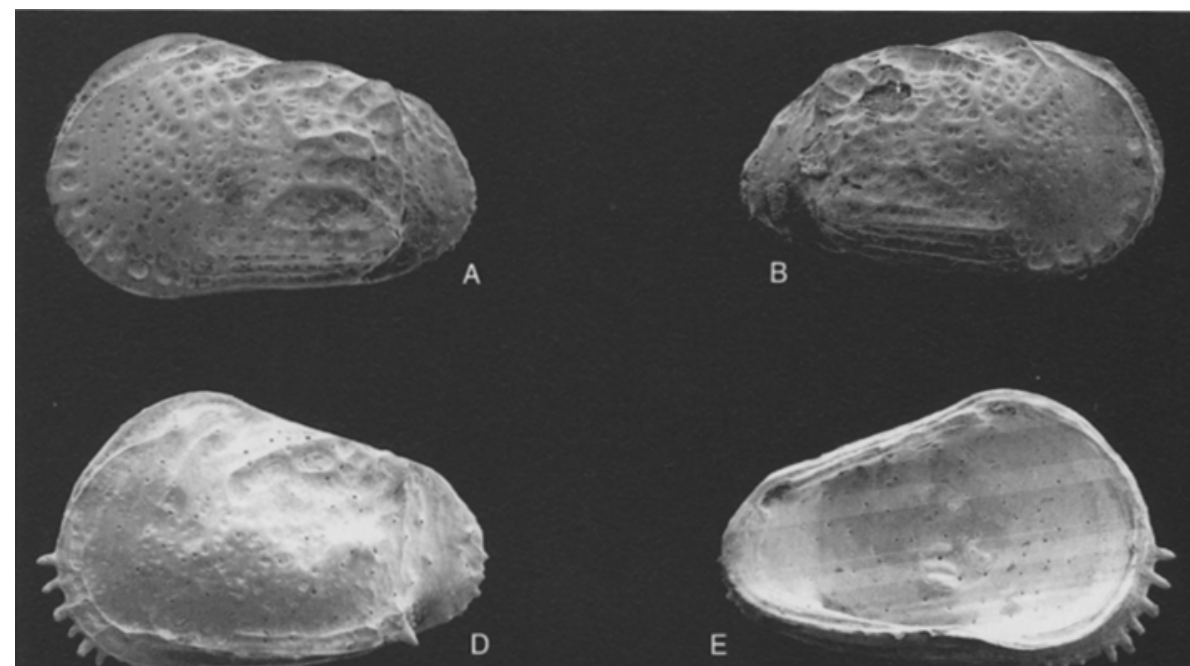

D
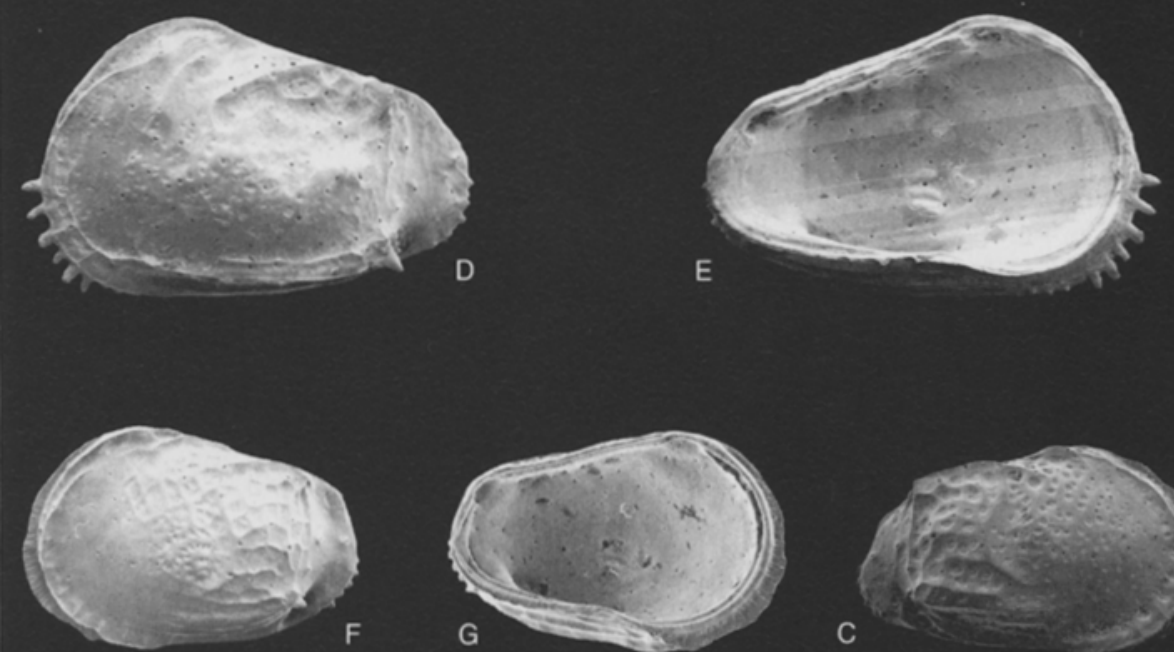

C
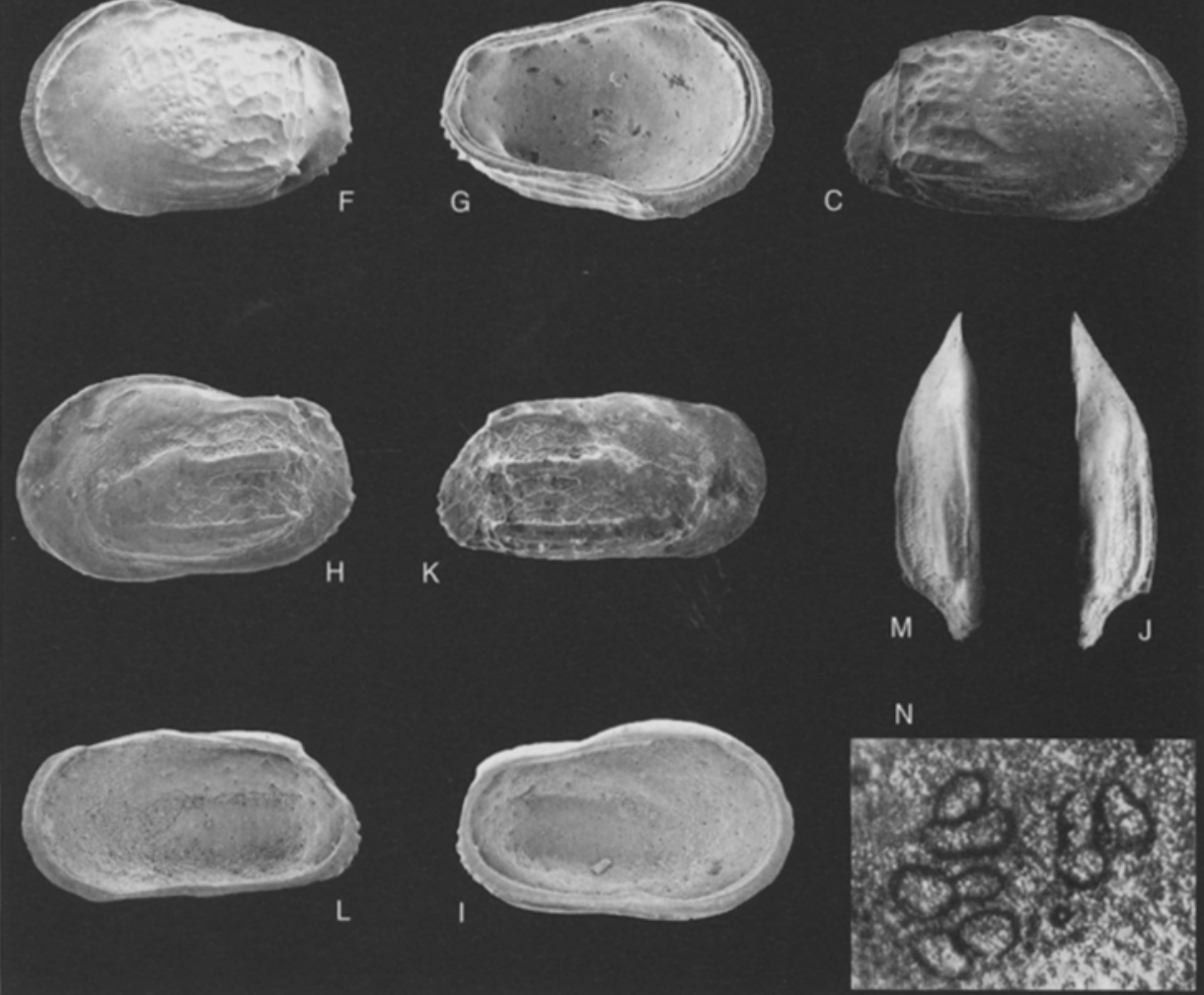

Fig. 36: A-C: Philoneptunus tricolonos n. sp.

Recent, sample BX 140; South Tasman Rise, off south coast Tasmania, Australia; S49 $10.84^{\prime}$, E $150^{\circ} 10.13^{\prime}$ 1636 m. - juv. A-1 L (1.07/0.67); A: external view. SMF Xe 21554. - juv. A-1 R (1.05/0.62); B: external view. SMF Xe 21554, - juv. A-3 R (0.87/0.52); C: external view. SMF Xe 21554

D-E: Philoneptunus paeminosus WHatLeY, MILLSON \& AXRESS 1992

Recent, sample BX153, South Tasman Rise, off south coast Tasmania, Australia; S47 $46.85^{\prime}$, E147 $55.13^{\prime}$, 1874 m. - female L (1.07/0.67); D: external view; E: internal view. SMF Xe 21558.

F-G: Philoneptunus sp.

Recent, sample BX161, South Tasman Rise, off south coast Tasmania, Australia; S46 $33.18^{\prime}$, E149 $04.96^{\prime}$, 3685 m. - juv. L (0.82/0.55); F: external view; G: internal view. SMF Xe 21559.

H-N: Phacorbabdotus sp.

Recent, sample BX116, Emerald Basin, off south coast South Island, New Zealand;

S55 $40.03^{\prime}, \mathrm{E} 159^{\circ} 25.00^{\prime}, 4462 \mathrm{~m}$. - female L (0.82/0.55); H: external view; I: internal view; J: dorsal view. SMF Xe 21560. - female R (0.82/0.47); K: external view; L: internal view; M: dorsal view; N: detail of the central muscle scars photographed in external view in transmitted light, $\times 85$. SMF Xe 21560. - All magnifications are $\times 43$ unless otherwise stated. 
P. gigas JELLINEK \& SWANSON (2003) is larger and carries a well defined reticulation posteriorly. It has a sub-rectangular outline and lacks the median ridge.

P. neesi JellineK $\&$ SWANSON (2003) has smooth posterior and anterior margins and a rectangular meshwork arranged in concentrical rows around the SCT.

P. provocator JELLINEK \& SWANSON (2003) is much smaller and more stout, with narrower muri and larger, shallower fossae.

Philoneptunus paeminosus WHATLEY, MiLlson \& AYREss 1992 (Figs. 36D-E)

* 1992 Philoneptunus paeminosus WhatLeY et al.: 49, pl. 2 figs. $7-14$

Material: Two adult and 15 juvenile valves. - SMF Xe 21558.

Dimensions: Female L 1.05-1.07/0.65-0.67.

Distribution: Holocene of the South Tasman Rise. Common in sample BX153 (1874 m).

Remarks: Apart from the smaller dimensions, P. paeminosus differs from $P$. tricolonos $\mathrm{n}$. $\mathrm{sp}$. in its weaker ornamentation, made of round and small solae, the less pronounced ribs, the more developed spines anteriorly and the presence of a well developed spine at the posterior edge of the ventral rib.

\section{Philoneptunus sp. \\ (Figs. 36F-G)}

Material: 13 juvenile valves. - SMF Xe 21559.

Dimensions: juvenile L 0.82/0.55; R 0.82/0.55 (larger moults).

Distribution: Holocene of the South Tasman Rise. Rare in sample BX161 (3658 m).

Remarks: These juvenile valves belong to a species of Philoneptunus with a posterior reticulation, similar to what has been described for $P$ neesi JELlinek \& SWANSON or $P$. gigas JeLLINEK \& SWANSON. It should be noticed that these juveniles represent the deepest record of the genus Philoneptunus (see also initial remarks).

\section{Subfamily Buntoniinae Apostolescu 1961}

\section{Genus Phacorhabdotus Howe \& LAurencich 1958}

Type species: Phacorhabdotus texanus Howe \& LAURENCICH 1958.

Remarks: This genus was erected on Cretaceous specimens from Texas and Arkansas. VAN DEN BOLD (1965) suggested that the genus Ambocythere evolved from a lineage of species within the genus Phacorhabdotus. Following COLEs et al. (1990), P. has a stratigraphical range of Lower PalaeoceneLower Miocene in the $\mathrm{N}$ Atlantic Ocean and Lower Oligocene-Quaternary in the Pacific Ocean.

\section{Phacorhabdotus sp.}

(Figs. 36H-N)

Material: 8 adult and 8 juvenile valves. - SMF Xe 21560-21561.

Dimensions: Female L $0.80-0.82 / 0.52-0.55, \mathrm{R} 0.77-$ $0.82 / 0.45-0.47$; male L $0.82-0.85 / 0.50-0.55$, R $0.80-0.82 /$ $0.42-0.45$.

Distribution: Holocene of the Emerald Basin. Rare in samples BX110 (3907 m) and BX116 (4462 m).

Description: Valves sub-rectangular in shape. Maximum length below mid-height, maximum height at anterior cardinal angle. Maximum width within posterior half. Anterior margin evenly rounded in L especially, bearing a thin and fragile flange. Posterior margin asymmetrically rounded, with the ventral half denticulate. Dorsal margin in L sinuous, horizontal in the posterior half and convex in the anterior; in $\mathrm{R}$ sinuosity less pronounced, in male slightly convex. Ventral margin slightly concave in the oral region. Ornament consisting of three parallel, longitudinal. smooth ridges and a faint reticulation. The ridges are low, wide anteriorly and abruptly truncate posteriorly. The dorsal-most shortest and gently arched; the median horizontal and with a simple pore at its postero-ventral margin; the ventral ridge is the longest. Ridges merge behind the zone of the adductor muscle attachment. Reticulation consists of polygonal meshes with thin and low muri, that become weaker anteriorly. The solae are covered by round pits (11-18 in each mesh) and the muri bear pore conuli. The pore conuli are concentrated in the posterior where the reticulation is more pronounced.

Internally: anterior margin evenly rounded, posterior asymmetrically rounded. Ventral margin almost straight in $\mathrm{R}$, stightly arched in the mouth area in L. Vestibulum not developed. Radial pore-canals short and sinuous, 9 anteriorly and 8 posteriorly, emerging through the marginal denticles. On the antero-ventral half, five false pore-canals alternate to the rrue ones. Hinge badly preserved in all specimens. $R$ anterior tooth low, slightly curved, median element smooth, posterior element elongate and smooth. Elements in the L complementary. In the $\mathrm{R}$, above the hinge line a smooth groove is located most likely to accommodate the dorsal-most part of the $\mathrm{L}$, which is swollen and bent down.

MS were visible on one single valve and consist of a vertical row of four adductors and two frontal scars. The lower two adductors are divided and sub-rounded, the second uppermost elongate and the uppermost oval. These two are very close to each other, almost fused. The posterior frontal scar is vertically elongated and the adjacent anterior is heartshaped.

Males slightly more elongate and more slender than females. In juveniles the reticulation is absent and only the ventral ridge is developed.

Remarks: The poor preservation of the specimens prevented a specific determination. However, Phacorhabdotus sp. is similar to Phacorhabdotus sp. AYress (1988: 808-809, pl. 30 figs. 22-24) from the Pleistocene of the SW Pacific Ocean. AxREss' species is slightly larger, the ridges are slightly rounded and the ornamentation in the anterior region is more pronounced. Additionally, the meshwork lacks round 
pits but have secondary fossae. $P$ sp. is also close to $P$. posteropunctissima Coles \& WhaTley (1989) from the Middle Eocene-Lower Miocene of the North Atlantic, the latter, however, displays a stronger ornamentation in the posterior half and is larger. The presence of $P$. sp. in Recent sediments from the Emerald Basin confirms the occurrence of the genus in the Quaternary of the Pacific Ocean.

\section{Genus Ambocythere VAN DEN BOLD 1958}

Type species: Ambocythere keiji VAN DEN BOLD 1958.

Remarks: This genus was erecred to accommodate Eocene to Recent specimens from the Caribbean Region. The distribution was later extended to the Central America Region and the North Atlantic Ocean by van DEN Bold (1965) who also included in the genus Cythere stolonifera BRADY (1880), from the South Atlantic (Cape of Good Hope). Furthermore, scattered findings were recorded from the South Atlantic and among those, few species of Ambocythere were recorded from Recent sediments of the Atlantic Ocean at depth exceeding $2000 \mathrm{~m}$ (Tab. 9).

Records of Ambocythere in the Recent of the Pacific are not common and limited to shallow waters. MCKENZIE (1974) reported Ambocythere sp. aff. stolonifera (BRADY 1880) and another species related to $A$. bodjonegoroensis (KINGMA 1948). Those two species were recovered from different localities along the south-west coast of Australia between $50 \mathrm{~m}$ and $90 \mathrm{~m}$. Ambocythere sp. is also recorded in the waters around Japan at depths not exceeding $300 \mathrm{~m}$ by IKEYA \& CRONIN (1993).

Ambocythere sinuosa n. sp.

(Figs. 37A-O)

1990 Ambocythere sp. 3057. - DiNGLE et al.: 301-303, figs. $34 \mathrm{~A}, 35 \mathrm{~A}$.

Derivation of name: From the Latin adjective sinuosus = sinuous; referring to the sinuous shape of the median ridge.

Holotype: Female R (0.62/0.37), Figs. 37I-O. - SMF Xe 21562.
Paratypes: 15 adult and 4 juvenile valves. - SMF Xe 21563-21565.

Dimensions (of paratypes): Female L $0.60-0.65 / 0.35$ 0.37 , R 0.57-0.62/0.32-0.37; male L 0.67-0.72/ 0.35-0.37, R $0.65-0.67 / 0.32-0.35$.

Type locality: RV SONNE cruise no. SO 136, site 32, station 156; box-corer sample from the South Tasman Rise, off $\mathrm{S}$ Tasmania, Australia, at $3208 \mathrm{~m}$ water depth; $\mathrm{S} 47^{\circ} 00.09^{\prime}, \mathrm{E} 149^{\circ} 30.93^{\prime}$.

Distribution: Holocene of the South Tasman Rise. Very rare in sample BX156 (3208 m). Rare in samples BX147 (2177 m) and BX161 (3658 m).

Diagnosis: An Ambocythere species with a sinuous median ridge. Reticulate among the medial ridges, the ventral ridge and the marginal rim, and on the posterior.

Description: Valves sub-rectangular in shape. Greatest length below mid-height, greatest height at anterior cardinal angle. Anterior margin evenly rounded, posterior asymmetrically rounded. Dorsal margin straight, tapering to posterior just behind the anterior hinge element. The marginal rim is blade-shaped and extends from the dorsal margin, behind the anterior hinge element, along the anterior and the ventral margins where it tapers towards the ventral ridge. The posterior ventrally caudate margin with a small tubercle at midheight and a narrow flange with 4-6 small tubercles. Surface with three longitudinal ridges. The dorsal-most is short and deflected downwards posteriorly, in males this ridge almost connects with the median ridge but slops gently in females. Median ridge longer and sinuous; the ventral ridge is the longest and most prominent, slightly converging towards median ridge at extremities. Both the median and the ventral ridge with a small tubercle at posterior end. A faint median sulcus runs slightly obliquely between the dorsal and the median ridges. The secondary ornamentation consists of a faint reticulation, organised in polygonal meshes with sievetype pores in conjunctive positions on the thin muri. This rericulation extends along the posterior margin, between the ridges and between the ventral ridge and the marginal rim. The remainder of the surface is smooth with scattered sievetype pores (6-9) organised in a constant pattern. In dorsal view, greatest width at posterior third, corresponding with maximum extension of the ventral ridge.

Internally: posterior margin blunt, acuminate, ventral margin arched near oral region. Inner lamella widest antero-

Table 9: List of Ambocythere species recovered in the Recent of the Atlantic Ocean, exceeding 2000 $m$ of depth.

\begin{tabular}{llc}
\hline species & author & depth [m] \\
\hline ramosa VAN DEN BOLD 1965 & BENSON et al. 1983 & $2938-3210$ \\
cf. A. ramosa VAN DEN BOLD 1965 & WHATLEY \& COLES 1987 & 2445 \\
ramosa VAN DEN BOLD 1965 & MADDOKS \& STEINECK 1987 & 3506 \\
sp. 3057 & DINGLE et al. 1990 & 2070 \\
\hline
\end{tabular}




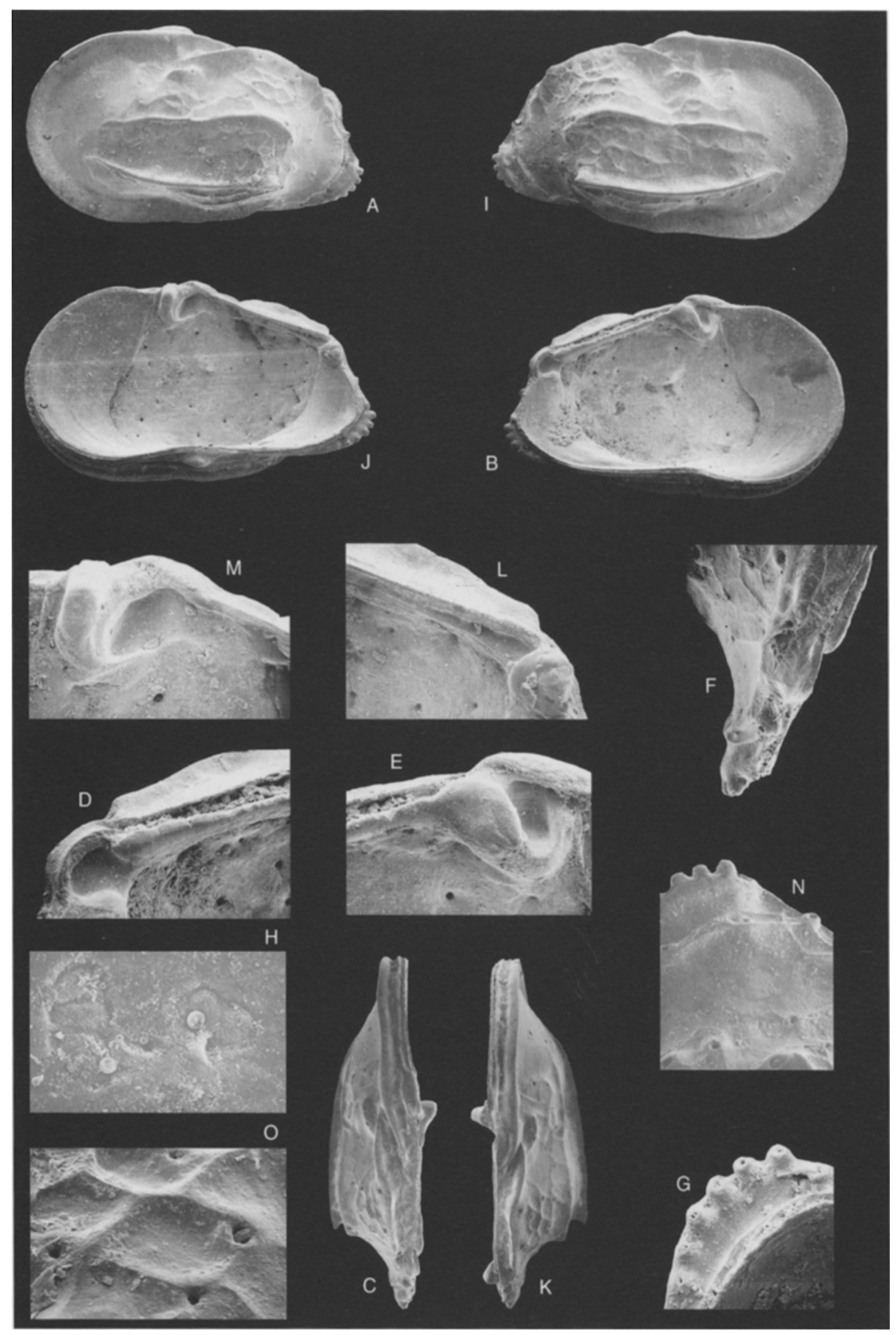

Fig. 37: Ambocythere sinuosa n. sp.

Recent, sample BX156, South Tasman Rise, off south coast Tasmania, Australia; $\$ 47^{\circ} 00.09^{\prime}$, E149 $30.93^{\prime}$, $3208 \mathrm{~m}$. - female L (0.60/0.35), paratype; A: external view; B: incernal view; C: dorsal view; D: posterior hinge element, $\times 230$; E: anterior hinge element, $\times 230$; F: dorsal view of the posterior margin showing the typical posterior tubercle and the lobation of the median bar , $\times 190$; G: internal view of the posterior flange with eroded hollow tubercles, $\times 293$; H: central muscle scars and mandibular scars, $\times 420$. SMF Xe 21563. - female R $(0.62 /$ 0.37 ), holotype; I: external view; J: internal view; K: dorsal view; L: posterior hinge element, $\times 230$; M: anterior hinge element, $\times 230$; $N$ : detail of the posterior flange in external view, $\times 220$; O: rhomboidal meshes of the secondary ornamentation, $\times 442$. SMF Xe 21562. - All magnifications are $\times 87$ unless otherwise stated. 
dorsally, significant narrowing ancero-ventrally, posteriorly widest medially. Selvage faint, line of concrescence parallel to the inner margin. Anterior with 21 long, widely spaced, large, marginal pore-canals which often bifurcate at mid-length. Posterior marginal pore-canals 10 thin, bifurcate medially; postcro-ventrally three canals bifurcate exiting through six small posterior spines. Hinge in $\mathrm{R}$ consisting of a narrow, elongate AT, bearing three faint lobes dorsally. The adjacent socket is deep and smooth, its dorsal narrow groove extends to the posterior cardinal angle where a round, knob-like tooth occurs. At the extremities of the median bar of the $\mathrm{L}$, a faint lobation occurs, significant dorsally.

MS pattern consisting of a vertical row of four adductor scars very tightly paired. The upper and lowermost round, medial pair elongate. Antennular scar heart-shaped. Sexual dimorphism pronounced, males more elongate and with stronger dorsal ridge. Juveniles (A-2, A-3) with reticulation but a weaker median ridge.

Remarks: Juvenile specimens of $A$. sinuosa were compared with a juvenile female $\mathrm{L}$ of Ambocythere sp. 3057 illustrated by Dingle et al. (1990: 301-303, Figs. 34A, 35A). The specimens display many similarities but until adult specimens from the SE Atlantic Ocean become available the relationship remains indeterminate.

- A. sinuosa n. sp. is similar to A. caudata VAN DEN BOLD (1965) in its dimensions, the outline, the projecting flange at posterior end and the faint cross-ridge connecting the dorsal and median ridges. Secondary reticulation, the length of the main ridges and the partern of the marginal pore-canals are however area of contrasts.

- A. ramosa VAN DEN BOLD (1965) is smaller, with a different pattern of secondary ornamentation and of radial pore-canals.

- A. subreticulata VAN DEN BOLD (1958a) is smaller and lacks a sub-central sulcus. The longitudinal ridges are weaker but the secondary ornamentation described by VAN DEN BOLD is similar to that of $A$. simuosa n. sp.

- A. recta JellineK \& SWANSON (2003) is smaller, its median ridge is straight, it has a number of secondary ridges parallel to the main ridges and has faint radial ridges on the anterior rim.

- A. christinae Jeluinek \& Swanson (2003) is smaller, with reticulation only on the posterior third, much more pronounced ridges but a weaker sub-central sulcus.

Using available literature, the record of $A$. sinuosa n. sp. at $2177-3658 \mathrm{~m}$ is the deepest for any species of Ambocythere from the South Pacific. Although the population structure is anomalous, with the four juveniles representing the A-2 moult or younger, some specimens had dried remains of soft parts intact and on this basis they are considered autochthonous.

\section{Subfamily Pennyellinae Neace 1975}

Genus Rugocythereis Dingle, LoRd \& BOOMER 1990

$$
\text { 'Type species: 'Oxycythereis' horrida WhaTlFy } \& \text { COLES }
$$
1987.

Included species: 'Oxycythereis' horrida WhaTLEY \& COLES (1987), 'Oxycythereis' buntoniaformis AyRESs (1988), Rugocythereis horrida Dingle et al. (1990), Rugocythereis reticulata AYRESS (1993b), Rugocythereis reticulata AYrESS (1993c), ? Rugocythereis horrida MajORAN \& DINGLE (2001a), ? Rugocythereis horrida MajoRAN \& Dingle (2001b).

Remarks: This genus was erected by Dingle et al. (1990) to include specimens from the south-eastern Atlantic, collected at depths variable from $730 \mathrm{~m}$ to $2916 \mathrm{~m}$. They referred their specimens to $R$. horridus, formerly described as 'Oxycythereis' horridus by WhatLEY \& COLES (1987). The nomen nudum 'Oxycythereis' was first used for Eocene-Pliocene specimens from the Indian Ocean DSDP Leg 24 (BENSON 1974). In this paper BENSON introduced several 'nomina nuda 'but 'Oxycythereis' was used formally despite the fact that it was never described. The genus was further listed in a number of different stratigraphic records (BENSON 1975a: Fig. 3; Whatley 1983: Tab. 2) but again without descriptions or illustrations were given. Only DUCASSE \& PeYrouquet (1979: pl. 3 fig. 3) provided a picture of a right valve of Oxycythereis dorsoserata from the Quaternary of the sourh-west margin of the Rockall Plateau, which may be referred to BraDY's Cythere dorsoserrata, although the name was misspellt and no reference to the original author was given. WHATLEY \& COLES (1987) assumed that Cythere dorsoserrata BRADY belongs to Oxycythereis. BRADY (1880: 102-103, pl. 23 figs. la-d) recovered his specimens from $2565 \mathrm{~m}$ of depth in S Atlantic (Tristan d'Acunha) and gave a length of 0.77 for a carapace. PUR \& Hulings (1976: 274-275, pl. 15 figs. 1-4) described as lectotype a $\mathrm{R}$ with dimensions of $0.56 / 0.47$. This is clearly a mistake since those proportions for the valve are unexpected and, in fact, when measured from the plate, indicate an actual length of 0.84 . The original slide labelled no. BM 81.5.19 contains the single $\mathrm{R}$ of the hololectotype (Fig. 38).

A second slide, labelled with the same number which probably hosted the $\mathrm{L}$ of the carapace described by BRADY, was empty. Puri \& Hulings's specimen $(0.85 / 0.45)$ has a triangular posterior margin, and a holamphidont type. The vestibula are well developed, and the median hingegroove is smooth (Fig. 38D) and not coarsely crenulate in the anterior part as reported by PURI \& Hulings's. These characters are remarkably different from those displayed in Oxycythereis species and for these reasons $C$. dorsoserrata cannot belong to the genus Rugocythereis.

Whatley \& COLES illustrated several specimens from the Miocene-Quaternary of the North Atlantic and referred them to different species of Oxycythereis (1987: 76-78, pl. 5 figs. 14-25). With respect to the binary nomenclature their new species Oxycythereis horridus is more correctly named Oxycythereis horrida, since the gender of the genus is feminine. Coles \& Whatley (1989: 102-104, pl. 4 figs. 13-17, pl. 5 figs. 1-5) stated that Oxycythereis is synonymous with Pennyella NEALE (1974) a genus erected on Upper Cretaceous specimens from Western Australia. Their assumption was that 


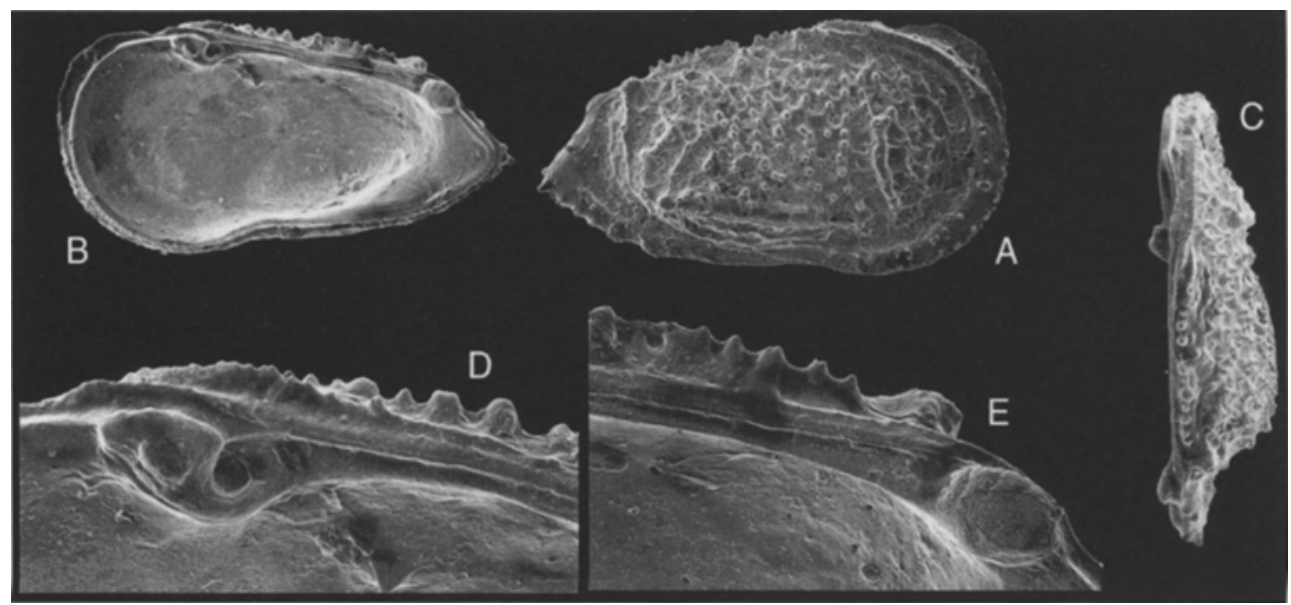

Fig. 38: Cythere dorsoserrata BRADY 1880.

Recent from the S Atlantic, Challenger station $335\left(\mathrm{~S} 32^{\circ} 24.00^{\prime}\right.$, W13 $\left.05.00^{\prime}\right), 2565 \mathrm{~m}$. - Hololectotype (NHM no. BM 81.5.19) designated by Puri \& Hulings (1976: 274-275, pl. 15 figs 1-4). R (0.85/0.45); A: external view, negative number $071085, \times 55$; B: internal view, negative number $071131, \times 55$; $\mathrm{C}$ : dorsal view, negative number $071179, \times 55$; D: detail of the anterior hinge element, negative number $071134, \times 55$; E: detail of the posterior hinge element, negative number $071133, \times 330$. [pictures were taken and provided by Dr. J. WHITTAKER, Department of Palaeontology, The Natural History Museum, London].

Oxycythereis BENSON was based on Cythere dorsoserrata BRADY (1880). DingLe et al. (1990) erected Rugocythereis to include those forms of Oxycythereis which did not fit the genus Pennyella. The main differences between the two genera are summarised in Tab. 10.

DINGLE et al. (1990), following the scheme of COLES \& WHATLEY, included Cythere dorsoserrata BRADY in Rugocythereis. The inclusion of $C$. dorsoserrata BRADY either in Pennyella or Rugocythereis is not appropriate because, in both cases, it would mean a large variability of the generic characters. In fact, both Pennyella and Rugocythereis lack vestibula, whereas C. dorsoserrata has well developed vestibula. Considering all those elements, the synonymy proposed by Dingle et al. needs to be modified. They included in Rugocythereis specimens probably belong to Pennyella as $P$. fortedimorphica Coles \& Whatley (1989) and P. praedorsoserrata Coles \& Whatley (1989) which display holamphidont hinges and antero-marginal rims. Oxycythereis sp. 1 and sp. 2 (WHATLEY \& Coles 1987) can probably be referred to Pennyella.

Table 10: Main differences between the genera Pennyella and Rugocythereis.

\begin{tabular}{lll}
\hline Genus & Pennyella & Rugocythereis \\
\hline hinge type & Holamphidont & Paramphidont \\
marginal ridges & Present & Absent \\
anterior rim & Present & Absent \\
posterior rim & Present & Present \\
flange & Absent & Present \\
\hline
\end{tabular}

Rugocythereis horrida (WHATLEY \& COLES 1987)

(Figs. 39A-R)

* 1987 'Oxycythereis' horrida WHATLEY \& COLEs: 76-78, pl. 5 figs. 18-22.

1990 Rugocythereis horrida. - DINGLE et al.: 320-322, Figs. 47B, D-F.

? 1990 Rugocythereis horrida. - DINGLE et al:: 320-322, Fig. $47 \mathrm{C}$.

? 2001a Rugocythereis horrida. - MAJORAN \& DINGLE: 83, Fig. 5k.

2001b Rugocythereis horrida. - Majoran \& Dingle: 214, pl. 1 fig. 21 (juvenile).

Material: 124 adult and 185 juvenile valves. - SMF Xe 21566-21571.

Dimensions: female L $0.85-0.87 / 0.52-0.57$; $\mathrm{R} 0.80$ $0.87 / 0.50-0.52$; male L $0.90-0.92 / 0.47-0.50$; R $0.85-0.90 /$ $0.45-0.47$.

Distribution: Holocene of the South Tasman Rise. Very rare in samples BX156 (3208 m) and BX165 (4067 m); rare in sample BX161 (3685 m); very common in samples BX138 (3022 m) and abundant in sample BX147 (2177 m).

Remarks: The following observations supplement the description provided by WhaTleY \& COLES (1987) and DinGLE et al. (1990). The ornamentation consists of tubercles and bullae which, on the sub-central ventral area, are organised in 4-6 parallel rows, terminating posteriorly in a stout, prominent tubercle. Normal pores intramural and sieve-type. They exit scattered on the surface and on pore-conuli at posterior margin.

Internally, ventral margin concave medially with a snap knob (on the R) as additional closing mechanism (Fig. 39R). Marginal pore-canals simple and straight, 18-22 anteriorly 


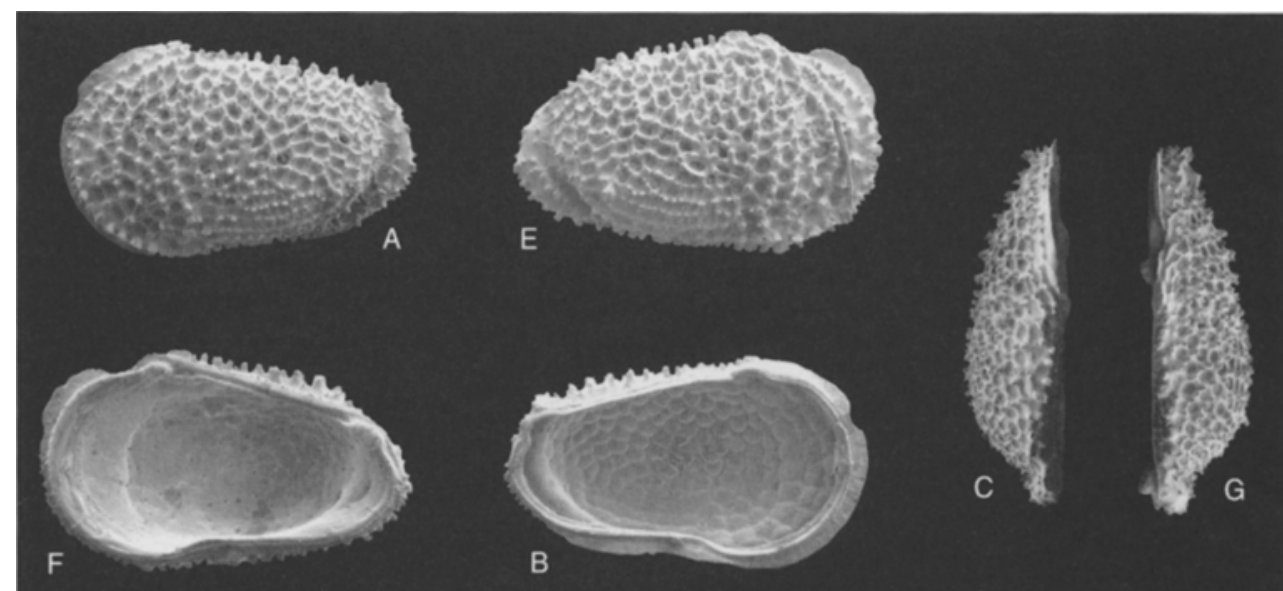

$\mathrm{F}$
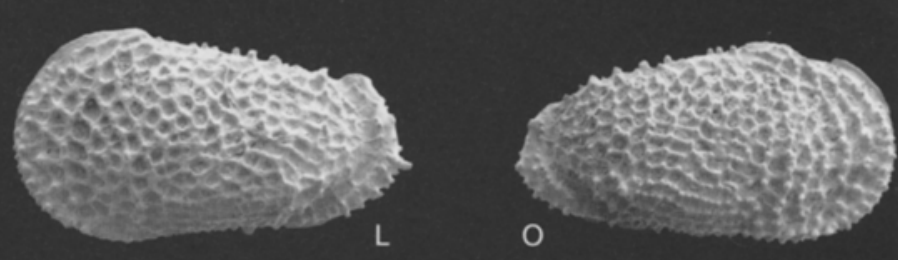

L
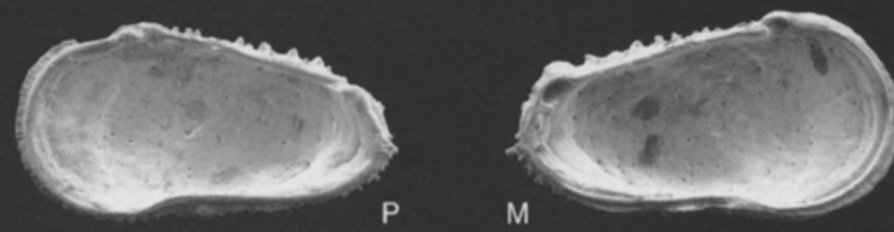

$\mathrm{H}$
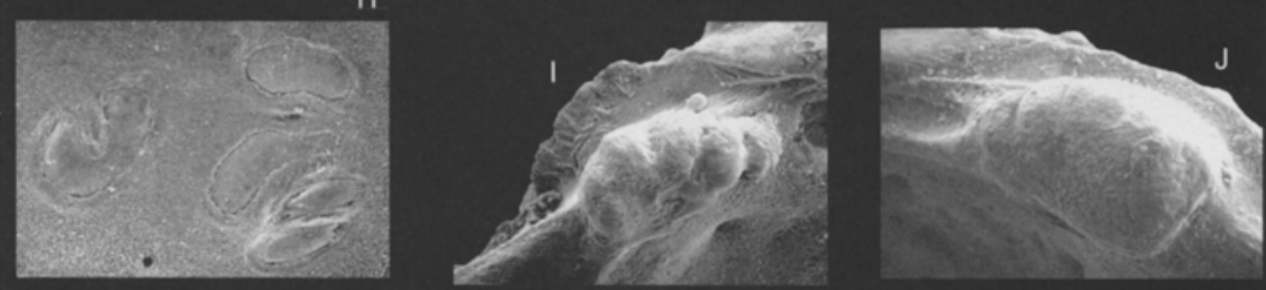

D

K

R
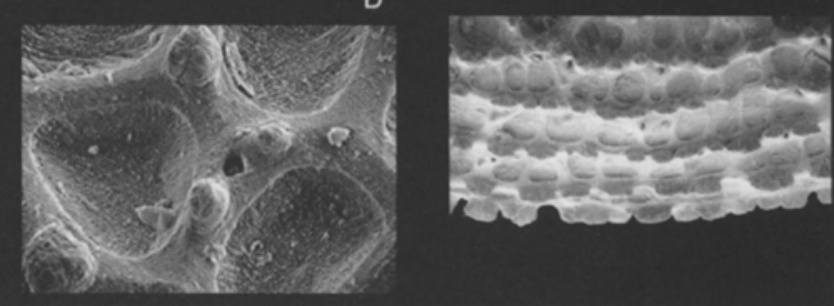

Fig. 39: Rugocythereis horrida (WhatLEY \& COLES 1987)

Recent, sample BX147, South Tasman Rise, off souch coast Tasmania, Australia; $\$ 48^{\circ} 29.99^{\prime}$, E149 $06.75^{\prime}$, 2177 m. - female L (0.85/0.52); A: external view; B: internal view; C: dorsal view; D: central ornamentation and sieve-type pore, $\times 486$. SMF Xe 21566. - female $\mathrm{R}(0.87 / 0.52)$; E: external view; F: internal view; G: dorsal view; H: central muscle scars, $\times 290$; I: anterior hinge element, $\times 312$; J: posterior hinge element, $\times 312$; K: ventral ornamentation with blade-shaped spines, $\times 156$. SMF Xe 21566. - male L (0.92/0.50); L: external view; M: internal view; N: dorsal view. SMF Xe 21566. - male R (0.90/0.47); O: external view; P: internal view; Q: dorsa view; R: additional closing mechanism, $\times 390$. SMF Xe 21566. - All magnifications are $\times 45$ unless otherwise stated. 
and 12-14 posteriorly. Hinge antimerodont. $R$ with a multilobate (4-5 lobes) AT with a narrow groove dorsally; smooth median groove. The PT has a faint lobation most visible in dorsal view. Hinge elements in $\mathrm{L}$ complementary. A small hinge ear is developed above the AS and extends anteriorly. Central MS consisting of four adductor scars arranged in a vertical row. The two lowermost are very close to each other and drop-shaped, the uppermost medial boomerang-shaped, with the anterior portion sloped ventrally, the uppermost large and oval. Frontal scar large and U-shaped. Sexual dimorphism well developed.

Whatley \& Coles (1987: 76-78, pl. 5 figs. 18-22) reported this species from the Miocene-Quaternary sediments of the North Atlantic, the Pliocene-Quaternary of the SW Pacific Ocean and the Miocene of the Indian Ocean. Dingle et al. (1990) recorded it from the Quaternary of the SE Atlantic. Based on that data it is concluded that presently this taxon occurs in water depths of $730 \mathrm{~m}$ to $3526 \mathrm{~m}$. In the samples from the Tasman Sea, the largest number of specimens occur between $2177 \mathrm{~m}$ and $3022 \mathrm{~m}$ of depth, whereas in the deeper samples only juveniles were recovered.

Although the genus was erected by DINGLE et al.(1990), the specific determination of the Tasman Sea species is based mainly on the description and the illustrations provided by Whatley \& Coles(1987). In fact, Dingle et al. (1990: 320322, Figs. 47B-F) did not provide an emended diagnosis for the species horrida and the specimens they illustrated are poorly preserved. Moreover, the dimensions (0.73-0.74/ 0.43-0.45 measured from the plates) of their specimens are smaller than those reported by WHATLEY \& COLES or those of the Tasman Sea specimens. The poorly preserved specimen they illustrate in their Fig. $47 \mathrm{C}$ bears triangular spines and it is only tentatively included in the present species. The specimen illustrated by MAJORAN \& DiNGLE (2001a: 83, Fig. 5K) as $R$. horridus from the Late Miocene of the Southern Ocean displays a slightly different pattern of ornamentation, with subdued reticulation.

$R$. borrida is similar to 'Oxycythereis' buntoniaformis (AYRESS 1988) which is stouter, lacks blade-like tubercles on the external ventral margin and has weakly developed hinge ear.

\section{Rugocythereis tethys $\mathrm{n} . \mathrm{sp}$}

(Figs. 40A-P)

Derivation of name: From the Greek name Tethys. Tethys was one of the Nereids (sea nymphs) and the wife of Okeanus. With reference to the gender of the genus and the oceanic environment.

Holotype: Male C (1.12/0.60/0.54), Figs. 40A-O. SMF Xe 21572.

Paratypes: 135 adult and 289 juvenile valves. - SMF Xe 21573-21578.

Dimensions (of paratypes): Female L 1.07-1.10/0.570.60 , R 1.05-1.07/0.55-0.57; male L 1.12-1.17/ 0.60-0.62, R $1.10-1.12 / 0.55-0.57$.

Type locality: RV SONNE cruise no. SO 136, site 13 station 082; box-corer sample from the Campbell Plateau, off SE South Island, New Zealand, at $1681 \mathrm{~m}$ water depth; $S 55^{\circ} 20.07^{\prime}, \mathrm{E} 166^{\circ} 39.96^{\prime}$.
Distribution: Holocene of southern and eastern Campbell Plateau and of the South Tasman Rise. Very rare in sample BX141 (1690 m). Rare in sample BX138 (3022 $\mathrm{m})$.Very common in samples BX031 (1568 m), BX082 (1681 $\mathrm{m})$ and BX153 (1874 m). Abundant in BX140 (1636 m).

Diagnosis: Large species of Rugocythereis with unusual ornamentation, composed of polygonal meshes with low muri enclosing circular pits. Blind and with weak SCT.

Description: Shape sub-trapezoidal. Greatest length slightly below mid-height, greatest height at anterior cardinal angle. Anterior margin asymmetrically rounded with a prominent antero-dorsal flange. Posterior margin sub-triangular, rounded-acuminate, bearing a single spine on the posteriormost extremity of the rim. Dorsal and ventral margin converging posteriorly. Dorsal margin straight, slightly incurved before the posterior cardinal angle. Ventral margin straight. In dorsal view posterior rim flat, greatest width within posterior third. Sexual dimorphism well pronounced. Valve surface covered with small, circular to oval fossae. A faint reticulation covers the surface, becoming coarser towards the margins. The reticulation is formed by polygonal meshes with low muri enclosing a variable number of pits (3-6). Antero-ventral and postero-ventral margins with a row of small tubercles, openings of marginal pore-canals. Sieve-type pore-canals open on the muri. The posterior rim bears a row of small spines on its smooth surface. A row of large meshes, without pits connects the rim with the postero-ventral inflation. The area of the central MS is smooth, with small pits. Juveniles display a stronger reticulation, with short fat tubercles on the anteroventral area and on the dorsal margin.

Internally: ventral margin concave medially, where a snap knob is present as additional closing mechanism. Fused zone narrow with a very narrow anterior vestibulum. Selvage strong, parallel to the outer margin. Radial pore-canals straight, 25-28 anteriorly and 18 posteriorly. Hinge antimerodont. In the $\mathrm{R}$, small multi-lobate AT, triangular-shaped in dorsal view. Narrow and smooth median groove. PT wedge shaped, with faint lobations distally. Hinge elements in $\mathrm{L}$ complementary.

Central MS consisting in a vertical row of four adductor scars and a single frontal scar. The two lowermost adductor scars are small and very close to each other, drop-shaped; the second uppermost scar is large, deflected ventrally; the uppermost scar is large and bean-shaped, separated from the three lower scars. The frontal scar has an asymmetric U-shape, with undulated proximal arm.

Remarks: On the South Tasman Rise only juveniles of this species were recovered, although in large numbers. Adult valves were available from the Campbell Plateau and kindly provided by Dr. T. JellineK (Senckenberg Museum, Germany). Taking into account that in sample BX037 only juveniles occur, the optimum depth is between $1568 \mathrm{~m}$ and 1681 $\mathrm{m}$.

Rugocythereis tethys n. sp. differs from $R$. horrida because of its larger dimensions, different kind of ornamentation, lack of tubercles and presence of a posterior ventro-lateral spine. It is close to $R$ reticulata Ayress (1993b: 141-140, Figs. 9S-U; 1993b: Fig. 3M) from the Late Oligocene of South Canter- 


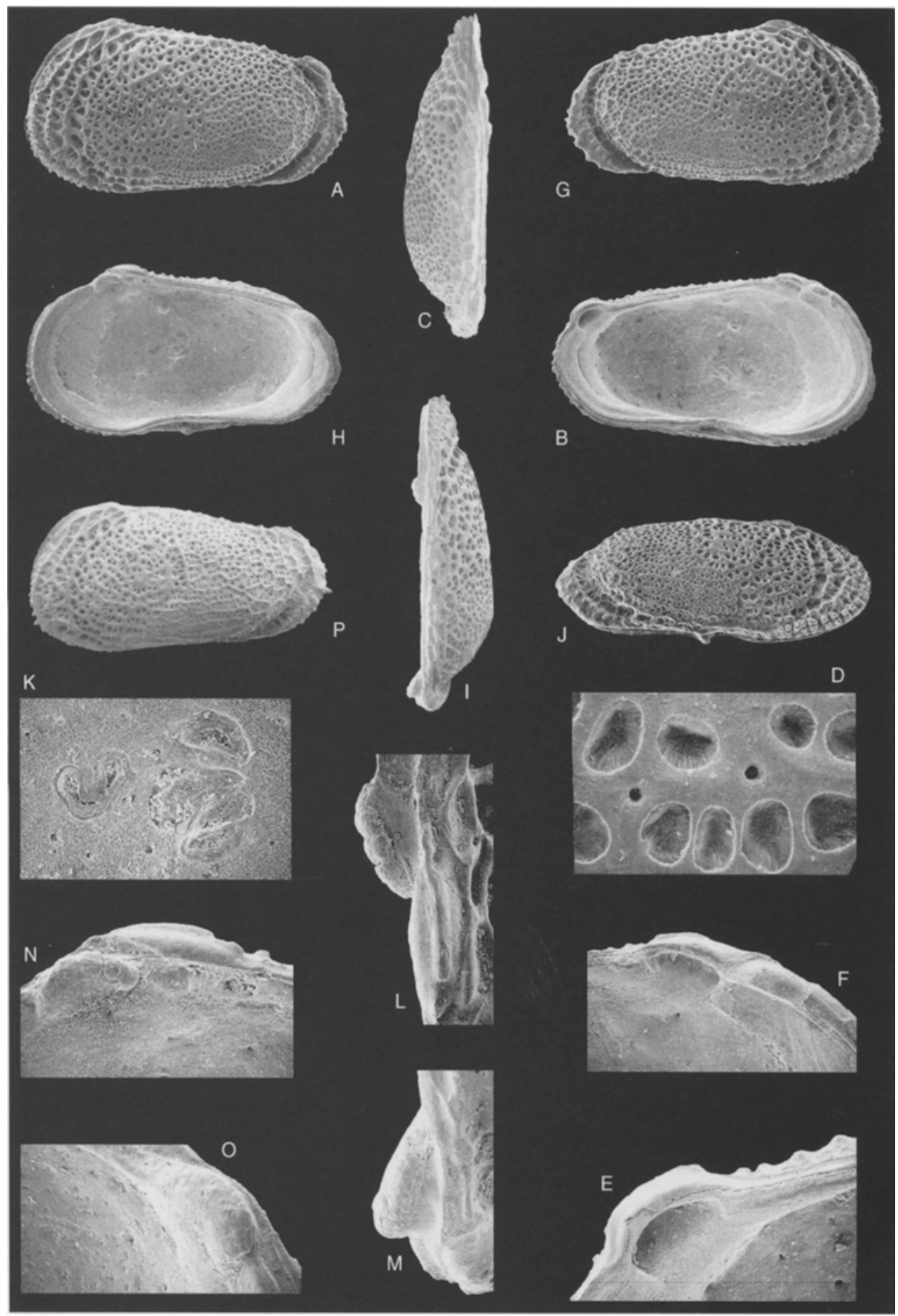

Fig. 40: Rugocythereis tethys n. sp.

Recent, sample BX082, southern Campbell Plateau, off SE South Island, New Zealand; S55 $20.07^{\prime}$, E166 $39.96^{\prime}, 1681 \mathrm{~m}$. - male C (1.12/0.60/0.54), holotype; A: L (1.12/0.60), external view; B: internal view; C: dorsal view; D: surface ornamentation and simple pores, $\times 380$; E: posterior socket, $\times 137$; F: anterior socket, $\times 137$; G: $\mathrm{R}(1.10 / 0.55)$, external view; $\mathrm{H}$ : internal view; I: dorsal view; J: ventral oblique view showing the additional closing mechanism; K: central muscle scars, $\times 190$; L: anterior hinge elements in dorsal view, $\times 187$; $\mathbf{M}$ : posterior hinge elements in dorsal view, $\times 187 ; \mathrm{N}$ : anterior tooth, $\times 160$; O: posterior tooth, $\times 160$. SMF Xe 21572. - Recent, sample BX 140; South Tasman Rise, off south coast Tasmania, Australia; $\$ 49^{\circ} 10.84^{\prime}$, E150 $10.13^{\prime}, 1636$ m. - juv. L (1.02/0.50), paratype; P: external view. SMF Xe 21575. - All magnifications are $\times 44$ unless otherwise stated. 
bury (New Zealand) with which shares the reticulate ornament and the weak SCT. However $R$. tethys is larger, has lower muri, larger fossae and is blind.

\section{Subfamily Unicapellinae DINGLE 1981}

Remarks: Dingle (1981), studying Campanian and Maastrichtian sediments of sourh-east Africa, erected the subfamily Unicapellinae to accommodate blind, reticulate to foveolate untypical trachyleberidids (see MS), with a prominent SCT, a strongly to moderately developed hinge ear in L and nodose, spinose or bullate surface features. The following genera were included: Paleoabyssocythere and Atlanticythere Benson (1977), Herrigocythere GrÜNDEL (1973) and Dutoitella Dingle (1981). Apart from Dutoitella, the remaining genera are exclusively fossil.

\section{Genus Dutoitella Dingle 1981}

\section{Type species: Dutoitella dutoiti DINGLE 1981.}

Remarks: In the original diagnosis of the genus Dutoitella, Dingle emphasised the non-reticulate character of the valves. Although in the descriptions of $D$. dutoiti (type species) and D. mimica, a faint reticulation is always described, particularly in the anterior region. The hinge of Dutoitella is described as hemiamphidont and the MS, not observed in the type species but in D. mimica, display subdivided antennular and second adductor MS. COlES \& WHATLEY (1989) modified the description of DINGLE and described an evolutionary phylogeny in Dutoitella. They included in the genus heavily reticulated forms and observed a variation in the hinge system, with a loss of lobation in the terminal elements of the hinge attributed to Maastrichrian species, resulting in an holamphidont hinge in more recent species. Following this ampliated diagnosis, DINGLE et al. (1990) included in Dutoitella the species "Cythereis" crassinodosa GuERNET (1985) from the
Eocene of the Indian Ocean, 'Suhmicythere' Benson et al. (1983) from the Recent of the deep North Pacific and Cythere submi Brady (1880) from the Recent of North Pacific. BENSON used for the first time in 1974 (pl. 1 figs. 7-8) the nomen nudum 'Submicythere' (with a clear reference to BRADY's species) to describe reticulate species from the Pliocene of the Indian Ocean.

A genus closely related to Dutoitella is Taracythere, erected by AYRESS (1995) for specimens from the Late Eocene of New Zealand. They have a strong resemblance with Dutoitella, especially with respect to the external ornamentation, but Taracythere has a distinct postero-ventral marginal spine and typical trachyleberidid muscle-scars.

\section{Dutoitella submi (BRADY 1880)}

(Fig. 41)

* 1880 Cythere suhmi BRADY: 106-107, pl. 26 fig. 3a-d. non 1880 Cythere suhmi BRADY: 106-107, pl. 26 fig. 3e-h. 1976 Cythere suhmi. - PURI \& Hulings: 290, pl. 17 figs. 7-10.

non 1987 'Sumicythere' suhmi. - WHATLEY \& COLEs: 80, pl. 6 figs. 18-21.

non 1990 Dutoitella suhmi. - DINGLE et al.: 293-298, Figs. 27E-F, 30A-B, 31A, C, F.

Remarks: BRADY (1880) recorded Cythere suhmi at 4140 $m$ of depth in station $241\left(\mathrm{~N} 35^{\circ} 41.00^{\prime}, \mathrm{E} 157^{\circ} 42.00^{\prime}\right)$ and off Prince Edward's Island at $90-280 \mathrm{~m}$. The specimens illustrated on his pl. 26 were referenced as a female adult from station 241 (fig. 3a-d) and a juvenile from Prince Edward's Island (fig. $3 \mathrm{e}-\mathrm{h}$ ). In both plate and description no reticulation is described. The adult specimen displays pointed spines whereas the juvenile specimen displays blade-like spines and only one pointed spine at the posterior edge of the ventral ridge. Both display a SCT. The dimensions reported by BRADY are $1 / 24$ of an inch which corresponds to $1.06 \mathrm{~mm}$ and not to $1.95 \mathrm{~mm}$ as has been stated. Puri \& Hulings (1976) designated a lectotype selected from specimens from station

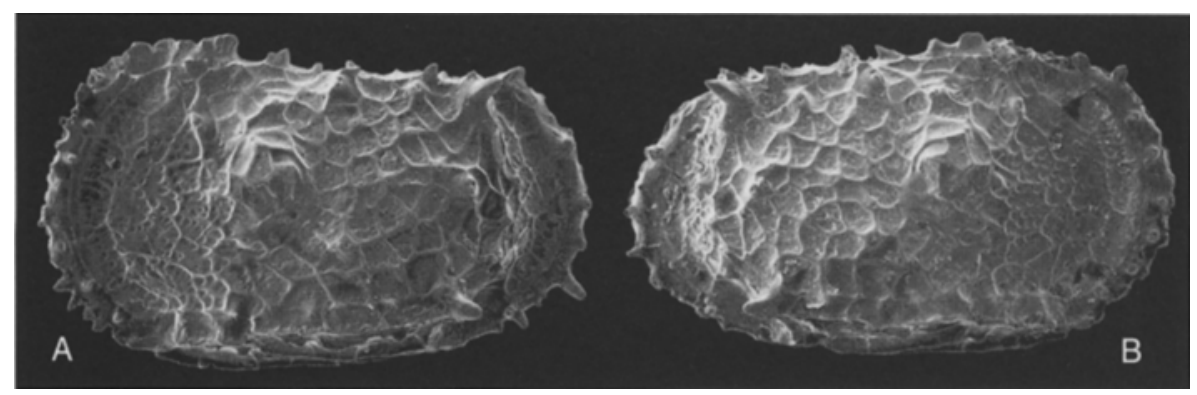

Fig. 41: Dutoitella submi (BRADY 1880).

Recent of the NW Pacific, Challenger station $241\left(\mathrm{~N} 35^{\circ} 41.00^{\prime}, \mathrm{E} 157^{\circ} 42.00^{\prime}\right), 4206 \mathrm{~m}$. -

Hololectotype (NHM no. BM 80.38.119) adult carapace disarticulated by PURI \& Hulings (1976: 290-291, pl. 17 figs 7-12); A: L (1.15/0.67) external view, negative number P068263; $\times 65$; B: R $(1.15 / 0.65)$ external view, negative number P068302; $\times 65$. [pictures were taken and provided by Dr. J. WhitTAKFR, Department of Palaeontology, The Natural History Museum, London]. 
241. Although they indicated the shape and ornamentation conformed to BRADY's description, their specimens are reticulated all over the surface and the dimensions are different (1.15-1.21/0.68). They described holamphidont hinge and central muscle scars with the four adductors arranged in a vertical row and a divided frontal scar.

Dr. J. E. WhitTaker (The Natural History Museum of London) provided SEM photographs of the lectotype of $C y$ there suhmi, a carapace which has been disarticulated and refigured by PURI \& Hulincs (catalogue no. BM 80.38.119). It is evident from the pictures (Fig. 41) that D. submi has a secondary ornamentation which consists of 8-14 round punctae within the meshes of the reticulation. Anteriorly, these punctae may surround a tiny smooth area, in sub-central position within each mesh of the primary reticulation. The secondary ornamentation is lacking on the SCT and on the dorsal area of the valves; it is partially developed between the posterior part of the dorsal margin and the ventral ridge. This ventral ridge bears a strongly pointed spine at its posterior edge.

D. suhmi sensu Whatley \& COLES (1987: pl. 6 figs. 18-19) lacks the secondary ornamentation, has a suppressed primary reticulation anteriorly and is smaller (1.03/0.57-0.63 measured from the plate). D. suhmi sensu Dingle et al. (1990: Fig. 27E) is much smaller $(0.56 / 0.33$ measured from the figure) and lacks the secondary ornamentation.

\section{Dutoitella spinaplana $\mathrm{n} . \mathrm{sp}$. (Figs. 42A-P)}

Derivation of name: Composed word from the Latin noun spina $=$ spine and the adjective planus = flat; referring to the ventral ridges and the antero-ventral frill made of flat spines.

Holotype: Male L (1.07/0.62), Figs. 42A-C. - SMF Xe 21579.

Paratypes: 23 adult and 46 juvenile valves. - SMF Xe 21580-21581.

Dimension (of paratypes): Female L 1.07-1.10/0.650.67 , R 1.00-1.07/0.60-0.65; male L 1.07-1.10/0.57-0.62, R 1.05-1.07/0.60-0.62.

Type locality: RV SONNE cruise n. SO 136, site 26, station 138; box-corer sample from the South Tasman Rise, off S Tasmania, Australia, at $3022 \mathrm{~m}$ water depth water depth; $\$ 49^{\circ} 13.06^{\prime}, \mathrm{E} 151^{\circ} 05.77^{\prime}$.

Distribution: Holocene of the South Tasman Rise. Very common in sample BX138 (3022 m).

Diagnosis: Blind, reticulate species, with antero-ventral blade-like spines, prominent SCT and strong posterior median ridge. Dorsal margin with three pointed spines and three pairs of pore-conuli and flat spines.

Description: Shape sub-rectangular, maximum length at mid-height, maximum height at hinge ear. Anterior margin rounded ornate ventrally with blunt, blade-like, striate spines. Ventral margin slightly convex, because of the ventral swelling. Posterior margin asymmetrically rounded with a marginal rim less developed than anterior equivalent. Dorsal margin straight with anterior hinge ear in the L. Surface reticulation pattern consisting of irregular polygonal fossae. Ventral area with three secondary ridges composed of flat spines which merge toward posterior. The main ventral ridge may have a single spine at the posterior extremity. In dorsal view, maximum width corresponding to the SCT. SCT well developed, not reticulate, deflected posteriorly. Posterior median ridge not reticulate, slightly arched with a pore conulus at its posterior edge. SCT and median ridge divided by a sulcus which originates medially on the dorsal margin and is deflected anteriorly behind the SCT. Dorsal margin with short ocular ridge, more evident in the $\mathrm{R}$, followed by three to five dorsal spines and a row of three pore-conuli paired with blade- like spines. Vertical (L) to sub-vertical (R) posterior ridge, with three pore conuli, two at the extremities and one medial. Normal pore-canals on pore conuli, always in conjuncrive position with respect to the reticulation and constant in males and females. Marginal pore-canals straight and scattered, occasionally branched, 21-25 anteriorly, 12-16 posteriorly.

Internally: vestibulum not developed, duplicature wider posteriorly, selvage strong. Ventral margin concave in the oral region. Hinge holamphidont. In the $\mathrm{R}$, smooth, stout and round PT with adjacent round, smooth socket; median groove smooth, stepped AT which is proximally slightly lobate. In the L, hinge elements complementary. The smooth and strong bar ends anteriorly in a lobate widening. The hinge ear is well developed and carries a spiny extension.

The four adductor scars are arranged in a vertical row, the boomerang-shaped second uppermost being the largest. Antennular scar divided. The SCT hosts only the antennular scar whereas the adductor scars are located on its posterior edge.

In smaller instars, the reticulation is absent whereas the sub-central tubercle and the ventral ridges, though subdued, are developed. The posterior sub-vertical ridge carries 2-3 pointed spines, and the antero-dorsal extension small bullae. The hinge is hemimerodont with tri-quadri-lobate AT and smooth PT.

Remarks: The Dutoitella subdivided second adductor scar observed by Dingle et al. (1990: 296, Fig. 31) was not observed in the adult specimens of $D$. spinaplana $n$. sp. All the instars have subdivided second adductor, some of the younger ones (L) may have subdivided first adductor and non-divided second adductor.

This species differs from Dutoitella submi (BRADY 1880) for its slender outline, the less pronounced median ridge and the reticulate ornament.

It differs from 'Suhmicythere' BENSON et al. (1983: pl. 1 fig. 8) which is larger ( 1.55 measured from the plate), has no median ridge and a less pronounced SCT.

It differs from $D$. submi sensu WhaTleY \& COLES (1987) which lacks the median ridge, has suppressed reticulation and flattened and wide posterior. 'Submicythere' BENSON (1974) is here considered conspecific with the specimens of WHATLEY $\&$ COLES.

It differs from D. suhmi sensu Dingle et al. (1990) because of its dimensions (D. spinaplana is larger), the suppressed median ridge and the more pointed posterior margin. 


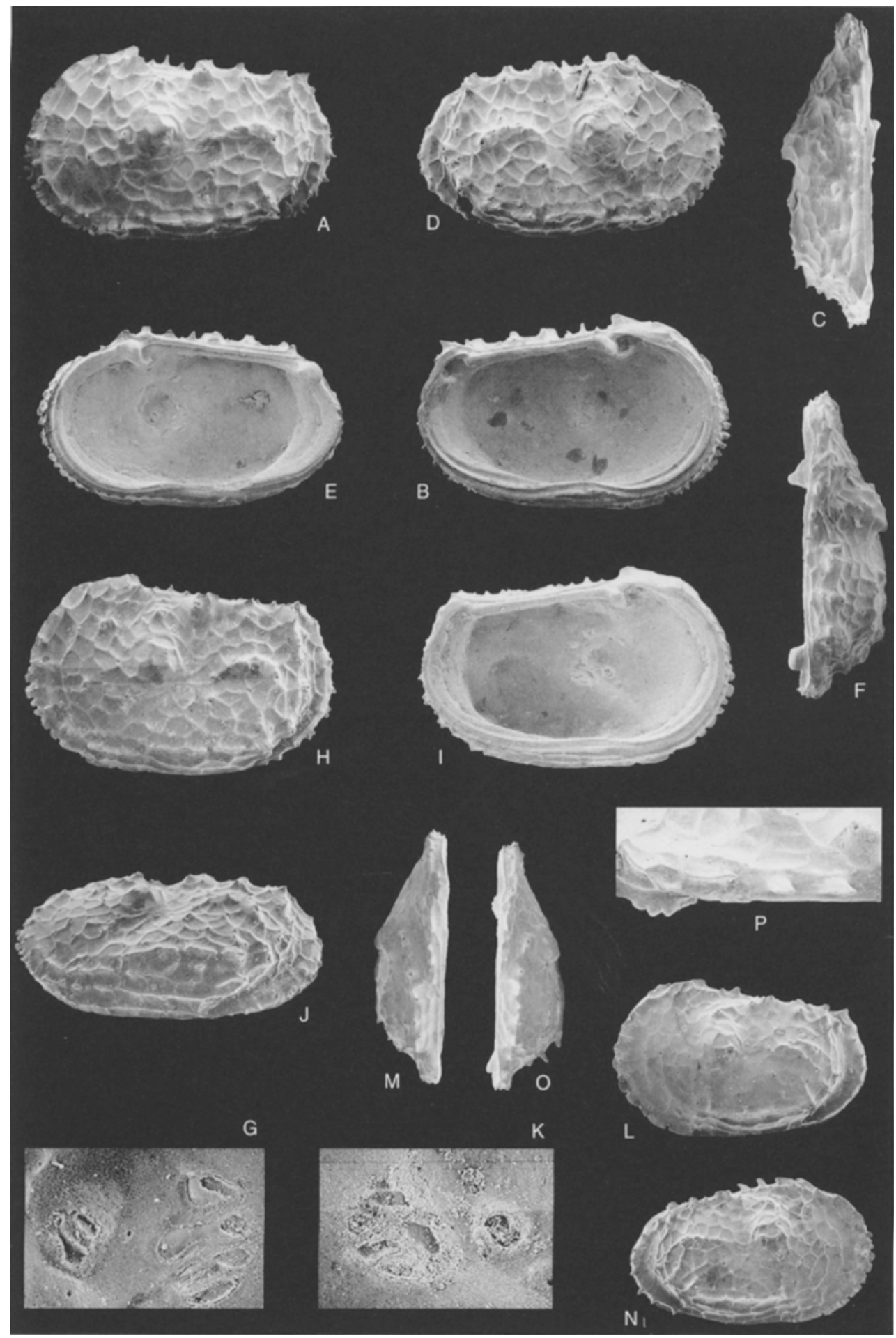

Fig. 42: Dutoitella spinaplana n. sp.

Recent, sample BX138, South Tasman Rise, off south coast Tasmania, Australia; $\$ 49^{\circ} 13.06^{\prime}$, E151 $05.77^{\prime}$, 3022 m. - male L (1.07/0.62), holotype; A: external view; B: internal view; C: dorsal view. SMF Xe 21579. male R (1.05/0.60), paratype; D: external view; E: internal view; F: dorsal view; G: central muscle scars, $\times 210$. SMF Xe 21580. - female L (1.07/0.65), paratype; $\mathrm{H}$ : external view; I: internal view; J: oblique view showing the four segmented ventro-lateral ridges; K: central muscle scars, $\times 210$. MF Xe 21580. - juv. L $(0.87 / 0.52)$, paratype; L: external view; M: dorsal view. SMF Xe 21580. - juv. R (0.85/0.52), paratype; N: external view; O: dorsal view; P: detail of the antero-dorsal margin showing the lobate tooth and the two dorsal bullae, $\times 120$. SMF Xe 21580. - All magnifications are $\times 44$ unless otherwise stated. 


\author{
Family Hemicytheridae PURI 1953 \\ Subfamily Thaerocytherinae HAZEL 1967
}

\section{Genus Poseidonamicus Benson 1972}

Type species: Poseidonamicus major Benson 1972.

Remarks: BENSON (1972) erected this genus on Recent material, recovered at about $3000 \mathrm{~m}$ of depth from the Mozambique Channel. A full description of the type species was not provided but the characters on which he based the genus are clarified in the descriptions of the other three species he erected ( $P$. minor, P. pinto $i, P$ nudus). In the comparison with other genera he focussed on Cythere viminea BRADY (I 880: 94, pl. 18 figs. 3a-c) which he considered congeneric (BENson 1972: pl. 11 fig. 15, as P. viminea nomen dubium) but with some doubts about the specific assignment since the hololectotype was a broken specimen from Prince Edward Island at $2475 \mathrm{~m}$ of depth. He also observed that BRADY not only illustrated under the name Cythere dictyon forms belonging to both genera (Bradleya and Poseidonamicus), but he also did not differentiate $C$. dictyon from $C$. viminea. Unfortunately, BENSON failed to clarify that relationship and added further to the confusion by illustrating the specimens of $C y$ there dictyon as belonging to Poseidonamicus.

BENSON (1983: Fig, 12) investigated the evolutionary changes in the architectural framework of three species of Poseidonamicus, using the variability of the postero-lateral region of the reticulum to test his hypothesis. These observations were made on forms of Poseidonamicus with a recognisable posterior reticular field pattern. The pattern of this area was observed in each of the species herein studied and was proved to be constant within a species, and therefore a valuable taxonomic tool (Fig. 43).
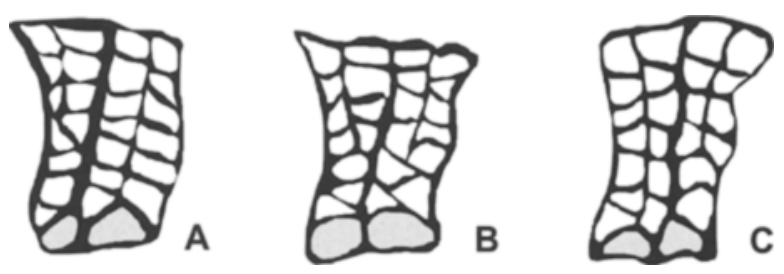

Fig. 43: Schematic drawings of the postero-lateral region of the reticulum of the left valve of three species of Poseidonamicus. - A: Poseidonamicus major BENSON 1972; B: Poseidonamicus ocularis WHATLEY, Downing, Kesler \& Harlow 1986; C: Poseidonamicus sp.
Poseidonamicus major BENSON 1972

(Figs. 44A-N, 43A)

* 1972 Poseidonamicus major Benson: 52, pl. 8 fig. 5, pl. 10 figs. 1-6.

1983 Poseidonamicus aff. P. major. - BENSON \& PEYPOUQueT: 813 , pl. 3 fig. 1 .

1983 Poseidonamicus major. - BENSON: 404, Fig. 1 A.

1986 Poseidonamicus major. - WhATLEY et al.: 389, pl. 1 fig. 1 (= juvenile).

non 1987 Poseidonamicus sp. cf. P. major. - WhATLEY \& COLES : 81, pl. 6 fig. 11.

1988 Poseidonamicus ex gr. major. - AYREss: 813, pl. 31 figs. 1-6.

1990 Poseidonamicus major. - Dingle et al.: 325, Fig. 50A, D, F, 51.

non 1998 Poseidonamicus major - GUERNET: 525 ff, pl. 2 fig. 10.

non 2000 Poseidonamicus sp. cf. P. major. - DiDIE \& BaUCH: 111 , pl. 4 figs. 6-7.

Material: 23 adults and 48 juveniles valves. - SMF Xe 21582-21584.

Dimensions: Female L 1.05-1.10/0.65-0.67, R 0.951.07/0.57-0.65; male L 1.05-1.12/0.62-0.70; R 1.05-1.12/ $0.57-0.60$.

Distribution: Holocene of the South Tasman Rise. Very common in samples BX147 $(2177 \mathrm{~m})$ and BX138 $(3022 \mathrm{~m})$. Very rare in sample BX153 $(1874 \mathrm{~m})$.

Remarks: The fact that BENSON (1972) failed to give a full description of the type species has led to some confusion. Additionally, the differences between $P$. major, $P$ minor and $P$. pintoi are not striking. AYREss (1988) later suggested that $P$. major and $P$. minor are probably the same species.

From the micrographs and the drawings provided by BEN. SON (1972) it is possible to identify some characters useful in the identification of the species:

- horizontal dorsal carina.

- arrangement of the posterior reticular field between the dorsal and the ventro-lateral carinae.

- morphology of the five short ribs on the dorsal margin.

WHATLEY et al. (1986) emended the original generic diagnosis providing short remarks about the distribution of the type-species and illustrating an A-1 specimen. WhatLEY \& COLES (1987) illustrated one specimen from the Pliocene of the North Atlantic which has a different dorsal morphology than that of $P$. major, i.e. it lacks the five short ribs. They stated that "the Atlantic forms are quite distinct from those with which the authors are familiar in the Indian Ocean for example". Probably, this is a new/different species. Dingle et al. (1990: Fig. 50) found specimens of P. major in the deep of the South Atlantic Ocean. Of the two specimens they illustrated only the right valve is herein considered as belonging to $P$. major. The $\mathrm{L}$ lacks the five dorsal ribs replaced by a straight carina parallel to the dorsal carina. The position of the latter is lower than in $P$. major and at least three meshes occur within the two carinae. The specimen illustrated by GUERNET (1998) from the Upper Miocene-Pleistocene of the 


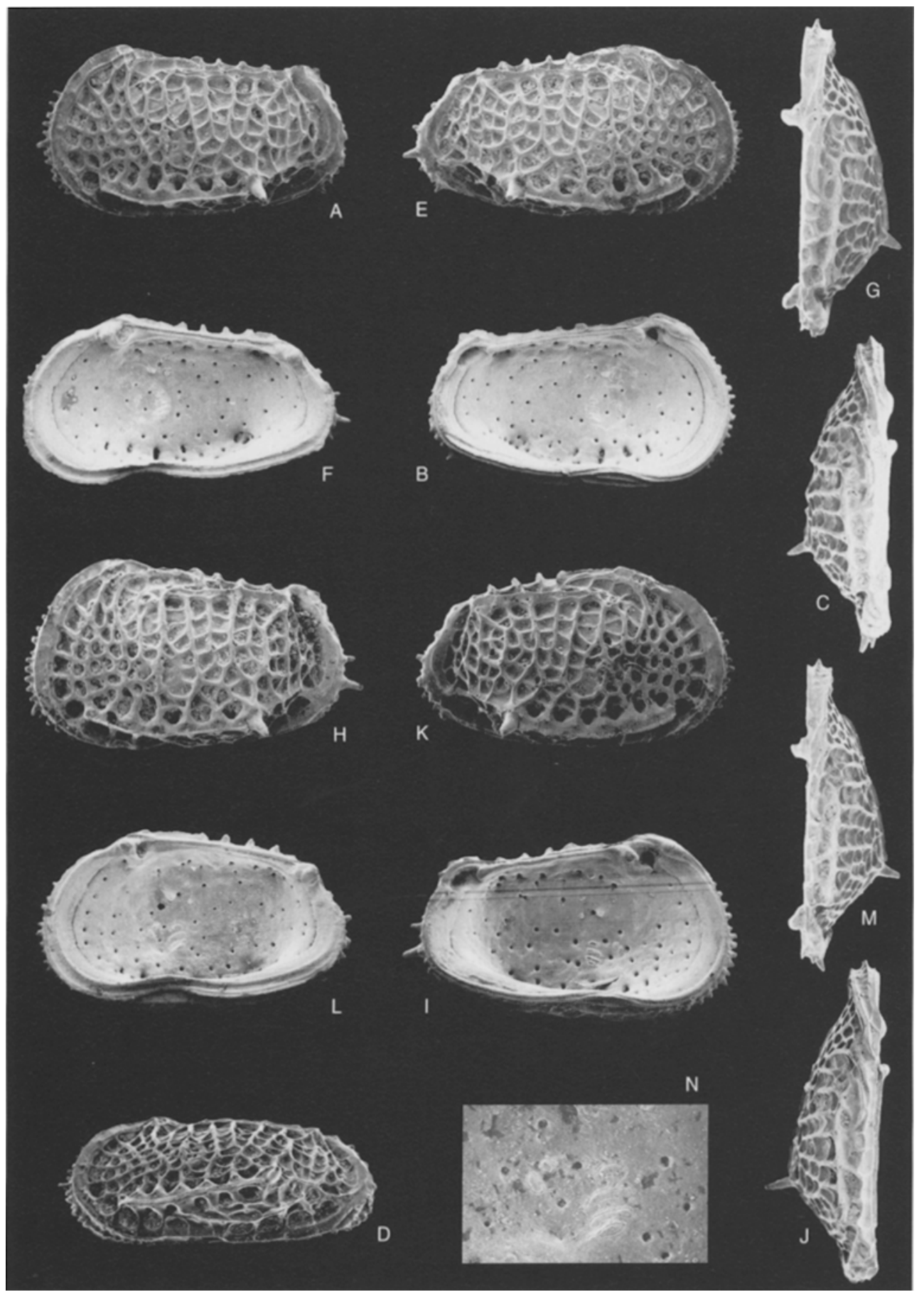

Fig. 44: Poseidonamicus major BENSON 1972

Recent, sample BX147, South Tasman Rise, off south coast Tasmania, Australia; S48 $29.99^{\prime}$, E149 $06.75^{\prime}$ 2177 m. - male L (1.05/0.62); A: external view; B: internal view; C: dorsal view; D: oblique ventral view showing the caperate ventral ridge. SMF Xe 21582. - male R (1.12/0.60); E: external view; F: internal view; G: dorsal view. SMF Xe 21582. - female L (1.10/0.67); H: external view; I: internal view; J: dorsal view. SMF Xe 21582. - female R (1.07/0.65); K: external view; L: internal view; M: dorsal view; $N$ : central muscle scars, $\times 112$. SMF Xe 21582. - All magnifications are $\times 43$ unless otherwise stated. 
Atlantic Ocean lacks the horizontal dorsal carina and the five dorsal ribs, it also has a different arrangement of muri and fossae on the posterior.

Poseidonamicus ocularis

Whatley, Downing, Kesler \& Harlow 1986

(Figs. 45A-Q, 43B)

* 1986 Poseidonamicus ocularis Whatley et al.: 390, pl. 1 figs. 9-13.

Material: Over 800 adult and juvenile valves. - SMF Xe 21585-21589.

Dimensions: Female L $0.85-0.87 / 0.45-0.50$, R 0.82 $0.85 / 0.45-0.47$; male L $0.80-0.82 / 0.42-0.45$, R $0.80-0.85 /$ $0.40-0.45$.

Distribution: Holocene of the South Tasman Rise. Abundant in samples BX140 (1636 m) and BX147 (2177 $\mathrm{m})$. Very common in sample BX141 $(1690 \mathrm{~m})$. Common in sample BX153 (1874 m).

Remarks: WHATLEY et al. (1986) described P. acularis from the Quaternary of the Western Pacific Ocean, including the Tasman Rise (DSDP site 281). The small ocular structure, to which the specific name refers, did not necessarily function (Whatley et al. 1996). In fact, in the specimens herein studied no ocular pit was observed internally. Additionally, in many adult specimens an open pore was detected at the edge of the AT (Fig. 45I). Through transmitted light, it was possible to see that on the outer ocular region a small normal pore occurs (Fig. $45 \mathrm{~N}$ ), which opens internally into the AS (Fig. 45D). The ocular feature is most likely a complex structure linked to some tactile/sensory function, under conditions in which eyes are of no use as in the deep see.

\section{Poseidonamicussp.}

(Figs. 46A-N, 43C)

1987 Poseidonamicus sp. cf. P. major. - WhATLEY \& Coles: 81 , pl. 6 fig. 11

1988 Poseidonamicus ex gr. P. miocenicus. - STEINECK et al.: 605, pl. 2 figs. 8-9.

1988 Poseidonamicus ex gr. P. major. - STEINECK et al.: 605, pl. 2 figs. 10-11.

2000 Poseidonamicus sp. cf. P. major. DIDIE \& BaUCH: 111, pl. 4 figs. 6-7.

2003 Poseidonamicus minor. - Jellinek \& SWanson: 70, pl. 70, figs. 3-4.

Material: Over 300 adult and juvenile valves. - SMF Xe 21590-21597.

Dimensions: Female L $0.92-1.02 / 0.55-0.60$, R $0.92-$ 1.00/0.55-0.60; male L $0.92-1.10 / 0.55-0.65$, R $0.90-1.07 /$ $0.50-0.57$.

Distribution: Holocene of the South Tasman Rise. Very common in sample BX141(1690 m); common in sam- ples BX138 (3022 m), BX156 (3208 m), BX161 (3685 m) and BX165 (4067 m); abundant in sample BX147 (2177 m).

Remarks: Although this species is moderately abundant in the samples studied it remains an indeterminate species because it displays characters intermediate between $P$. major, $P$. minor and P. pintoi.

Poseidonamicus sp. differs from $P$. major in its dorsal carina which slopes anteriorly, only two-three ribs on the dorsal margin which are not present in juveniles and a different arrangement of the postero-lateral reticulation. The two species share a similar outline and dimensions.

It differs from $P$. minor BENSON (1972: 53, pl. 10 figs. 13-14) in that the vertical muri are not stronger than the horizontal equivalent and because it lacks the two vertical ridges on the posterior end. For the same reasons, $P$. minor (JELLINEK \& SWANSON 2003) cannot be referred to the BENSON species but most likely to this species. $P$. sp. and $P$. minor display the same oblique development of the dorsal carina and the same number of ribs on the dorsal margin.

It differs from P. pintoi (BENSON 1972) because of the larger dimensions, the more pointed posterior and the oblique anterior. Moreover, $P$. pintoi seems to be a typical Atlantic species. $P$. sp. and $P$. pintoi display the same development of the reticular pattern, without main differences in the emphasis of vertical and horizontal muri.

Finally, ic differs from P. miocenicus BENSON (1983) because it has much narrower muri, especially the vertical elements and a more regular reticular pattern in the postero-ventral region.

Until a certain definition of $P$. major, $P$. minor and $P$. pintoi does not exist, based on soft anatomies especially, determination at specific level will remain problematic.

\section{Poseidonamicus cf. P. anteropunctatus Whatley, Downing,} KeSLER \& HaRLOW 1986

(Figs. 46O-P)

Material: 27 juvenile valves. - SMF Xe 21598-21600.

Dimensions: juv. L. $0.85 / 0.50$, R. $0.87 / 0.47$ (larger moults).

Distribution: Holocene of the Emerald Basin. Rare in sample BX116 (4462 m). Holocene of the South Tasman Rise. Rare in samples BX161 (3685 m) and BX165 (4067 m).

Remarks: Only juvenile valves were recovered and few adult fragments. The peculiar reticular pattern of the anterior field, with shallow fossae each subdivided in 3-5 punctae is very similar to that described by WHATLEY et al. (1986: 389, pl. 1 figs. 4-8). Neither in the plates nor in the description did those author mention a subdivision of the solae in the posterior field as it occurs in the specimens studied. P. anteropunctatus was originally found in Miocene to Quaternary sediments from the South West Pacific. The material studied is too rare and poorly preserved for a more accurate determination. 


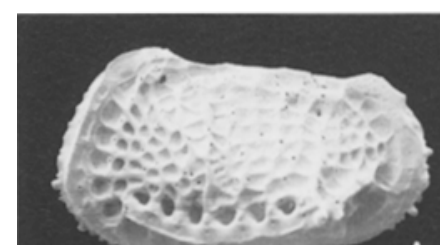

A

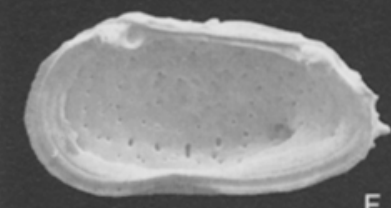

F
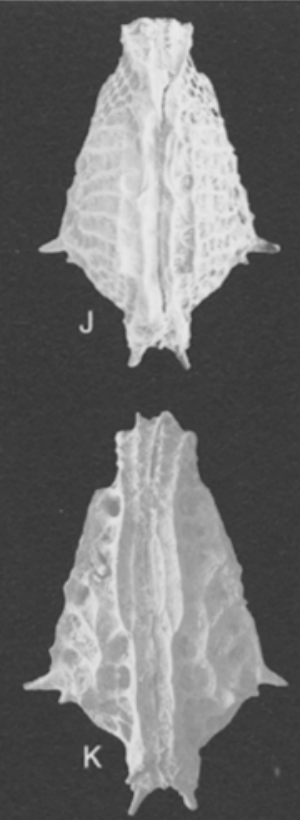

C

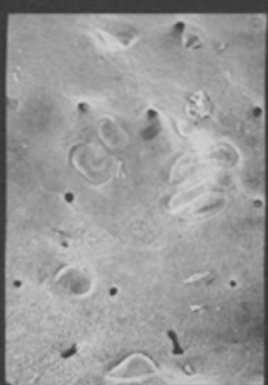

O

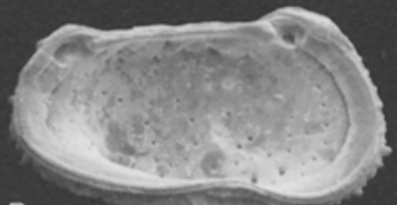

B

E
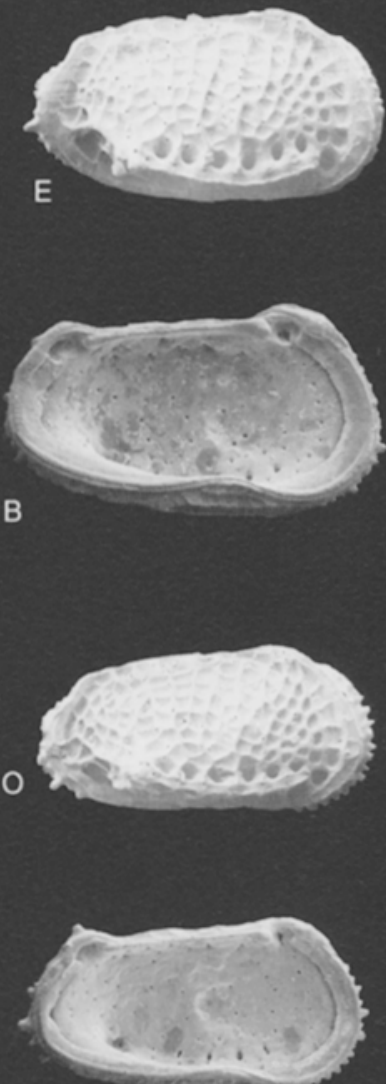

M

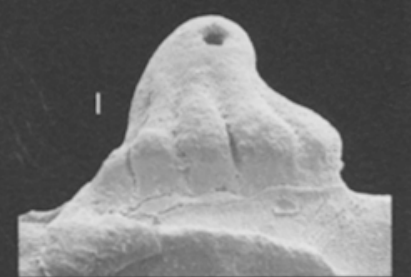

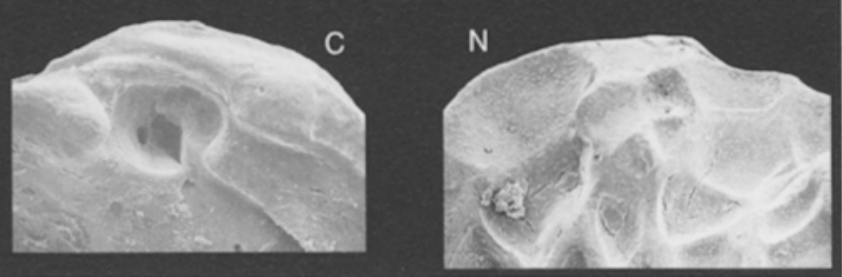

Fig. 45: Poseidonamicus ocularis Whatley, Downing, Kester \& Harlow 1986

Recent, sample BX 140; South Tasman Rise, off south coast Tasmania, Australia; S49 $10.84^{\prime}$, E150¹0.13', $1636 \mathrm{~m}$. - female L (0.87/0.50); A: external view; B: internal view; C: anterior hinge element, $x 170$; D: posterior hinge element, $\times 170$. SMF Xe 21585. - female R (0.82/0.45); E: external view; F: internal view; G: posterior hinge element, $\times 188 ; \mathrm{H}$ : anterior hinge element, $\times 188$; I: dorsal view of the anterior hinge element, $\times 355$. SMF $\mathrm{Xe} 21585$. - female C $(0.85 / 0.47 / 0.47)$; J: dorsal view, $\times 38 ; \mathrm{K}$ : ventral view. SMF Xe 21585. - male L (0.80/ $0.42)$; L: external view; $M$ : internal view; $N$ : fossae on the lateral surface in the ocular region, $\times 204$. SMF Xe 21585. - male R (0.80/0.40); O: external view; P: internal view; Q: central muscle scars, fulcral point and two dorsal muscle scars, $\times 147$. SMF Xe 21585. - All magnifications are $\times 45$ unless otherwise stated. 


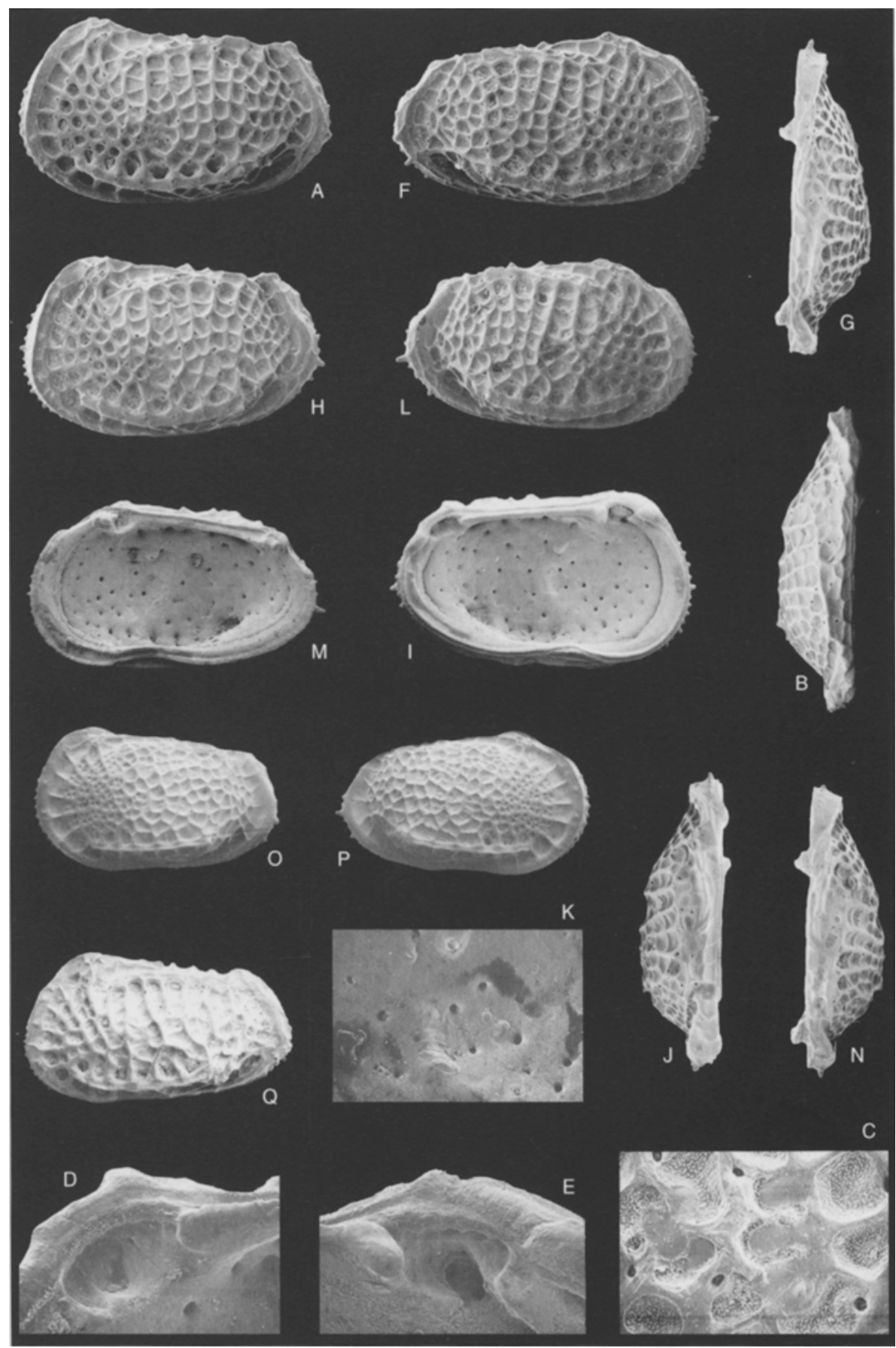

Fig. 46: A-N: Poseidonamicus sp.

Recent, sample BX165, South Tasman Rise, off south coast Tasmania, Australia; S45 $18.26^{\prime}$, E147 $55.13^{\prime}, 4067 \mathrm{~m}$. - male L (1.05/0.62); A: external view; B: dorsal view; C: detail of the lateral surface ornamentation on the muscle-scars area, $\times 180$; D: detail of the posterior socket, $\times 164$; E: detail of the anterior socket, $\times 164$. SMF Xe 21590. - male R (1.07/0.57); F: external view; G: dorsal view. SMF Xe 21590. - Recent, sample BX161, South Tasman Rise, off south coast Tasmania, Australia; S46 $33.18^{\prime}$, E149 $04.96^{\prime}, 3685 \mathrm{~m}$. - female L (1.02/0.60); H: external view; I: internal view; J: dorsal view; K: central muscle scars, x138. SMF Xe 21592. - female R (1.00/0.60); L: external view; M: internal view; N: dorsal view. SMF Xe 21592.

O-P: Poseidonamicus. cf. P. anteropunctatus Whatley, DownIng, KesLer \& Harlow 1986

Recent, sample BX165, South Tasman Rise, off south coast Tasmania, Australia; S45 $18.26^{\prime}$, E147 $55.13^{\prime}, 4067 \mathrm{~m}$. - juv. L (0.85/0.50); O: external view. SMF Xe 21598. - juv. R (0.87/0.47); P: external view. SMF Xe 21598.

Q: Poseidonamicus cf. P. minor BENSON 1972

Recent, sample BX153, South Tasman Rise, off south coast Tasmania, Australia; S47 $46.85^{\prime}$, E149 $23.73^{\prime}, 1874 \mathrm{~m}$. - ? male L (0.92/0.52); Q: external view. SMF Xe 21601 - All magnifications are $\times 40$ unless otherwise stated. 
Poseidonamicus cf. P. minor BENSON 1972

(Fig. 46Q)

Material: 2 adult and 13 juvenile valves. - SMF Xe 21601.

Dimensions: ? male L $0.92 / 0.52$.

Distribution: Holocene of the South Tasman Rise. Rare in sample BX153 (1874 m).

Remarks: All specimens were very fragile and poorly preserved but still exhibit the enhanced vertical muri and the four ribs on the dorsal margin. P. minor BENSON (1972: 5354, pl. 10 figs. 13-18), from the Pleistocene-Recent of the SE Pacific, is described with a punctate anterior field and with slightly larger dimensions $(0.98 / 0.60)$. WHATLEY et al. (1986: 389, pl. 1 figs. 2-3) reported this species from Middle Miocene to Quaternary sediments of the SW Pacific and illustrated two small specimens $(0.87 / 0.58$ and $0.93 / 0.54)$ from the Quaternary. Because of the smaller dimensions, the lack of the punctate anterior field and the bad preservation, these specimens are just compared with BENSON's species.

\section{Genus Bradleya HorNiBrooK 1952}

Type species: Cythere arata BRADY (1880).

Remarks: Hornibrook established the genus for a group of Cenomanian to Recent species from New Zealand.

The detailed work of Benson (1972) alluded to the fact that the recognition of different species of Bradleya is difficult due to the complex pattern of ornamentation. This complexity had led to an unclear concept of the genus, which led BENSON to title his paper: "The Bradleya problem". Although 30 years have passed since its publication, the paper of BENSON is still a key reference for both its methodology and illustrations. WHATLEY et al. (1984), after an examination of samples from the SW Pacific, described several new species of Bradleya. In order to facilitate the recognition of the species, they proposed a division into: the $B$. dictyon group and the non- $B$. dictyon group. They recognised the bridge as a morphological element to distinguish those groups. In the studied samples, all the species, except $B$. dictyon, belong to the non- $B$. dictyon group.

\section{Bradleya mesembrina n. sp.}

(Figs. 47A-K, 48B)

Derivation of the name: From the Greek adjective mesembrinos = Southern; referring to the Southern Ocean where this species has been found.

Holotype: Female L (1.00/0.60), Figs. 47A-D. - SMF Xe 21602.

Paratypes: 46 adult and 322 juvenile valves. - SMF Xe 21603-21609.

Dimension (of paratypes): Female L 1.00-1.15/0.600.70, R 0.97-1.10/0.57-0.70; male L 1.02-1.15/0.60-0.65, R 1.05-1.12/0.57-0.62.

Type locality: RV SONNE cruise no. SO 136, site 28, station 140; box-corer sample from the S Tasman Rise, off S
Tasmania, Australia, at $1636 \mathrm{~m}$ water depth; $\$ 49^{\circ} 10.84^{\prime}$, $\mathrm{E} 150^{\circ} 10.13^{\prime}$.

Distribution: Holocene of the South Tasman Rise. Very common in samples BX138 (3022 m), BX140 (1636 m), BX147 (2177 m), BX153 (1874 m), BX161 (3685 m). Rare in sample BX141 (1690 m) and BX156 (3208 m).

Diagnosis: Medium-sized Bradleya with thick muri. Fossae fused in the posterior area. Postero-dorsal and anteroventral carinae pronounced. Weak ocular ridge. Surface of the fossae covered with a secondary reticulation, formed by small chains of circular pits.

Description: Robust sub-rectangular species of the non- $B$. dictyon group (WHATLEY et al. 1984). Anterior margin asymmetrically rounded (L) to evenly rounded (R). Posterior margin truncated in $\mathrm{R}$, asymmetrically rounded in $\mathrm{L}$. Thick marginal rims, anterior of which with short spines, posterior bearing few spines medially. Dorsal margin sinuous due to the pronounced dorsal carina and the hinge ear. Ventral margin straight. Greatest length below mid-height, greatest height at anterior cardinal angle. Well developed reticulum with pronounced muri some of which are suppressed. As a result, many fossae are fused, especially posteriorly. Antero-ventral carina strong or suppressed near the ocular ridge area. Postero-dorsal carina short, extending from the posterior rim till immediately above the MS zone, where it is deflected into the irregular bridge structure. Each solum of the fossae is covered with small circular pits arranged in chains, surface of muri smooth as is the exterior surface above the MS attachment point. Normal pores both in conjunctive and disjunctive positions. They are sieve-type but the sieve plate is in different positions: closer to the internal surface when they are intramural, closer to the outer surface when they open on the solum (Figs. 47J-K). Marginal pore-canals straight, simple, occasionally bifurcate in the ventral area, 21-27 anteriorly, 1013 posteriorly. In dorsal view, maximum width in the posterior third at the edge of the ventral carina.

Internally: dorsal margin straight, ventral margin slightly concave in the oral region. Inner lamella wide, vestibulum not developed, selvage moderately strong. Hinge holamphidont. $\mathrm{R}$ with stepped AT and kidney-shaped PT, median groove smooth with a small, round socket opening behind the AT. L with deep AS and adjacent round tooth, median bar smooth and widening at both ends. PS wide with peculiar oblique incisions inside. Adductor MS consist of a vertical row of four: the upper most oval, the second uppermost elongate and the lower two smaller, elongate and close to each other. Two frontal scars, the lowermost drop-shaped and larger than the round posterior one.

In juveniles, the younger the instars the more the secondary reticulation expands on the muri. In many specimens, a horizontal median carina is present, parallel to the other two. The hinge is paramphidont with faintly lobate PT.

Remarks: Any similarity between $B$. mesembrina n. sp. and B. nomani (BrADY) (1866: pl. 61 figs. 5a-d and 1880: pl. 17 figs. 3a-d, pl. 26 figs. $4 \mathrm{a}-\mathrm{b})$ is difficult to determine since the drawings provided by BRADY lack detail. He illustrated several specimens of which some "are doubtfully referred to Cythere normani" (1880: pl. 26). BENSON (1972) 


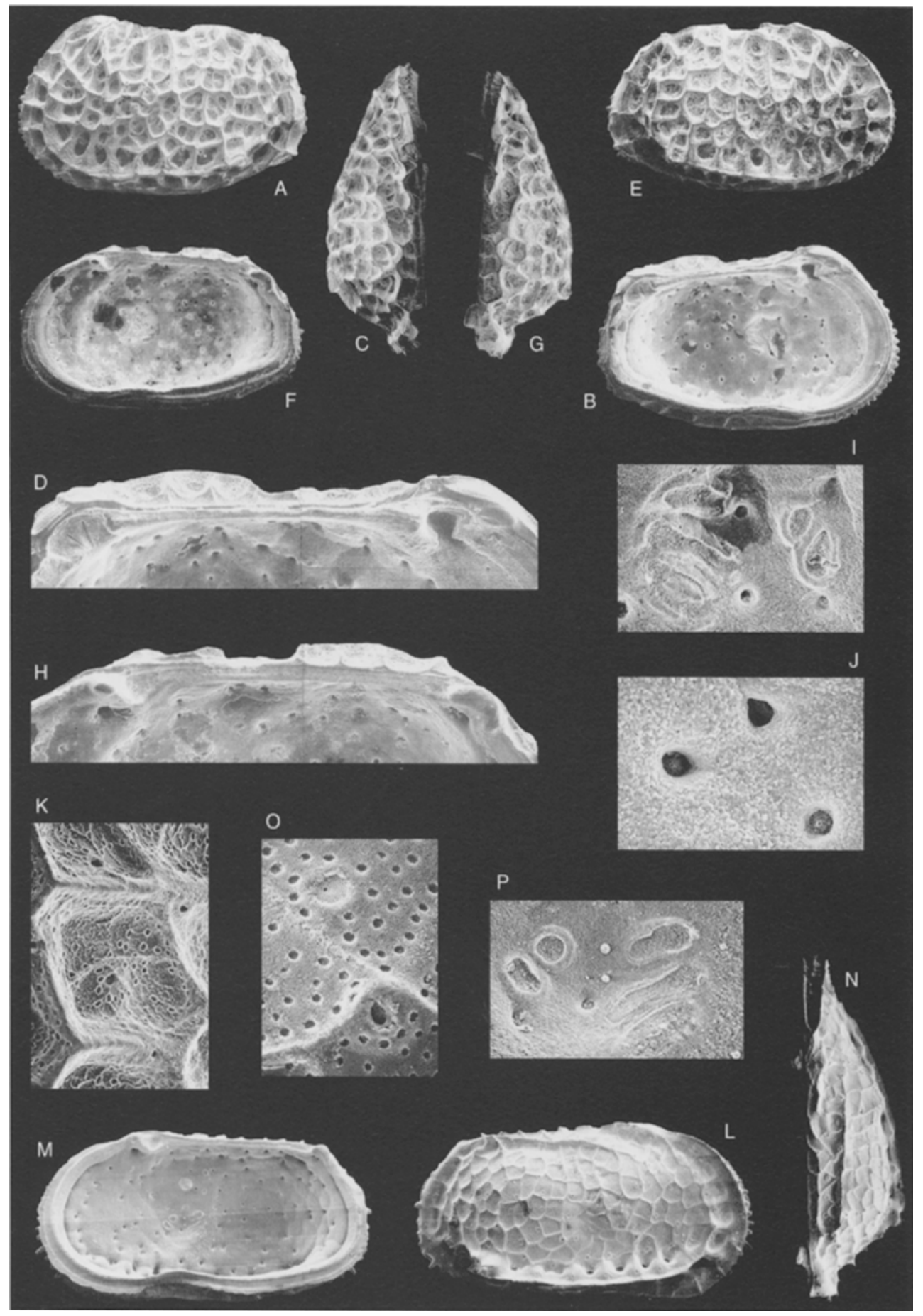

Fig. 47: Bradleya mesembrina n. sp.

Recent, sample BX 140; South Tasman Rise, off south coast Tasmania, Australia; S49 $10.84^{\prime}$, E150 $10.13^{\prime}$, 1636 m. - female L (1.00/0.60), holotype; A: external view; B: internal view; C: dorsal view; D: hinge elements, $\times 93$. SMF Xe 21602. - female R (0.97/0.57), paratype; E: external view; F: internal view; G: dorsal view; $H$ : hinge elements, $\times 93$; I: central muscle scars, $\times 194$; J: internal view of sieve-type pore canals, $\times 354$; K: surface ornamentation, $\times 243$. SMF Xe 21603.

L-P: Bradleya cupa JellineK \& SWANSON (2003)

Recent, sample BX161, South Tasman Rise, off south coast Tasmania, Australia; S46 33.18', E149 $04.96^{\prime}$, 3685 m. - R (1.15/0.62); L: external view; M: internal view; $N$ : dorsal view; O: surface ornamentation and sieve-type normal pores, $\times 416$; P: central muscle scars, $\times 184$. SMF Xe 21610. - All magnifications are $\times 45$ unless otherwise stated. 


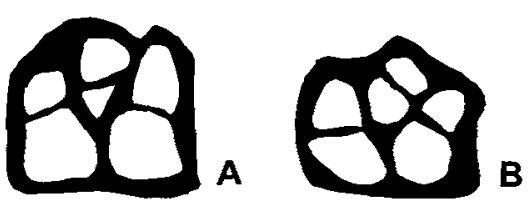

Fig. 48: Schematic drawing of the postero-ventral reticular pattern of right valves. - A: Bradleya nor mani (from FoSTER \& KAESLER, 1988); B: Bradleya mesembrina n. sp. are extremely large $(1.38 / 0.80)$. JELLINEK \& SWANSON recovered living specimens in $927 \mathrm{~m}$ of water depth, in the southeastern Campbell Plateau and figured specimens with celation of the sieve pores. The latter feature lacks in the specimens from the South Tasman Rise, maybe due to erosion. The recovery of this species along the South Tasman Rise and at abyssal depths expand the geographical and barhymetrical range of the species.

\section{Bradleya cf. B. dictyon (BRADY 1880)}

(Figs. 49A-C)

considered only the specimens figured by BRADY (1880) on pl. 17 to be synonymous. Foster \& KAESLER (1988) had a different opinion, because they had the opportunity to study the original material of BRADY (1866) dredged from Abrolhos Bank, off Brazil, at unknown depth, from which they designated a lectorype. $B$. mesembrina $\mathrm{n}$. sp. is similar to $B$. norma$n i$ as illustrated by BENSON (1972: Fig. 13c, pl. 2 fig. 7, pl. 7 fig. 8 , pl. 8 fig. 6) and by Foster \& KaEsler (1988). In $B$. normani sensu FOSTER \& KAESLER the secondary reticulation covers only the muri and not the solae; the bridge structure and also the postero-ventral reticular pattern are different. The latter, as suggested by FOSTER \& KAESLER, is formed by the arrangement of six fossae between the ventral carina and the posterior part of the vertical loop. Compared with the lectotype and the morphs illustrated by FOSTER \& KAESLER (1988: Fig. 1/33) the postero-ventral reticular pattern of $B$. mesembrina differs in the relative position of the fossae and the different organisation of the fusion processes of the fossae (Fig. 48).

Juveniles of $B$. mesembrina resemble those of $B$. antarctica HARTMANN (1989) because of presence of the three parallel horizontal carinae, a feature which is lost in the adults of the species from the South Tasman Rise.

Another similar species was recorded by WHATLEY et al. (1996: 69, pl. 3 fig. 14) as Poseidonamicus sp. from shallow depth $(74 \mathrm{~m})$ of the southern part of the Strait of Magellan. The specimen they illustrated has a very suppressed ocular ridge and is smaller but displays a similar pattern of sub-divided solae on the postero-ventral area.

\section{Bradleya cupa JeLINEK \& SWANSON 2003}

(Figs. 47L-P)

Material: 2 adult and 16 juvenile valves (1 juv. C). SMF Xe 21610. 0.60 .

Dimensions: R 1.15-1.22/0.62-0.70; juv. L 1.10 /

Distribution: Holocene of the South Tasman Rise. Common in sample BX161 (3685 m).

Remarks: This extremely large species occurs only at site 33 with well preserved juveniles and only two adult Rs. WHATLEY et al. (1984) recovered this species in Quaternary sediments of the Campbell Plateau, off south coast of New Zealand, at $1214 \mathrm{~m}$ of depth. The dimensions they reported
Material: 38 juvenile valves. - SMF Xe 21611-21612.

Dimensions: juv. L $0.87 / 0.47$; juv. R $0.95 / 0.52$.

Distribution: Holocene of the South Tasman Rise. Common in samples BX140 (1636 m) and BX153 (1874 m).

Remarks: This species is very similar to $B$. dictyon as described by BENSON (1972: 34-38, Fig. 13B, 15, pl. 11 fig. 18). He designated a lectotype from BRADY's material, hosted at the British Museum, clarifying the concept of the species because he assumed that BRADY identified under Cythere dictyon at least three species of two genera. In fact, BRADY (1880: 99, pl. 24 figs. 1a-y) illustrated several specimens trying to illustrate this "widely-distributed and variable species".

In the juveniles from the Tasman Rise, the postero-dorsal loop is always present as is the bridge structure which is typical for the species. The reticulum is not foveolate, as it is described for the BENSON specimens, but it is unclear whether this is a reflection of the ontogenetic development.

Bradleya dictyon was found in Holocene-Quaternary specimens in the Atlantic Ocean (BENSON 1972 and 1977), in the Southern Ocean (BENson 1972) and in the Pacific and Indian oceans (AYRESS 1988).

Type species: Harleya davidsoni JeLlineK \& SwANSON 2003.

Remarks: This genus was introduced to accommodate species with intermediate characters between the genera $\mathrm{Bra}$ dleya and Poseidonamicus. To date, Harleya has been found only in the southern hemisphere (Tab. 11).

The ornamentation of the type species is described by JeLLINEK \& SWANSON as an "irregular to polygonal meshwork" and they also concluded that one of the differences between Harleya and Poseidonamicus was the lack of the ridge and cell pattern. Additionally, in comparison with Poseidonamicus, $H$. lacks the central mural loop, the dorsal carina and the anterior reticular field composed of round fossae. In contrast with Bradleya, $H$. has a suppressed ocular ridge, lacks the bridge structure, the postero-dorsal loop and the median ridge.

Celation of the reticulum occurs commonly in the Hemicytheridae. For example, in the type species of Bradleya ( $B$. arata) overgrowth of the muri show extreme development. In both Bradleya and Poseidonamicus species lacking reticulation

\section{Genus Harleya Jeldinek \& SWanson 2003}




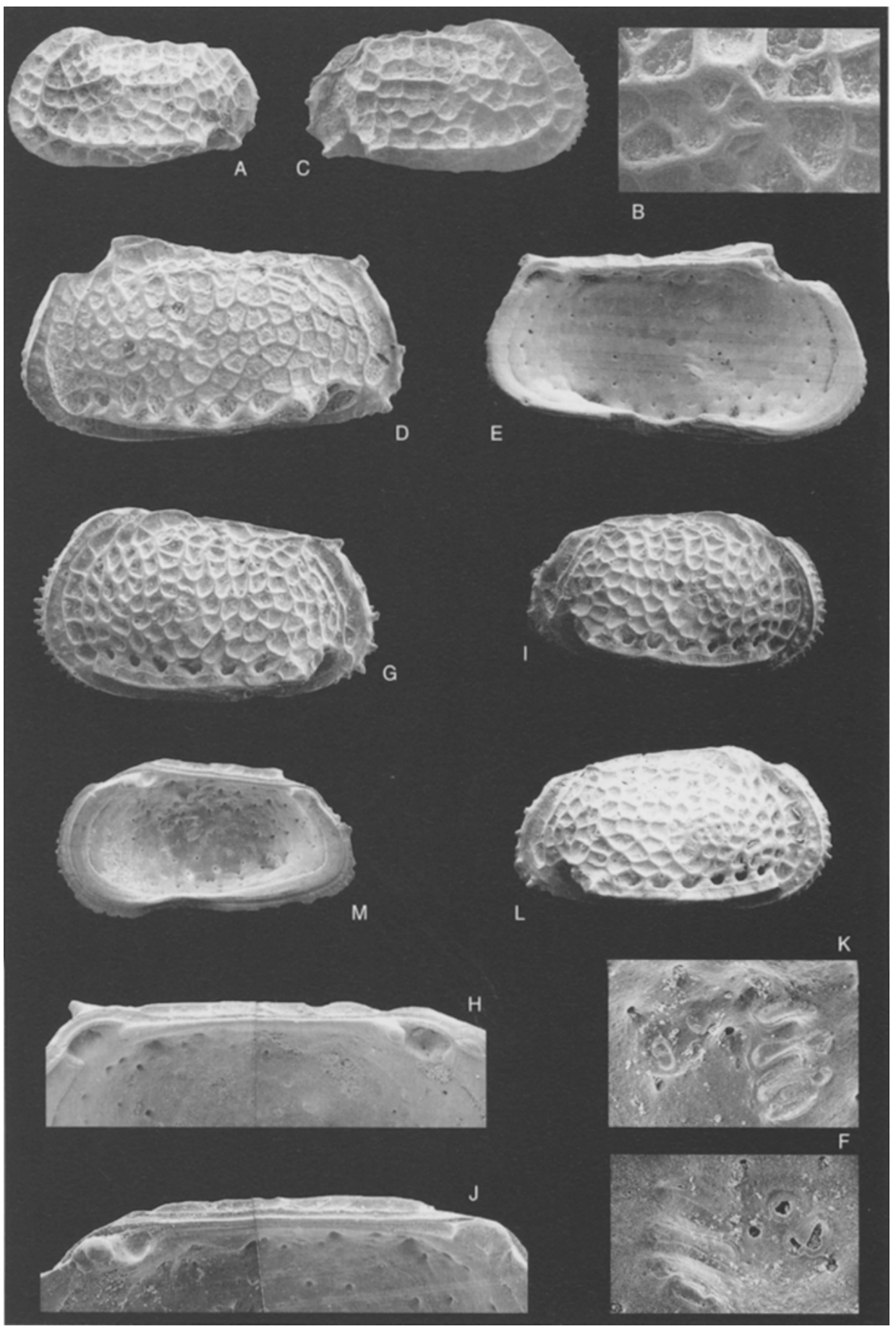

Fig. 49: A-C: Bradleya cf. B. dictyon (BRADY 1880)

Recent, sample BX153, South Tasman Rise, off south coast Tasmania, Australia; S47 $46.85^{\prime}$, E147 $55.13^{\prime}$, $1874 \mathrm{~m}$. - juv. L (0.87/0.47); A: external view; B: detail of the external ornamentation on the central muscle scars area, x109. SMF Xe 21611. - juv. R (0.95/0.52); C: external view. SMF Xe 21611.

D-F: Harleya cf. H. ansoni (Whatley, MogVilevsky, Ramos \& Coxill 1986)

Recent, sample BX153, South Tasman Rise, off south coast Tasmania, Australia; S47 $46.85^{\prime}$, E147 $55.13^{\prime}$, $1874 \mathrm{~m}$. - female L (1.32/0.72); D: external view; E: internal view; F: central muscle scars, $\times 134$. SMF Xe 21613.

G-M: Harleya sp.

Recent, sample BX141, South Tasman Rise, off south coast Tasmania, Australia; S49 08.34', E14954.98', $1690 \mathrm{~m}$. - male L (1.15/0.65); G: external view; $\mathrm{H}$ : detail of the hinge, $\times 75$. SMF Xe 21614. - female $R$ (1.02/0.57); I: external view; J: detail of the hinge, $\times 84$; K: central muscle scars, $\times 175$. SMF Xe 21614. Recent, sample BX140; South Tasman Rise, off south coast Tasmania, Australia; $\$ 49^{\circ} 10.84^{\prime}$, E150 $10.13^{\prime}$, 1636 m. - male R (1.12/0.60); L: external view; M: internal view. SMF Xe 21616. - All magnifications are $\times 42$ unless otherwise stated. 
Table 11: Distribution of the species of Harleya with their geographical and depth ranges.

\begin{tabular}{|c|c|c|c|}
\hline species & author & geographic location & $\operatorname{depth}[\mathrm{m}]$ \\
\hline davidsoni & JeLIINEK $\&$ SWANSON in press & S Pacific Ocean $\$ 50^{\circ}-S 55^{\circ}$ & $1362-3440$ \\
\hline ansoni & (WHATLEY et al. 1998) & $S$ Atlantic Ocean $S 53^{\circ}-S 61^{\circ}$ & $990-2370$ \\
\hline sp. & (WhatLEY et al. 1998) & $S$ Atlantic Ocean $\$ 53^{\circ}-S 61^{\circ}$ & $1270-1408$ \\
\hline (P. pintot) & (WhaTLEY et al. 1998) & S Atlantic Ocean $S 53^{\circ}-S 62^{\circ}$ & $1340-3925$ \\
\hline cf. H. ansoi & present paper & Tasman Sea $\$ 49^{\circ}-\$ 47^{\circ}$ & $1636-1874$ \\
\hline sp. & present paper & Tasman Sea $\$ 49^{\circ}-\$ 47^{\circ}$ & $1636-1874$ \\
\hline
\end{tabular}

are represented by $B$. nuda BENSON (1972), B. glabra JELLINEK \& SWANSON (2003) and $P$. nudus BENSON (1972). It is not surprising therefore, that in Harleya a similar development of the ornamentation may occur, such that celate taxa and those with well developed reticulum are included in this genus.

\section{Harleya cf. H. ansoni \\ (Whatley, Moguilevsky, Ramos \& Coxill 1998)} (Figs. 49D-F)

Material: One broken adult and 46 juvenile valves. SMF Xe 21613.

Dimensions: L 1.32/0.72; juv R 1.12/0.55.

Distribution: Holocene of the Emerald Basin and the South Tasman Rise. Common in sample BX153 (1874 m).

Remarks: This species displays an ornamentation pattern which coincides with that described for $H$. ansoni (WHATley, Moguilevsky, Ramos \& Coxill 1998: 132, pl. 5 fig. 11) from the Scotia Sea and from the Campbell Plateau (JELLINEK \& SWANSON 2003). Both authors reported dimensions slightly smaller than those of the adult specimen recovered in the present study.

\section{Harleya sp.}

(Figs. 49G-M)

Material: 21 adult and 149 juvenile valves. - SMF Xe 21614-21617.

Dimensions: Female L 1.05-1.10/0.60-0.62, R 1.021.07/0.57-0.60; male L 1.02-1.15/0.60-0.65; R 1.07-1.12/ $0.55-0.60$.

Distribution: Holocene of the South Tasman Rise. Very common in sample BX140 (1636 m), BX141 (1690 m) and BX153 (1874 m).

Description: Medium-sized Harleya with weakly pronounced cardinal angle in $\mathrm{R}$, more pronounced in $\mathrm{L}$. Sub-rec- tangular in shape. Anterior margin rounded, slightly asymmetrical in the L. Posterior margin obliquely truncated. Thick marginal rims, anterior with 16 short, thick marginal denticles, posterior with 7 denticles and a longer postero-dorsal spine. Dorsal margin straight with cardinal angles more pronounced in the L. Ventral margin slightly concave in the oral region, not obscured by the ventral carina. Maximum length below mid-height, maximum height at anterior cardinal angle, maximum width behind the posterior culmination of the ventral carina. Reticulum well developed. Fossae without a preferred orientation and variable in shape. Muri and solae smooth, with sieve-type pores both in disjunctive and conjunctive positions, some developed as pore conuli. The dorsal part of the ocular ridge is well developed and forms a peculiar arch with three fossae just posterior to the anterior cardinal angle. In some of the specimens, a faint central mural loop can occur, but this is not a constant feature. The external MS area is smooth, characterised by larger muri and/or fused muri. Strong ventral carina, deeply excavated and almost ponticulate. Marginal pore-canals not easily discriminated due to the thickness of the valves but they seem to be slightly sinuous, simple and thin; 25 anteriorly, 18 posteriorly.

Internally: dorsal margin straight, ventral margin slightly concave in the oral region. Inner lamella wide without vestibulum. Hinge holamphidont. $\mathrm{R}$ with a round and stepped AT, circular adjacent socket, smooth groove which expands posteriorly, large and bean-shaped PT. In the L, wide AS and round adjacent tooth connects with a smooth bar, wide PS. In the PS, a pore occurs, which exits through the postero-dorsal spine. Adductor MS in a vertical row of four, the lowermost elongated, the middle two dumbbell-shaped, and the upper oval. Three frontal scars composed of two small, round posterior and a large anterior which is elongated along the vertical axis. This MS pattern was observed in all of the adults except one $L$, where the anterior and lower posterior frontal scars were fused.

In juveniles, the anterior and the lower posterior frontal scars may be closer and also fused. The hinge is paramphidont with a slightly lobate PT.

Remarks: This species differs from all other Harleya taxa in its well developed network of smooth meshes which characterises the ornamentation. 
H. sp, is larger than P. pintoi (BENSON 1972), lacks the round solae on the anterior and the dorsal carina, and has three antennular scars. The species is left under open nomenclature because of the poor preservation and the low number of adult valves recovered.

\section{Family Rockalliidae}

Whatley, Uffenorde, Harlow, Downing \& Kesler 1982

Remarks: The relatively recent history of the family Rockalliidae is a consequence of increased deep-ocean sampling which resulted in the recovery of this rare small ostracod. Whatley et al. (1982) erected the family Rockalliidae to accommodate Rockallia enigmatica WhatLey, Frame \& WhITTAKER (1978)from NE Atlantic, three species from Eocene, Neogene and Quaternary sediments of SW Pacific and two species from Oligocene-Miocene of NW Europe. The family was monotypic, represented only by the species Rockallia enigmatica and subsequently only by the genus Arcacythere HorNIBROOK (1952), considered by AYRESS (1991) as a senior synonym of Rockallia. Hornibrook erected the genus Arcacythere (1952: 31-32, pl. 2, figs. 33-35) to accommodate the New Zealand fossil species $A$. chapmani. The specimen he figured has a hinge with a crenulate median element, four adductor scars in a vertical row and one slightly V-shaped antennular scar. Hanai (1957a) erected the new subfamily Pectocytherinae including the three genera: Arcacythere, Munseyella Bold (1957a) (quoted "Toulminia" in HanaI's paper) and Pectocythere HANAI (1957a: 472). Undoubtedly, those three genera have several features in common, accepting the limitation of microscope observations. HaNAI stated that "the hingement of Arcacythere does not display any differentiation of the median element; however, its thick box-shaped carapace with circumscribed ridge and characteristic overlapping of left valve over right at anterior cardinal angle suggests a close relationship of Arcacythere to Pectocythere."

Unfortunately the poor illustrations of the Pectocytherinae do not provide the detail necessary for comparison with the Rockalliidae. But in more recent lirerature it is be apparent that the constant features of Pectocythere are a crenulate median element of the hinge and a vestibulum more developed than in Arcacythere, whereas the ornamentation, the position of paired anterior pore-conuli and the MS pattern are very similar to those of the Rockallidae. The relationship between Pectocytherinae and Rockalliidae remains unresolved with respect to the systematic position of Arcacythere and Rockallia (Tab. 12).

\section{Genus Rockallia Whatley, Frame \& WhitTaker 1978}

Type species: Rockallia enigmatica Whatley, Frame \& WHITTAKER 1978.

Included species: Arcacythere sp. McKenzie (1974), Rockallia enigmatica Whatley, Frame \& WhitTaker (1978), indet. gen. 3. Ducasse \& Peypouquet (1979), Rockallia eocenica Whatley, Uffenorde, HaRlow, Downing \& Kesler (1982), Rockallia inceptiocelata WHATLEY, UfFENORDE, HARLOW, DOWNING \& KeSLER (1982), Rockallia vscripta WhatLEY, Uffenorde, Harlow, Downing \& KesLer (1982), Rockallia woutersi Whatley, UfFenorde, Harlow, Downing \& Kesler (1982), Rockallia sp. Whatley, Uffenorde, Harlow, DownING \& KESLER (1982), Rockallia aff. R. enigmatica BENSON \& Peypouquer (1983), Rockallia sp. A. Cronin (1983), Arcacythere sp. aff. A. chapmani MCKENZIE, REYMENT \& REYMENT (1991), Arcacythere sp. aff. A chapmani McKenzie, ReYmeNT \& REYMent (1993), Arcacythere hornibrooki Yassini (1995).

\section{Rockallia enigmatica Whatley, Frame \& Whittaker 1978} (Figs. 50P, 51B)

* 1978 Rockallia enigmatica WhatLey, Frame \& WhITTAKER: 24, pl. 5 figs. 137-144.

1987 Rockallia enigmatica. - WHATLEY \& COLES: 80, pl. 2 figs. 3-5.

1990 Rockallia enigmatica. - MALZ: 143, Fig. 5/2.

Material: 2 adult valves from the Middle Miocene of the Rockall Plateau, North Atlantic Ocean (DSDP Leg 81) [kindly provided by Dr. T. JeLLiNEK, Senckenberg Museum, Frankfurt am Main].- SMF Xe 21622.

Dimensions: L $0.60 / 0.32$, R 0.57/0.30.

Remarks: In order to compare the two genera forming comprising the family Rockalliidae, one specimen of Rockallia enigmatica from topotypic material is illustrated. Rockallia enigmatica has also been found in Miocene and Pliocene sediments of the North Atlantic also by WHATLEY \& COLES (1987) and MaLz (1990).

Table 12: Different taxonomic classification of the genera Arcacythere and Rockallia.

\begin{tabular}{lllll}
\hline & Hornibrook 1952 & HanaI 1957a & Whatley et al 1982 & AYress 1991 \\
\hline Superfamily & & & Cytheracea & Cytheracea \\
Family & & Cytheridae & Rockallidae & Rockallidae \\
Subfamily & Cytherinae & Rockallidae & & \\
Genus & Arcacythere & Arcacythere & Rockallia & Arcacythere \\
\hline
\end{tabular}




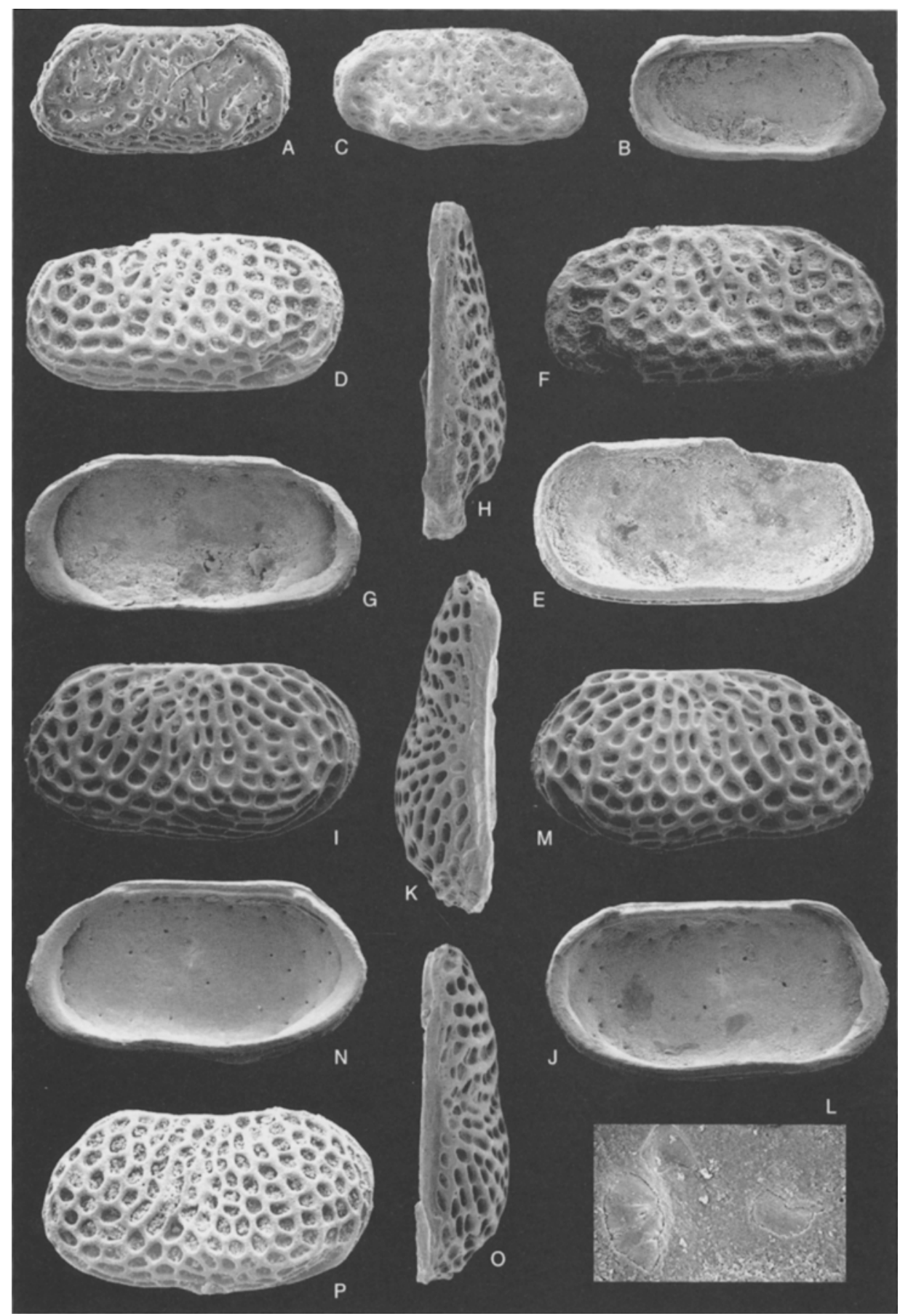

Fig. 50: A-C: Arcacythere aff. A. chapmani Honnibrook 1952

Lower Miocene, east coast of South Island, New Zealand; courtesy of Dr. K.M. Swanson, Univ. Canterbury, New Zealand. - L (0.45/0.22); A: external view; B: incernal view. SMF Xe 21618. - R (0.45/0.20); C: external view. SMF Xe 21618 .

D-H: Rockallia sp. A

Recent, sample BX153, South Tasman Rise, off south coast Tasmania, Australia; $547^{\circ} 46.85^{\prime}$, E1 $147^{\circ} 55.13^{\prime}$, $1874 \mathrm{~m}$. - ? female L $(0.60 / 0.30)$; D: external view; E: internal view. SMF Xe 21619. - ? female R $(0.60 /$ $0.30)$; F: external view; G: internal view; H: dorsal view. SMF Xe 21619.

I-O: Rockallia sp. B

Recent, sample BX138, South Tasman Rise, off south coast Tasmania, Australia; $\$ 49^{\circ} 13.06^{\prime}$, E $151^{\circ} 05.77^{\prime}$, 3022 m. - L (0.60/0.32); I: external view; J: internal view; K: dorsal view; L: central muscle scars, $\times 293$. SMF Xe 21621. - R (0.60/0.32); M: external view; N: internal view; O: dorsal view. SMF Xe 21621.

P: Rockallia enigmatica Whatley, Frame \& WhitTaker 1978

Middle Miocene, Rockall Plateau, North Atlantic; DSDP Leg 81, site 554A; courtesy of Dr. T. JellineK, Senckenberg Museum, Germany. - L (0.60/0.32); P: external view. SMF Xe 21622. - All magnifications are $\times 84$ unless otherwise stated. 

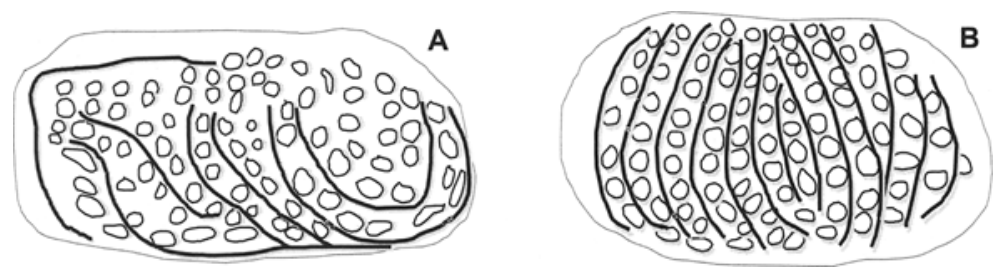

Fig. 51: Schematic drawings of the type species Arcacythere chapmani HoRnibrooK (A) [from Ayress (1991)] and Rockallia enigmatica Whatley, Frame \& Whittaker (B) showing the contrasting ornamentation: only main muri are represented, muri and fossae on the marginal areas are omitted.

\section{Rockallia sp. A}

(Figs. 50D-H)

Material: 4 adults and 3 juvenile valves. - SMF Xe 21619-216120.

Dimensions: ? female L $0.60 / 0.30$; R $0.57-0.60 / 0.27-$ 0.30 ; ? male L 0.60/0.27.

Distribution: Holocene of the South Tasman Rise. Very rare in samples BX140 (1636 m) and BX153 (1874 m).

Remarks: A large species characterised by sub-rectangular posterior margin with thick elevated muri. Fossae large and oval to polygonal. Differs from other species of Rockallia for its peculiar sub-central area within which is a row of three small fossae bordered by thick oval muri. For its dorsal outline especially, it appears to be closely related to Rockallia eocenica WHATLEY et al. (1982), but it is left under open nomenclature because of poor preservation and a lack of specimens.

\section{Rockallia sp. B}

(Figs. 50I-O)

Material: 5 adults and 2 juvenile valves. - SMF Xe 21621.

Dimensions: L $\quad 0.60-0.62 / 0.32-0.35 ; \mathrm{R} \quad 0.57-0.60 /$ $0.27-0.32$.

Distribution: Holocene of the South Tasman Rise. Rare in sample BX138 (3022 m).

Description: Large species of Rockallia. Anterior margin asymmetrically rounded, deflected ventrally. Posterior margin rounded, slightly acuminate at mid-height or slightly above (in L). Dorsal margin slightly upturned posteriorly with a pronounced cardinal angle. Ventral margin of $\mathrm{L}$ slightly concave in the oral region, more concave in the $\mathrm{R}$ and with a 'keel' in the posterior half. Maximum length below mid-height; maximum height at the ventral keel, maximum width in the posterior third. Strongly ornamented. Two rows of unusual fossae extend around and parallel to the outer margin. The distal row is characterised by small celate fossae, especially evident in the postero-dorsal area of $\mathrm{L}$; the second row is composed of deep, elongate-ovate fossae the largest of which is located at the postero-ventral angle in both valves. Dimensions of remaining fossae increase from the upper medial to the margins and they become more sub-rounded. A small node is present in the area of the central MS, as well as two more nodes which correspond to the dorsal MS, close to the dorsal margin. Simple normal pores (15-18) on the muri, with two pore conuli at both ends with the posterior one more developed.

Internally: dorsal margin straight, ventral margin with a slight oral concavity in both valves. The asymmetry of the posterior and anterior margins is well pronounced with the posterior with greatest extension just below mid-height, the anterior above mid-height. Inner lamella narrow with very small vestibula (only partially preserved in the specimens examined). Selvage strong, sub-peripheral. Marginal pore-canals not visible. Hinge lophodont, with smooth elements. PT more pronounced than AT. In dorsal view, two smooth areas are visible above the teeth to accommodate the overlapping $L$. MS arranged in a vertical row of four adductors and a beanshaped frontal scar. A sub-round to sub-triangular fulcral point is visible. Two sub-round dorsal MS occur below the hinge structure. Sexual dimorphism was not observed in the few specimens recovered.

Remarks: $R$. sp. B differs from $R$. enigmatica because of the celate fossae in the dorsal and postero-dorsal marginal areas and the oval-elongate fossae in the postero-ventral area of both valves. It differs from $R$. sp. A in that it is more swollen, with more rounded anterior and posterior and a less pronounced posterior rim.

It differs from all the other species of Rockallia because of the size and the different pattern of ornamentation. It is left under open nomenclature due to the lack of specimens.

Genus Arcacythere HornibrooK 1952 1952.

Type specics: Arcacythere chapmani HORNiBROOK

Included species: Arcacythere chapmani HorNIBrooK (1952), Arcacythere sp. MCKENZIE (1974), Arcacythere chapmani Ayress (1991), Arcacythere aff. chapmani AYress (1991), Arcacythere cf. eocenica Arress (1991), ? Arcacythere aurani BAbinot \& Colin (1992), Arcacythere rugosa Majoran (1995).

Remarks: The genus Arcacythere was erected by HorNIBROOK (1952: 31-32, pl. 2 figs. 33-35) to accommodate the species $A$. chapmani from the Upper Cretaceous to the Middle Miocene of New Zealand. Arress (1991) studied the type 
specimens of A. chapmani (housed at the New Zealand Geological Survey), emended the diagnosis of Arcacythere chapma$n i$ and provided SEM micrographs of four specimens from the type locality (Waiau River, Clifden, Southland). It is probable that not all the specimens illustrated in AYress (1991: pl. 1 figs. $1,6-11,18-19)$ represent the type species, in fact the specimens illustrated in figs. $2-5$ have larger dimensions $(0.50 / 0.21)$ and/or a differing shape when compared to those reported by HorNiBROOK $(0.44-0.40 / 0.20-$ 017). The scanning electron microscope photos indicate that some of the features described by HoRNibrook, e.g. the crenulate elements of the hinge, were not correct. Ayress compared $A$. chapmani with additional specimens from the Tertiary of New Zealand. He included all the species of Rockallia described by WhatLeY et al. $(1978,1982)$ in the genus Arcacythere which then became the only genus representing the family Rockalliidae. It is possible that the two genera exist separately and the following elements are considered distinctive:

- Arcacythere has a truncated posterior whereas Rockallia has a sub-rounded to bluntly acuminate posterior end.

- Arcacythere has thick marginal rims along both ends, Rockallia may have only a posterior rim.

- Arcacythere has a pronounced antero-dorsal ridge.

- Rockallia has a sub-central node.

- Ornamentation consisting of muri and fossae. In $A$. muri dominate and fossae are small and vary in shape and size (Fig. 51A). This is also well expressed in A. rugosa MAJORAN where fossae are not apparent and the ornamentation consists of a network of muri. In $R$. large fossae prevail and may be partially celate (Fig. 51B).

Significantly, McKenzie (1974: 160) indicated "two lineages of Arcacythere" with different time-ranges. He illustrated two different specimens. One $\mathrm{L}$ of a juvenile Rockallia sp. (his pl. 4 fig. 10) from the Recent of the Banks Strait belonging to a lineage with a range Upper Eocene-Recent range and a R of Arcacythere sp. (his pl. 4 fig. 11) which occurs in sediments of Middle Eocene-Lower Miocene age. He also reported living forms of the latter had been recovered from the Sahul Shelf (NW Australia) but those were not illustrated or described.

Taking the splitting in two genera into account, the family Rockalliidae would be represented by Arcacythere, a fossil genus known only from the Late Cretaceous-Middle Miocene of New Zealand (Ayress 1991) and Australia (Majoran 1995) and by Rockallia which is distributed in S Pacific, Europe and Atlantic (Whatley et al. 1982, Benson 1983) from Eocene to Recent. Arcacythere aurani Babinot \& CoLIN (1992), described from the Late Cretaceous of Madagascar displays a different ornamentation and an extremely wide anterior marginal zone. It is here considered to tentatively belong to this genus. Further findings of Cretaceous specimens from Madagascar and India with preserved internal features could confirm its systematic position.
Arcacythere sp. aff. A. chapmani HoRNiBroOK 1952

(Figs. 50A-C)

1991 Arcacythere aff. A. chapmani. - AYress: 224, pl. 1 figs. 12-13.

non 1991 Arcacythere sp. aff. A. chapmani. - MCKEnZIE, Reyment \& Reyment: 158, pl. 6 fig. 5.

non 1993 Arcacythere aff. A. chapmani. - MCKENZIE, REYMENT \& REYMENT: 93, pl. 3 fig. 26.

Material: 4 adult valves from the Lower Miocene of the east coast of South Island (New Zealand); courtesy of Dr. K.M. Swanson, University of Canterbury, New Zealand. SMF Xe 21618.

Dimensions: L $0.45 / 0.22$; R 0.45/0.20.

Description: Small, sub-rectangular inequivalve species. Maximum length at mid-height or slightly below. Maximum height medially in the $\mathrm{L}$ and at the postero-ventral keel in $\mathrm{R}$. Valves of different shapes. $\mathrm{R}$ with a straight dorsal margin, rounded posterior, asymmetrically rounded anterior, mid-ventral curvature and postero-ventral keel. Left valve with straight to slightly concave dorsal, asymmetrically rounded anterior. Ventral margin straight or with a slight mid-ventral curvature and a postero-ventral keel, more developed in the R. Surface ornamentation consisting of thick muri and oval to elongate fossae. The fossae vary in size and become larger ventrally. Fossae organised in vertical and semicircular rows separated by muri of variable width. Prominent muri border the posterior rim, becoming thinner ventrally; the anterior equivalent terminates dorsally, immediately behind the anterior hinge element. Along the outer margin, a double row of fossae, occasionally fused, occurs. This aspect of the morphology is well expressed in the drawings of HORNIBROOK (1952). In dorsal view, the carapace is sub-rectangular in shape with maximum width at posterior half. Marginal rims well developed, especially posteriorly. Normal pore-canals open on muri. Marginal pore-canals few and straight.

Internally: selvage strong, inner lamella narrow to moderarely wide. Hinge lophodont. Small, smooth teeth with a wide median groove in the $\mathrm{R}$. Thick bar and deep sockets in the L. Central MS consisting of a vertical row of four adductor scars, in intimate contact and interdigitating; a reniform frontal scar and a large sub-triangular fulcral point occurring above and forward of the adductor scars. Sexually dimorphic.

Remarks: This species has different proportions to those of $A$. chapmani. It also has more thick muri and a slightly convex dorsal margin of the $\mathrm{R}$. It is very similar to $A r$ cacythere sp. aff. A. chapmani as figured by Arress (1991: pl. 1 figs. 12-13). Both the species illustrated by MCKenzIE et al. $(1991,1993)$ from the Late Oligocene of Australia are not to be considered conspecific because they display a different outline and ornamentation pattern and they lack the heavy marginal rims.

A. sp. aff. A. chapmani Hornibrook has been found in the Early and Middle Miocene of South Island, New Zealand. Since it was not the aim of this project to study Miocene ostracods of New Zealand and only four valves were available, it is left under open nomenclature. With further findings and 
with a clearer description of the type species, it will be possible to provide more accurate caxonomic determinations for this taxon.

\section{Family Krithidae Mandelstam 1958}

\section{Genus Krithe Brady, Crosskey \& RoberTson 1874}

Type species: Ilyobates praetexta SARS 1866.

Remarks: Brady, Crosskey \& Robertson (1874: 183185) gave the new name Krithe to the genus Ilyobates erected by SARS (1866), which was a valid genus name in Coleoptera. In the type description, the extreme simplicity of the valves is expressed as follows: "Valves thin and pellucid, subovate, truncate behind; smooth and shining, and set with very small distant papillae. Hinge-joint simple, formed by a slight projection of the left valve, which is received into a corresponding depression of the right." SARS (1866: 60) in his description of the genus specifies the character of the hinge with "nullibus dentibus" (no teeth). Significantly, most part of both descriptions focuses on soft parts, despite the fact that this genus is very seldom found living, especially in deep waters. The little biological data available are based on a shallow, cryophilic species, $K$. pretexta praetexta from Gullmarn fjord (Sweden), maintained and observed in aquarium over a number of years (MCKenzie et al. 1989, Majoran \& AGreNiUS 1995, Agrenius et al. 1997).

Brady, Crosskey \& Robertson considered $K$ praetexta (SARS 1866) from the Recent of Norway as a junior synonym of $K$. bartonensis (JONES 1857) from the Eocene of England. KEIJ (1957) studied topotypic material of $K$. bartonensis from the Barton Clay and did not mention $K$. praetexta in the synonymy list, whereas VAN MORKHOVEN (1963: 343) clearly stated that the type species of Krithe is $K$. praetexta, being different from $K$. bartonensis. Abate et al. (1993: 351), after comparison of topotypic material of $K$. praetexta with the illustrations of KEIJ (1957), considered both species valid. Additionally, the comparison of KEIJ illustrations of the Eocene specimens with the drawings of the Recent species provided

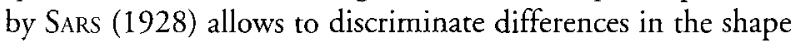
of the two species and in the development of the anterior vestibulum (narrower in $K$. praetexta). For these reasons $K$. praetexta (SARS 1866) is herein considered the type species of Krithe.

The discrimination of differenc species of Krithe is a demanding task. The smooth surface of the valves, combined with the simple hinge and the similarity in shape, provide reasons why in many papers most Krithe species are left under open nomenclature. Recently, several researches attempted to establish protocols for species discrimination. As well as valve shape, size and MS, attention has been paid to the morphology of the vestibula, and, the number and the arrangement of false and true radial pore-canals. COles et al. (1994) examined specimens of Krithe from the Middle Palacocene to the Quaternary of the North Atlantic, identified six different types of anterior vestibulum and described in detail the 'antero-dorsal radial pore-canals complex' (ADRPC) defined by four false pore-canals located on the dorsal side of the vestibulum neck (Fig. 52).

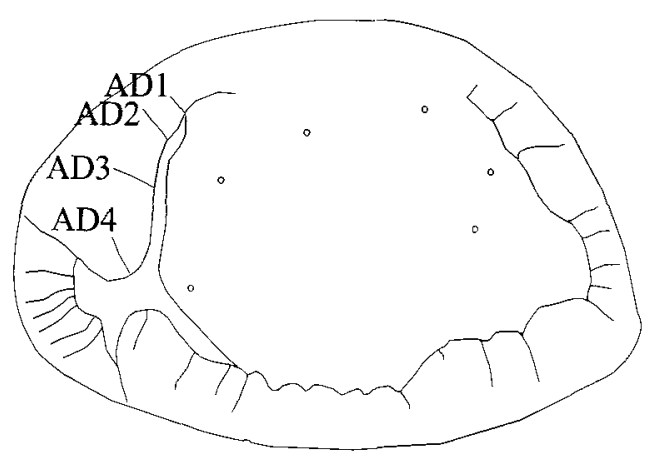

Fig. 52: Schematic camera lucida drawing of a left valve of a Krithe species. The antero-dorsal radial pore canals complex (ADRPC) is defined by four false pore canals on the dorsal neck: AD1-AD4. - From CoLEs et al. (1994).

These canals, numbered from the dorsal-most, are:

AD1: short, very short or absent.

AD2: short, elongate or present as normal pore-canal.

AD3: elongate, very short or absent.

AD4: absent, very short, short and, when emerging at the vestibular neck, elongate or very elongate.

The leading character is the elongate $\mathrm{AD} 2, \mathrm{AD} 3$ or $\mathrm{AD} 4$ and this in combination with the other characters defines seven types of ADRPC arrangement.

This system of identification was followed by AYrEss et al. (1999) in a study on Krithe species from the Early Miocene to the Recent of the Tasman Sea and off Southern Australia. The methodology they proposed (see COLEs et al. 1994, AYrESS et al. 1999 for an exhaustive explanation of the method) assumes that the specimens are well preserved and transparent, such that a detailed study of the inner lamella is possible. It should not be difficult to count the ADRPC and to discriminate which is the longest, however problems arise when some of these false pore-canals are replaced by normal porecanals (NPCs). In fact, if this system is to be followed, NPCs should be also considered in the ADRPC type recognition because they may vary from RPC (radial pore-canal) to NPC within one species, be homologous with RPCs in other species. AYress et al. (1999: 6) wrote about $K$. compressa: "The width of the anterior fused zone varies somewhat, and the normal pore close to AD1 sometimes become a short AD2. In species which have ADRPC of type 2 there is no normal pore in this position but instead a long RPC is present. For this reason we suggest that the normal pore is homologous to $\mathrm{AD} 2$ in other species. Therefore, to maintain natural relationships of the ADRPC system, we include the normal pore when counting ADRPC's. Thus, we assign this species to an ADRPC category of type 1B." It is clear that the specimens must be sufficient well preserved, such that NPCs are not obliterated by erosion/dissolution. On the other hand, in very well preserved valves, where valves are thick or inflated, NPCs can be confused with false RPCs.

Kempf $(1986,1995)$ lists 151 species of Krithe and 25 subspecies. To those, the five new species recognised by ArrESS et al. (1999) and the various species left under open nomenclature must also be added. 

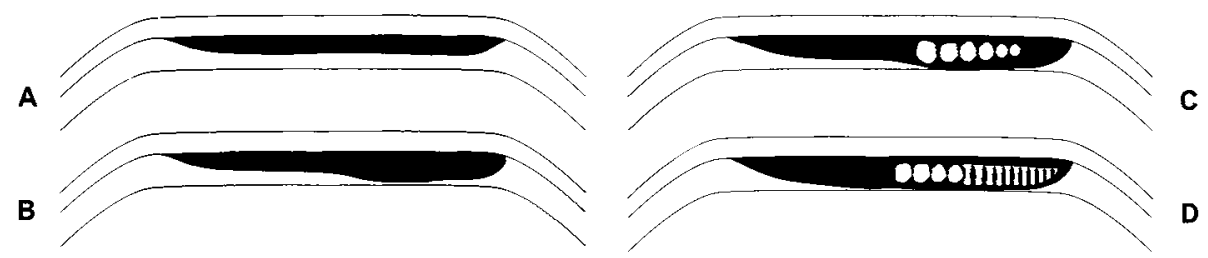

Fig. 53: Schematic drawings of hingement styles in right valves of Krithe A: adont hinge; B: adont hinge with widening posterior; C: pseudadont hinge with a posterior row of small denticles; D: pseudadont hinge with a central row of few denticles and a denticulate bar at posterior.

The application of ADRPC methodology has, in my opinion, led to a misinterpretation of some characters. For example, PucketT (1997), in a study of Krithe from the Upper Cretaceous of the Gulf Coast (North America), applied this method with emphasis on the arrangement of the ADRPC. As he states (1997; 153), "the shape of the vestibulum in specimens collected from the chalk and from the nearshore deposits is different", whereas he found our that the arrangement and position of the ADRPC is constant. As a consequence of this observation, PUCKETT referred all the specimens to the species $K$. cushmani AleXANDER (1929) and included at least two morphotypes, one with a pocker- and the other with a mushroom-shaped vestibulum. PUCKETT considered the arrangement and number of ADRPC as a specific character of more importance than the shape of the anterior vestibulum. COLES et al. (1994: 73-74) considered the shape of the anterior vestibulum as "a very useful specific character, notwithstanding that it is moderately variable within certain species", and further on, "most species can be readily referred to one of the four main types (of anterior vestibulum)." An approach contrasting with that of PUCKETT was adopted by RODRIGUEZ-LAZARO \& CRONIN (1999) in which species of Krithe from 47 core-tops from the Little Bahama Bank (Florida) were studied. Those authors applied the 'ColEs system' considering the shape of the vestibula as the main character and the distribution and length of ADRPC as secondary (Rodriguez-Lazaro \& Cronin 1999: pl. 1 figs. 9-10; $K$. species with same vestibulum type and different ADRPC arrangement).

An additional consequence of the application of the 'COLES system' is that characters as the hinge are devalued or not considered at all. For example, in ArRESS et al. (1999) none of the new described species are accompanied by a description of the hinge, suggesting that all those species have the 'typical' adont hinge. However, from literature, it is evident that Krithe species with a crenulate posterior segment in both groove and bar (= pseudadont hinge) also occur.

During this study, about 4000 specimens of Krithe were recovered, which represents $38 \%$ of the total number of ostracod specimens isolated for the entire project. For every species the average dissolution index $\left(\mathrm{Cl}_{\mathrm{AV}}\right)$ following SWANSON \& VAN DER LINGEN (1994) was calculated. The observations on the inner lamella were possible only on specimens with $\mathrm{CI}$ higher than the $\mathrm{CI}_{\mathrm{AV}}$ of the species.

Camera lucida drawings of the best preserved specimens were made to discriminate the ADRPC arrangement in each of the species. Then, the shape of the anterior vestibulum, outline and dimensions of the valves were compared with the badly preserved specimens. Since in many of the cases the observation of the ADRPC was possible only on few specimens, another kind of taxonomic descriptor had to be identified and this was based primarily on the hinge type (Fig. 53). Species recovered in this study (Tab. 13) were divided in three informal groups:

Table 13: List of the 10 species of Krithe recorded in this study with the corresponding hinge, vestibulum and ADRPC type, the maximum dimensions of the female $\mathrm{L}$ and the depth range in the $\mathrm{S}$ Tasman Rise-Emerald Basin.

\begin{tabular}{llllcc}
\hline Krithe & hinge type & dimensions female $L$ & vestibulum shape & ADRPC type & depth range [m] \\
\hline sp. 1 & adont & $1.22 / 0.65$ & mushroom & 1 & $3022-4067$ \\
sp. 2 & adont & $1.27 / 0.62$ & large pocket & 1 & 1636 \\
sp. 3 & adont & $1.15 / 0.77$ & Y & 3 & $4462-3208$ \\
sp. 4 & adont & $1.15 / 0.60$ & $?$ & $?$ & 1874 \\
sp. 5 & adont & $0.87 / 0.50$ & large pocket & 1 & 3907 \\
sp. 6 & pseudadont reverse & $1.15 / 0.67$ & large pocket & 1 & $1874-3685 ?$ \\
sp. 7 & pseudadont & $1.05 / 0.57$ & large pocket & 1 & $1636-2177$ \\
sp. 8 & pseudadont & $1.10 / 0.55$ & small pocket & $?$ & $2177-3022$ \\
sp. 9 & pseudadont & $1.10 / 0.55$ & small pocket & 1 & $1636-2177$
\end{tabular}


- the Krithe group with an adont hinge (Figs. 53A-B).

- the $K$. reversa group, which includes species with reverse overlap of the valves and a pseudadont hinge.

- the Krithe group with a pseudadont hinge (Fig. 53C-D).

The pseudadont hinge in Krithe species is slightly more complicated than the generalised hinge described in GRÜNDEL (1974: Fig. 1.6) which is medially crenulate. In Krithe, the crenulation may occur posteriorly and be differentiated into denticles and lamellae (Fig. 53).

The main reference for the description of Krithe species are the papers of COLFs et al. (1994) and AYrEss et al. (1999). These provide micrographs and drawings and a description of each new species which invariably include detail of the ADRPC system. In most of the cases, in the current literature illustrations and descriptions provide insufficient detail to establish clear definitions of each taxa.

In this study, when counting the marginal pore-canals only the true pore-canals are reported. The false pore-canals were observed but not counted because, in many cases, the valves were so thick and NPCs are easily confused with false RPCs.

\section{Krithe group with adont hinge}

Remarks: This group includes all species with a simple adont hinge, which was defined by van MORKHOVEN (1962: 72 , Fig. 66A) as "a groove along the dorsal margin of the larger valve into which fits the edge of the smaller valve" (Fig. 53A). In some Krithe species this simple hinge is modified by a secondary accommodation groove in the R. Moreover, the simple hinge may have a groove which is deeper and larger posteriorly to receive the protruding edge of the $\mathrm{R}$ [as in $K$. surugensis ZHOU \& IKEYA 1992: 1112, figs. 3, 9/6-12, 10/56] (Fig. 53B). A list of included species has not been provided because this is the most common hinge type described for Krithe species, an observation which may arise simply because many published hinge descriptions are superficial at best.

\section{Krithe sp. 1}

(Figs. 54A-E, 55A)

Material: 95 adult and more than 220 juvenile valves. SMF Xe 21623-21626.

Dimensions: Female L $1.17-1.22 / 0.60-0.65$, R 1.14 1.22/0.60-0.65; male L 1.27-1.35/0.62-0.67, R 1.25-1.30/ $0.50-0.55$.

Distribution: Holocene of the South Tasman Rise. Abundant in samples BX138 (3022 m) and BX161 (3685 $\mathrm{m})$. Common in sample BX156 (3208 m).

Description: A very large species, with marked sexual dimorphism males much more slender than females. Shape sub-trapezoidal. Maximum length slightly below mid-height, maximum height at posterior cardinal angle in female, at mid-length in male. Anterior margin evenly rounded, asymmetrically rounded in female L. Posterior outline with protruding truncation on the lower half, where the invagination is located, more evident in males. Dorsal outline convex with a slight anterior depression in the R. Ventral outline nearly straight in males, convex in females. Surface smooth with scattered sieve-type normal pores. In several male Rs, a circular protrusion was observed in the posterior half. No internal feature or any difference in the arrangement of the pores corresponds to this protrusion. In dorsal view, maximum width medially. The posterior invagination is almost vertical in the $\mathrm{R}$ and slightly oblique in $\mathrm{L}$.

Internally: posterior margin truncated and sub-angular in males, with the outline of the valves projecting beyond. Ventral margin almost straight, with a small accommodation groove medially in $\mathrm{L}$ to accommodate the protruding ventral margin of the R. Hinge adont with a wide, smooth groove in the $\mathrm{L}$ which accommodates the simple bar of the $\mathrm{R}$. Marginal pore-canals sinuous, simple, 10-12 anteriorly and 3-4 posteriorly. ADPRC type 1 (AD3 elongate). The two dorsal-most true PCs share the same base and have a false PC between; on the ventral side of the vestibulum some PCs are arranged in pairs sharing the same base, each pair consisting of a false and a true PC. Anterior vestibulum mushroom-shaped, posterior equivalent narrow.

MS consisting of four adductor scars in a vertical row and a single dorsal scar. The lowermost adductor is small and rounded, the lower middle is oval, the upper middle elongate and dumbbell-shaped, the uppermost scar round and with a slight incision on the dorsal side. The frontal scar is fourleafed clover-shaped with two of the leaves weakly developed. The juveniles can be distinguished from juveniles of other species because of the obvious protrusion of the invagination process.

Remarks: The specimens are bad preserved $\left(\mathrm{Cl}_{\mathrm{AV}}=4\right)$. The observations on the inner lamella were possible on one adult specimen only. Such a large species, with an adont hinge, ADPRC 1 and mushroom shape vestibulum is similar to $K$. triangularis Coles et al (1999). This, they recorded in the Tasman Sea at depths from $1125 \mathrm{~m}$ to $3281 \mathrm{~m}$, from the Early Miocene to Recent. $K$. sp. I is larger with a less acuminate and more truncate posterior, has ADI as short pore-canal and not as normal pore, displays no variation in the degree of posterior acumination. Krithe sp. 2 Coles et al. (1999) has a similar shape but belongs to the ADRPC type 2 and has a much narrower posterior vestibulum. Krithe trinidadensis VAN DEN BOLD (1960) has a different outline and belongs to the ADRPC type 3.

Krithe sp. 2
(Figs. 54F-J)

Material: 4 adult and 12 juvenile valves. - SMF Xe 21627.

Dimensions: Female L 1.20-1.27/0.55-0.62, R 1.271.35/0.57-0.70.

Distribution: Holocene of the South Tasman Rise. Common in sample BX140 (1636 m).

Description: A very large, sub-trapezoidal species, for which no males were found. Maximum length slightly below mid-height in $\mathrm{L}$ and in the lower half in R. Maximum height 

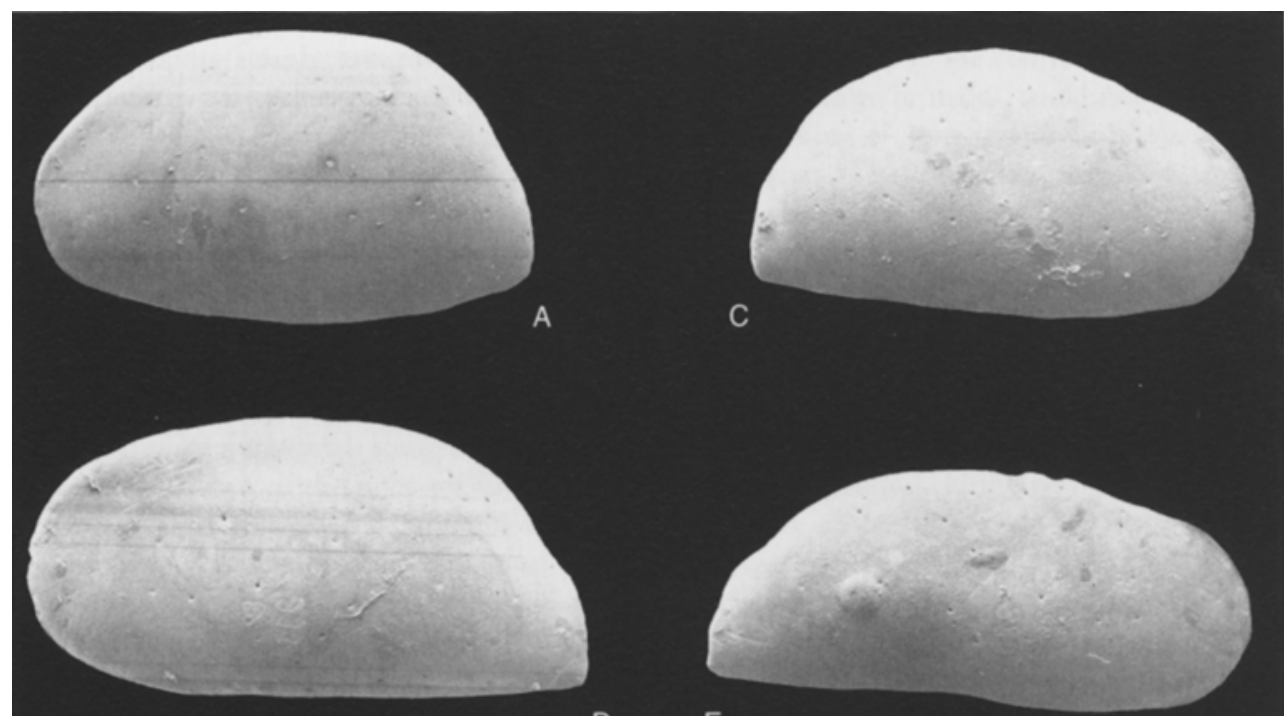

D

E
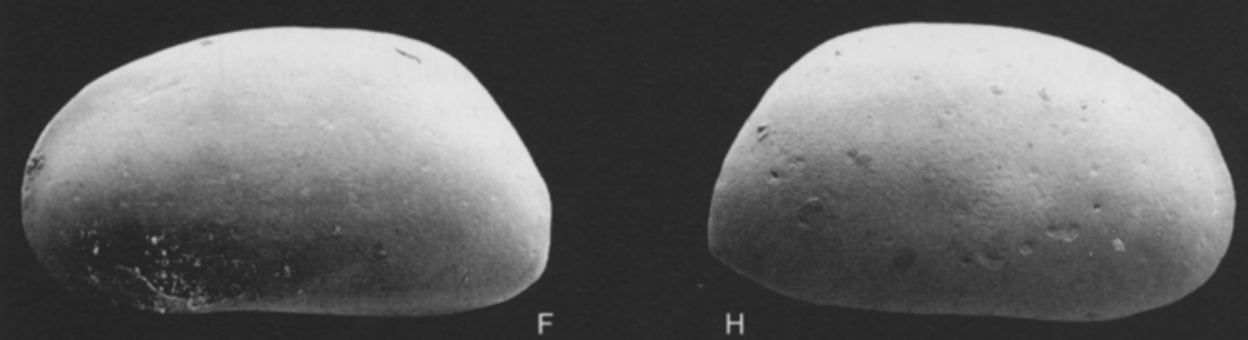

H
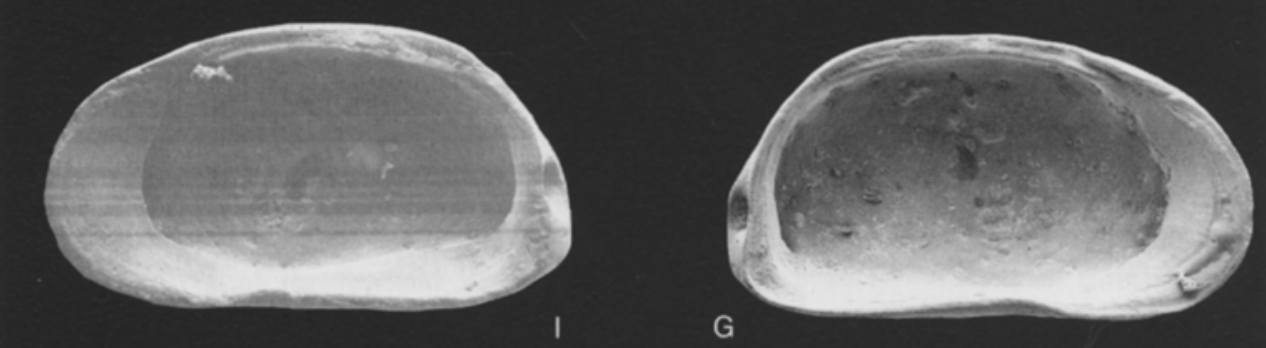

B
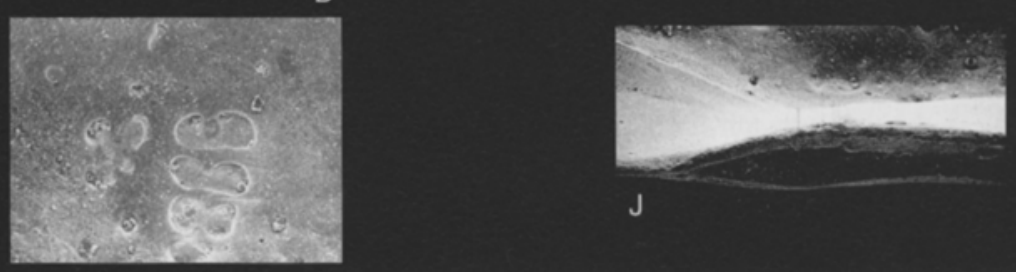

J

Fig. 54: A-E: Krithe sp. 1

Recent, sample BX138, South Tasman Rise, off south coast Tasmania, Australia; S49 $13.06^{\prime}$, E151 $05.77^{\prime}$, $3022 \mathrm{~m}$. - female L (1.22/0.65); A: external view; B: detail of the central muscle scars, $\times 116$. SMF Xe 21623. female R (1.22/0.65); C: external view. SMF Xe 21623. - male L (1.35/0.67); D: external view. SMF Xe 21623. - male R (1.30/0.55); E: external view. SMF Xe 21623.

F-J: Krithe sp. 2

Recent, sample BX140; South Tasman Rise, off south coast Tasmania, Australia; $449^{\circ} 10.84^{\prime}, \mathrm{E} 150^{\circ} 10.13^{\prime}$, 1636 m. - female L (1.27/0.62); F: external view; G: internal view. SMF Xe 21627. - female R (1.27/0.57); H: external view; I: internal view; J: detail of the additional closing mechanism on the ventral side, $\times 88$. SMF Xe 21627. - All magnifications are $\times 45$ unless otherwise stated. 
A

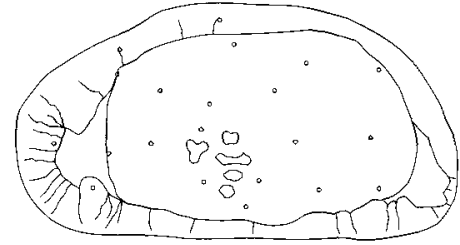

C

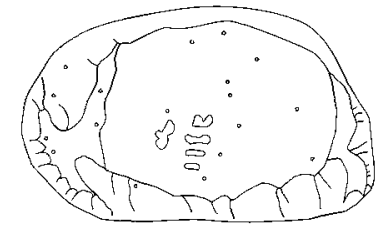

$E$

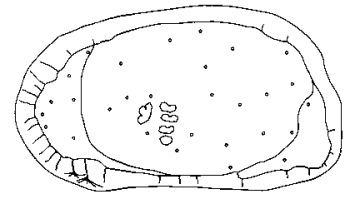

$\mathrm{G}$

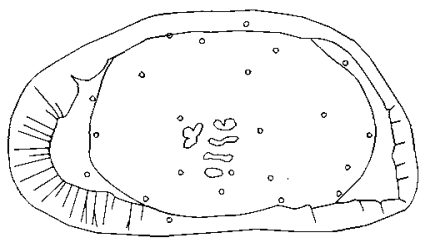

I
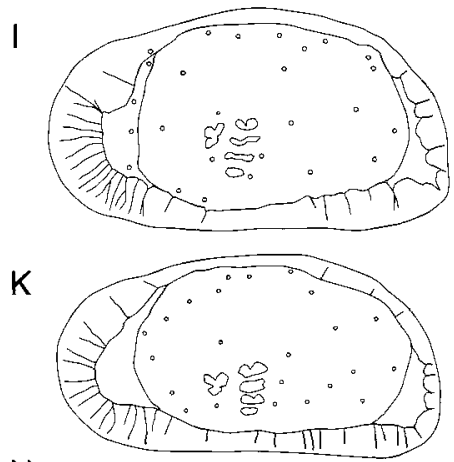
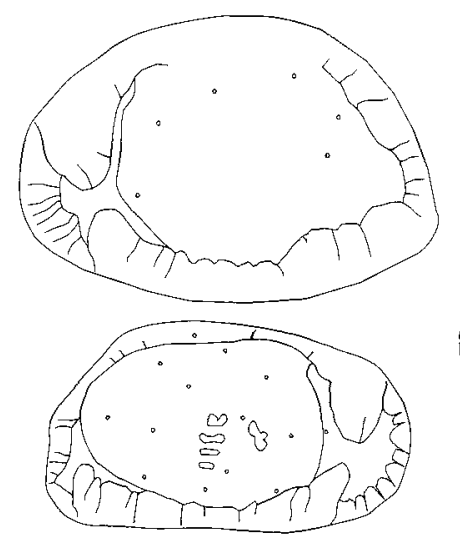

$\mathrm{D}$

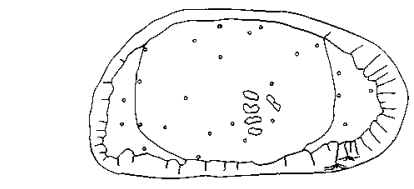

F

B
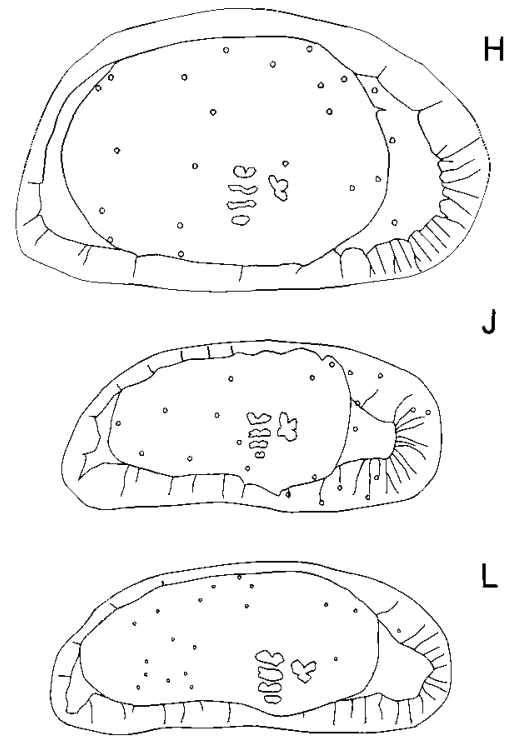

$\mathrm{N}$
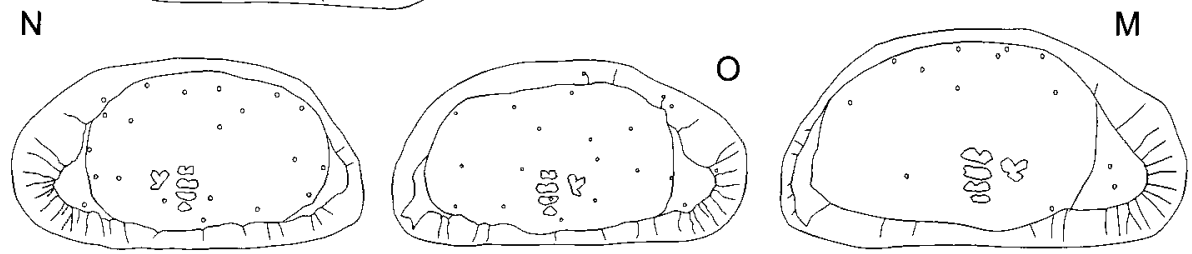

Fig. 55: Camera lucida drawings of valve features of Krithe species.

All figures are external views - All magnifications are approx. $\times 50$.

A: Krithe sp. 1. Sample BX138, South Tasman Rise, off south coast Tasmania, Australia; S49 $13.06^{\prime}$ E151 $05.77^{\prime}, 3022 \mathrm{~m}$; female L, (1.17/0.60). B-D; Krithe sp. 3. Sample BX165, South Tasman Rise, off south coast Tasmania, Australia; $545^{\circ} 18.26^{\prime}$ E147 $55.13^{\prime}, 4067 \mathrm{~m}$. - B: female L (1.15/0.77); C: male L (1.00/0.57); D: male R (0.97/0.55). E-F: Krithe sp. 5. Sample BX110, Emerald Basin, off south coast South Island, New Zealand, $\$ 56^{\circ} 40.87^{\prime}$ E160 $14.86^{\prime}, 3907 \mathrm{~m}$. - E: female L (0.87/0.50); F: female R $(0.87 / 0.45)$. G-I: Krithe sp. 6. Sample BX147, South Tasman Rise, off sourh coast Tasmania, Australia; S48 29.99' E14906.75', 2177 m. - G: female L (1.12/0.65); H: female R (1.30/0.77); I: female L (1.10/0.62). J: Krithe sp. 7. Sample BX147, South Tasman Rise, off south coast Tasmania, Australia; S48 29.99' E14906.75', 2177m; male R (1.02/0.45). K-M: Krithe sp. 9. Sample BX140; South Tasman Rise, off south coast Tasmania, Australia; S49 $10.84^{\prime} \mathrm{E} 150^{\circ} 10.13^{\prime}, 1636 \mathrm{~m}$. K: female L (1.05/0.52); L: male R, (1.10/0.50); M: female R, (1.12/0.60). N-O: Krithe sp. 10. Sample BX138, South Tasman Rise, off south coast Tasmania, Australia; $\$ 49^{\circ} 13.06^{\prime}$ E151 $05.77^{\prime}, 3022 \mathrm{~m}$. - N: female $L(0.97 / 0.50) ;$ O: female R (1.00/0.50). 
at posterior cardinal angle. Anterior margin evenly rounded. Postero-dorsal outline sloping steeply toward the acuminate posterior, with an obvious truncation in L. Dorsal outline convex. Ventral outline almost straight. Surface smooth with scattered sieve-type normal pore-canals. In dorsal view, maximum width in the anterior half. The posterior invagination is aligned obliquely in both valves.

Internally: ventral margin with a deep and long accommodation groove opening in front of the mid-point and extending almost until the postero-ventral angle. Hinge adont with a wide smooth groove in the $\mathrm{L}$ which accommodates the simple bar of the R. Marginal pore-canals straight and simple. Their number is unclear due to of the poor preservation of the valves. ADPRC type 1 (AD3 elongate). Anterior vestibulum large and pocket-shaped. Posterior vestibulum small with a ventral expansion. MS consisting of a vertical row of four adductor scars. The lowermost scar is small and round, the lower middle is oval, the upper middle is large and dumbbellshaped; the uppermost scar is $U$ shaped, the frontal scar is four-leafed clover-shaped.

Remarks: The specimens were bad preserved $\left(\mathrm{CI}_{\mathrm{AV}}=\right.$ 4) and many details could not be observed. This large species is similar to $K$. triangularis COLEs et al (1999) with which it contrasts because of the different shape of the vestibulum and less acuminate posterior in males. With its large dimensions it differs from the other $K$. species which are present in sample BX140.

Krithe sp. 3

(Figs. 56A-F, 55B-D)

Material: 43 adult and 570 juvenile valves. - SMF Xe 21628-21631.

Dimensions: female L 1.12-1.15/0.75-0.77, R 1.071.10/0.67-0.70; male L 1.00-1.22/0.57-0.70, R 0.97-1.17/ $0.55-0.67$

Distribution: Holocene of the Emerald Basin. Very rare in sample BX116 (4462 m). Holocene of the South Tasman Rise. Very rare in sample BX156 (3208 m), abundant in samples BX161 (3685 m) and BX165 (4067 m).

Description: A very large, thick shelled, sub-trapezoidal species, with a moderate sexual dimorphism. Maximum length at mid-height, maximum height right behind midlength. Anterior margin evenly rounded. Postero-dorsal margin sloping steeply towards the posterior. In males, a mid-posterior shoulder near the posterior invagination interrupts the slope. Dorsal outline arched with a slight anterior depression in the anterior half of the R. Ventral outline convex. Surface smooth with scattered sieve-type normal pores, which are very large and deep. In dorsal view, maximum width around midlength. The posterior invagination oblique in both valves.

Internally: ventral margin with a small accommodation groove located medially in the L. Hinge adont with a wide smooth groove in $\mathrm{L}$ which accommodates the simple bar of the R. Marginal pore-canals sinuous, simple, 8-12 anteriorly and 4-6 posteriorly. ADPRC type 3 (AD4 elongate), with $\mathrm{AD} 4$ rising from the vestibular neck. Anterior vestibulum Yshaped, wider in males. On the tips of the ' $Y$ ', the longest marginal pore-canals open, which are slightly arched, with a shape that looks like the continuation of the wings. Posterior vestibulum large in males, could not be observed in females. MS consisting of a vertical row of four widely separated adductor scars. The lowermost scar small and oval, the lower middle oval, the upper middle elongate and dumbbellshaped, the uppermost scar oval or V-shaped with very open wings. The frontal scar is four-leafed clover-shaped. In some specimens the more horizontal 'leaves' are very reduced such that it appears like elongate-oval and incised.

Remarks: The specimens were poorly preserved $\left(\mathrm{Cl}_{\mathrm{AV}}\right.$ $=4)$ and on many a chitinous lamina covered the entire internal surface of the valves.

This species is similar in shape to $K$ morkhoveni morkhoveni VAN DEN BOLD (1960) sensu COLEs et al (1994: 94, Figs. $4 \mathrm{~d}-\mathrm{h}$ ) who provided a long synonymy list including species from all over the world within the time range Oligocene to Recent. This was the result of their broadening of the definitions of the species in a number of areas. For example, in their remarks they stated that the length range of this species is from 0.67 to 0.87 whereas they reported the range of dimensions for the specimens studied as $0.67-1.04$. Additionally, the ADRPC pattern and the width of the inner lamella were considered variable and their illustrations of the vestibulum indicate considerable variation in that structure as well. VAN DEN BOLD described $K$. morkhoveni from the Lower Miocene of Trinidad and reported dimensions of 0.68 for his specimens and a mushroom-shaped vestibulum. $K$. morkhoven $i$ is not recorded from the Tasman sea (AYREss et al. 1999).

The females of $K$.sp. 3 have outline and dimensions similar to $K$. trinidadensis VAN DEN BOLD (1958b) sensu COLES et al. (1994). A wide range of dimensions (0.87-1.58) and shape of the anterior vestibulum (from Y- to small pocket-shaped) also appear to be accepted for this species. VAN DEN BOLD (1958b: pl. 1 fig. 3) erected $K$. trinidadensis for OligoceneMiddle Miocene specimens (0.93-1.00) and he figured specimens with a Y-shaped vestibulum. AYress et al. (1999) reported $K$. trinidadensis from the continental slope off Tasmania at depths ranging from $1476 \mathrm{~m}$ to $2346 \mathrm{~m}$. With these considerations in mind, some specimens of Krithe sp. 3 could be assigned to $K$. morkhoveni morkhoveni sensu COLES et al. (1994) whereas others (females) to $K$. trinidadensis sensu Coles et al. (1994). In my opinion, the range of variability proposed by previous authors for these species is too wide and, $K$ sp. 3 do not comply with the original descriptions of the VAN DEN BOLD's species. In all probability Krithe sp. 3 represents a new species.

\section{Krithe sp. 4 \\ (Figs. 56G-L)}

Material: 39 adult valves. - SMF Xe 21632.

Dimensions: Female L 0.95-1.15/0.53-0.60, R 1.05$1.10 / 0.47-0.55$; male L $1.07-1.15 / 0.45-0.47$, R $1.07-1.12 /$ $0.43-0.45$.

Distribution: Holocene of the South Tasman Rise. Common in sample BX153 (1874 m). 


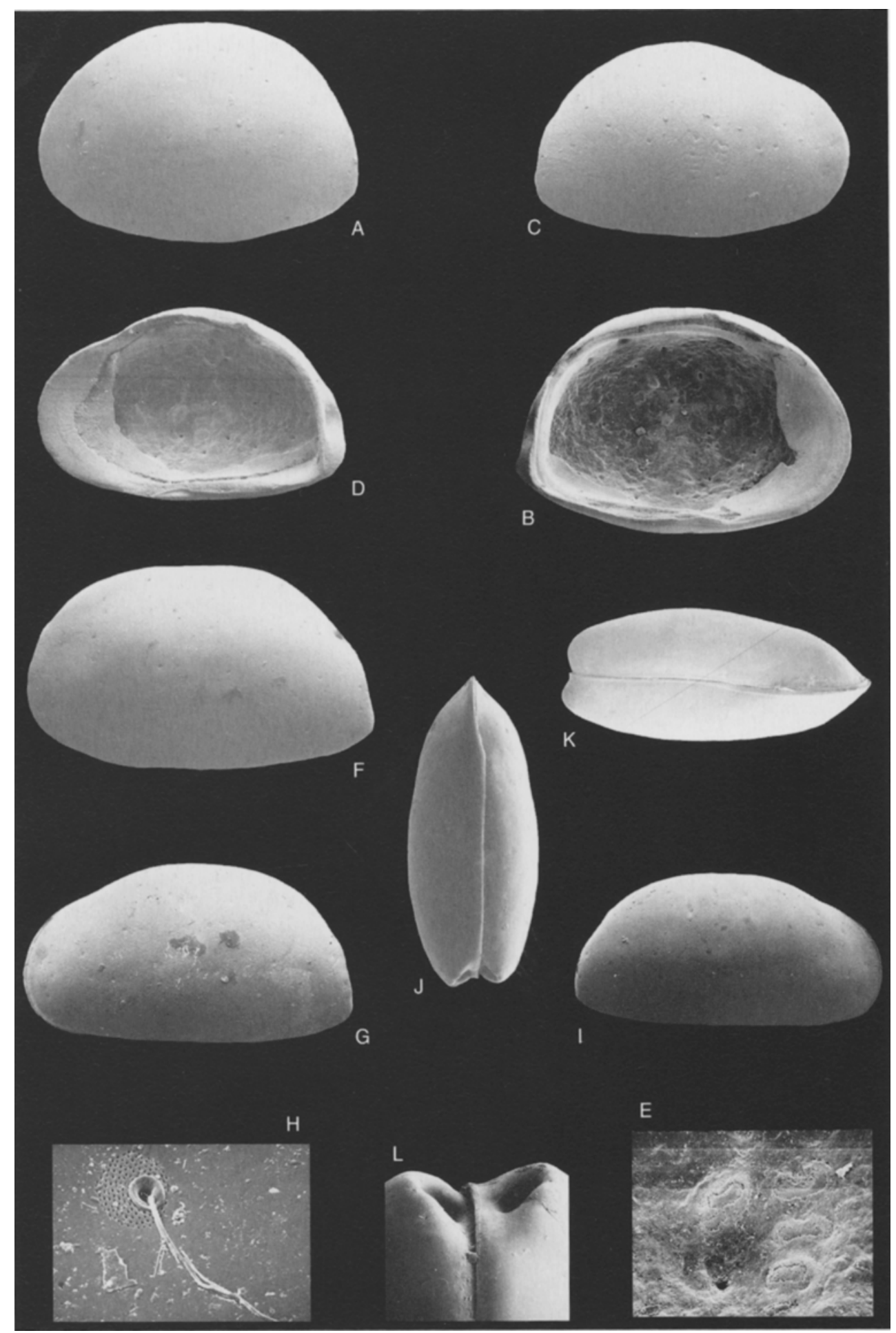

Fig. 56: A-F: Krithe sp. 3

Recent, sample BX165, South Tasman Rise, off south coast Tasmania, Australia; $445^{\circ} 18.26^{\prime}$, E14 $17^{\circ} 55.13^{\prime}$, 4067 m. - female L (1.12/0.75); A: external view; B: internal view. SMF Xe 21628. - female R (1.07/0.67); C: external view; D: internal view; E: detail of the central muscle scars, $\times 144$. SMF Xe 21628. - male L (1.22/ $0.70)$; F: external view. SMF Xe 21628.

G-L: Krithe sp. 4

Recent, sample BX153, South Tasman Rise, off south coast Tasmania, Australia; S47 $46.85^{\prime}$, E147 $145.13^{\prime}$, $1874 \mathrm{~m}$. - female L (1.15/0.60); G: external view; H: detail of a sieve type plate with funnel pore opening in eccentric position, $\times 884$. SMF Xe 21632. - female R (1.05/0.47); I: external view. SMF Xe 21632. - male C (1.07/0.45/0.43); J: dorsal view; K: ventral view; $\mathrm{L}$ : detail of the posterior invagination, $\times 113$. SMF Xe 21632. - All magnifications are $\times 45$ unless otherwise stated. 
Description: A medium-sized species with obvious sexual dimorphism. Males sub-rectangular, females sub-trapezoidal. Maximum length in the lower half, maximum height at mid-length in females, at posterior cardinal angle in males. Anterior margin evenly rounded, posterior outline asymmetrically truncated in the lower half. Dorsal outline straight in males, convex in females with an anterior depression. Ventral outline straight. Surface smooth with scattered small, round, funnel-like normal pores, surrounded by eccentric sieve plate. In dorsal view, maximum width medially. The posterior invagination is pronounced and more developed in the $\mathrm{L}$.

Internally: ventral margin sinuous in females, straight in males, with accommodation groove medially in the L. Hinge adont. The median bar in the $\mathrm{R}$ is parallel to the dorsal margin. $\mathrm{L}$ without accommodation groove, but with a depression close to the dorsal margin which accommodates the dorsal edge of the R. Marginal pore-canals and type of vestibulum not visible. MS consisting of four adductor scars in a vertical row and a single dorsal scar. The lowermost scar small and round, the lower median oval and incised mid-ventrally, the upper median elongate, the uppermost incised medially. The frontal scar is four-leafed clover-shaped, with 'leaves' of equal dimensions. Juveniles not recovered.

Remarks: This taxon is scarcely represented. Many characters could not be observed due to poor preservation $\left(\mathrm{CI}_{\mathrm{AV}}=5\right)$ and for this reason no comparison was made with other Krithe species.

\section{Krithe sp. 5}

(Figs. 55E-F)

Material: 5 adult and 2 juvenile valves. - SMF Xe 21633-21634.

Dimensions: female L $0.82-0.87 / 0.47-0.50 ; \mathrm{R} 0.80$ $0.87 / 0.40-0.45$; male L; R 0.85-0.97/0.43-0.47.

Distribution: Holocene of the Emerald Basin. Rare in sample BX110 (3907 m).

Description: A small sub-crapezoidal species, with obvious sexual dimorphism. The description is based primarily on females because the male valves were poorly preserved. Maximum length slightly above mid-height, maximum height at anterior posterior cardinal angle. Anterior margin evenly rounded, posterior outline asymmetrically rounded, truncate in the lower half. Dorsal outline convex. Ventral outline straight. Surface smooth with scattered sieve-type normal pores. The posterior invagination vertical in dorsal view. The maximum width within the anterior half.

Internally: posterior margin sloping almost vertically with the outline of the valves projecting beyond, ventral margin without accommodation groove around mid-length. Hinge adont. A thin groove is present on the dorsal margin of the $\mathrm{L}$, to accommodate the smooth bar of the $\mathrm{R}$. Anterior vestibulum large and pocket-shaped, marginal pore-canals straight and simple, 15-16 anteriorly and 5-7 posteriorly. The last two PCs on the ventral margin of the vestibulum are multifurcate, each with 5-6 thin canals arranged in a fan. ADPRC type 1 (AD3 elongate), posterior vestibulum large, expanded dorsally. MS consisting of four adductor scars in a vertical row and a single dorsal scar. The lowermost scar small and round, the lower median oval and incised medially, the upper median elongate and deeply incised dorsally, the uppermost oval. The frontal scar is four-leafed clover-shaped with 'leaves' of equal dimensions.

Remarks: Although one of the best preserved species $\left(\mathrm{Cl}_{\mathrm{AV}}=2\right)$ in term of number of specimens is poorly represented. It is the smallest species recovered in this study and also occurs at the greatest depth. A female carapace with soft parts intact was recovered which provided the results presented herewith.

In outline and shape of the anterior vestibulum it resembles $K$. compressa (Seguenza 1880) sensu Ayress et al. (1999: Fig. 3A). That species was recovered by SEguenzA from Early Pleistocene sediments near Monasterace (Calabria, Southern Italy) and in Early Pleistocene sediments from the San Nicola Section (Gela, Sicily) by ABATE et al. (1993: 358) which stated that "the shape and the characters of the anterior vestibulum appear almost constant." The illustration they provided clearly shows that the vestibulum is not as variable as illustrated by AYress et al. (1999). Krithe sp. 5 differs from $K$. compressa because it is larger and has an expanded posterior vestibulum. $K$. sp. 5 is also similar to $K$ antisawanensis IsHIZAKJ (1966) sensu AYREsS et al. (1999: Figs. 3E-F) with which it shares the ADRPC type, shape of the vestibula and dimensions. According to the specific name, $K$ antisawanensis should have a reversed pseudadont hinge compared with $K$. sawanensis, whereas $K . \mathrm{sp} .5$ has a simple adont hinge. AYRESS et al. (1999) found $K$. antisawanensis in the Tasman Sea ranging from $686 \mathrm{~m}$ to $3403 \mathrm{~m}$ of depth. IsHIZAKI erected $K$. antisawanesis on Miocene specimens from Japan and reported maximum dimensions of $0.97 / 0.50$.

\section{Krithe reversa group}

Included species: Krithe reversa VAN DEN BOLD (1958b), Krithe sawanensis Hanal (1959), Krithe spec. 06/158 HarTMANN (1987), Krithe sp. 13 ZhaO \& WhatLey (1997).

Remarks: The reversal of valve overlap and the large size makes $K$. reversa a species easy to recognise within the Krithe species complex. As a consequence, all species with a reversed valve overlap are usually attributed to $K$. reversa or $K$. gr. reversa, and therefore it has a wide geographical and bathymetrical distribution: the Atlantic and South Pacific oceans with depth range 850-3552 m.

In the present author's opinion within this group are included a variety of morphotypes which exhibit substantial variations in outline, dimension and shape of the vestibulum. For these reasons, the synonymies for $K$. reversa given by Coles et al. (1994) and Ayress et al. (1999) are herein not accepted and regarded as incorrect. Moreover, AYress et al. (1999) included in the synonymy Krithe sp. 4 of DINGLE et al. (1990: 282-283, Fig. 22E) which is described as having a tooth-like structure at the anterior end of the $\mathrm{R}$, but for which only a micrograph of the external $\mathrm{R}$ was provided. Krithe reversa was erected by VAN DEN BOLD (1958b: 399) for specimens from the Miocene of Trinidad. From his illustra- 
tions (pl. 1 figs. $4 \mathrm{a}-\mathrm{g}$ ) it is apparent that the vestibulum, of both males and females, is pocket-shaped.

Hanal (1959: 303) erected $K$. sawanensis on specimens from the Pliocene Sawane Formation (now Lower Pleistocene, see ZHOU \& IKEYA 1992). His illustrations also display a pocket-shaped vestibulum. WHATLEY \& ZHAO (1993) reported $K$. sawanensis from the South China Sea within the depth range of $560-4200 \mathrm{~m}$ and stated that $K$. sawanensis may be a junior synonym of $K$, reversa. IsHIzAKI \& IRIZUKI (1990) reported $K$. sawanensis from Toyama Bay, central Japan, between $210 \mathrm{~m}$ and $1390 \mathrm{~m}$ but did not figure their specimens. ZHOU \& IKEYA (1992) described $K$. sawanensis from Suruga Bay. That population of $K$. sawanensis has a peculiar distribution in that specimens occurring between $120 \mathrm{~m}$ and $650 \mathrm{~m}$ have a mushroom-shaped vestibulum and dimensions of 1.09/0.56 for females, and 1.10/0.54 for males (measured from Fig. 8), whereas specimens occurring between $920 \mathrm{~m}$ and $1350 \mathrm{~m}$ have a pocket-shaped vestibulum and are smaller: females 1.04/0.58, males 1.04/ 0.50. CoLes at al. (1994) provided a long synonymy list for the reversed species and clearly accept the suggestion of WHATLEY \& ZHAO (1993), that $K$. sawanensis is a junior synonym of $K$. reversa. AYRESS (1988) described contrasting distributions for $K$. reversa with bathyal (Pleistocene) and abyssal (latest Pliocene-Pleistocene) populations being discriminated on the basis of the size. Smaller specimens $(1.08 / 0.53)$ belong to the first group, larger specimens $(1.22 / 0.59)$ to the second. ZHAO \& WHATLEY (1997) recovered $K$. reversa in the east China Sea and described a depth/size relationship: specimens recovered between $400 \mathrm{~m}$ and $800 \mathrm{~m}$ being larger (1.08-1.04) than those from $>800 \mathrm{~m}(0.98 / 1.05)$.

From the literature it would appear that four species of Krithe with a reverse overlap of the valves have separate species status: $K$. reversa VAN DEN BOLD, $K$. sawanensis HaNAl, $K$. sp. 13 Zhao \& Whatley, $K$. spec. 06/158 Hartmann. All these species have a reversed pseudadont hinge.

Krithe sp. 6

(Figs. 57A-L, 55G-I)

Mate rial: 97 adult and more than 500 juvenile valves. SMF Xe 21635-21638.

Dimensions: Female L 1.07-1.15/0.57-0.67, R 1.151.30/0.65-0.77; male L 1.12-1.17/0.50-0.55, R 1.15-1.22/ $0.52-0.62$.

Distribution: Holocene of the South Tasman Rise. Abundant in samples BX147 (2177 m) and BX153 (1874 $\mathrm{m})$. Common in sample BX161 (3685 m).

Description: Large, sub-rectangular species, with reverse valve overlap. Pronounced sexual dimorphism: males longer and slender than females. Maximum length just below mid-height, maximum height slightly in the posterior half. Anterior margin evenly rounded, posterior outline slightly truncate on the lower half. Dorsal outline convex and slightly sinuous with an anterior depression in the $\mathrm{L}$, parallel to the outer margin. Ventral outline nearly straight, with a slight concavity in the oral region. Surface smooth with sieve-type normal pores in scattered but constant positions. An elongate depression, parallel to the outer margin, is located at the ante- rior cardinal angle of the $\mathrm{R}$. In dorsal view, maximum width medially, posterior end with oblique invaginations on both valves. The $\mathrm{R}$ overlaps the $\mathrm{L}$ dorsally where a hinge ear envelopes the anterior depression of the $\mathrm{R}$ dorsal margin.

Internally: strong selvage, posterior margin clearly truncated with the outline of the valves projecting beyond. Ventral margin sinuous, with a short groove located medially on the $\mathrm{L}$, to accommodate the protrusion of the R. Valve overlapping also occurs ventrally. Marginal pore-canals straight, 1520 anteriorly and 6-8 posteriorly. The dorsal-most true PC has a wide base from which two false PCs also extend. The $\mathrm{PC}$ on the ventral side are bifurcate. ADPRC type 1 (AD 3 elongate). Anterior vestibulum large and pocket-shaped, posterior vestibulum moderately wide and extends to the postero-dorsal margin. MS consisting of four central adductor scars in a vertical row: lowermost small and oval, lower middle elongate and dumbbell-shaped, upper middle slightly $S$ shaped, the uppermost with dorsal margin incised, almost divided. Frontal scar four-leafed clover-shaped. The hinge is pseudadont. In the $L$, a row of 10-13 small teeth occurs between the posterior edge and mid-length which merges into a smooth median bar anteriorly. Above the denticles is a smooth groove. In the $\mathrm{R}$ a hinge ear characterises the anterior cardinal angle under which a deep, large groove is located, smooth until mid-length where it becomes locellate.

In juveniles the reverse overlap is difficult to observe and distinguish these from juveniles of other species is time consuming. MS are more complex in juveniles, with the upper two adductor scars often being subdivided.

Remarks: The specimens recovered are much larger than those given by VAN DEN BOLD (1958b) for $K$. reversa specimens from Trinidad (1.04-1.09/0.56-0.52), by WHATLEY $\&$ COLES (1987) for $K$. reversa specimens from the N Atlantic (0.98-1.12/ 0.47-0.48) and by AYREss et al. (1999) for $K$. reversa specimens from the Tasman Sea $(1.00 / 0.52)$. There are also small differences in the shape of the vestibula. For this reason and because of the lack of precise definition for $K$. reversa, it is preferred to leave the present taxon, within the reversa group but under open nomenclature.

The specimens were poorly preserved $\left(\mathrm{CI}_{\mathrm{AV}}=4\right)$. Some female specimens display a slightly different shape of the vestibulum: upturned anterior and smaller posterior (Fig. 55I), but have appropriate dimensions, outline, ADPRC type and number of marginal PC to be classified as $K$. sp. 6 .

The specimens recovered from sample BX161 are even worse preserved $\left(\mathrm{CI}_{\mathrm{AV}}=5\right)$ and for this reason it was not possible to study the characters of the inner lamella. However they have appropriate dimensions, an identical outline and denticles in some of the adult $\mathrm{L}$, and consequently they are regarded as belonging to $K$. sp. 6 .

\section{Krithe group with pseudadont hinge}

Included species: Krithe sp. Benson (1965), Kantisawanensis IsHIZAKI (1966), Krithe sp. 4 Dingle et al. (1990), $K$ aquilonia COLES et al. (1994), $K$ crassicaudata VAN DEN BOLd sensu COles et al. (1994), K. minima Coles et al. (1994), K. (Austrokrithe) magna Hartmann (1994), ? Krithe 


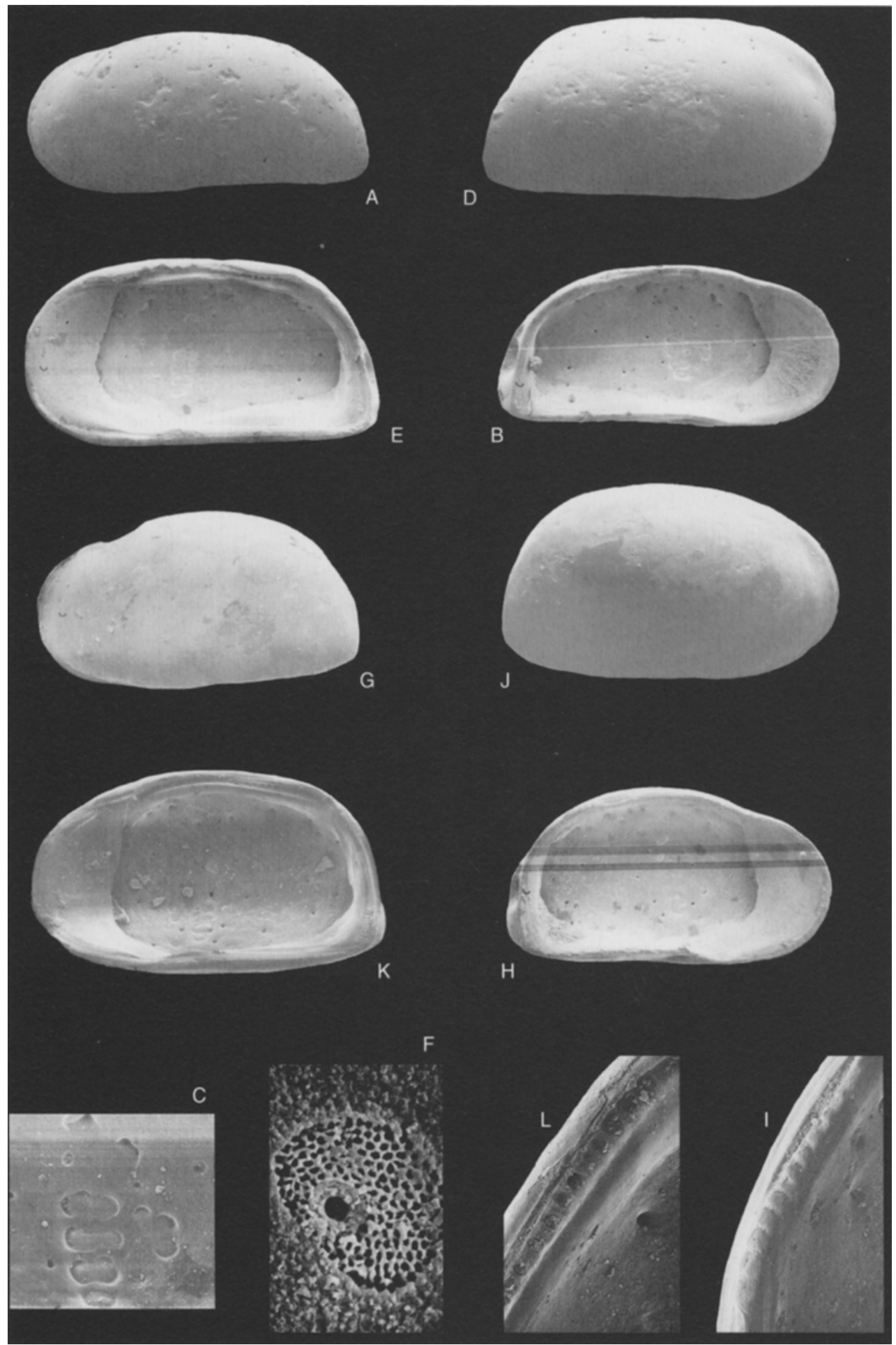

Fig. 57: Krithe sp. 6

Recent, sample BX147, South Tasman Rise, off south coast Tasmania, Australia; S48 $29.99^{\prime}$, E1 $149^{\circ} 06.75^{\prime}$, 2177 m. - male L (1.17/0.55); A: external view; B: internal view; C: central muscle scars, $\times 115$. SMF Xe 21635. - male R (1.22/0.62); D: external view; E: internal view; F: derail of a sieve type plate of a normal pore, $\times 1550$. SMF Xe 21635. - female L (1.12/0.60); G: external view; H: internal view; I: detail of the denticles on the posterior part of the median bar, $\times 167$. SMF Xe 21635. - female R (1.15/0.65); J: external view; K: internal view; L: detail of the locellate posterior part of the median groove, $\times 167$. SMF Xe 21635. - All magnifications are $\times 45$ unless otherwise stated. 
magna sensu WhatLey et al. (1998), ? K. minima Coles et al. sensu AYREss et al. (1999).

Remarks: SARs described Krithe as a genus without teeth ('nullis dentibus' in his description 1865: 59). This was confirmed by MCKENZIE et al. (1989) in a description of Krithe praetexta praetexta (SARS 1866) collected from the Gullmar Fjord, at about $45 \mathrm{~m}$ of depth.

However, many species referred to Krithe present a pseudadont hinge in which postero-medial portions of the hinge are differentiated and variable. Modification includes: an arched hinge bar in the $\mathrm{R}$, which is raised posteriorly and with few denticles and a complementary locellate groove in the L (as in $K$ aquilonia Coles et al. 1994) (Fig. 55B) or a horizontal hinge bar with a finely denticulate posterior end and a complementary finely locellate groove (as in $K$. magna HARTMANn 1994) (Fig. 55C). The hinge character has always undervalued, and as a consequence in many descriptions it is not described at all or described simply as "pseudadont", without additional details.

In ZHAO \& WHATLEY (1997: 204) a list of species with a pseudadont hinge is provided. Unfortunately, much of the relevant literature was not available and species left under open nomenclature by the authors were not described. For these reasons they have been not included in the Krithe group with pseudadont hinge.

Hartmann (1994) erected the subgenus Austrokrithe to accommodate specimens of Krithe with an aberrant strahl in the respiratory plate of the maxillula. In the diagnosis of the subgenus he refers also to a pseudadont hinge with a row of small teeth. He based his diagnosis on living specimens dredged from $133 \mathrm{~m}$ in the waters around the Antarctic peninsula. Whatley et al. (1998: pl. 2 figs. 23-24) considered those characters insufficient to establish a subgenus and referred their specimens from the Scotia Sea to Krithe magna. It is also apparent that the latter specimens are much longer (0.97-1.06 compared to 0.70 of the HARTMANN species), display a more rounded outline, especially at posterior, and were recovered at depths of between $1155 \mathrm{~m}$ and $3925 \mathrm{~m}$. Probably, they belong to a different species. The question as to the validity of the subgenus Austrokrithe is very complicated. Recovery of more living specimens of Krithe could help to define the relationship between forms with pseudadont hinges and aberrant strahlen, or that the latter character also occurs in forms with adont hinge. For the time being it is preferred to retain forms with a pseudadont hinge as a separate though informal group.

Significantly, after a substantial review of the literature, it appears that species with a pseudadont hinge are very common in the Pacific and Southern oceans, with the exception of K. minima found by Coles et al (1994: 90) in Quaternary sediments from the North Atlantic, between $28^{\circ}$ and $68^{\circ} \mathrm{N}$. For this taxon they described the hinge as a "right valve hinge bar finely denticulate at posterior end." The same species has been recorded by RoDriguez-LAZARo \& CRONIN (1999) in the Little Bahama Bank (NW Atlantic) and by AYress et al. (1999) in the Tasman Sea but no description of the hinge was provided. The description of $K$. minima is not very coherent since it displays contrasting vestibulum shape: crescent-shape in the Atlantic (CoLES et al. 1994: Figs. 3EE-JJ) and ' $Y$ '-shape in the Tasman sea (Ayress et al. 1999: Figs. 3K-L).
Krithe sp. 7

(Figs. 58A-J, 55J)

Material: 142 adult and 501 juvenile valves. - SMF Xe 21639-21642.

Dimensions: Female L $0.95-1.05 / 0.55-0.57$, R 0.951.00/0.55-0.60; male L 1.00-1.05/0.47-0.50; R 1.02-1.07/ $0.45-0.48$.

Distribution: Holocene of the South Tasman Rise. Abundant in samples BX140 (1636 m), BX141 (1690 m) and very common in sample BX147 $(2177 \mathrm{~m})$

Description: A medium-sized species, males sub-rectangular in shape and more elongated than the sub-trapezoidal females. Maximum length below mid-height, maximum height in the anterior half in males and at mid-length in females. Anterior margin evenly rounded, posterior outline slightly truncate in the lower half. Dorsal outline straight in males L, slightly arched in R; convex in females with a slightly anterior depression. Ventral ourline nearly straight. Surface smooth with scatrered sieve-type normal pores. In dorsal view, maximum width in the posterior half. The posterior invagination is not pronounced, forming an obtuse angle with the dorsal margin.

Internally: ventral margin sinuous, with a short accommodation groove medially in the R. Posterior margin sloping steeply towards the posterior end. Hinge pseudadont, with wide, sinuous groove in the $\mathrm{L}$, locellate in the posterior half; simple median bar in the $\mathrm{R}$, posterior half bearing denticles. Anteriorly the denticles are well developed and separated, whereas posteriorly they are grouped together to form a slightly lobate bar. Marginal pore-canals straight and simple, 13-14 anteriorly and 4-5 posteriorly. The four dorsal-most true pore-canals are paired, whereas the third last ventral true pore-canal is bifurcate. ADPRC type 1 (AD3 elongate). Anterior vestibulum small, pocket-shaped; posterior equivalent moderately wide, males with a peculiar convexity dorsally. MS consisting of four adductor scars in a vertical row and a single dorsal scar. The lowermost adductor scar small and oval, the medial pair incised medially and bilobate at their posterior ends, the uppermost deeply incised medially and Ushaped. The frontal scar is four-leafed clover-shaped, with the longer axis oblique. This structure of the frontal scar has been observed as a constant character in all the specimens studied. Juveniles with the same MS pattern and hinge structure.

Remarks: This poorly preserved species $\left(\mathrm{Cl}_{\mathrm{AV}}=4\right)$ may be referred to $K$ antisawanensis ISHIZAKI (1966) with which shares the same shape of the vestibulum, ADRPC type and hinge structure. However, $K$. sawanensis is $<1 \mathrm{~mm}$ long (ZHOU \& IKEYA 1992: Fig. 4), has a different frontal scar (not quadri-lobate) and was erected to accommodate Miocene specimens from north-east Japan. It has been found in the Recent of the South Korean Sea, East China Sea and Japan Sea at a depth range of $15-320 \mathrm{~m}$. The specimens referred to $K$. sawanensis by AYRESS et al. (1999) are shorter (0.77-0.80), with a wider posterior vestibulum. They were recovered from the Tasman Sea, within a depth range of 686-3403 m with a stratigraphical range from the Middle Miocene to Recent. They probably belong to a different species. 

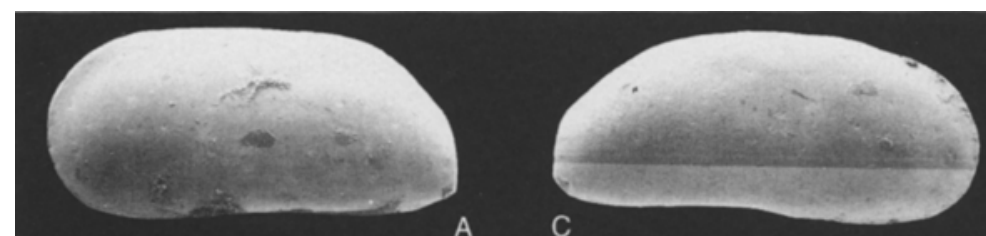

C

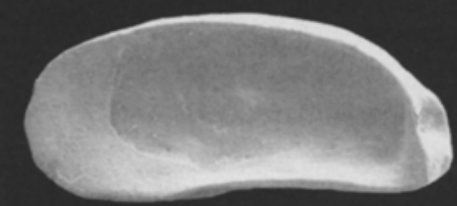

D

\section{B}

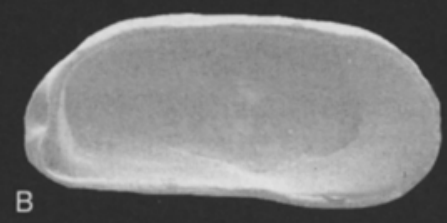

$\mathrm{E}$

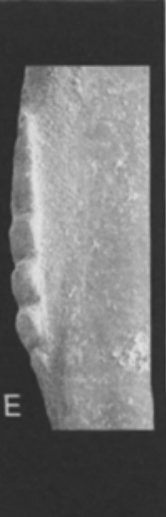

1

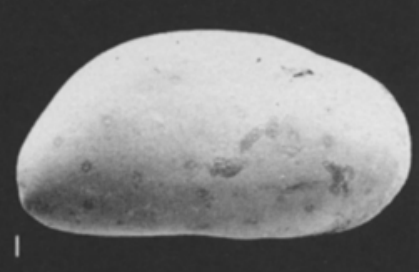

G

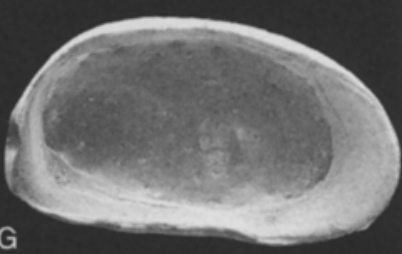

O

K

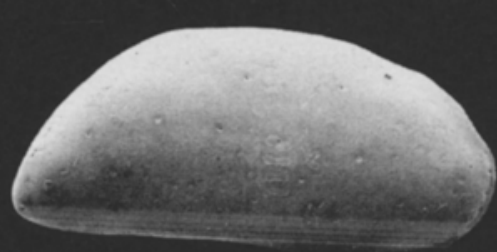

M
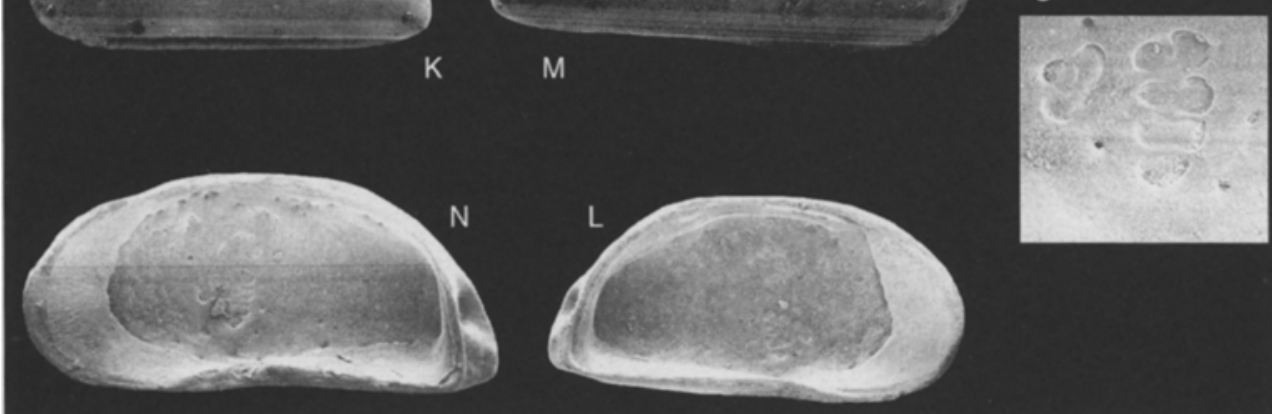

Fig. 58: A-J: Krithe sp. 7

Recent, sample BX147, South Tasman Rise, off south coast Tasmania, Australia; S48 29.99', E149 $06.75^{\prime}$ 2177 m. - male L (1.00/0.47); A: exrernal view; B: internal view. SMF Xe 21639. - male R (1.02/0.45); C: external view; D: internal view; $\mathrm{E}$ : detail of the denticles on the posterior part of the median bar, in dorsal view $\times 233$. SMF Xe 21639. - female L (0.95/0.55); F: external view; G: internal view; H: detail of the locellate median bar at posterior, $\times 133$. SMF Xe 21639. - female R (0.95/0.55); I: external view; J: internal view. SMF Xe 21639.

K-O: Krithe sp. 8

Recent, sample BX138, South Tasman Rise, off south coast Tasmania, Australia; $\$ 49^{\circ} 13.06^{\prime}$, E151 $05.77^{\prime}$, $3022 \mathrm{~m}$. - female L (1.00/0.55); K: external view; L: internal view. SMF Xe 21643. - female R (1.15/0.65); M: external view; $\mathrm{N}$ : internal view; O: central muscle scars, $\times 125$. SMF Xe 21643. - All magnifications are $\times 45$ unless otherwise stated. 
Krithe sp. 8

(Figs. 58K-O)

Material: 9 adult valves. - SMF Xe 21643-21644.

Dimensions: Female L 1.00-1.10/0.55-0.62, R 1.121.15/0.60-0.65; male L 1.17-1.20/0.55-0.57, R 1.15/0.57.

Distribution: Holocene of the South Tasman Rise. Rare in sample BX138 (3022 m) and very rare in sample BX147 (2177 m).

Description: A large, sub-trapezoidal species, with a pointed posterior. Maximum length in the lower half, maximum height at mid-length. Anterior margin asymmetrically rounded. Posterior outline with a protruding truncation on the lower half in the $\mathrm{L}$, pointed in the R. Dorsal outline almost straight in the L, slightly arched in the R. Ventral outline straight. Surface smooth with scattered sieve-type normal pores. In dorsal view, maximum width in the posterior third. In dorsal view, maximum width in the posterior third. Surface smooth with scattered sieve-type pores.

Internally: posterior margin steeply sloping from posterior cardinal angle towards the posterior end, forming a $70^{\circ}$ angle with the ventral margin; ventral margin slightly sinuous, with a pronounced accommodation groove about mid-length in L. Hinge pseudadont with wide sinuous median groove in the $\mathrm{L}$, expanded at the both ends and locellate in the posterior half. In the $\mathrm{R}$, complementary bar with denticles in the posterior half. Vestibulum small pocket shaped. Marginal porecanals could not be observed because of poor preservation. MS consisting of four adductor scars in a verrical row and a single dorsal scar. The lowermost adductor scar small and rounded, the lower middle oval, the upper medium elongate and deeply incised, the uppermost elongate and with a deep, U-shaped incision on the centre of the dorsal side. The frontal scar is four-leafed clover-shaped. No juveniles were found.

Remarks: The specimens were very poorly preserved $\left(\mathrm{Cl}_{\mathrm{AV}}=5\right)$ such that observations on the inner lamella were not possible. The outline resembles that of $K$ triangularis COLEs et al (1994), recorded from the Early Miocene to Recent of the Tasman Sea at depths ranging from $1125 \mathrm{~m}$ to $3281 \mathrm{~m}$. K. triangularis, however, is described as having an adont hinge.

Krithe sp. 9

(Figs. 59A-H, 55K-M)

Material: 132 adult and more than 1000 juvenile valves. - SMF Xe 21645-21648.

Dimensions: Female L 1.05-1.10/0.52-0.55, R 1.05$1.12 / 0.52-0.60$; male L $1.05-1.10 / 0.45-0.50$, R 1.05-1.10/ $0.45-0.50$.

Distribution: Holocene of the South Tasman Rise. Abundant in samples BX140 (1636 m), BX141 (1690 m) and BX147 (2177 m), common in sample BX156 (3208 m).

Description: A medium-sized sub-trapezoidal species. Maximum length just below mid-height, maximum height at posterior cardinal angle in L, medially in R. Anterior margin evenly rounded, posterior outline slightly truncate in the low- er half, more evident in the male Ls. Dorsal outline convex with a slightly anterior depression in the $\mathrm{R}$. Ventral outline slightly sinuous. Surface smooth with scattered sieve-type normal pores. In dorsal view, maximum width in the anterior half. The posterior invagination is very pronounced.

Internally: ventral margin with a narrow accommodation groove around mid-length which extends towards posterior in the $\mathrm{R}$. Hinge pseudadont. In the $\mathrm{R}$ the hinge bar displays faint lobations at mid-length grading into $4-5$ well defined denticles. These denticles merge posteriorly, forming a short denticulate bar. In the $\mathrm{L}$ the groove is smooth but with locellae to accommodate the denticles. The dorsal outer margin is protruding over the locellae forming a hinge-ear which fits the smooth and flat dorsal margin of the R. Marginal pore-canals straight and simple, 17 anteriorly and 8 posteriorly. ADPRC type 1 (AD3 elongate). Anterior vestibulum large and pocket-shaped, posterior equivalent small, with a ventral prolongation. MS consisting of four adductor scars in a vertical row and a single dorsal scar. The lowermost adductor scar small and oval, the lower middle oval with a faint incision dorsally, the upper medium large, oval and bilobate posteriorly, the uppermost deeply incised. The frontal scar is fourleafed clover-shaped, elongated along the vertical axis.

Remarks: This species was moderately well preserved $\left(\mathrm{Cl}_{\mathrm{AV}}=3\right)$. It is slightly larger than Krithe sp. 7 , has a larger anterior vestibulum and a smaller posterior vestibulum. The position of the MS in females is more ventral than in $K$. sp. 7. It is very difficult to distinguish from each other the juveniles of the two species because in the smaller instars the differences in the vestibulum are not apparent. Additionally, $K$. sp. 9 always has slightly higher valves.

In outline, dimensions and ADPRC type it is similar to $K$. dolichodeira VAN DEN BOLD (1946) sensu AyRFss et al. (1999: 6) which displays a mushroom-shaped vestibulum. It is also similar to K. spatularis Dingle et al. (1990) from the Recent of the SE Atlantic Ocean which displays an upturned large pocket-shaped vestibulum and a more triangular posterior. Unfortunately, no data was available about the hinge.

K. sawanensis sensu Ayress et al. (1999) is also very similar, with respect to the hinge, vestibulum type and outline, but is much smaller $(<1 \mathrm{~mm})$.

Krithe sp. 10

(Figs. 59I-L, 55N-O)

Material: 12 adult and 31 juvenile valves. - SMF Xe 21649-21650.

Dimensions: Female L $0.97-1.02 / 0.50-0.60$, R $0.97-$ 1.00/0.48-0.50; male L $1.00-1.02 / 0.45-0.47$, R. 1.00-1.05/ $0.42-0.45$.

Distribution: Holocene of the South Tasman Rise. Common in sample BX138 (3022 m) and BX156 (3202 m).

Description: A medium-sized, sub-trapezoidal species. Maximum length below mid-height, maximum height at posterior cardinal angle. Anterior margin evenly rounded, posterior outline slightly truncate in the lower half especially in the $\mathrm{L}$. Dorsal outline convex in the $\mathrm{R}$, with an anterior depres- 


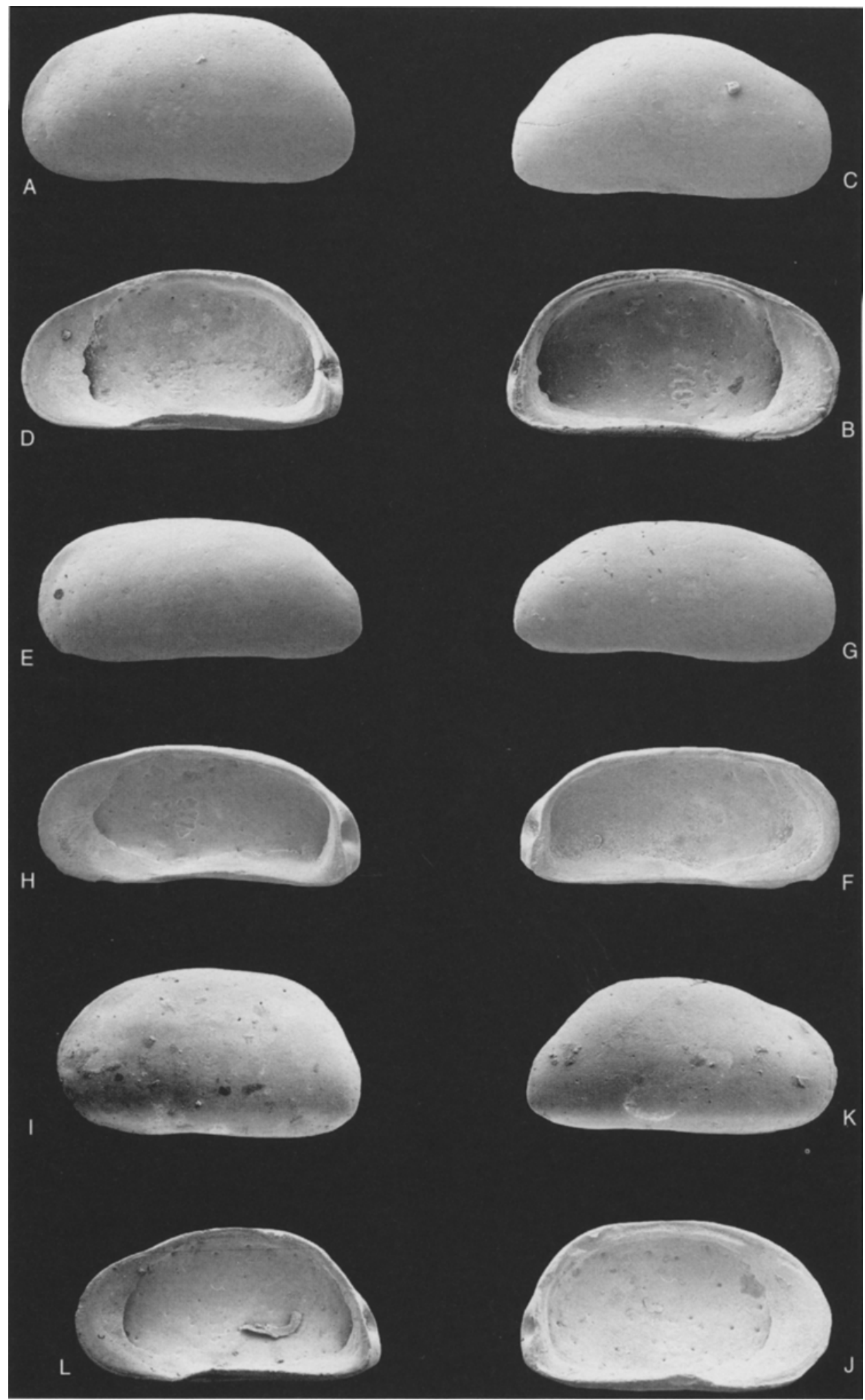

Fig. 59: A-H: Krithe sp. 9

Recent, sample BX140; South Tasman Rise, off south coast Tasmania, Australia; S49 $10.84^{\prime}$, E150 $10.13^{\prime}$ $1636 \mathrm{~m}$. - female L (1.10/0.55); A: external view; B: internal view. SMF Xe 21645. - female R (1.05/0.52); C: external view; D: internal view. SMF Xe 21645. - male L (1.05/0.45); E: external view; F: internal view. SMF Xe 21645. - male R (1.05/0.45); G: external view; H: internal view. SMF Xe 21645.

I-L: Krithe sp. 10

Recent, sample BX138, South Tasman Rise, off south coast Tasmania, Australia; S49 $13.06^{\prime}$, E $151^{\circ} 05.77^{\prime}$, $3022 \mathrm{~m}$. - female L (1.02/0.60); I: external view; J: internal view. SMF Xe 21649. - female R (1.00/0.50); K: external view; L: internal view. SMF Xe 21649. - All magnifications are $\times 48$. 
sion, almost straight in the $\mathrm{L}$ and in males. Ventral outline slightly sinuous. In dorsal view, maximum width in the posterior half. The posterior invagination is not very pronounced and symmetrically oblique in borh valves. Surface smoorh with scattered sieve-type normal pores.

Internally: ventral margin almost straight, with an obvious accommodation groove medially which extends towards posterior in the $R$. Hinge pseudadont. In the $\mathrm{L}$ the groove bears 5 locellae on the anterior part of the posterior half. The $\mathrm{R}$ has a complementary bar, displaying a faint lobation at the posterior extremity. Marginal pore-canals straight and simple, 13 anteriorly and 6-8 posteriorly. ADPRC type 2 (AD2 elongate). Anterior vestibulum small and pocket-shaped; posterior equivalent small. MS consisting of four adductor scars in a vertical row and a single dorsal scar. The lowermost adductor scar small and triangular, the lower middle oval with a faint incision dorsally, the upper medium large, oval and incised dorsally, the uppermost deeply incised. The frontal scar is four-leafed clover-shaped.

Remarks: Few specimens were found of this moderately well preserved species $\left(\mathrm{CI}_{\mathrm{AV}}=3\right)$. The sub-trapezoidal shape of the $\mathrm{R}$, the oval outline of the $\mathrm{L}$ and the different ADPRC type make differentiate it from Krithe sp. 7. It is similar to $K$. compressa (Seguenza 1880) sensu Ayress et al. (1999: Figs. $3 A-D)$ which is smaller, has an adont hinge and an ADPRC type 1 . In their dimensions and ADPRC type, the $\mathrm{L}$ valves are similar to $K$. dilata AYRESs et al. (1999: 13-14, Figs. 6AD) which has a mushroom-shaped vestibulum and was found in shallower waters $(355-1321 \mathrm{~m})$ in the Tasman Sea.

\section{Family Macrocyprididae G.W. MÜLLER 1912}

\section{Genus Macropyxis MaDDocks 1990}

\section{Type species: Macrocypris sapeloensis DARBY 1965.}

Remarks: This cosmopolitan genus was described by MADDOCKS (1990) to include species from the Holocene of all over the oceans, recovered with a wide depth range (49$6134 \mathrm{~m})$. She recognised several species from the $S$ Pacific and from the Tasman Sea (M. eltaninae, $M$. kalbi and five species under open nomenclature). Unfortunately, the intraspecific variation in valves morphology is not pronouncec such that, without soft parts, the decision to place specimen in one species or another would be speculative.

\section{Macropyxis sp.}

(Figs. 60A-G)

Material: 7 adult and 9 juvenile valves. - SMF Xe 21651-21652.

Dimensions: ? Female L 1.53/0.70, R 1.50-1.55/ $0.55-0.62$; ? male L 1.53/0.55; R 1.52-1.55/0.57-0.60.

Distribution: Holocene of the South Tasman Rise. Rare in sample BX165 (4067 m) and very rare in sample BX147 (2177 m) and BX138 (3022 m).
Remarks: The specimens recovered in samples BX147 and BX138 are all juveniles. In sample BX165, two adult carapaces with intact soft parts and three stained adult valves were found.

This species is referred to Macropyxis because it has well developed hinge, branching radial pore-canals, small MS and the gently arched dorsal margin. Moreover, it was possible to see that setae, exiting from funnel pores, are unbranched as reported by MADDOCKS for the genus.

- The following comparisons refer all ro species erected and studied by MADDOCKS (1990):

- M. eltaninae (68, Figs. 6.8, 7.7, pls 20.10-12, 21.10-12) from the Drake Sea and the Peru-Chile Trench (3149$5666 \mathrm{~m}$ ), is longer and more slender than $M$. sp., has a much sharper postero-ventral angle and a more sinuous ventral margin of the $\mathrm{L}$.

- M. kalbi (70, Fig. 6.20, pls 18.3-6, 19.2-6) from the eastern Pacific (259-6134 m), is much longer, displays a more extended postero-ventral angle and a dorsal margin with a median angle.

- M. sp. 14 (79, Fig. 6.3, pl. 24.10) from the Tasman Sea $(1047 \mathrm{~m})$ displays a more slender outline and a more sinuous ventral margin.

- M. sp. 15 (79, Figs. 6.5, 7.4, pls 16.8, 17.8) from the Tasman Sea $(769 \mathrm{~m})$ is larger and more stout with a different shape of the dorsal margin.

- M. sp. 16 (79, Figs. 1.5, 6) from the south-western Pacific Ocean $(2888 \mathrm{~m})$, is extremely large (3.15/1.24). Only drawings are provided, displaying a shape very similar to $M$. sp.

- M. sp. 17 (79, Fig. 10.1, pl. 20.1) from the eastern Pacific Ocean, south of Panama (2197 m), has a very complicated and broader anterior inner lamella and is much longer and more slender.

- M. sp. 46 (80, pls 20.9, 21.9) from the west coast of Chile $(3824-3739 \mathrm{~m})$ is much longer, has sub-rounded cardinal angles in the $\mathrm{R}$ and a slightly convex ventral margin in the $\mathrm{L}$.

As can be seen from the above comparisons, the differences between the species occur in the dimensions and in the outline. The specific determination of $M$. sp. will be possible only with an accurate study of the soft parts.

\section{Family Xestoleberididae SARS 1928}

\section{Genus Xestoleberis SARS 1866}

Type species: Cythere aurantia BAIRo 1838.

Remarks: The genus Xestoleberis is one of the most recurrent in the ostracod literature. In KEMPF (1986, 1995) about 356 species are reported. Being a genus characterised by a smooth or slightly ornate carapace, the taxonomy is often based on the outline and internal characters. As for Krithe, the description of a Xestoleberis species often lacks detail and as a consequence simply adds to an already confused scheme. 

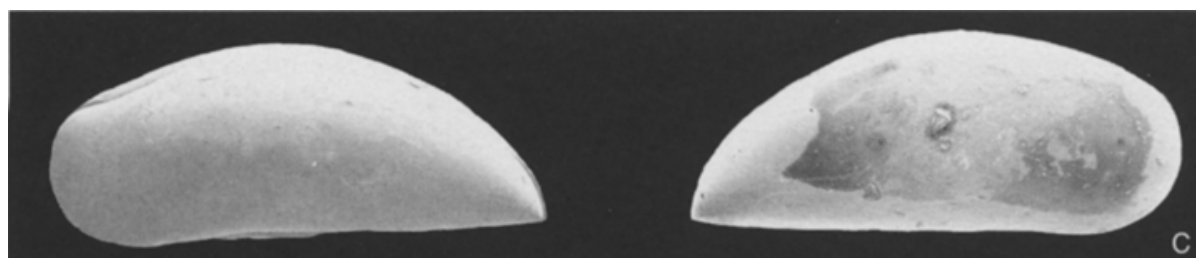

A

D
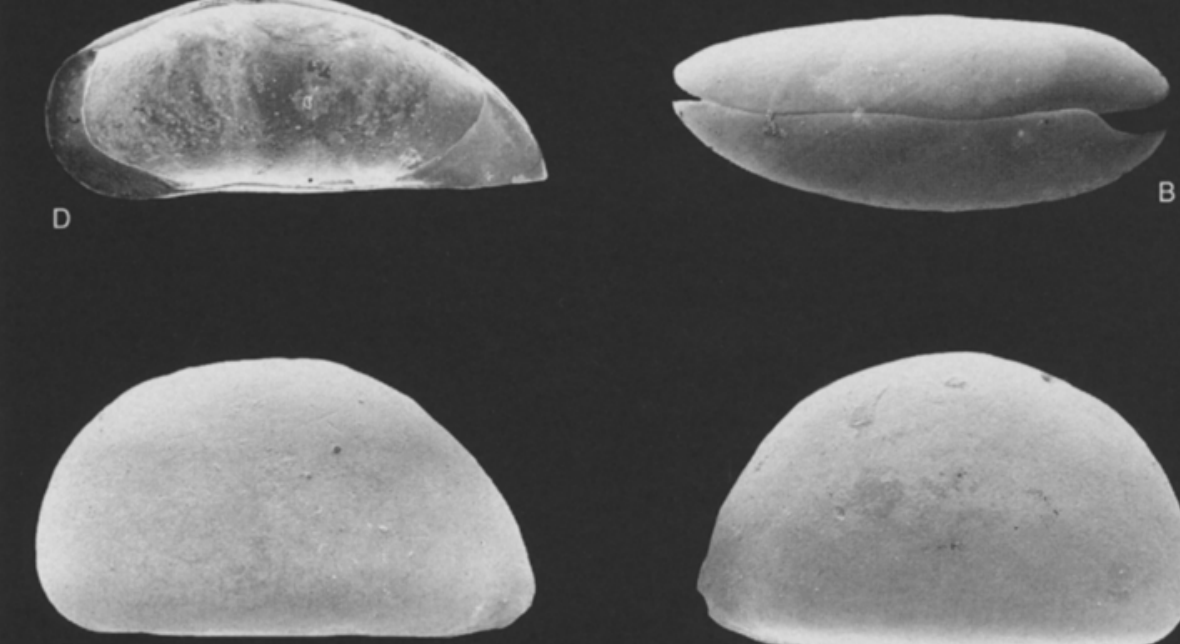

$\checkmark$
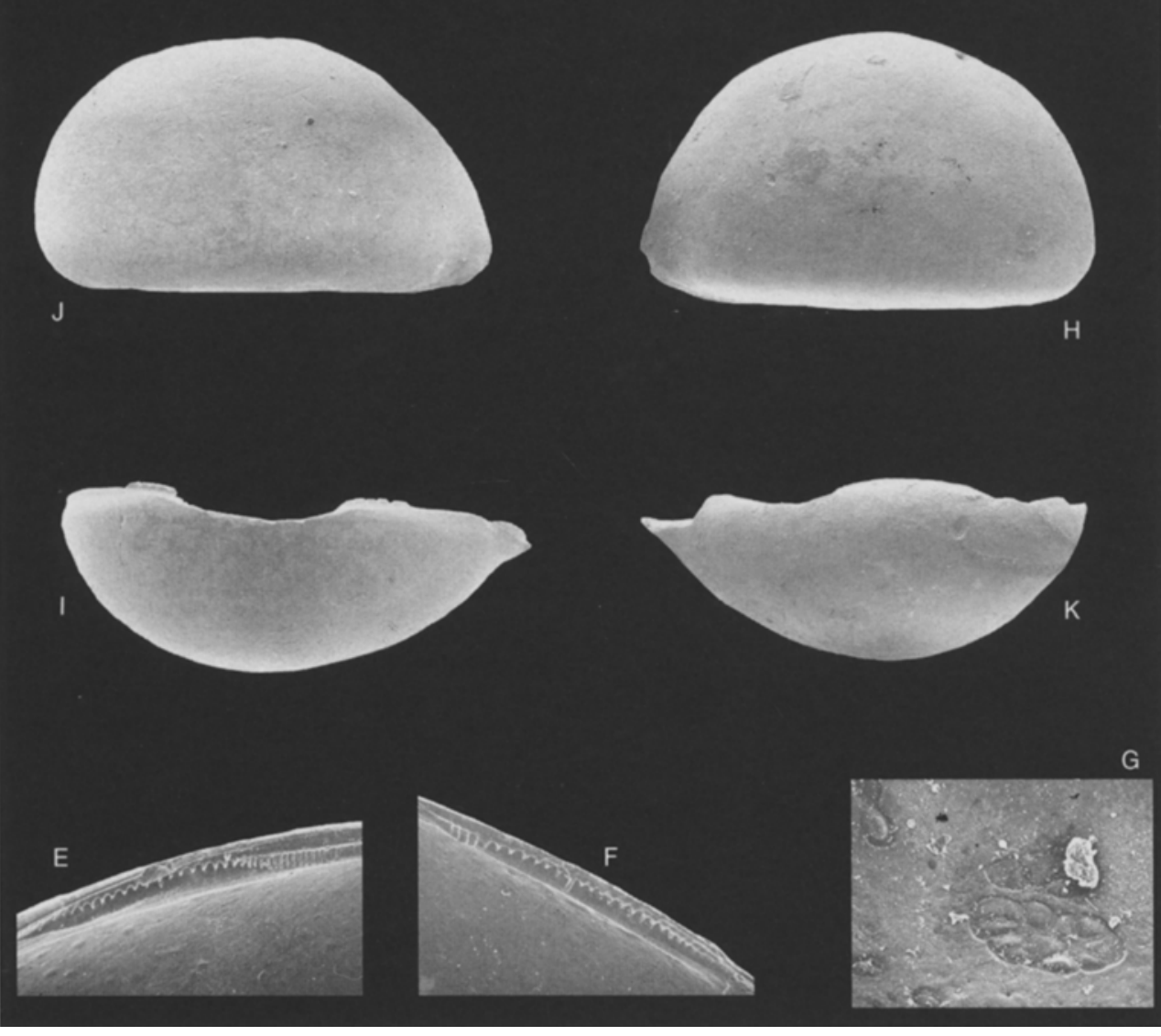

Fig. 60: A-G: Macropyxis sp.

Recent, sample BX165, South Tasman Rise, off south coast Tasmania, Australia; S45 $18.26^{\prime}$, E147 $7^{\circ} 55.13^{\prime}$, $4067 \mathrm{~m}$. - ? male C, (1.53/0.57/0.60); A: external view of L; B: dorsal view, showing the hinge line. SMF Xe 21651. - ? female R (1.55/0.62); C: external view; D: internal view; $E$ : detail of the anterior hinge element, $\times 142$; F: detail of the posterior hinge element, $\times 142$; G: central muscle scars, $\times 161$. SMF Xe 21651. - All magnifications are $\times 35$ unless otherwise stated.

$\mathrm{H}-\mathrm{K}$ : Xestoleberis sp.

Recent, sample BX153, South Tasman Rise, off south coast Tasmania, Australia; S47 $46.85^{\prime}$, E147 $145.13^{\prime}$, $1874 \mathrm{~m}$. - female L (0.62/0.35); H: external view; I: dorsal view. SMF Xe 21653. - female R (0.60/0.37); J: external view; K: dorsal view. SMF Xe 21653. - All magnifications are $\times 86$. 


\section{Xestoleberis sp.}

(Figs. 60H-K)

Material: 6 adult and 19 juvenile valves. - SMF Xe 21653-21655.

Dimensions: Female L $0.62 / 0.35$, R $0.60-0.62 / 0.37-$ 0.40 ; male L $0.60-0.62 / 0.35-0.37$; R $0.60 / 0.35$.
Distribution: Holocene of the South Tasman Rise. Rare in sample BX140 (1636 $\mathrm{m})$ and common in sample BX153 (1874 m).

Remarks: This species has a straight ventral margin and acuminate posterior. All the specimen recovered were characterised by a very fragile shell which was often eroded. No MS or marginal pore-canals could be observed. For these reasons it is left under open nomenclature.

Acknowledgements

This PhD Thesis has been carried out at the Ludwig Maximilians University (Munich, Germany), under the supervision of Prof. AleXANDER AltenbaCH who provided part of the samples and constant encouragement and help in many practical and theoretical matters. I would also like to express my gratefulness to the Senckenberg Museum (Frankfurt am Main, Germany) which provided me working space and allowed me to use many of its facilities, including the SEM and the laboratory. Dr. Thomas JellineK (Senckenberg Museum) very kindly provided me part of the samples, all the literature regarding the ostracod taxonomy and some of the material which was used for comparison. During his visits to the Senckenberg Museum, Dr. Hejnz MaLz guided me through the maze of the ostracod collections also providing useful suggestions about taxonomic matters. Dr. KerRy M. SWANSON (University of Canterbury, Christchurch, New Zealand) provided his expertise about the studied area and the material used for comparison. Moreover, the present work benefited from his critical reading and valuable comments. Dr. ULRICH Struck (Geo-Bio Zentrum, Munich) performed all the isotope measurements, provided the most helpful literature about this topic and critically discussed the results. The late Dr. Rucharo Benson (Smithsonian Museum, Washington/DC) provided the picture of the paratype of Henryhowella evax (ULRICH \& BASSLER 1904) and many suggestions about the problems connected with this genus. Dr. Richard Dingle (University of Copenhagen) provided helpful and up-to-date information about the distribution of the genus $D u$ - toitella, together with some related literature. Dr. DICK VAN HARTEN (Free University of Amsterdam) helped to contact the curators of the Utrecht Micropaleontological Collection, which kindly allowed me to loan material from the SissingH (1971) collection. Dr. JOHN WHITTAKER (National History Museum, London) provided access to the Challenger ostracod collection. He also organised some working space in the Paleontological Department during the time I spent at the NHM and took all the SEM pictures of the selected specimens. Additionally, many individuals assisted me by contributing literature and expertise: Prof. Dr. Pere Anadón (CSIS Institut de Ciencies de la Terra "J. Almera", Barcelona, Spain), Prof. Dr. Patrick DE DeCKKER (Australian National University, Canberra, Australia), Dr. ClaU. DIA DiDIE (Alfred-Wegener Institut für Polar und Meeresforschung, Bremerhaven, Germany), Prof. Dr. Elsa Guıozzi (Università di Roma 3, Italy), Prof. Dr. David Horne (University of Greenwich, UK), Prof. Dr. Julio Rodriguez-Lazaro (Universidad del Pais Vasco, Bilbao, Spain), Dr. RafFafle Sardella (Università "La Sapienza", Roma, Italy). The late Mrs. URSULA SCHWIEGER patiently developed and printed hundreds of SEM micrographs together with Miss CLAUDIA Franz (both Senckenberg Museum, Frankfurt am Main, Germany) who also helped to solve many practical problems mostly due to my initial ignorance of the German language. I would like to extend my thanks and gratitude to Dr. R. MATZKE-KarASZ for her warm hospitality in Munich and to ANDREA MaZzINI, who contributed to the final layout of the present work.

\section{References}

Abate, S., Barra, D., Aifllo, G. \& Bonaduce, G. (1993): The genus Krithe Brady, Crosskey \& Robertson, 1874 (Crustacea: Ostracoda) in the Pliocene - Early Pleistocene of the M. San Nicola section (Gela, Sicily). - Bollettino della Società Paleontologica Italiana 32 (3): 349-366; Modena.

Agrenjus, S., Majoran, S. \& Kucera, M. (1997): The effect of temperature on shell size and growth rate in Krithe praetexta praetexta (SARS, 1866). - In: Horne, D.J. \& MarTens, K. [Eds.]: Evolutionary biology and ecology of Ostracoda. - Hydrobiologia 419: 141-148; Dordrecht (Kluwer).

Aiello, G., Barra, D., Bonaduce, G. \& Russo, A. (1996): The genus Cytherella JONES, 1849 (Ostracoda) in the Iralian Tortonian-Recent. - Revue de Micropaléontologie 39 (3): 171-190; Paris.

Alexander, C.I. (1933): Shell structure of the Ostracode Genus Cytheropteron and fossil species from the Cretaceous of Texas. Journal of Paleontology 7 (2): 181-214; Tulsa OK.

Anadón, P., Gliozzi, E. \& Mazzini, I. (2002): Palaeoenvironmental reconstruction of marginal marine environments from combined paleoecological and geochemical analyses on ostracods. - In:
Holmes, J.A. \& ChIvas, A.R. [Eds.]: The Ostracoda: applications in Quaternary Research. - Geophysical Monograph Series 131: 227-247; Washington DC (AGU).

ANGEL, M. (1990): Food in the deep ocean. - In: R.C. WhatLeY \& C. Marbury [Eds.]: Ostracoda and global events. - Proceedings of the $10^{\text {th }}$ International Symposium on Ostracoda: 273-285; Cambridge (Chapman \& Hall).

APOSTOLescu, V. (1961): Contribution a l'étude paléontologique (ostracodes) et stratigraphique des bassins Crétacés et Tertiaires de l'Afrique Occidentale. - Revue de l'Institut Française du Pétrol, 16 (7-8): 779-865; Paris.

Ascoli, P. (1965a): Preliminary ecological study on Ostracoda from bottom cores of the Adriatic Sea. - In: H.S. PURI [Ed.]: Ostracods as ecological and palaeoecological indicators. - Proceedings

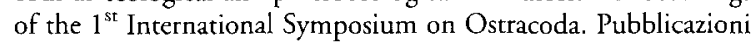
della Stazione Zoologica di Napoli, 33 (1964): 213-246; Napoli.

Ascoli, P. (1965b): Crociera Talassografica Adriatica 1955. VI. Ricerche ecologiche sugli ostracodi contenuti in 16 carote prelevate 
sul fondo del mare adriatico. - Archivio di Oceanografia e Limnologia, 14 (1): 69-137; Venezia.

Ascolı, P. (1969): First data on the ostracod biostratigraphy of the Possagno and Brendola sections (Paleogene, NE Italy). - Mémoires du Bureau de Recherches Géologiques et Minières, 69: 5171; Paris.

AtHersuch, J. (1979): On Pelecocythere sylvesterbradleyi ATHERSUCH gen. et sp. nov. - Stereo Atlas of Ostracod Shells, 6 (3): 13-20; Llandudno.

Athersuch, J. \& HorNe, D.J. (1984): A review of some European genera of the Family Loxoconchidae (Crustacea: Ostracoda). Zoological Journal of the Linnean Society, 81: 1-22; London.

Ayress, M.A. (1988): Late Pliocene to Quaternary Deep-Sea Ostracoda from the Eastern Indian and Southwestern Pacific Ocean. Unpubl. Doctoral Thesis, Univ. of Wales, Aberystwyth, 2 Vols.: 1088 pp.; Aberystwyth.

Ayress, M.A. (1991): On Arcacythere Hornibrook, 1952 (Cytheracea, Ostracoda, Crustacea), a senior synonym of Rockallia WHATLEY, FRAME \& WhITTAKER, 1978. - Journal of Micropaleontology, 10 (2): 223-226; London (Geol. Soc.).

Ayress, M.A. (1993a): On Kuiperiana juglandica AYress sp. nov. Stereo-Arlas of Ostracod Shells, 19 (17): 75-78; London.

AYRESS, M.A. (1993b): Ostracod biostratigraphy and palaeoecology of the Kokoamu Greensand and Otekaike Limestone (Late Oligocene to Early Miocene), North Otago and South Canterbury, New Zealand. - Alcheringa, 17: 125-151; Sydney.

Ayress, M.A. (1993c): Middle Eocene Ostracoda (Crustacea) from the coastal section, Bortonian Stage, at Hampden, South Island, New Zealand. - New Zealand Natural Sciences, 20: 15-21; Christchurch.

Ayress, M.A. (1994): Cainozoic palaeoceanographic and subsidence history of the eastern margin of the Tasman Basin based on Ostracoda. - In: Lingen, G.J. van der, Swanson, K.M. \& Muir, R.]. [Eds.]: Evolution of the Tasman Sea Basin: 139-157; Rotterdam (Balkema).

Ayress, M.A. (1995): Late Eocene Ostracoda (Crustacea) from the Waihao District, South Canterbury, New Zealand. - Journal of Paleontology, 69 (5): 897-921; Tulsa OK.

AYRESS, M.A. (1996): New species and biostratigraphy of Late Eocene cytherurid Ostracoda from New Zealand. - Revista Española de Micropaleontología, 28 (3): 11-36; Madrid.

Ayress, M.A., Barrows, T., Passlow, V. \& Whatley, R.C. (1999): Neogene to Recent species of Krithe (Crustacea: Ostracoda) from the Tasman Sea and off Southern Australia with description of five new species. - Records of the Australian Museum, 51 (1): 1-22, Sydney.

Ayress, M.A., Nell, H., Passlow, V. \& SWanson, K.M. (1997): Benthonic ostracods and deep watermasses: a qualitative comparison of Southwest Pacific, Southern and Atlantic Oceans. Palaeogeography, Palaeoclimatology, Palaeoecology, 131: 287 302; Amsterdam (Elsevier).

BABINOT, J.F. \& COLIN, J.P. (1992): On Arcacythere aurani BABINOT \& CouIn sp. nov. - Stereo-Atlas of Ostracod Shells 19 (2): (21) 91-94; London.

Bassiouni, M.A.A. (1962): Ostracoden aus dem Mittelmiozän in NW-Deurschland. - Roemeriana 3: 1-99; Clausthal-Zellerfeld.

BATE, R.H. (1972): Upper Cretaceous Ostracoda from the Carnarvon Basin, Western Australia. - Special papers in Palaeontology, 10: 1-85; London (Palaeont. Assoc.).

Benson, R.H. (1965): Recent marin Podocopid and Platycopid Ostracodes of the Pacific. - In: H.S. Puri [Ed.]: Ostracods as ecological and palaeoecological indicators. - Proceedings of the $1^{\text {st }} \mathrm{In}$ - ternational Symposium on Ostracoda. Pubblicazioni della Stazione Zoologica di Napoli, 33 (1964): 387-420; Napoli.

BENSON, R.H. (1972): The Bradleya problem, with descriptions of two new psychrospheric genera, Agrenocythere and Poseidonamicus (Ostracoda: Crustacea). - Smithsonian Contribution to $\mathrm{Pa}-$ leobiology, 12: 1-138; Washington DC.

Benson, R.H. (1974): Preliminary report on the ostracodes of Leg 24. - Initial Reports of the Deep Sea Drilling Project, 24: 10371043; Washington DC.

BENSON, R.H. (1975a): The origin of the psychrosphere as recorded in changes of deep-sea ostracode assemblages. - Lethaia, 8: 6983; Oslo.

BENSON, R.H. (1975b): Morphologic stability in Ostracoda. - In: SWAin, F.M. [Ed.]: Biology and paleobiology of Ostracoda. Proceedings of the $4^{\text {th }}$ meeting of the Ostracod workers in Newark (Delaware) 1972. Bulletins American Paleontology, 65 (282): 13-46; Ithaca NY (Paleont. Res. Inst.).

Benson, R.H. (1977): The Cenozoic ostracode faunas of the Săo Paulo Plateau and the Rio Grande Rise (DSDP Leg. 39, sites 356 and 357). - Initial Reports of the Deep Sea Drilling Project, 39: 869-883; Washington DC

BENSON, R.H. (1978): The paleoecology of the ostracodes of DSDP Leg 42A. - Initial Reports of the Deep Sea Drilling Project, 35: 777-787; Washington DC

BENSON, R.H. (1983): Biomechanical stability and sudden change in the evolution of the deep-sea ostracode Poseidonamicus. - Paleobiology, 9 (4): 398-413; Washington DC.

Benson, R.H., DelGrosso R.M. \& Steineck, P.L. (1983): Ostracode distribution and biofacies, Newfoundland continental slope and rise. - Micropaleontology, 29 (4): 430-453; New York (AMNH).

Benson, R.H. \& Peypouquet, J.-P. (1983): The upper and mid-bathyal Cenozoic ostracode faunas of the Rio Grande Rise found on Leg 72 deep sea drilling project. - Initial Reports of the Deep Sea Drilling Project, 72: 805-818; Washington DC.

Benson, R.H. \& Sylvester-Bradley, P.C. (1971): Deep sea ostracodes and the transformation of ocean to sea in the Tethys. - In: OertLI, H.J. [Ed.]: Paléoécologie des Ostracodes. - Bullettin Centre Recherches Pau-SNPA, 5 (Suppl.): 63-91; Pau.

Bertels, A. (1969): "Rocaleberidinae", nueva subfamilia (Ostracoda, Crustacea) del limite Cretacico-Terciario de Patagonia septentrional (Argentina). - Ameghiniana, 4 (2): 116-171; Buenos Aires.

Blake, C. (1933): New Crustacea from Mount Desert Region. Biological Survey of the Mount Desert Region, V: 229-241; Philadelphia (Wistar Inst. of Anatomy and Biol.).

BlASZYK, J. (1987): Ostracods from the Oligocene Polonez Cove formation of King George Island, West Antarctica. - Palaeontologia Polonica, 49: 63-81; Warszawa/Krakow.

BOLD, W.A. VAN DEN (1946): Contribution to the study of Ostracoda with special reference to the Terriary and Cretaceous microfauna of the Caribbean region. - Dissertation Rijks-Universiteit Utrecht: 167 pp.; Amsterdam.

BOLD, W.A. VAN DEN (1957a): Ostracoda from the Paleogene of Triridad. - Micropaleontology, 3 (1): 1-18; New York (AMNH).

BOLD, W.A. VAN DEN (1957b): Oligo-Miocene Ostracoda from Southern Trinidad. - Micropaleontology, 3 (3): 231-254; New York (AMNH).

BOLD, W.A. VAN DEN (1958a): Ambocythere, a new genus of Ostracoda. - Annals and Magazine of Natural History, Ser. 12, 10: 801-813; London. 
BOLD, W.A. VAN DEN (1958b): Ostracoda of the Brasso formation of Trinidad. - Micropaleontology, 4 (4): 391-418; New York (AMNH).

BOLD, W.A. VAN DEN (1960): Eocene and Oligocene Ostracoda of Trinidad. - Micropaleontology, 6 (2): 145-196; New York (AMNH).

BOLD, W.A. VAN DEN (1965): New species of the ostracod genus $A m$ bocythere. - Annals and Magazine of Natural History, Ser. 13, 8: 1-18; London.

Bonaduce, G., Barra, D. \& Aiello, G. (1999): The genus Henryhowella PURI, 1957 (Crustacea, Ostracoda) in the Atlantic and Mediterranean from Miocene to Recent. - Bollettino della Società Paleontologica Italiana, 38 (1): 59-72; Modena.

Bonaduce G., Ciampo G. \& Masoli, M. (1975): Distribution of Ostracoda in the Adriatic Sea. - Pubblicazioni della Stazione Zoologica di Napoli, 40: 304 pp.; Napoli.

Bonaduce, G., Ciliberto, B., Masoli, M., Minichelli, G. \& PugliESE, N. (1983): The deep-water benthic ostracodes of the Mediterranean. - In: MADDOCKS, R.F. [Ed.]: Application of Ostracoda. - Proceedings of the $8^{\text {th }}$ International Symposium on Ostracoda, Univ. Houston Geosciences: 459-472; Houston TX.

BOOMER, I. (1999): Late Cretaceous and Cainozoic bathyal Ostraco$\mathrm{da}$ from the Central Pacific (DSDP Site 463). - Marine Micropaleontology, 37: 131-147; Amsterdam (Elsevier).

BRADY, G.S. (1866): On new or imperfectly known species of marine Ostracoda. - Transactions of the Zoological Society of London, 5 (5): 359-393; London.

BRADY, G.S. (1869): Quelques entomostraces de Maurice. - In: Fo LIN, L. DE \& Perier, L. [Eds.]: Les Fonds de la Mer, 1: 162-176; Paris.

BRADY, G.S. (1880): Report on the Ostracoda. Report on the scientific results of the voyage of the H.M.S. Challenger during the years 1873-76. - Zoology, Vol., 1 (III): 184 pp.; London.

BradY, G.S. (1890): On Ostracoda collected by H. B. Brady, Esq., L. L.D., F.R.S., in the South Seas Islands. - Transactions of the Royal Society of Edinburgh, 35: 489-525; Edinburgh.

Brady, G.S., Crosskey, H.W. \& Robertson, D. (1874): A monograph of the post-Tertiary Entomostraca of Scotland including species from England and Ireland. - Annual volumes (monographs) of the Palaeontographical Society, 28 (1/5): 232 pp:; London.

Brady, G.S. \& Norman, A. M. (1889): A monograph of the marine and freshwater Ostracoda of the North Atlantic and of NorthWestern Europe. I. Podocopa. - Scientific Transactions of Royal Dublin Society, Ser. 2, 4 (2): 63-270; Dublin.

Buzas, M.A., Culver, S.J., Jorissen, F.J. (1993): A statistical evaluation of the microhabitats of living (stained) infaunal benthic foraminifera. - Marine Micropaleontology, 20: 311-320; Amsterdam (Elsevier).

Carter, L., Carter, R.M., McCave, I.N. \& Gamble, J. (1996): Regional sediment recycling in the abyssal SW Pacific. - Geology 24: 735-738; Boulder CO.

CarTer, L. \& MCCAVE, I.N. (1997): The sedimentary regime beneath the Deep Western Boundary Current inflow to the Southwest Pacific Ocean. - Journal of Sedimentary Research 67 (6): 1005-1017; Tulsa OK

CARTER, L. \& WILKIN, J. (1999): Abyssal circulation around New Zealand - a comparison between observations and a global circulation model. - Marine Geology 159: 221-239; Amsterdam (Elsevier).

Chapman, F. (1915): Report on the Foraminifera and Ostracoda obtained by the F.I.S. "Endeavour" from the East Coast of Tasmania, and off Cape Wiles, South Australia. - In: (Biological) Re- sults of the fishing experiments carried on by the F.I.S. "Endeavour" 1909-1914, 3: 1-51; British Commonwealth of Australia.

CHISWELL, S.M. (1994): Variability in sea surface temperature around New Zealand from AVHRR images. - Marine and Freshwater research, 28: 179-192; Victoria (CSIRO).

Chivas, A.R., De Deckker, P. \& Shelley, J.M.G. (1983): Magnesium, strontium and barium partioning in nonmarine ostracode shells and their use in paleoenvironmental reconstructions - a preliminary study. - In: MADDOCKS, R.F. [Ed.]: Application of Ostracoda. - Proceedings of the $8^{\text {th }}$ International Symposium on Ostracoda, Univ. Houston Geosciences: 238-249; Houston TX.

Chivas, A.R., De DeckKer, P., Wang, S.X. \& Call, J.A. (2002): Oxygen-isotope systematics of the nektic ostracod Australocypris robusta. - In: Holmes, J.A. \& CHIVAs, A.R. [Eds.]: The Ostracoda: applications in Quaternary Research. - Geophysical Monograph Series, 131: 301-313; Washington DC (AGU).

Ciampo, G. (1984): Alcuni ostracodi del Miocene superiore Piemontese. - Bollettino della Società Paleontologica Italiana, 22 (3): 247-262; Modena.

Colaiongo, M.L. \& PASINI, G. (1980): La ostracofauna plio-pleistocenica della Sezione Vrica in Calabria (con considerazioni sul limite Neogene/Quaternario): - Bollettino della Società Paleontologica Italiana, 19 (1): 44-126; Modena.

Coles, G., Ayress M.A. \& Whatley, R.C. (1990): A comparison of North Atlantic and Pacific Cainozoic deep-sea Ostracoda. - In: Whatley, R.C. \& Maybury, C. [Eds.]: Ostracoda and global events. - Proceedings of the $10^{\text {th }}$ International Symposium on Ostracoda: 287-301; Cambridge (Chapman \& Hall).

Coles, G. \& Whatley, R.C. (1989): New Palaeocene to Miocene genera and species of Ostracoda from DSDP sites in the North Arlantic. - Revista Española de Micropaleontología, 21 (1): $81-$ 124; Madrid.

Coles, G., Whatley, R.C. \& Moguilevsky, A. (1994): The ostracod genus Krithe from the Tertiary and Quaternary of the North Atlantic, - Paleontology, 37 (1): 71-120; London.

CONNEL, R.D. \& SiKES, L. (1997): Controls on Late Quaternary sedimentation of the South Tasman Rise. - Australian Journal of Earth Sciences, 44: 667-675; Victoria (Blackweli).

CORREGE, T. (1993): The relationship between water masses and benthic ostracod assemblages in the Western Coral Sea, Southwest Pacific. - Palaeogeography, Palaeoclimatology, Palaeoecology, 105: 245-266; Amsterdam (Elsevier).

Coryell, H.N. \& Fields, S. (1937): A Gatun Ostracoda fauna from Cativa, Panama. - American Museum Novitates, 956: 1-18; New York (AMNH).

Crane, J.M. (1965): Upper Cretaceous ostracodes of the Gulf Coast area. - Micropaleontology, 11 (2): 191-254; New York (AMNH).

CRONIN, T.M. (1983): Bathyal ostracodes from the Florida-Hatteras slope, the Straits of Florida, and the Blake Plateau. - Marine Micropaleontology, 8: 89-119; Amsterdam (Elsevier).

Cronin, T.M. (1996): Deep water North Atlantic ostracods and Pliocene palaeoceanography. - In: MogullevskY, A. \& WhatLeY, R.C. [EDS.]: Microfossil and Oceanic environments: Palaeoceanography-Benthos, 1: 39-46; Aberystwyth.

Dall'Antonta, B. \& Bossio, A. (2001): Middle Miocene ostracods from the Salentine Peninsula, - Rivista Italiana di Paleontologia e Stratigrafia, 107 (3): 395-424; Milano.

DAVEY, F.J. (1977): Marine seismic measurements in the New Zealand region. - New Zealand Journal of Geology and Geophysics, 20: 719-777; Wellington. 
DEACON, G. (1937): The Hydrology of the Southern Ocean. - Cambridge University Press: 124 pp.; Cambridge.

De DeCKKer, P. DE (2002): Ostracod palaeoecology. - In: Holmes, J.A. \& CHIVAS, A.R. [Eds.]: The Ostracoda: applications in Quaternary Research. - Geophysical Monograph Series, 131: 121134; Washington DC (AGU).

Deltel, B. (1964): Nouveaux ostracodes de l'Éocène et de l'oligocène de l'Aquitaine méridionale. - Actes de la Société Linnéenne de Bordeaux, 100: 129-221; Bordeaux.

DidiE, C. \& BAUCh, H.A. (2000): Species composition and glacialinterglacial variations in the ostracode fauna of the northeast Atlantic during the past 200,000 years. - Marine Micropaleontology, 40: 105-129; Amsterdam (Elsevier).

Didiè, C. \& BAUCH, H.A. (2002): Implications of upper Quaternary stable isotope records of marine ostracodes and benthic foraminifers for paleoecological and paleoceanographical investigations. - In: Holmes, J.A. \& Chivas, A.R. [Eds.]: The Ostracoda: applications in Quaternary Research - Geophysical Monograph Series, 131: 279-299; Washington DC.

DingLe, R.V. (1981): The Campanian and Maastrichtian Ostracoda of South-East Africa. - Annals of the South African Museum, 85 (1): 181 pp.; Cape Town.

DiNgLe, R.V. (1984): Mid-Cretaceous Ostracoda from Southern Africa and the Falkland Plateau. - Annals of the South African Museum, 93 (3): 97-211; Cape Town

DiNGLE, R.V. (1993): Quaternary ostracods from the continental margin off South-Western Africa. Part II. Minor taxa. - Annals of the South African Museum, 103 (1): 165 pp.; Cape Town.

Dingle, R.V. \& LoRD, A.R. (1990): Benthic Ostracoda and deep water-masses in the Atlantic Ocean. - Palacogeography, Palaeoclimatology, Palaeoecology, 80: 213-235; Amsterdam (Elsevier).

Dingle, R.V., LoRD, A.R. \& BoOMer, I.D. (1989): Ostracod faunas and water-masses across the continental margin off southwestern Africa. - Marine Geology, 87: 323-328; Amsterdam (Elsevier).

Dingle, R.V., LoRD, A.R. \& BoomeR, I.D. (1990): Deep-water quaternary Ostracoda from the continental margin off South-Western Africa (SE Atlantic Ocean). - Annals of the South African Museum, 99 (9): 245-366; Cape Town.

Do Carmo, D.A. \& SanguinetTr, Y.T. (1999): Taxonomy and palaeoceanographical significance of the genus Krithe in the Brazilian margin. - Journal of Micropaleontology, 18 (2): 1-12; London (Geol. Soc.).

Ducasse, O. \& Peypouquet, J.-P. (1979): Cenozoic ostracodes: their importance for bathymetry, hydrology and biogeography. - Initial Reports of the Deep Sea Drilling Project, 48: 343-363; Washington DC.

Exon, N.F., Marshall, J.F, McCorkle, D.C., Alcock, M., Chaproniere, G.C.H., Connell, R., Dutton, S.J., Elmes, M., Findlay, C., Robertson, L., Rollet, N., Samson, S., Shafik, S. \& WhitMORE, G.P. (1995): AGSO Cruise 147 Report-Tasman rises geological sampling cruise of Rig Seismic: stratigraphy, tectonic history and palaeoclimate of the offshore Tasmanian region. - Australian Geological Survey Organisation Record, 1995/56: 159 pp.; Canberra.

FORESTER, R.M. (1980): A systematic revision of the ostracodes species described by ULRICH and BASSLER and by MALKIN from the Chesapeake Group in Maryland and Virginia. - Geological Survey Professional Paper, 1128: 1-21; Washington DC.

FosTeR, D.W. \& KAESLER, R.L. (1988): On Bradleya normani (BRA DY). - Stereo-Atlas of Ostracod Shells 15 (1): (9) 33-36; London.

Françols, R., Bacon, M., Altabet, M.A. \& Labeyrie, L.D. (1993): Glacial/interglacial changes in sediment rain rate in the SW In- dian sector of Subantartic waters as recorded by ${ }^{230} \mathrm{Th},{ }^{231} \mathrm{~Pa}, \mathrm{U}$, and $\delta^{15} \mathrm{~N}$. - Paleoceanography, 8: 611-629; Washington DC (AGU).

Gou, Y.S. \& CHEN, D.Q. (1988): On the occurence of Javanella and Saida in the Pliocene of the Leizhou Peninsula, Guangdong, China. - In: HanaI, T., IKeYA, N., \& IsHIZAKI, K. [Eds.]: Evolutionary biology of Ostracoda, its fundamental and applications. Proceedings of the $9^{\text {th }}$ International Symposium on Ostracoda: 797-803; Amsterdam (Elsevier).

Grafenstein, U. von, Erkenkeuser, H. \& Trimborn, P. (1999): Oxygen and carbon isotopes in modern fresh-water ostracod valves: assessing vital offsets and autoecological effects of interest for paleodimate studies. - Palaeogeography, Palaeoclimatology, Palaeoecology, 148: 133-152; Amsterdam (Elsevier).

GRUNDEL, J. (1966): Taxonomische, biostratigraphische und variationsstatistische Untersuchungen an den Ostracoden der Unterkreide in Deutschland. - Freiberger Forschungshefte, Ser. C, 200: 105 pp.; Leipzig.

GRÜNDEL, J. (1973): Zur Entwicklung der Trachyleberididae (Ostracoda) in der Unterkreide und in der tieferen Oberkreide. Zeitschrift für Geologische Wissenschaften, 1 (11): 1463-1474; Berlin.

GRÜNDEL, J. (1974): Einige Bemerkungen zu den bei Ostracoden (Crustacea) auftretenden Schloßtypen. - Biologische Rundschau, 12 (1): 60-62; Jena (Gustav Fischer).

Guernet, C. (1982): Contribution a l'étude des faunes abyssales: les ostracodes Paléogènes du bassin des Bahamas, Atlantique Nord (DSDP leg. 44). - Révue de Micropaléontologie, 25 (1): 40-56; Paris.

Guernet, C. (1985): Ostracodes Paléogènes de quelques sites "D.S.D.P." de l'Océan Indien (legs 22 et 23). - Révue de Paléobiologie, 4 (2): 279-295; Genève.

Guernet, C. (1998): Neogene and Pleistocene ostracodes, sites 959 and 960, Gulf of Guinea. - Proceedings of the Ocean Drilling Program, Scientific Results, 159: 525-531; Washington DC.

Guernet, C. \& Bellier, J.P. (2000): Ostracodes Paléocènes et Éocènes du Blake Nose (Leg ODP 171B) et évolution des environnements bathyaux au large de la Floride. - Révue de Micropaléontologie, 43 (4): 249-279; Paris.

GueRnet, C. \& Moullade, M. (1994): Ostracodes en milieu océanique profond (Atlantique central) au passage Miocène-Pliocène. Révue de Micropaléontologie, 37 (4): 257-274; Paris.

Hammer, Ø., Harper, D.A.T., \& Ryan P. D. (2001): PAST: Paleontological Statistics Software Package for Education and Data Analysis. - Palaeontologia Electronica, 4(1): 9 pp., http://palaeo-electronica.org/2001_1/past/issue1_01.htm.

HanaI, T. (1957a): Studies on the Ostracoda from Japan: 2. Subfamily Pectocytherinae, new subfamily. - Journal of the Faculty of Science, University of Tokyo, 10 (3): 469-482; Tokyo.

Hanal, T. (1957b): Studies on the Ostracoda from Japan: 3. Subfamily Cytherurinae G.W. MüLLeR (emend. G.O. SARS 1925) and Cytheropterinae n. subfam. - Journal of the Faculty of Science, University of Tokyo, 11 (1): 11-36; Tokyo.

Hanai, T. (1959): Studies on the Ostracoda from Japan: 4. Family Cytherideidae SARS 1925. - Journal of the Faculty of Science, University of Tokyo, 11 (3): 291-308; Tokyo.

Hanal, T. (1961): Studies on the Ostracoda from Japan: hingement. - Journal of the Faculty of Science, University of Tokyo, 13 (2): 354-377; Tokyo.

HARTEN, D. VAN (1990): Modern abyssal ostracod faunas of the eastern Mid-Atlantic Ridge area in the North Adlantic and a comparison with the Mediterranean. - In: WHATLEY, R.C. \& MAYBURY, C. [Eds.]: Ostracoda and global events. - Proceedings of 
the $10^{\text {th }}$ International Symposium on Ostracoda: $321-340$; Cambridge (Chapman \& Hall).

Harten, D. van (1996): The case against Krithe as a tool to estimate the depth and oxygenation of ancient oceans. - In: Moguilevs. KY, A. \& WhatLeY, R.C. [Eds.]: Microfossil and Oceanic environments; Palaeoceanography-Benthos, 1: 297-304; Aberystwyth.

Harten, D. van \& Droste, H.J. (1988): Mediterranean deep-sea ostracods, the species poorness of the Eastern Basin as a legacy of an Early Holocene Anoxic Event, - In: HANAI, T., IKEYA, N., \& IsHIZAKI, K. [Eds.]: Evolutionary biology of Ostracoda, its fundamentals and applications. - Proceedings of the $9^{\text {th }}$ International Symposium on Ostracoda: 721-737; Amsterdam (Elsevier).

Hartmann G. (1975): Ostracoda. - In: Bronns, H.G. [Ed.]: Klassen und Ordnungen des Tierreichs. - Arthropoda. Crustacea. 2. Book, IV part: 569-785; Jena (Gustav Fischer).

Hartmann G. (1985): Ostracoden aus der Tiefsee des Indischen Ozeans und der Iberischen See sowie von ostatlantischen sublitoralen Plateaus und Kuppen mit einer Tabelle der bislang bekannten rezenten Tiefseeostracoden. - Senckenbergiana Maritima, $17(1 / 3) ; 89-146$, Frankfurt a.M.

Hartmann G. (1987): Antarktische benthische Ostracoden II. Auswertung der Fahrten der "Polarstern" Ant. III/2 und der Reisen der "Walther Herwig" 68/1 und 2. 2.Teil: Elephant Island und Bransfield Straße. - Mitteilungen aus dem hamburgischen zoologischen Museum und Institut, 84: 115-156; Hamburg.

HaRTMAnN G. (1989): Antarktische benthische Ostracoden V. Auswertung der Südwinterreise von FS "Polarstern" (PS9/V-1) im Bereich Elephant Island und der Antarktischen Halbinsel. Mitteilungen aus dem hamburgischen zoologischen Museum und Instituc, 86: 231-288; Hamburg.

HaRTMANn G. (1993): Antarktische benthische Ostracoden IX. Ostracoden von der Antarktischen Halbinsel und von der Isla de los Estados (Feuerland/Argentinien), Auswertung der "Polarstern"-Reise PS ANT/X/1b. - Mitreilungen aus dem hamburgischen zoologischen Museum und Institut, 90: 227-237; Hamburg.

HARTMANN G. (1994): Antarktische benthische Ostracoden X. Bemerkungen zur Gattung Krithe mit Beschreibung einer neuen Untergattung Austrokrithe. - Mitteilungen aus dem hamburgischen zoologischen Museum und Institut, 91: 77-79; Hamburg.

Hartmann G. (1997): Antarktische und subantarktische Podocopa (Ostracoda). - In: WÄGELE, J.W., \& SIEG, J. [Eds.]: Synopses of the Antarctic benthos, 7: 355 pp.; Königstein (Koeltz).

Hartmann, G. \& Purr, H.S. (1974): Summary of neontological and paleontological classification of Ostracoda. - Mitteilungen aus dem hamburgischen zoologischen Museum und Institut, 70: 7 73; Hamburg.

Hayward, B.W., Neil, H., Carter, R., Grenfell, H.R. \& Hayward, J.J. (2002): Factors influencing the distribution patterns of Recent deep-sea benthic foraminifera, east of New Zealand, Southwest Pacific Ocean. - Marine Micropaleontology, 46: 139-176; Amsterdam (Elsevier).

HAZEL, J.E, (1967): Classification and distribution of the Recent Hemicytheridae and Trachyleberididae (Ostracoda) off northeastern Norch America. - US Geological Survey, Professional Paper, 564: 1-49; Washington DC.

HAZEL, J.E. (1968): Ostracodes from the Brightseat Formation (Danian) of Maryland. - Journal of Paleontology, 42 (1): 100-142; Tulsa OK
Herrig, E. (1968): Zur Gattung Saida Hornibrook (Ostracoda, Crustacea) in der Oberkreide. - Geologie, 17 (8): 871-998; Berlin.

HiLl, B.L. (1955): Reclassification of winged Cythereis and winged Brachycythere. - Journal of Paleontology, 28 (1954) (6): 804826; Tulsa OK.

Holmes, J.A. (1996): Trace-element and stable-isotope geochemiscry of non-marine shells in Quaternary palaeoenvironmental reconstruction. - Journal of Paleolimnology, 15: 223-235; Dordreche (Kluwer).

Holmes, J.A. \& Chivas, A.R. (2002): Ostracod shell chemistry Overview. - In: HOLmes, J.A. \& ChIVAS, A.R. [Eds.]: The Ostracoda: applications in Quaternary Research. - Geophysical Monograph Series, 131: 185-204; Washington DC (AGU).

Horne, D.J., Cohen, A. \& Martens, K. (2002): Taxonomy, Morphology and Biology of Quaternary and living Ostracoda. - In: HOLMES, J.A. \& ChIVAS, A.R. [Eds.]: The Ostracoda: applications in Quaternary Research. - Geophysical Monograph Series, 131: 5-36; Washington DC (AGU).

HORNE, D.J. \& WhitTakeR, J.E. (1988): On Cytheropteron latissi mum (Norman). - Stereo-Atlas of Ostracod Shells, 15 (2): (27) 127-132; London.

Hornibrook, N. DE B. (1952): Terriary and Recent marine Ostracoda of New Zealand. - Paleontological Bullettin of the New Zealand Geological Survey, 18: 1-82; Wellington.

Hornibrook, N. DE B. (1953): Some New Zealand Tertiary Ostracoda useful in stratigraphy. - Transactions of the Royal Society of New Zealand, 81: 303-311; Wellington.

HOWE, H.V. \& LAURENCICH, L. (1958): Introduction to the study of Cretaceous Ostracoda. - Louisiana State University Press: 536 pp.; Baton Rouge LA.

Howe, H.V. \& LaW, J. (1936): Louisiana Vicksburg Oligocene Ostracoda. - Geological Bulletrin of the Lousiana Geological Survey, 7 (1-8): 96 pp; New Orleans LA.

Howe, R.C. (1963); Type Saline Bayou Ostracoda of Lousiana. Geological Bulletrin of the Lousiana Geological Survey, 40: 62 pp.; Baton Rouge LA.

HulinGS, N.C. (1967): Marine Ostracoda from the western North Atlantic Ocean: Labrador Sea, Gulf of St. Lawrence and off Nova Scotia. - Crustaceana, 13 (3): 310-328; Leiden.

IKEYA, N. \& CRONIN, T.M. (1993): Quantitative analysis of Ostraco$\mathrm{da}$ and water masses around Japan: application to Pliocene and Pleistocene paleoceanography. - Micropaleontology, 39 (3): 263-281; New York (AMNH).

IsHIZAKI, K. (1966): Miocene and Pliocene ostracodes from the Sendai area, Japan. - Science reports of the Tohoku University, Ser. 2 (Geology), 37 (2): 131-163; Sendai.

ISHIZAKI, K. \& GUNTHER, F.J. (1974): Ostracoda of the family Cytheruridae from the Gulf of Panama. - Science reports of the Tohoku University, Ser. 2 (Geology), 45 (1): 1-50; Sendai.

IshIZAKI, K. \& IrIzUKI, T. (1990): Distribution of bathyal ostracodes in sediments of Toyama Bay, Central Japan. - Courier Forschungsinstitut Senckenberg, 123: 53-67; Frankfurt a.M.

JeLLINEK, T. \& SwANSON K.M. (2003): Report on the taxonomy, biogeography and phylogeny of mostly living benthic Ostracoda (Crustacea) from the deep-sea samples (Intermediate Wacer depths) from the Challenger Plateau (Tasman Sea) and Campbell Plateau (Southern Ocean), New Zealand. - Abhandlungen Forschungsinstitut Senckenberg, 558: 329 pp; Frankfurt a.M.

JoNES, T.R. (1857): A monograph of the Tertiary Entomostraca of England. - Palaeontographical Society, 9 (5/8): 68 pp.; London. 
Jorissen, F.J., STIGTer, H.C. DE \& Widmark, J.G.V. (1995): A conceptual model explaining benthic foraminiferal microhabitats. Marine Micropaleontology, 26: 3-15; Amsterdam (Elsevier).

KAYE, P. (1964): Ostracoda of the genera Eucytherura and Cytheropteron from the Speeton Clay. - Geological Magazine, 101 (2): 96-106; London.

Keatings, K.W., Heaton, T.H.E. \& Holmes, J.A. (2002): Carbon and oxygen isotope fractionation in non-marine ostracods: $\mathrm{Re}$ sults from a 'natural culture' environment. - Geochimica et Cosmochimica Acta, 66 (10): 1701-1711; Amsterdam (Elsevier).

KeIJ, A.J. (1957): Eocene and Oligocene Ostracoda of Belgium. Memoires, Institut Royal des Sciences Naturelles de Belgique, 136: 210 pp.; Bruxelles.

KEIJ, A.J. (1975): Note on three Holocene Indo-Malysian ostracod species. - Proceedings Koninklijke Nederlandse Akademie van Wetenschappen, ser. B, 78 (3): 231-241; Amsterdam.

KEMPF, E.K. (1986): Index and bibliography of Marine Ostracoda 1. Index A. - Geologisches Institut der Universität zu Köln, Sonderveröffentlichungen, 50:762 pp.; Köln.

KEMPF, E.K. (1995): Index and bibliography of Marine Ostracoda 6 Index A. Supplement 1. - Geologisches Institut der Universität zu Köln, Sonderveröffentlichungen, 100: 239 pp.; Köln.

KemPF, E.K. \& NinK, C. (1993): Henryhowella asperrima (Ostracoda) aus der Typusregion (Miozän: Badenian, Wiener Becken), -Geologisches Institut der Universität zu Köln, Sonderveröffentlichungen, 70: 95-114; Köln.

KINGMA J.T. (1948): Contribution to the knowledge of the Young Cenozoic Ostracoda from the Malayan Region. - Ph.D. Thesis, Utrecht University: 118 pp.; Utrecht.

KozUR, H. (1973): Beiträge zur Ostracodenfauna der Trias. - Geologisch-Paläontologische Mitteilungen Innsbruck, 3 (5): 1-41; Innsbruck.

LARWOOD, J.G. \& Whatley, R.C. (1993): Tertiary to Recent evolution of Ostracoda in isolation on seamounts. - In: MCKENZIE, K.G. \& JONES, P. J. [Eds.]: Ostracoda in the Earth and Life Sciences: 531-549; Rotterdam (Balkema).

LuTZE, G.F. \& ThIEL, H. (1989): Epibenthic foraminifera from elevated microhabitats: Cibicidoides wuellersdorfi and Planulina ariminensis. - Journal of Foraminiferal Research, 19: 153-158; Washington DC (Cushman Foundation).

Mackensen, A., Schumacher, S., Radke, J. \& Schmidt, D.N. (2000): Microhabitat preferences and stable carbon isotopes of endobenthic foraminifera: clue to quantitative reconstruction of oceanic new production? - Marine Micropaleontology, 40: 233258; Amsterdam (Elsevier).

MadDocks, R.F. (1969a): Recent ostracodes of the Family Pontocyprididae chiefly from the Indian Ocean. - Smithsonian Contributions to Zoology, 7: 1-56; Washington DC.

MadDocks, R.F. (1969b): Revision of Recent Bairdiidae (Ostracoda). - United States National Museum Bulletin, 295: 1-126; Washington DC.

MADDOCKs, R.F. (1976): Pussellinae are interstitial Bairdiidae (Ostracoda). - Micropaleontology, 22 (2): 194-214; New York (AMNH).

MADDOCKS, R.F. (1990): Living and fossil Macrocyprididae (Ostracoda). - Paleontological Contributions of the University of Kansas, Monograph, 2: 189 pp.; Lawrence KS.

MadDocks, R.F. \& STEINECK, P.L. (1987): Ostracoda from experimental wood-island habitats in the deep sea. - Micropaleontology, 33 (4): 318-355; New York (AMNH).

Majoran, S. (1995): On Arcacythere rugosa Majoran sp. nov. Stereo-Atlas of Ostracod Shells, 22 (1): (9) 33-36, London.
Majoran, S. \& Agrenius S. (1995): Preliminary observations on living Krithe praetexta praetexta (SARS, 1866), Sarsicytheridea bradit (NORMAN, 1865) and other marine ostracods in aquaria. - Journal of Micropalaeontology, 14: 1-46; London (Geol. Soc.).

Majoran, S. \& Dingle, R.V. (2001a): Palaeoceanographical changes recorded by Cenozoic deep-sea ostracod assemblages from the South Atlantic and the Southern Ocean (ODP Sites 1087 and 1088). - Lethaia, 34: 63-83; Oslo.

Majoran, S. \& Dingle, R.V. (2001b): Cenozoic deep-sea ostracods from Southwestern South Atlantic (DSDP/ODP sites 329, 513 and 699). - Revista Española de Micropaleontología, 33 (2): 205-215; Madrid.

Malz, H. (1990): Tiefseearten leben länger. - Natur und Museum, 120 (5): 139-152; Frankfurt a.M.

Mandelstam, M.I. (1958a): New Ostracode genera and species. Trudy Vnigri, new Ser. (Microfauna SSSR: 9), 115: 232-299; Leningrad. [in Russian]

Mandelstam, M.I. (1958b): - In: BubiKjan, S.A. [ED.]: Ostracoda from Paleogene deposits of the Erevan Basin. - Izvestiya Akademii Nauk Armyanskoy SSR, Seriya Geologicheskii i Geograficheskii Nauk, 11 (3): 3-16; Erevan.

MAYBURY, C.A. (1990): On Loxocorniculum grateloupianum (BosQUET), - Stereo-Atlas of Ostracod Shells, 17 (1): (13) 69-72; London.

McCoY, FW. (1991): Southern Ocean sediments: Circum-Antartic to $30^{\circ} \mathrm{S}$. - In: HaYes, D.E. [Ed.]: Marine Geological and Geophysical Atlas of the Circum-Antarctic to $30^{\circ} \mathrm{S}$. - Antarctic Research Series, 54: 37-46; Washington DC (AGU).

McKenzie, K.G. (1967): Recent Ostracoda from Port Phillip Bay, Victoria. - Proceedings of the Royal Sociery of Victoria, 80 (1): 61-106; Melbourne.

McKenzie, K.G. (1974): Cenozoic Ostracoda of the Southeastern Australia with the description of Hanaiceratina new genus. Geoscience and Man, 6: 153-182; Baton Rouge LA.

McKenzie, K.G. \& Bonaduce, G. (1993): Partial redescriptions of some Trachyleberididae and Hemicytheridae from the Bay of Naples, comparisons and a reappraisal of Trachyleberidid-Hemicytherid classification. - In: MCKenzie, K.G. \& Jones, P.J. [Eds.]: Ostracoda in the earch and life sciences. - Proceedings of the $11^{\text {th }}$ international Symposioum on Ostracoda, Warnambool 1991: 599-620; Rotterdam (Balkema).

McKenzie, K.G., Majoran, S., Emami, V. \& Reyment, A.R. (1989): The Krithe problem - first test of PeypouQuet's hypothesis, with a redescritpion of Krithe praetexta praetexta (Crustacea, Ostracoda). - Palaeogeography, Palaeoclimatology, Palaeoecology, 74: 343-354; Amsterdam (Elsevier).

McKenzie, K.G., Reyment, A.R. \& ReymenT, E.R. (1991): EoceneOligocene Ostracoda from South Australia and Victoria, Australia. - Revista Española de Paleontología, 6 (2): 135-175; Madrid.

McKenzie, K.G., Reyment, A.R. \& Reyment, E.R. (1993): Eocene Ostracoda from the Browns Creek clays at Browns Creek and Castle Cove, Victoria, Australia. - Revista Española de Paleontología, 8 (1): 75-116; Madrid.

Morkhoven, F.P.C.M. van (1962): Post-Paleozoic Ostracoda. Their morphology, taxonomy and economic use. Volume 1, General. 204 pp.; Amsterdam (Elsevier).

Morkhoven, F.P.C.M. van (1963): Post-Paleozoic Ostracoda. Their morphology, taxonomy and economic use. Volume 2, Generic Descriptions. -478 pp.; Amsterdam (Elsevier).

MülLeR, G.W. (1894): Die Ostracoden des Golfes von Neapel und der angrenzenden Meeresabschnitte. - Herausgegeben von der 
Zoologische Station zu Neapel, 21: 404 pp.; Berlin (Friedlander \& Sohn).

MÜlLER, G.W. (1908): Die Ostracoden der Deutschen Südpolar-Expedition 1901-1903. - In: DrYGalski, E. vON [Ed.]: Deutsche Südpolar-Expedition, 10 (Zoologie 2) (2): 51-181; Berlin (Reimer).

Müller, G.W. (1912): Crustacea: Ostracoda. - Das Tierreich, 31 (1-33): 434 pp.; Berlin.

MUNSEY, G.C. jr. (1953): A Paleocene ostracode fauna from the Coal Bluff Marl Member of the Naheola Formation of Alabama. Journal of Paleontology, 27 (1): 1-20; Tulsa OK.

NeAle, J.W. (1965): Some factors influencing the distribution of Recent British Ostracoda. - In: PURI, H.S. [Ed.]: Ostracods as ecological and palaeoecological indicators. - Proceedings of the $1^{\text {st }}$ International Symposium on Ostracoda. Pubblicazioni della Stazione Zoologica di Napoli, 33 (1964): 247-296; Napoli.

NeALE, J.W. (1967): An ostracod fauna from Halley Bay, Coats Land, British Antartic Territory. - British Antartic Survey Scientific Reports, 58: 1-50; London.

Neale, J.W. (1974): On Pennyella pennyi gen. et sp. nov. - Stereo-Atlas of Ostracod Shells, 2 (2): (21) 125-132; Leicester.

NEALE, J.W. (1975): The ostracod fauna from the Santonian chalk (Upper Cretaceous) of Gingin, Western Australia. - Special papers in Paleontology, 16: 81 pp.; London (Palaeont. Assoc.).

Neale, J.W. (1988): The anatomy of the ostracod Pelecocythere purii sp. nov. and some features connected with the abyssal mode of life in this and some other deep waters forms. - In: HANAI, T., IKEYA, N. \& ISHIZAKI, K. [Eds.]: Evolutionary biology of Ostracoda, its fundamentals and applications. - Proceedings of the $9^{\text {th }}$ International Symposium on Ostracoda: 709-720; Amsterdam (Elsevier).

OrSi, A.H., WhitworTh, T. \& Nowlin, W.D. (1995): On the meridional extent and fronts of the Antarctic Circumpolar Current. Deep Sea Research, 42: 641-673; Amsterdam (Elsevier).

Passlow, V., Pinxian, W., Chivas, A.R. (1997): Late Quaternary palaeoceanography near Tasmania, southern Australia. - Palaeogeography, Palaeoclimatology, Palaeoecology, 131: 433-463; Amsterdam (Elsevier).

PePeR, H. (1986): Oxygen consumption rates of Baltic ostracods. Ophelia, 4 (suppl.): 191-199; Helsingør.

Peypouquet, J.-P. (1975): Ostracodes du bassin de Rockall. - Bullettin de la Societè Géologique Française, 17 (5): 886-895; Paris.

PuCKETT, T.M. (1997): The genus Krithe (Ostracoda) from the Campanian and Maastrichtian (Upper Cretaceous) of the northern US Gulf Coastal Plain. - Journal of Micropaleontology, 16: 145-157; London (Geol. Soc.).

PurI, H.S. (1953): The ostracode genus Hemicythere and its allies. Journal of the Washington Academy of Sciences, 43 (6): 169179; Menasha WI.

Puri, H.S. (1954): Contribution to the study of the Miocene of the Florida Panhandle, Part 3: Ostracoda. - Florida Geological Survey, Geological Bulletin, 36 (1953): 215-345; Tallahassee FL.

PURI, H.S. (1956): Two new Tertiary ostracode genera from Florida. - Journal of Paleontology, 30 (2): 274-277; Tulsa OK.

PURI, H.S. (1957): Henryhowella, new name for Howella PUR,, 1956. - Journal of Paleontology, 31 (5): 982; Tulsa OK.

PURI, H.S. (1971): Distribution of ostracodes in the oceans. - In: B.M. Funnell \& W.R. Riedel [Eds.]: The micropaleontology of the oceans: 163-169; Cambridge.

PuRI, H.S. \& Hulings, N.C. (1976): Designation of lectotypes of some ostracods from the Challenger Expedition. - Bullettin of the British Museum (Natural History), Zoology, 29 (5): $251-$ 315; London.

Rau, G.H., Takahashi, T. \& Des Marais, D.J. (1989): Latitudinal variacions in plankton $\delta^{13} \mathrm{C}$ : implications of $\mathrm{CO}_{2}$ and productivity in past oceans. - Nature, 341: 516-518; London.

Reuss, A.E. (1850): Die fossilen Entomostraceen des österreichischen Tertiärbeckens. - Naturwissenschaftliche Abhandlungen, 1. Ab., 3 (1): 41-92; Wien (Haidinger).

Rodriguez-Lazaro, J. \& Cronin, T.M. (1999): Quaternary glacial and deglacial Ostracoda in the thermocline of the Little Bahama Bank (NW Atlantic): palaeoceanographic implications. - Palaeogeography, Palaeoclimatology, Palaeoecology, 152: 339-364; Amsterdam (Elsevier).

Rosenfeld, A. \& Bein, A. (1978): A preliminary note on Recent ostracodes from shelf to rise sediments off Northwest Africa. 'Meteor' Forschungsergebnisse (C: Geologie und Geophysik), 29: 14-20; Stuttgart (Bornträger).

RugGierI, G. (1958): Alcuni ostracodi del Neogene italiano. - Atti della Società Italiana di Scienze Naturali 97 (2): 127-146; Milano.

RugGieri, G. (1967): Due Ostracofaune del Miocene alloctono della Val Marecchia. - Rivista Italiana di Paleontologia e Stratigrafia, 73: 351-384; Milano.

Sanguinetti, Y. (1979): Miocene ostracodes of the Pelota Basin, State of Rio Grande do Sul, Brasil. - Pesquisas, 12: 119-187; Porto Alegre.

SARS, G.O. (1866): Oversigt af Norges marine Ostracoder. - Forhandliger i Videnskabs-selskabet i Cristiania, 7: 130 pp.; Christiania.

SARS, G.O. (1928): An account of the Crustacea of Norway with short descriptions and figures of all species. - Ostracoda, $9(15 /$ 16): 241-277; Bergen.

SCHEnk, B. (2001): Benthische Foraminiferen der Tasmansee, ihre Faunengemeinchaften und Verteilungsmuster. - In: WEHRMANN, A. [Ed.]: PalBioSys 2001 - Gemeinsame Jahrestagung der Paläontologischen Gesellschaft und der Gesellschaft für Biologische Systematik, Abstracts. - Terra Nostra, 2001/6: 102; Berlin.

SeguenzA, G. (1880): Le Formazioni Terziarie della provincia di Reggio (Calabria). - Atti della Reale Accademia Nazionale dei Lincei, Ser. 3, 6: 3-446; Roma.

SissivgH, W. (1971): Bathycythere, a new genus of Ostracoda from the deep Southeastern Adriatic Sea. - Proceedings Koninkliike Nederlandse Akadademie van Wetenschappen, Ser. B, 74: 408416; Amsterdam.

SissingH, W. (1972): Late Cenozoic Ostracoda of the South Aegean Island Arc. - Utrecht Micropaleontological Bulletin, 6: 808816; Utrecht.

Sissingh, W. (1973): Carinovalva n. g. (Ostracoda), and comments on the ostracode genus Lixouria ULICZNY (1969). - Proceedings Koninklijke Nederlandse Akadademie van Wetenschappen, Ser. B, 76: 143-147; Amsterdam.

SisSINGH, W. (1974): On Bathycythere vanstraateni SISSINGH. Stereo-Atlas of Ostracod Shells, 2 (2): (22) 133-140; Leicester.

SMITH, A.J. \& HoRne, D.J. (2002): Ecology of marine, marginal marine and nonmarine ostracodes. - In: HOLMES, J.A. \& CHIVAS, A.R. [Eds.]: The Ostracoda: applications in Quaternary Research. - Geophysical Monograph Series, 131: 37-74; Washington DC (AGU).

Spero, H.J, Bijma, J., Lea, D.W. \& Bemis, B.E. (1997): Effect of seawater carbonate concentration on foraminiferal carbon and oxygen isotopes. - Nature, 390: 497-500; London.

STEINECK, P.L. (1981): Upper Eocene to Middle Miocene ostracode faunas and paleo-oceanography of the North Coastal Belt, Ja- 
maica, West Indies. - Marine Micropaleontology, 6: 339-366; Amsterdam (Elsevier).

Steineck, P.L., Dehier, D., Hoose, E.M. \& McCalla, D. (1988): Oligocene to Quaternary ostracods of the Central Equatorial Pacific (Leg 85, DSDP-IPOD). - In: HANAI, T., IKEYA, N., \& IsHiZAKI, K. [Eds.]: Evolutionary biology of Ostracoda, its fundamentals and applications. - Proceedings of the $9^{\text {th }}$ International Symposium on Ostracoda, 11:597-615; Amsterdam (Elsevier).

SWANsON, K.M. (1979): The marine fauna of New Zealand: ostracods of the Orago Shelf. - New Zealand Oceanographic Institute Memoir, 78: 1-56; Wellington.

Swanson, K.M. (1993): Late Quaternary and Recent benthic Ostracoda from the Eastern Tasman Sea. - Unpublished MSc Thesis of the Australian National University: 160 pp.; Canberra.

SWANSON, K.M. \& AYRESS, M.A. (1999): Cytheropteron testudo and related species from the SW Pacific with analyses of their soft anatomies, relationships and distribution. - Senckenbergiana biologica, 79 (2): 151-193; Frankfurt a.M.

Swanson, K.M. \& Lingen, G.J. VAN DER (1994): Podocopid ostracod dissolution - description of a new paleoenvironmental tool, with examples from the eastern Tasman Sea. - In: LiNGEN, G.J. VAN DeR, Swanson, K.M. \& Muir, R.J. [Eds.]: Evolution of the Tasman Sea Basin: 245-260; Rotterdam (Balkema).

SylVester-BRAdley, P.C. \& Benson, R. (1971): Terminology for surface features in ornate ostracodes. - Lethaia, 4: 249-286; Oslo.

SzCzechuRA, J. (1965): Cytheracea (Ostracoda) from the Uppermost Cretaceous and Lowermost Tertiary of Poland. - Acta Palaeontologica Polonica, 10 (4): 451-564; Warszawa.

THIEDE, J. et al. (1999): F.S. Sonne Cruise Report SO136-TASQWA Quaternary variability of Water Masses in the Southern Tasman Sea and Southern Ocean (SW Pacific Sector). - GEOMAR Report, 89: 78 pp.; Kiel.

TRESSLER, W.L. (1941): Geology and biology of North Atlantic deepsea cores berween Newfoundland and Ireland. Part 4. Ostracoda. - Geological Survey Professional Paper, 196-C: 95-104; Washington/D.C. (U.S. Dept. of the Interior).

Triebel, E. (1950): Homeomorphe Ostracoden-Gattungen. - Senckenbergiana, 31 (5/6): 313-330; Frankfurt a.M.

Trull, T., Rintoul, S.R., Hadfeld, M. \& Abraham, E.R. (2001): Circulation and seasonal evolution of polar waters south of Australia: Implications for iron fertilization of the Southern Ocean. Deep-Sea Research II, 48: 2439-2466; Amsterdam (Elsevier).

TuRpen, J.B. \& ANGeLl R.W. (1971): Aspects of molting and calcification in the ostracod Heterocypris. - Biological Bullettin, 140: 331-338; Woods Hole.

Ulrich, E.O. \& Bassler, R.S. (1904): Ostracoda. - In: Clark, W.B., Shattuck, G.B. \& Dall, W.H. [Eds.]: The Miocene Deposits of Maryland. - Reports of the Maryland Geological Survey, 2 (Miocene): 98-130; Baltimore.

VANNIER, J., ABE, K. \& IKUTA, K. (1998): Feeding in myodocopid ostracods: functional morphology and laboratory observations from video. - Marine biology, 132: 391-408; Berlin (Springer).

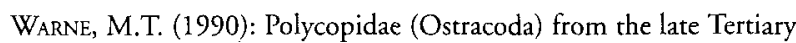
of the Port Phillip and western Port Basins, Victoria. - Proceedings of the Royal Society of Victoria, 102 (1): 59-66; Melbourne.

WARREN, B.A. (1981): Deep circulation in the world ocean. - In: B.A. Warren \& C. Wunsch [Eds.]: Evolution of Physical Oceanography, - MIT Press: 6-41; Cambridge MA.

WEFER, G. \& BERGER, W.H. (1991): Isotope paleontology: growth and composition of extant calcareous species. - Marine Geology, 100: 207-248; Amsterdam (Elsevier).
WhatLey, R.C. (1983): Some aspects of the palaeobiology of Tertiary deep-sea Ostracoda from the S.W. Pacific. - Journal of Micropaleontology, 2: 83-104; London (Geol. Soc.).

Whatley, R.C. (1985): Evolution of the ostracods Bradleya and Poseidonamicus in the deep-sea Cainozoic of the South-West Pacific. - Special Papers in Paleontology, 33: 103-116; London.

Whatley, R.C. \& Ayress, M.A. (1988): Pandemic and endemic distribution patterns in Quaternary deep-sea Ostracoda. - In: HANAI, T., IKEYA, N. \& IsHIZAKI, K. [Eds.]: Evolutionary biology of Ostracoda, its fundamentals and applications. - Proceedings of the $9^{\text {th }}$ International Symposium on Ostracoda: 739-755; Amsterdam (Elsevier).

Whatley, R.C., Chadwick, J., Coxill, D. \& Toy, N. (1988): The ostracod family Cytheruridae from the Antartic and South-West Atlantic. - Revista Española de Micropaleontología, 20 (2): 171-203; Madrid.

Whattey, R.C. \& Coles, G. (1987): The late Miocene to Quaternary Ostracoda of Leg 94, Deep Sea Drilling Project. - Revista Española de Micropaleontología, 19 (1): 33-97; Madrid.

Whatley, R.C. \& Downing, S.E. (1983): Middle Miocene Ostracoda from Victoria, Australia. - Revista Española de Micropaleontología, 15 (3): 347-407; Madrid.

Whatley, R.C., Downing, S.E., Kesler, K.J. \& Harlow, C. (1986): The ostracod genus Poseidonamicus from the Cainozoic of D.S.D.P. sites in the S.W. Pacific. - Revista Española de Micropaleontología, 18 (3): 387-400; Madrid.

Whatley, R.C., Frame, P. \& Whittaker, J.E. (1978); On Rockallia enigmatica gen. et sp. nov. - Stereo-Atlas of Ostracod Shells, 5 (2): (24) 137-144; Llandudno.

Whatley, R.C., Harlow, C., Downing, S.E. \& Kesler, K.J. (1984): New species of the ostracod genus Bradleya from the Tertiary and Quaternary of D.S.P.D.P. sites in the Southwest Pacific. Revista Española de Micropaleontología, 16 (1/3): 265-298; Madrid.

WhatLEY, R.C. \& MASSON, D.G. (1979): The ostracod genus Cytheropteron from the Quaternary and Recent of Great Britain. - Revista Española de Micropaleontología, 11 (2): 223-277; Madrid.

Whatley, R.C., Millson, K. \& Ayress, M.A. (1992): Philoneptunus, a new ostracod genus from the Cainozoic of Australasia. - Revista Española de Micropaleontología, 24 (3): 43-62; Madrid.

Whatley, R.C., Mogullevsky, A., Ramos, M.I.F. \& Coxill, D.J. (1998): Recent deep and shallow water Ostracoda from the Antartic Peninsula and the Scotia Sea. - Revista Española de Micropaleontología, 30 (3): 111-135; Madrid.

Whatley, R.C., Staunton, M., Kaesler, R.L. \& Moguilevsky, A. (1996): The taxonomy of Recent Ostracoda from the southern part of the Strait of Magellan. - Revista Española de Micropaleontología, 28 (3): 51-76; Madrid.

Whatley, R.C., Uffenorde, H., Harlow, C., Downing, S. \& KesLER, K. (1982): The Rockalliidae, a new Family of Cainozoic Ostracoda. - Journal of Micropaleontology, 1: 1-11; London (Geol. Soc.).

Whatley, R.C. \& Zhao, Q. (1993): The Krithe problem: a case history of the distribution of Krithe and Parakrithe (Crustacea, Ostracoda) in the South China Sea. - Palaeogeography, Palaeoclimatology, Palaeoecology, 103: 281-297; Amsterdam (Elsevier).

Whitmore, G.P. \& Belton, D.X. (1997): Sedimentology of the South Tasman Rise, south of Tasmania, from 'groundtruthed' acoustic facies mapping. - Australian Journal of Earth Sciences, 44: 677-688; Boston MA. (Blackwell). 
WHITAKER, J. (1981): On Hemicytherura cellulosa (NORMAN) Emend. - Stereo-Atlas of Ostracod Shells, 8 (1): 1-6; Llandudno.

XIA, J., EnGSTROM, D.R. \& ITO, E. (1997a): Geochemistry of ostracode calcite: Part 1 . An experimental determination of oxygen isotope fractionation. - Geochimica et Cosmochimica Acta, 61 (2): 377-382; Amsterdam (Elsevier).

Xia, J., Engstrom, D.R. \& ITO, E. (1997b): Geochemistry of ostracode calcite: Part 2 . The effects of water chemistry and seasonal temperature variation on Candona rawsoni. - Geochimica et Cosmochimica Acta, 61 (2): 383-391; Amsterdam (Elsevier).

YASSINI, I. (1995): Ostracoda. - In: YasSINI, 1. \& JONES, B.G. [Eds.]: Foraminifera and Ostracoda from estuarine and shelf environments on the southeastern coast of Australia, - University of Wollongong: 271-484; Wollongong.
ZEEBE, R.E. (1999): An explanation of the effect of seawater carbonate concentration on foraminiferal oxygen isotopes. - Geochimica et Cosmochimica Acta, 63 (13/14): 2001-2007; Amsterdam (Elsevier).

ZhaO, Q. \& WhatLey, R.C. (1997): Distribution of the genera Krithe and Parakrithe in bottom sediments of the East China and Yellow Seas. - Marine Micropaleontology, 32: 195-207; Amsterdam (Elsevier).

Zhou, B. \& Ikeya, N. (1992): Three species of Krithe (Crustacea Ostracoda) from Suruga Bay, central Japan. - Transactions and Proceedings of the Palaeontological Society of Japan, N. S., 166 (936): 1097-1115; Tokyo.

Manuscript received 28 February 2003 Revision accepted 18 June 2003

\section{Appendix}

Appendix A: List of all the studied samples and corresponding geographic location, site number, water depth, latitude and longitude. - The barren samples are not in bold.

\begin{tabular}{|c|c|c|c|c|c|}
\hline geographic location & site & sample & depth $[\mathrm{m}]$ & lat. ${ }^{\circ} S$ & long. ${ }^{\circ} \mathrm{E}$ \\
\hline Southern Challenger Plateau & 2 & $\mathrm{BX} 013$ & 1574 & $43^{\circ} 20.10^{\prime}$ & $167^{\circ} 41.89^{\prime}$ \\
\hline \multirow[t]{6}{*}{ East Campbell Plateau } & 3 & BX 019 & 4516 & $50^{\circ} 51.08^{\prime}$ & $176^{\circ} 53.20^{\prime}$ \\
\hline & 4 & BX 025 & 3436 & $50^{\circ} 39.04^{\prime}$ & $176^{\circ} 22.69^{\prime}$ \\
\hline & 5 & BX 031 & 1568 & $50^{\circ} 19.82^{\prime}$ & $175^{\circ} 34.85^{\prime}$ \\
\hline & 8 & BX 050 & 757 & $50^{\circ} 06.55^{\prime}$ & $174^{\circ} 15.57^{\prime}$ \\
\hline & 9 & BX 054 & 562 & $50^{\circ} 09.81^{\prime}$ & $173^{\circ} 21.99^{\prime}$ \\
\hline & 10 & BX 060 & 601 & $53^{\circ} 20.02^{\prime}$ & $169^{\circ} 15.05^{\prime}$ \\
\hline \multirow[t]{5}{*}{ South Campbell Plateau } & 11 & BX 068 & 981 & $54^{\circ} 05.01^{\prime}$ & $168^{\circ} 30.06^{\prime}$ \\
\hline & 12 & BX 076 & 1108 & $54^{\circ} 44.98^{\prime}$ & $167^{\circ} 29.95^{\prime}$ \\
\hline & 13 & BX 082 & 1681 & $55^{\circ} 20.07^{\prime}$ & $166^{\circ} 39.96^{\prime}$ \\
\hline & 14 & BX 088 & 2073 & $55^{\circ} 30.11^{\prime}$ & $165^{\circ} 52.18^{\prime}$ \\
\hline & 16 & BX 098 & 4154 & $55^{\circ} 34.89^{\prime}$ & $165^{\circ} 06.54^{\prime}$ \\
\hline \multirow[t]{2}{*}{ Emerald Basin } & 17 & BX 101 & 5005 & $\begin{array}{l}56^{\circ} 27.80^{\prime} \\
56^{\circ} 2087^{\prime}\end{array}$ & $\begin{array}{l}165^{\circ} 06.54^{\prime} \\
160^{\circ} 1486^{\prime}\end{array}$ \\
\hline & 20 & BX 116 & 4662 & $55^{\circ} 40.03^{\prime}$ & $159^{\circ} 2500^{\prime}$ \\
\hline & & & & & \\
\hline \multirow[t]{9}{*}{ South Tasman Rise } & 23 & BX 123 & 4194 & $52^{\circ} 59.89^{\prime}$ & $151^{\circ} 08.23^{\prime}$ \\
\hline & 26 & BX 138 & 3022 & $49^{\circ} 13.06^{\prime}$ & $151^{\circ} 05.77^{\prime}$ \\
\hline & 28 & BX 140 & 1636 & $49^{\circ} 10.84^{\prime}$ & $150^{\circ} 10.13^{\prime}$ \\
\hline & 29 & BX 141 & 1690 & $49^{\circ} 08.34^{\prime}$ & $149^{\circ} 54.98^{\prime}$ \\
\hline & 30 & BX 147 & 2177 & $48^{\circ} 29.99^{\prime}$ & $149^{\circ} 06.75^{\prime}$ \\
\hline & 31 & BX 153 & 1874 & $47^{\circ} 46.85^{\prime}$ & $149^{\circ} 23.73^{\prime}$ \\
\hline & 32 & BX 156 & 3208 & $47^{\circ} 00.09^{\prime}$ & $149^{\circ} 30.93^{\prime}$ \\
\hline & 33 & BX 161 & 3685 & $46^{\circ} 33.18^{\prime}$ & $149^{\circ} 04.96^{\prime}$ \\
\hline & 35 & BX 165 & 4067 & $45^{\circ} 18.26^{\prime}$ & $147^{\circ} 55.13^{\prime}$ \\
\hline
\end{tabular}


Appendix B: Number of valves in the large volume samples (LVS). - Juveniles and adults are not differentiated.

\begin{tabular}{|c|c|c|c|c|c|c|c|c|c|}
\hline \multirow[t]{2}{*}{ species } & \multicolumn{9}{|c|}{ sample } \\
\hline & 110 & 116 & 138 & 140 & 141 & 147 & 153 & 161 & 165 \\
\hline Ambocythere sinuosa n. sp. & & & & & & 4 & & 9 & \\
\hline Anchistrocheles sp. & & & & 3 & & & & & \\
\hline Apatihowella cf. A. rustica JeLlineK \& SWANSON 2003 & & & & 10 & & & 14 & & \\
\hline Apatibowella sp. & & & & & & & & 7 & \\
\hline Australoecia sp. & & & & & & 19 & & & 6 \\
\hline Aversovalva cf. $A$. antarctica (G.W. MÜlLeR 1908) & & & & 6 & & & & & \\
\hline Bairdoppilata sp. & & & 16 & & & & & & \\
\hline Bradleya cupa JeLlinek \& Swanson 2003 & & & & & & & & 14 & \\
\hline Bradleya dictyon (BRADY 1880) & & & & 7 & & & 29 & & \\
\hline Bradleya mesembrina $\mathrm{n} . \mathrm{sp}$. & & & 18 & 163 & 3 & 14 & 71 & 14 & \\
\hline Bythocypris sp. & & & & 11 & 1 & 3 & 23 & & \\
\hline Cytherella sp. & & & & & & 7 & & & \\
\hline Cytheropteron caputanatinus $\mathrm{n} . \mathrm{sp}$. & & & & 111 & 7 & 51 & 26 & & \\
\hline Cytheropteron dibolos n. sp. & & & & 29 & 10 & & 13 & & \\
\hline Cytheropteron sp. A & & & & 91 & & & 48 & & \\
\hline Cytheropteron sp. B & & & & & 42 & & 64 & & \\
\hline Cytheropteron sp. C & & & 6 & & 1 & & 1 & & \\
\hline Cytheropteron sp. D & & & & & & & 22 & & \\
\hline Cytheropteron sp. E & & & & 14 & 1 & & & & \\
\hline Debissonia fenestrata JELLINEK \& SWANSON 2003 & & & & 66 & 35 & & 60 & & \\
\hline Dutoitella spinaplana n. sp. & & & 56 & & & & & & \\
\hline Eucythere sp. & & & & 27 & & & 1 & & \\
\hline Fallacibowella caligo J ELLINEK \& SWANSON 2003 & & & 47 & 48 & 15 & 47 & 207 & 68 & 74 \\
\hline Fallacihowella sp. A & 15 & 22 & & & & & & & \\
\hline Fallacihowella sp. B & & & & & & 10 & & 29 & 4 \\
\hline Harleya ansoni (WhatLey, Maguilvesky, Ratios \& COXILl 1998) & & & & & & & 14 & & \\
\hline Harleya sp. & & & & 56 & 28 & 143 & & & \\
\hline Hemicytherura sp. & & & & & & 4 & & & \\
\hline Krithe sp. 1 & & & 160 & & & & & 53 & 23 \\
\hline Krithe sp. 2 & & & & 14 & & & & & \\
\hline Krithe sp. 3 & & 1 & & & & & & 344 & 226 \\
\hline Krithe sp. 4 & & & & & & & 42 & & \\
\hline Krithe sp. 5 & 7 & & & & & & & & \\
\hline Krithe sp. 6 & & & & & & 120 & 353 & 26 & \\
\hline Krithe sp. 7 & & & & 295 & 161 & 63 & & & \\
\hline Krithe sp. 8 & & & 8 & & & 3 & & & \\
\hline Krithe sp. 9 & & & & 33 & 146 & 490 & & & \\
\hline Krithe sp. 10 & & & 8 & & & & & & \\
\hline
\end{tabular}




\begin{tabular}{|c|c|c|c|c|c|c|c|c|c|}
\hline \multirow[t]{2}{*}{ species } & \multicolumn{9}{|c|}{ sample } \\
\hline & 110 & 116 & 138 & 140 & 141 & 147 & 153 & 161 & 165 \\
\hline Legitimocythere acanthoderma (BRADY 1880) & & & & 3 & & 95 & 11 & & \\
\hline Legitimocythere geniculata n. sp. & 12 & & 66 & & & & & 40 & 10 \\
\hline Legitimocythere sp. & 3 & & 9 & & & 3 & & 1 & 12 \\
\hline Macropyxis sp. & & & 1 & & & 3 & & & 5 \\
\hline Myrena sp. & & & & 12 & & & 10 & & \\
\hline Pelecocythere sp. & & & & & & & 4 & & \\
\hline Phacorabdotussp. & 7 & 9 & & & & & & & \\
\hline Philoneptunus tricolonos $\mathrm{n} . \mathrm{sp}$. & & & & 45 & 5 & 75 & & & \\
\hline Philoneptunus sp. juv. & & & & & & & & 11 & \\
\hline $\begin{array}{l}\text { Poseidonamicus cf. P. anteropunctatus } \\
\text { (WhatLEY, DOWNing, KeSLER \& HaRlow 1986) }\end{array}$ & & 6 & & & & & & 13 & \\
\hline Poseidonamicus major BENSON 1972 & & & 30 & & & 68 & 2 & & \\
\hline Poseidonamicus minor BENSON 1972 & & & & & & & 10 & & \\
\hline $\begin{array}{l}\text { Poseidonamicus ocularis } \\
\text { (WHATLEY, DOWNING, KESLER \& HARLOW 1986) }\end{array}$ & & & & 672 & 94 & 126 & 377 & & \\
\hline Poseidonamicus sp. & & & 17 & & 72 & 211 & & 55 & 32 \\
\hline Pseudobosquetina nobilis $\mathrm{n} . \mathrm{sp}$. & & & 44 & & & & & & \\
\hline $\begin{array}{l}\text { Rockallia sp. A } \\
\text { Rockallia sp. B }\end{array}$ & & & 6 & 2 & & & 10 & & \\
\hline Rotundracythere sp. & & & & 2 & & & 10 & & \\
\hline Rugocythereis horrida (WHATLEY \& COLES 1987) & & & 49 & & & 216 & & 9 & 5 \\
\hline Rugacythereis tethys n. sp. & & & 7 & 153 & 1 & & 74 & & \\
\hline Saida sp. & & & & 3 & & & & & \\
\hline Schlerochilus cf. S. reniformis (G.W. MÜLLER 1908) & & & & 4 & & & 3 & & \\
\hline Xestoleberis sp. & & & & 5 & & & 18 & & \\
\hline
\end{tabular}




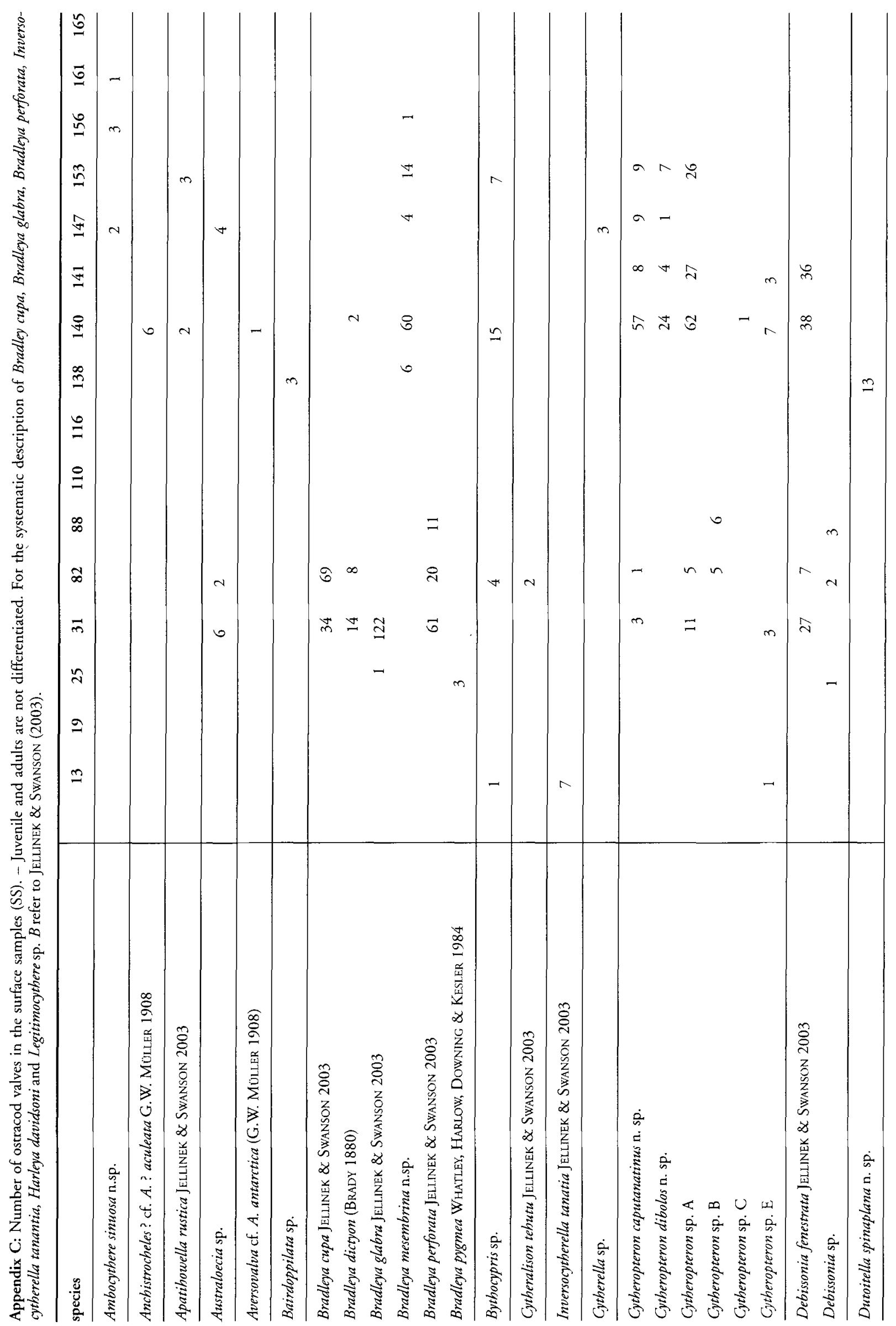




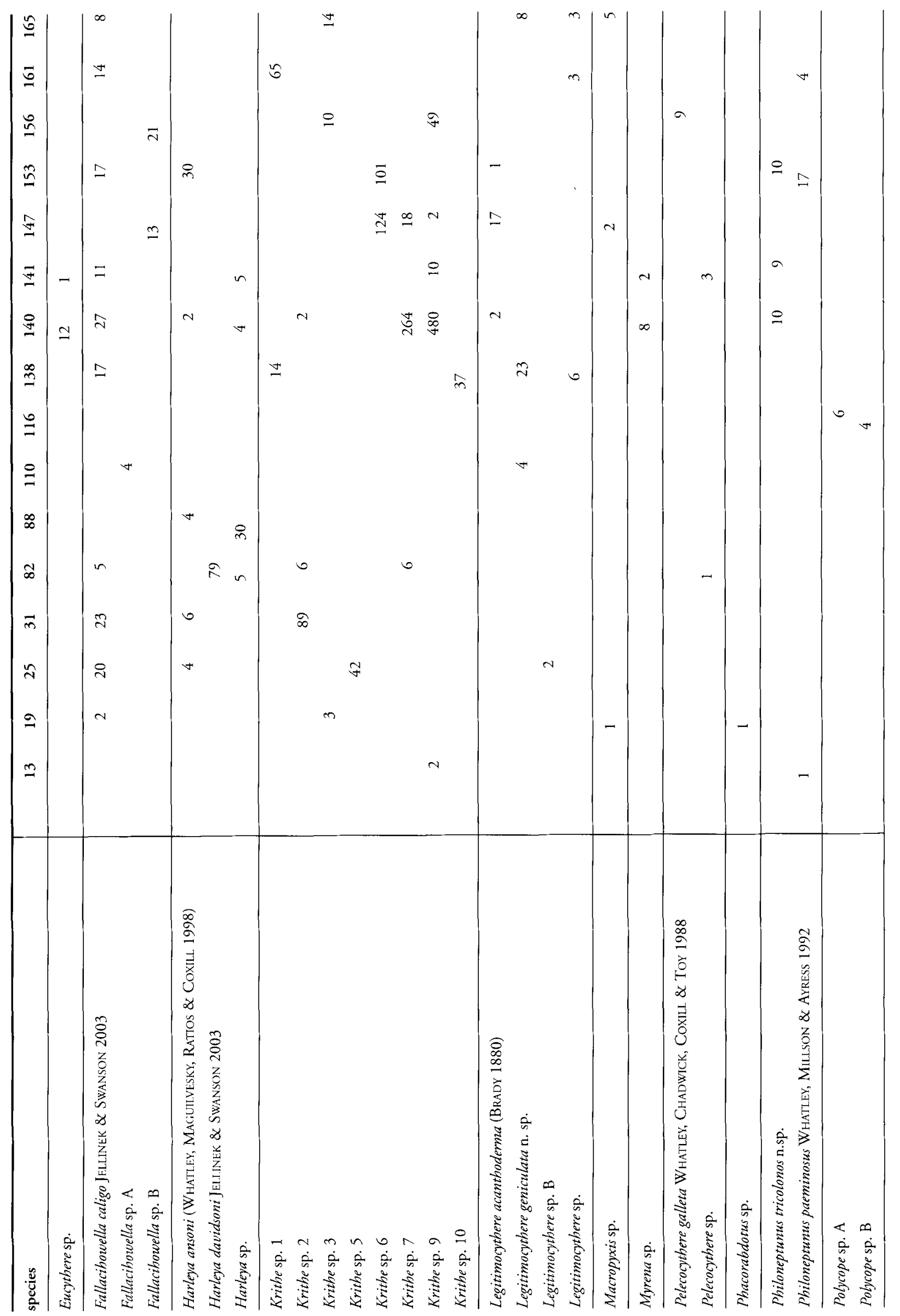




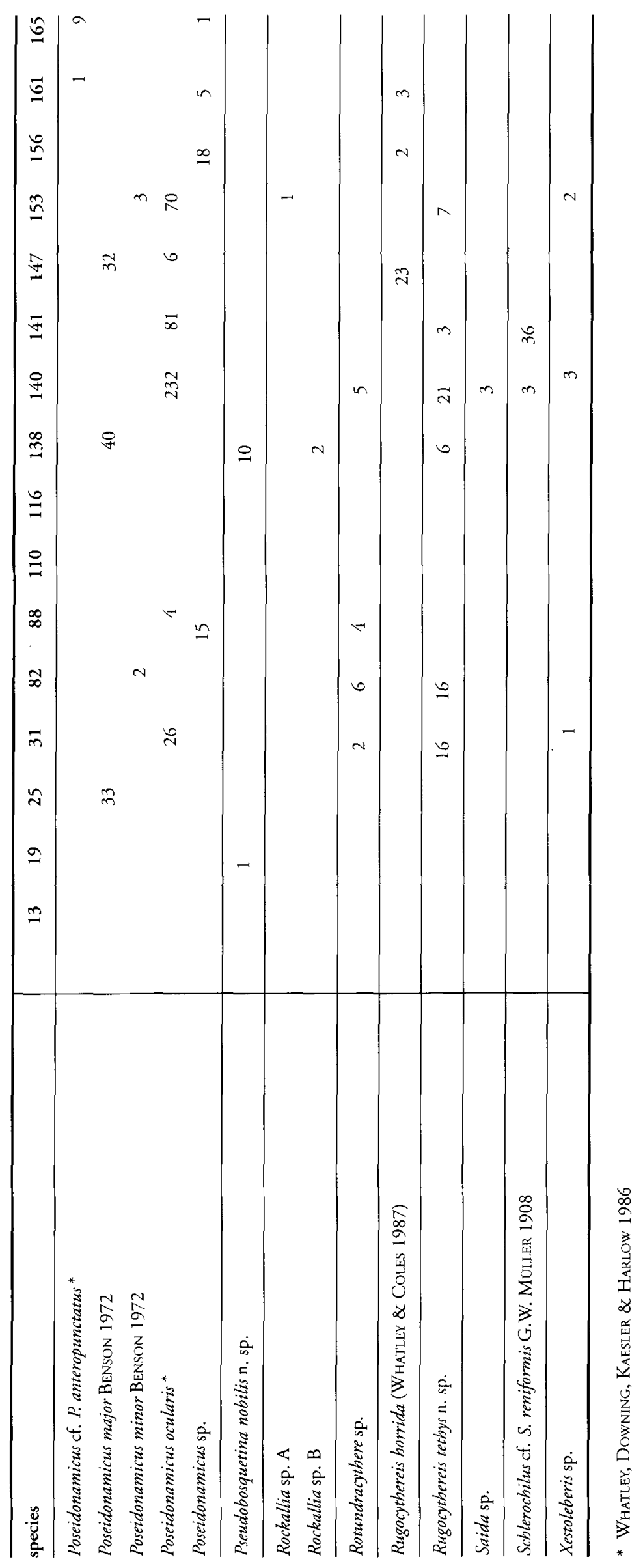

